\title{
IntechOpen
}

\section{Introduction to Diesel Emissions}

\author{
Edited by Richard Viskup
}





\section{Introduction to Diesel Emissions}

Edited by Richard Viskup 

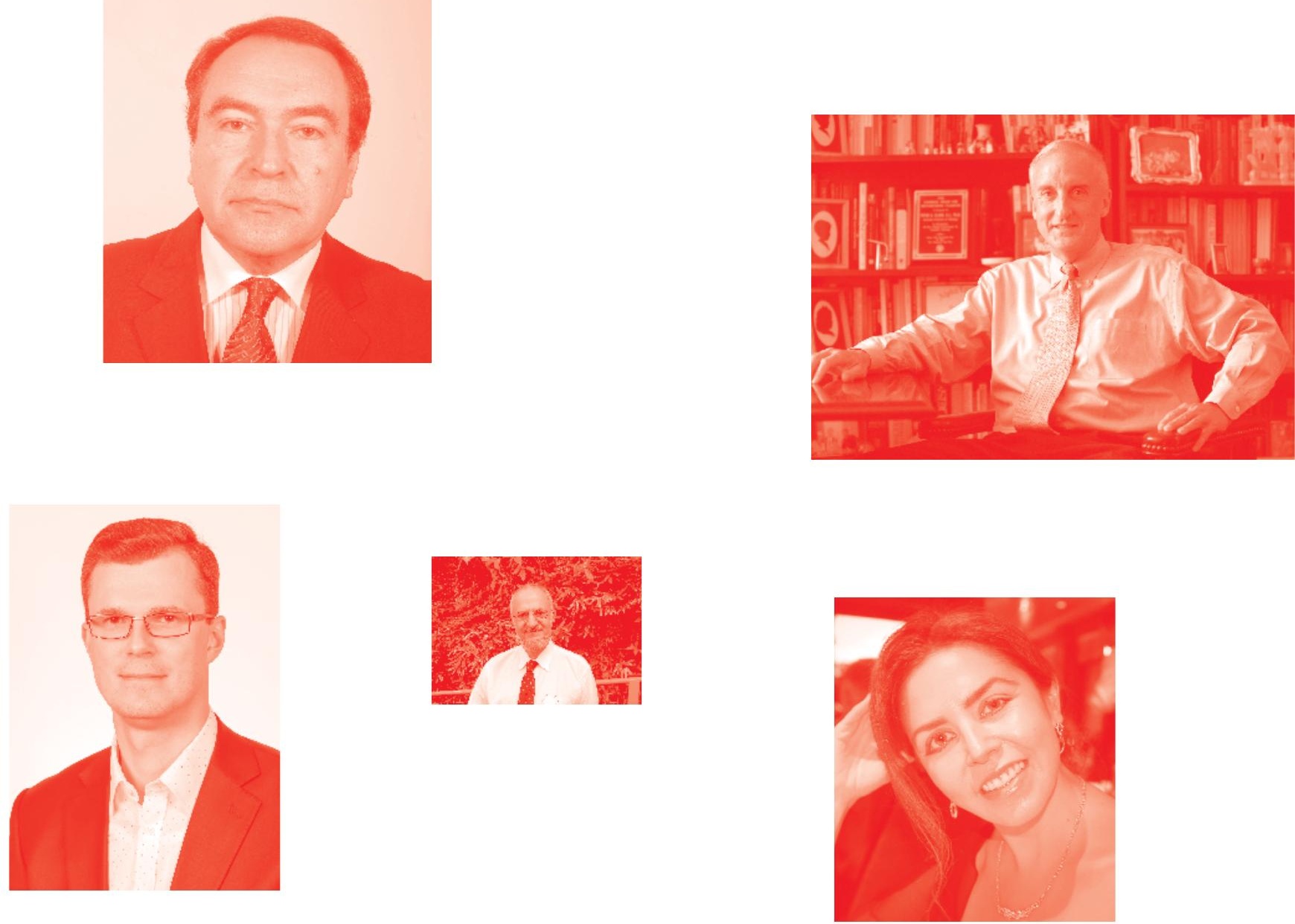

Supporting open minds since 2005
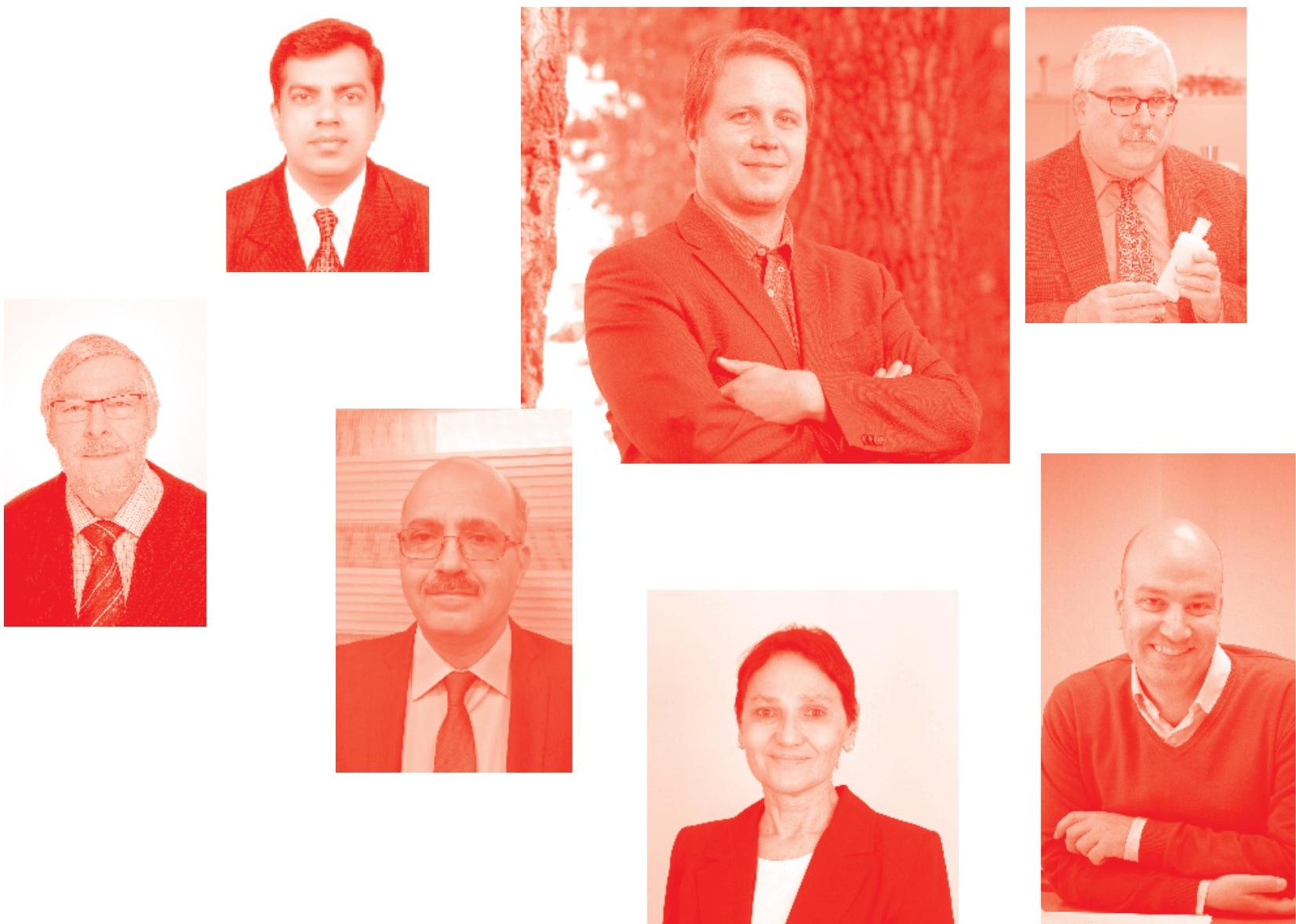
Introduction to Diesel Emissions

http: //dx. doi. org/10.5772/intechopen. 80733

Edited by Richard Viskup

\section{Contributors}

Aman Hira, Debasish Das, Ranjna Thakur, Melvin Victor Depoures, Damodharan Dillikannan, Gopal Kaliyaperumal, Ramakrishna Morla, Shivakumar Karekal, Ajit Godbole, Nehemiah Sabinus Alozie, Lionel Christopher Ganippa, Richard Viskup, Christoph Wolf, Werner Baumgartner

() The Editor(s) and the Author(s) 2020

The rights of the editor(s) and the author(s) have been asserted in accordance with the Copyright, Designs and Patents Act 1988. All rights to the book as a whole are reserved by INTECHOPEN LIMITED . The book as a whole (compilation) cannot be reproduced, distributed or used for commercial or non-commercial purposes without INTECHOPEN LIMITED's written permission. Enquiries concerning the use of the book should be directed to INTECHOPEN LIMITED rights and permissions department (permissions@intechopen.com).

Violations are liable to prosecution under the governing Copyright Law .

\section{(cc) BY}

Individual chapters of this publication are distributed under the terms of the Creative Commons Attribution 3.0 Unported License which permits commercial use, distribution and reproduction of the individual chapters, provided the original author(s) and source publication are appropriately acknowledged. If so indicated, certain images may not be included under the Creative Commons license. In such cases users will need to obtain permission from the license holder to reproduce the material. More details and guidelines concerning content reuse and adaptation can be found at http : //www . intechopen . com/copyright-policy . html.

\section{Notice}

Statements and opinions expressed in the chapters are these of the individual contributors and not necessarily those of the editors or publisher. No responsibility is accepted for the accuracy of information contained in the published chapters. The publisher assumes no responsibility for any damage or injury to persons or property arising out of the use of any materials, instructions, methods or ideas contained in the book.

First published in London, United Kingdom, 2020 by IntechOpen IntechOpen is the global imprint of INTECHOPEN LIMITED, registered in England and Wales, registration number: 11086078 , 7th floor, 10 Lower Thames Street, London,

EC3R 6AF, United Kingdom

Printed in Croatia

British Library Cataloguing-in-Publication Data

A catalogue record for this book is available from the British Library

Additional hard and PDF copies can be obtained from orders@intechopen.com

Introduction to Diesel Emissions

Edited by Richard Viskup

p. cm.

Print ISBN 978-1-78984-@35-3

Online ISBN 978-1-78984-@36-0

eBook (PDF) ISBN 978-1-78985-506-7 


\section{We are IntechOpen, \\ the world's leading publisher of Open Access books}

Built by scientists, for scientists

\section{$4,700+$}

Open access books available

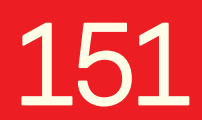

Countries delivered to
$120,000+$

International authors and editors

Our authors are among the

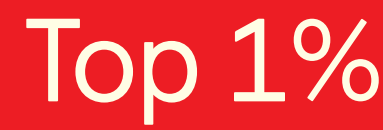

most cited scientists

Contributors from top 500 universities
$135 \mathrm{M}+$

Downloads

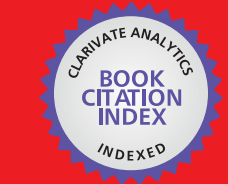

WEB OF SCIENCE ${ }^{\mathrm{MM}}$

Selection of our books indexed in the Book Citation Index in Web of Science ${ }^{\mathrm{TM}}$ Core Collection (BKCI)

\section{Interested in publishing with us? \\ Contact book.department@intechopen.com}

Numbers displayed above are based on latest data collected.

For more information visit www.intechopen.com 



\section{Contents}

Preface

Section 1

Diesel Engine and Exhaust Emissions

Chapter 1

Diesel Exhaust Emissions and Mitigations

by Nehemiah Sabinus Alozie and Lionel Christopher Ganippa

Chapter 2

Performance, Emissions, and Combustion Evaluations of a Diesel

Engine Fuelled with Biodiesel Produced from High FFA Crude Mahua

(Madhuca longifolia) Oil

by Aman Hira, Debasish Das and Ranjna Thakur

Section 2

Biodiesel and Alternative Fuels

Chapter 3

Alcohol Contribution over Conventional Fuel

by Melvin Victor Depoures, Damodharan Dillikannan

and Gopal Kaliyaperumal

\section{Section 3}

Soot and Diesel Particulate Matter

Chapter 4

Comparison of Different Techniques for Measurement of Soot and Particulate Matter Emissions from Diesel Engine

by Richard Viskup

Chapter 5

Analysis of Diesel Particulate Matter Flow Patterns in Different Ventilation and Operational Conditions of Underground Mines by Ramakrishna Morla, Shivakumar Karekal and Ajit Godbole

Chapter 6

Major Chemical Elements in Soot and Particulate Matter Exhaust Emissions Generated from In-Use Diesel Engine Passenger Vehicles by Richard Viskup, Christoph Wolf and Werner Baumgartner 



\section{Preface}

The first invention and development of the functional diesel engine was in 1897 by Rudolf Christian Karl Diesel, German inventor, more than 123 years ago. This invention has now been surpassed by development of very productive engines and mechanics. Current diesel engines are well known to many people around the world and serve in innumerable applications for various types of public transport, light and heavy duty transportation, for automotive, railway, maritime or aviation transportation, in different harsh environments, in construction, in mining, and for diverse industries. The light duty or heavy-duty diesel engines have some drawbacks. One of the main concerns is exhaust emissions generated by diesel engines.

This book discusses the generation of diesel exhaust emissions and mitigations, performance, emissions and combustion evaluations, utilisation of alternative biodiesel fuels, comparison of different techniques for measurement of soot and diesel particulate matter, analyses of diesel particulate matter flow pattern, and chemical composition of diesel particulate matter. The main concern of this book is to expand knowledge of readers and bring together the latest research findings related to diesel engine exhaust emissions.

The book "Introduction to Diesel Emissions" is divided into three main sections: Diesel Engines and Exhaust Emissions; Biodiesel and Alternative Fuels; and Soot and Diesel Particulate Matter. In these three sections, readers can find topics dealing with diesel combustion engines and exhaust emissions, and related references or internet links that can help to further inspire experts as well as non-experts in the importance of this subject.

In conclusion, I would like to thank all of the authors for rigorous preparation of individual chapters and I wish you a pleasant read.

RnDr. Dr. Eng. Richard Viskup, MSc., MPhil., PhD. Johannes Kepler University Linz, Linz, Austria, January 2020 

Section 1

\section{Diesel Engine and Exhaust Emissions}





\title{
Diesel Exhaust Emissions and Mitigations
}

\author{
Nehemiah Sabinus Alozie and Lionel Christopher Ganippa
}

\begin{abstract}
This chapter presents a concise treatment of diesel engine exhaust emissions and its mitigations. The working principle of the diesel engine is first given to establish the background and further to describe the influence of various parameters that affect the formation of engine exhaust emissions. The factors that influence exhaust emissions are linked to the engine design and the operating factors that promote good fuel-air mixing and combustion. These factors are air induction, fuel injection equipment, fuel injection schemes, in-cylinder gas exchange process and heat transfer. Thermochemistry essentially gives insight to the global reaction kinetics and how this is applied in practical engine combustion determinations in terms of equivalence ratios. Based on these, the fuel spray structure, atomization, penetration and the spray combustion model are described. The formation of exhaust emissions such as carbon monoxide, unburnt hydrocarbon and its intermediates, oxides of nitrogen and soot in diesel engines has been discussed. The techniques of their mitigation from the view of internal factors that deals with the optimization of engine design and it performance, as well as various exhaust after-treatment techniques used for $\mathrm{NO}_{\mathrm{x}}$ and soot reduction have been briefly discussed.
\end{abstract}

Keywords: diesel engine, fuel-air mixing, combustion, exhaust emissions, mitigations

\section{Introduction}

The diesel engine is a type of internal combustion engine invented in 1892 by Rudolf Diesel. It is so named in recognition of his patent which described a highly efficient, slow burning, compression ignition engine, where liquid fuel sprays were ignited solely by the heat of compression as piston reciprocates inside a cylindrical barrel. Compared to contemporary engines of that time especially the rival gasoline engine, it has superior efficiency in converting energy stored in liquid fuel to mechanical power. This superiority in fuel economy which has remained till date, is because diesel engine admits and compresses air only, (and can indeed be made to admit more externally compressed air into the cylinder) which is compressed to very high pressures and temperatures, before fuel is introduced into the combustion chamber as highly atomized sprays. Fuel-air mixing is achieved through combined factors of air swirl introduced through purposeful designed flow path, high fuel injection pressures, fine fuel atomization, and high temperature rapid fuel evaporation [1]. The high temperatures of the compressed air, reaches the auto-ignition temperature of the air-fuel mixture which burns and releases chemical energy in the fuel. Therefore, the way diesel fuel burns in the engine and the ultimate exhaust 
emissions are related to the way it is introduced, mixed and ignited in the chamber. This is also dependent on the properties of diesel fuel and the geometric profiles of the chamber itself. These factors determine the index of air utilization in the combustion process and define the nature of exhaust emissions. Issues of diesel engine exhaust emissions have been of concern for diesel engine researchers and developers such that, although the principles remain the same; substantial improvements have been made to the original engine described by Rudolf. These have ensured better engine combustion and emissions; however stringent regulations on modern diesel engine exhausts, have further led to incorporation of after-treatment devices to attain compliant levels.

\section{The working principles of diesel engine}

The diesel engine converts chemical energy stored in the fuel into work at the output shaft. This involves two steps; first is conversion of fuel chemical energy into thermal energy through combustion, followed by consequent conversion of thermal energy into mechanical energy by expansion of burning fuel in high pressure air. In effect, the following events take place: air induction, air compression, air and fuel mixing, burning of air-fuel mixture, expansion of the burning gases and their exhaust. These events or processes occur in four piston strokes during two revolutions of crankshaft. This gives the popular four-stroke cycle of induction stroke, compression stroke, power stroke during gas expansion and exhaust stroke, Figure 1. These events can also be arranged in a technology of two stroke operation using different design possibilities. Details of these are available in many standard diesel engine text books like [1-4] and only short summaries of these events are given with reference to Figure 1 as follows.

\subsection{Intake stroke}

The intake stroke is the period when piston moves down from the top dead center (TDC) to the bottom dead center (BDC). During this time, the intake valve is open while the exhaust valve is closed. In operation, the intake valve is timed to open shortly before the TDC and closes after the BDC. This enables

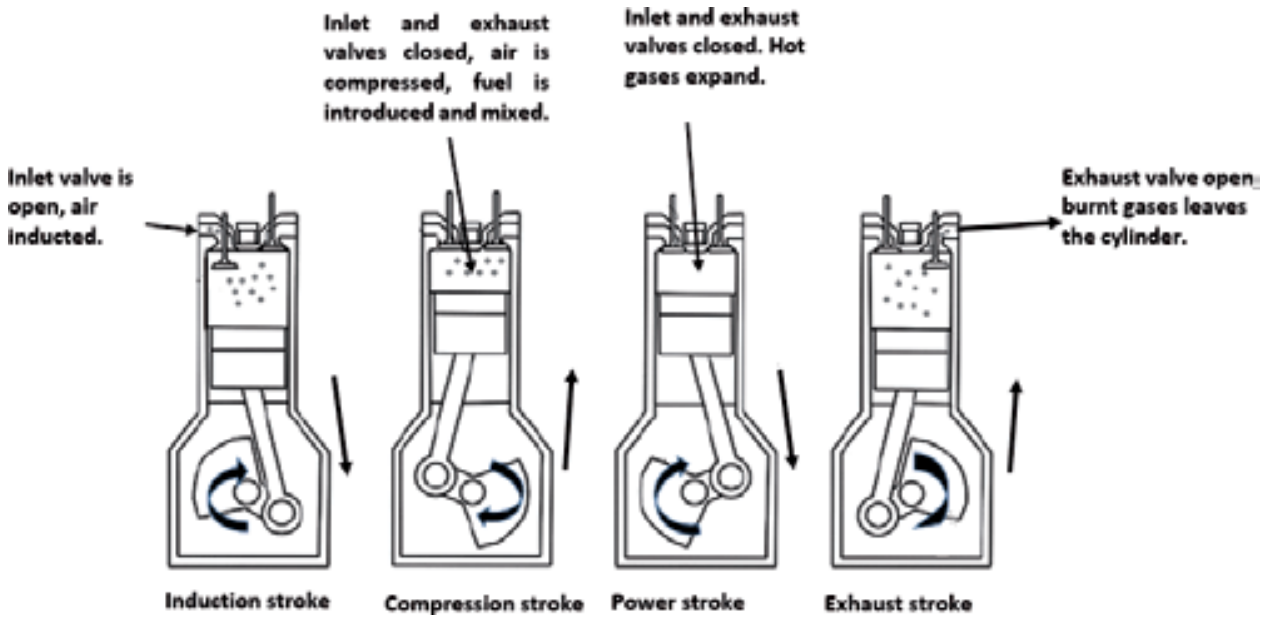

Figure 1.

The four-stroke cycle of typical diesel engine. 
fresh mass of filtered air to be drawn into the cylinder. The higher density fresh charge displaces burnt gases, thus enhances scavenging of the cylinder of burnt gases from previous cycle.

\subsection{Compression stroke}

This is the period when the piston moves up from BDC to TDC, and compresses the air inside the cylinder to a small fraction of the total cylinder volume. During this time, the intake and exhaust valves are closed; and as the piston approaches the TDC, diesel fuel is injected into the hot compressed air at a temperature sufficiently high to ignite the fuel, which burns and releases high thermal energy.

\subsection{Power or expansion stroke}

The expansion of high temperature and pressure burning gases pushes the piston down from the TDC to BDC giving the useful power stroke. This is also called the work stroke because the high pressure gases act on top of the piston surface. Its impact on the connecting rod is transmitted to the crankshaft causing it to rotate and produce useful work on the shaft. During this process, both valves are theoretically closed between the centers but practically, the exhaust valve is timed to open some degrees before BDC to initiate pressure drop inside the cylinder by allowing burnt gases to escape.

\subsection{Exhaust stroke}

The upward movement of the piston again from BDC to TDC pushes out the burnt gases through the fully open exhaust valve. As the piston approaches the TDC, the intake valve also opens. This allows admission of fresh air into the cylinder, the density of which is greater than that of burnt gases, displace them and fill up the cylinder again. The pressure drop created by early opening of the exhaust valve also reduces the work done by the piston in pushing out the burnt gases. The cycle then continues.

\section{Engine design factors that influence quality of exhaust emissions}

At the core of diesel engine performance analysis is the efficiency of combustion and quality of exhaust emissions. These are related to the air utilization and fuel economy. Many factors affect engine combustion efficiency, which can individually and collectively affect the quality of exhaust emissions. Of interest in diesel engine emissions are the factors that promote generation of regulated variables which include soot, which along with other adsorbed particles like condensates of unburnt hydrocarbon (UHC) and its intermediates, is generally called particulate matter (PM); oxides of nitrogen $\left(\mathrm{NO}_{\mathrm{x}}\right)$ and carbon monoxide $(\mathrm{CO})$. Their emissions into the atmospheric environment have impact on human health and are therefore regulated in the concentrations they could be emitted from modern engines. The factors that influence their generation include fuel injection pressure, injection timing, ignition delay, fuel atomization, spray-configuration, technique of supplying air, either quiescent or swirl and level of turbulence. These are related to the way fuel is introduced, mixed and ignited in the chamber to achieve good air utilization in the combustion process. Another inherent factor is the very nature and properties of diesel fuel. Every factor simply helps to achieve the underlying chemical balance in combustion equation which can be technically challenging 
in the complicated engine environment. To obtain a chemically correct fuel-air combustion in diesel engine is complicated due to the presence of partly premixed fuel and air, and mainly due to unsteady-turbulent diffusion burning encountered in rapid vaporization of liquid fuel, with very short time for the fuel and air mixing. Diesel fuels contain different fractions of alkyl and aromatic components and the combustion mechanisms depend on the molecular structures of different species. These structures are based on the intra-molecular carbon bonds that may be single, double or triple bonds; and straight, branched or ringed chains. They determine the combustion characteristics associated with diesel fuels [5].

The consideration of these factors with the aim of improving exhaust gas emissions through better air utilization to achieve better combustion has led to optimal designs of key operating parameters [6].

\subsection{Air induction}

The air induction system consists of air filter, ducts, intake manifold, intake port and intake valves. The air charge induced into the cylinder is related to power output, quality of combustion and exhaust emission during a cycle. Cylinder displacement is fixed based on engine geometry; therefore naturally aspirated capacity is constrained. Design improvement to increase induction capacity is by compressing air to higher density prior to introduction into the cylinder. This is referred to as boosting or supercharging. Typical method of supercharging diesel engines is by allowing a portion of the escaping exhaust gases at high thermal and kinetic energy levels to flow and expand through turbine blades. The power imparted on the shaft is used to drive a centrifugal compressor, axially connected on the same turbine shaft to compress more air into the cylinder. This is known as turbocharging and the increased air charge in the cylinder boosts the power output from the fixed cylinder volume. Optimal design of turbochargers has increased power-to-weight ratio, improved engine efficiency, lowered exhaust emission and in general engine downsizing $[1,3,4,7]$.

\subsection{Fuel injection equipment}

Fuel injection equipment systems are used to supply finely atomized fuel sprays into the combustion chamber at precisely controlled time. Types of injection systems include pump-line-nozzle (P-L-N) systems, unit injector and common rail injection systems. These are general categories of injection systems, each having distinct designs. Common in the P-L-N system are in-line (Figure 2), the distributor or rotary pumps and the unit pump designs which are either mechanically or electronically controlled. The unit injectors are known to deliver very high pressure because of active mechanical intensifiers like plungers or large cams as in the pressure-time (PT) controlled systems. They are similarly controlled either mechanically or electronically. The common rail injection system (Figure 3) in conjunction with electronic control has been developed to overcome some of the draw backs in P-L-N and unit injection pumps. Essentially, it has overcome the dependency of fuel injection pressure and quantity on engine speed, enabled flexibility in matching the fuel injection timing, and smoothening fluctuations due to cycle-to-cycle variability. In all versions, filtered diesel fuel is first lifted from the tank to main gallery of a high pressure pump. The high pressure pump then delivers fuel to the injectors, (which are of different nozzles tip profiles) to spray fuel into the combustion chamber. Modern engine fuel injection systems are controlled by dedicated electronics giving rise to precise fuel spray at high pressures; and the fuel spray profiles are matched to optimized chamber to improve combustion and level 


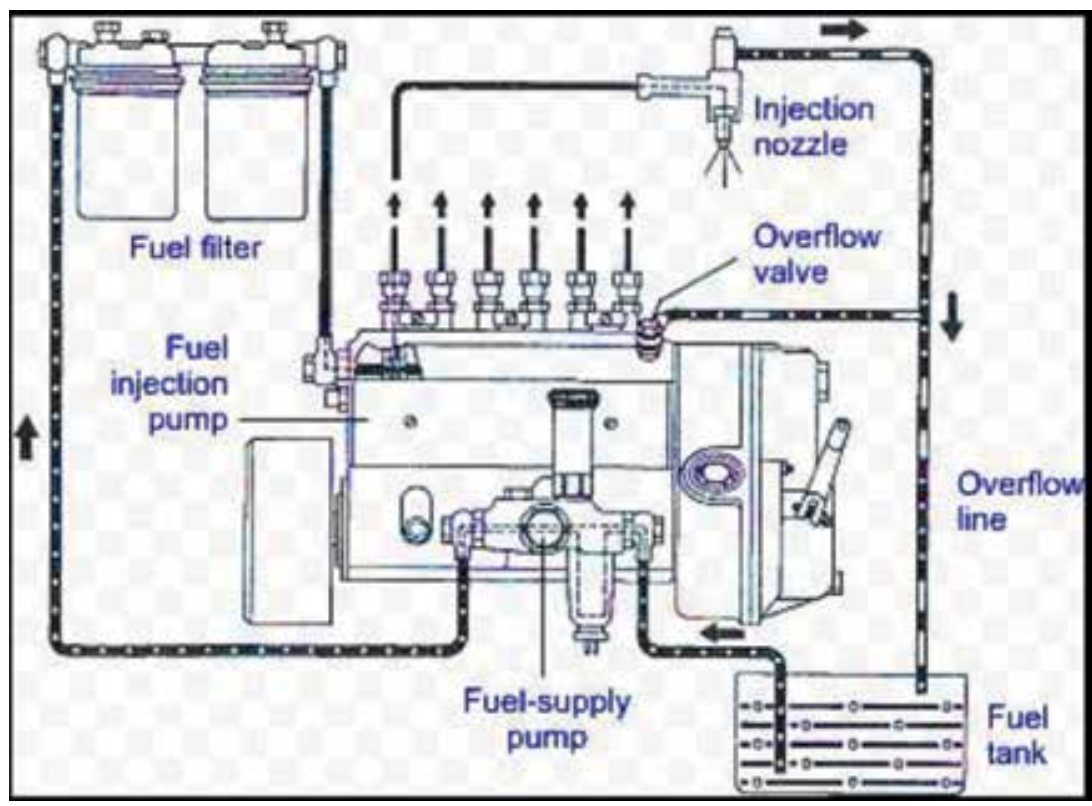

Figure 2.

Pump-line-nozzle system (adapted from DieselNet. Courtesy of Robert Bosch GmbH).

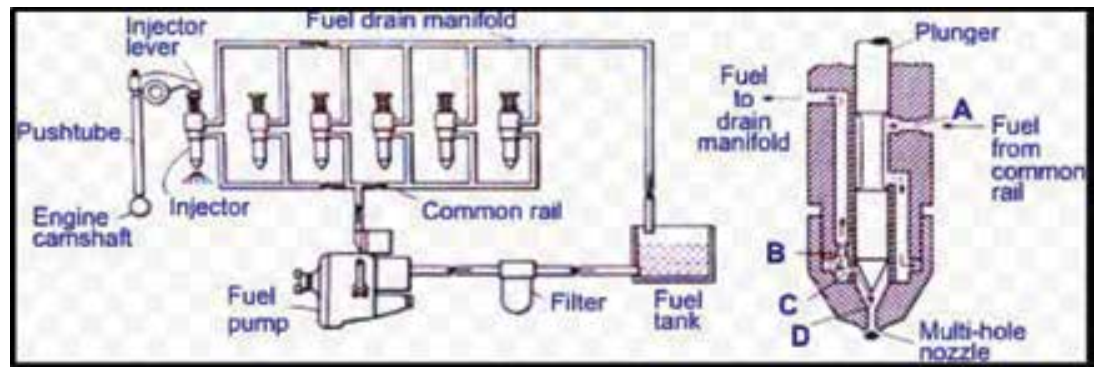

Figure 3.

Typical common rail lay-out of a typical Cummins PT fuel injection system (adapted from DieselNet. courtesy of Cummins Inc.).

exhaust emissions. Many manufacturers especially for heavy duty diesel engines have developed proprietary electronic fuel injection systems relevant to their total engine management system. Good discussions about different injection systems and their impact on exhaust emissions can be found on reference [3].

\subsection{Diesel fuel injection}

The scheme of injecting diesel fuel into the combustion chamber is multipurpose apart from mere delivery. The purposes are intricate functions that ensure efficient combustion and reduction of hazardous emissions. These include: timely control of fuel injection, control of right quantity of fuel delivered to meet engine duty or load and at high pressure to enhance good mixing with air. Good air-fuel mixture is an important parameter for efficient combustion through the injection of high pressure sprays that effectively entrains the compressed air in the combustion chamber. These functions are generally enhanced through different injection strategies. Studies have shown that splitting fuel injection into divided doses per 
combustion cycle reduces emissions [8-11]. This has enabled injection requirements to be met for different engine operating conditions since engines encounter varying demands, from low-speed, low-load; to medium and high-speed, high-load applications. Good fuel injection is synonymous with the choice of injection equipment which achieve the engine schedule of time, quantity and pressure. Injection pressures can range from 200 to 2000 bars or higher, with nozzle exit velocity of about $100-300 \mathrm{~m} / \mathrm{s}$. The in-cylinder air pressure is about 40-100 bars during the time of injection and about $15-25 \mathrm{~kg} / \mathrm{m}^{3}$ in density.

\subsection{In-cylinder and gas exchange processes}

The processes that occur inside the cylinder are usually described using the corresponding pressure — crank angle diagram. The sequence of valve actuations are numbered 1-4 in Figure 4 for a four stroke naturally aspirated diesel engine.

A momentary period of valve overlap expressed in degrees of crank angle occurs between points 1 and 4 when both valves are open. This period is significant to the engine performance and emission characteristics because the volumetric efficiency, particularly in the absence of boosting depends on the in-cylinder filling during this period. As valve openings and closures are not instantaneous, the timing is designed to ensure that both are fully open when the benefit of maximum pressure difference will cause the working fluid to flow across them. In current designs, the poppet valves are located in overhead position in the cylinder head. The geometric profiles of intake manifold, intake port and the poppet valves are designed to enhance air breathing capacity of the engine and also to impact swirl and/or squish motion to the bulk flow into the cylinder. The air utilization during combustion process is dependent on how well it is premixed with fuel sprays prior to combustion or accessible during diffusion burning. Engine combustion chamber is designed to complement the effect of fuel spray profile while the air motion enhances mixing/ burning process. The optimization of these engine elements are very significant to the level of exhaust emissions.

\subsection{Heat transfer}

The heat transfer considerations in the engine environment are complicated as all modes are involved within the combustion chamber. Preservation of the structural integrity and geometric profiles of the mating surfaces necessitates removal of heat generated during combustion, particularly from the hottest regions to avoid

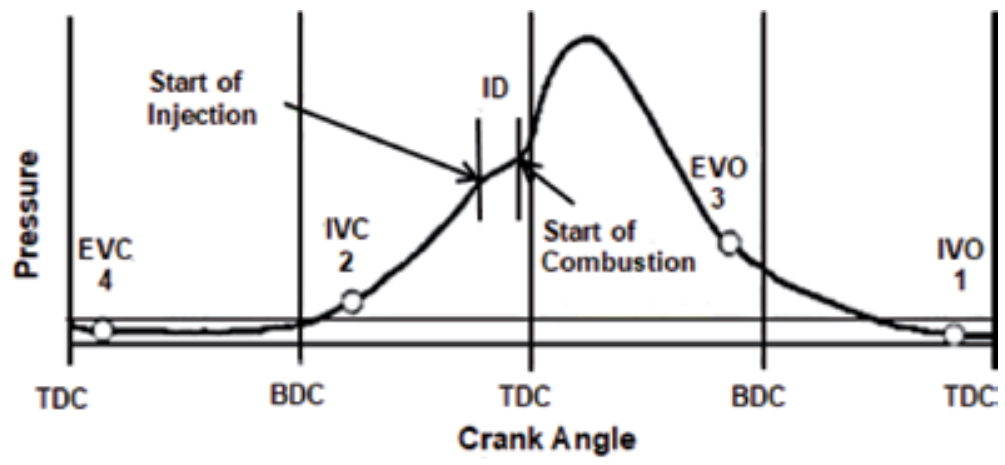

Figure 4.

In-cylinder pressure-crank angle diagram with sequence of valve actuations and processes in four stroke CI engine (IVO, intake valve open; IVC, intake valve closure; EVO, exhaust valve open; EVC, exhaust valve closure; TDC, top dead center; BDC, bottom dead center) $[1,3]$. 
distortion of these surfaces. Engine heat transfer involves use of cooling water jackets around the regions with highest heat fluxes; the hot water is then pumped to the radiator where heat is lost to ambient environment by forced convection. Some low duty designs adopt the use of air cooling as it flows across an increased surface area created by fins around the cylinder head and walls. The engine efficiency, performance and emissions are greatly affected by heat transfer as such; it is optimized to retain enough heat required to maintain normal engine working temperature and the excess transferred to the cooling medium. This explains the inefficiency usually encountered during cold starting when the work transfer to the piston is reduced as high heat transfer occurs to the chamber walls and other working parts for quick warm up. Similarly, during this transient period, heat transfer affects the process of forming gaseous and particulate matter emissions both within the cylinder and exhaust line where post combustion reactions occur.

\section{Thermo-chemistry}

The stoichiometric air-fuel ratio $(\mathrm{A} / \mathrm{F})_{\mathrm{s}}$ is the chemically correct air-fuel proportion that will completely burn to yield only water, carbon dioxide, and nitrogen. It is dependent on the chemical composition of the fuel. Engine combustion makes use of atmospheric air which contains nitrogen; therefore a general expression for complete combustion of a molecule of hydrocarbon fuel $\mathrm{C}_{\mathrm{a}} \mathrm{H}_{\mathrm{b}}$ with air is given as [1]:

$$
C_{a} H_{b}+(a+b / 4)\left(O_{2}+3.773 N_{2}\right)=a C O_{2}+(b / 2)_{2} O+3.773(a+b / 4) N_{2}
$$

Eq. (1) defines the stoichiometric ratio of fuel and air reaction that could be utilized for gravimetric analysis of complete fuel combustion in air. It depends on the fuel molecular structure. In engine combustion analysis, it is usual to also express $(\mathrm{A} / \mathrm{F})_{\mathrm{s}}$ as a reciprocal, meaning fuel-air ratio $(\mathrm{F} / \mathrm{A})_{\mathrm{s}}{ }^{-1}$. Either way is useful in expressing engine operating condition because during engine testing, both air and fuel flow rates are measured to determine if the mixture is rich or lean. The degree to which fuel is rich or lean, is central to engine performance analysis especially with regards to emission considerations. The products of combustion emitted in either of the mixture situation differ significantly due to fuel chemical composition and structure. In this regard, a parameter: equivalence ratio $(\phi)$ that expresses the actual fuel/air ratio to the stoichiometric value is normally adopted for expressing the composition of mixture.

$$
\phi=(F / A)_{\text {actual }} /(F / A)_{s}
$$

Alternatively, the inverse of $\phi$ could be used as relative air/fuel ratio $(\lambda)$, similarly defined as:

$$
\lambda=\phi^{-1}=(A / F)_{\text {actual }}(A / F)_{s}
$$

Comparatively, mixture strengths are expressed as follows:

Fuel rich mixture: $\phi>1, \lambda<1$

Fuel lean mixture: $\phi<1, \lambda>1$

Stoichiometric mixture: $\phi=\lambda=1$

From Eq. (1), exhaust emissions associated with engine combustion on stoichiometric condition are supposed to be carbon dioxide $\left(\mathrm{CO}_{2}\right)$, water vapor $\left(\mathrm{H}_{2} \mathrm{O}\right)$ and nitrogen $\left(\mathrm{N}_{2}\right)$. However this is not practically possible as other emissions like carbon 
monoxide (CO), unburnt hydrocarbons (UHC), oxides of nitrogen $\left(\mathrm{NO}_{\mathrm{x}}\right)$, oxides of sulfur (Sox) and soot are inevitably present. These emissions arise due to unsteady combustion, post combustion and engine cycle-to-cycle fluctuations. During combustion and about some degrees after the top dead center (TDC), the composition of combustion products corresponds to local equilibrium with respect to pressure, temperature and equivalence ratio. But as expansion stroke advances, recombination reactions of active species occur, and their compositions are changed. Due to fast changing cylinder condition during this period, recombination reaction is not able to maintain the species in chemical equilibrium. As the exhaust valve opens, exhaust flow process forces species compositions to freeze as they are expelled from the cylinder. By implication, even if the fuel-air mixture was lean, not all fuel species had opportunity to be fully oxidized. Also, it is not possible to equally match all the in-cylinder flow conditions in a multi-cylinder engine; therefore it is difficult to have the same exhaust composition from all cylinders. During testing, engines are calibrated to meet transient and stable operations of which fuel-air mixtures vary from rich to lean conditions, thereby giving various emission levels. Therefore evaluation of engine-out emissions is cumbersome and is best approached through experimental measurements [1].

\section{Diesel spray structure, atomization and spray combustion}

Prior to development of optical accessible engines with laser diagnostics, direct measurement of combustion events inside the engine cylinder was difficult; high speed movies were used to record the spread of fuel jets and flame propagations. Efforts were also made to calculate fuel injection rates from measurements of fuel injection parameters; and the associated heat release rates from engine pressure data in order to gain insights about the combustion process but, details could not be obtained about the true in-cylinder reactions. The development of laser diagnostics enabled in-situ measurements to be made as in-cylinder diesel-spray combustion reactions occur. It is through this approach that planar images have been recoded with good temporal and spatial resolutions, and generates data that offers better interpretations. The fuel spray trajectory, combustion and extinction is the conceptual basis for describing combustion in diesel engine. Currently, there are good insights into the complexity of fuel spray, lift-off length, air-fuel mixture formation, combustion and resultant emission formation through modelling and experiments. The conceptual model presented by Dec in 1997 based on laser sheet imaging [12] is the hallmark of several efforts made with his co-workers at Sandia National Laboratory and many other authors toward contributing to the current understanding. The laser sheet imaging diagnostics has revealed the true nature of in-cylinder processes like: entrainment of air as liquid fuel ejects from nozzle and mixes with hot swirling air to form combustible mixture, images of poly-aromatic hydrocarbons (PAHs), the auto-ignition event, soot formation which starts well from the upstream and central regions of the jet toward the head vortex, as well as the relative particle size distributions and concentrations of soot emission. Separate investigations made for fuel-air mixing, combustion and post-combustion reactions were used to establish the conceptual model (Figure 5) as a framework for describing spray combustion.

The original work of Dec used large bore diesel engine with nearly quiescent flow-field, and represented 'quasi-steady' free jet combustion without collision or wall impingement. Subsequent studies that gave information on fuel jet ignition and penetration, have dwelt on this model to elucidate the combustion phenomenon. Detailed information about these developments through modeling and experimental examinations can be checked in the following references: [13-21]. 


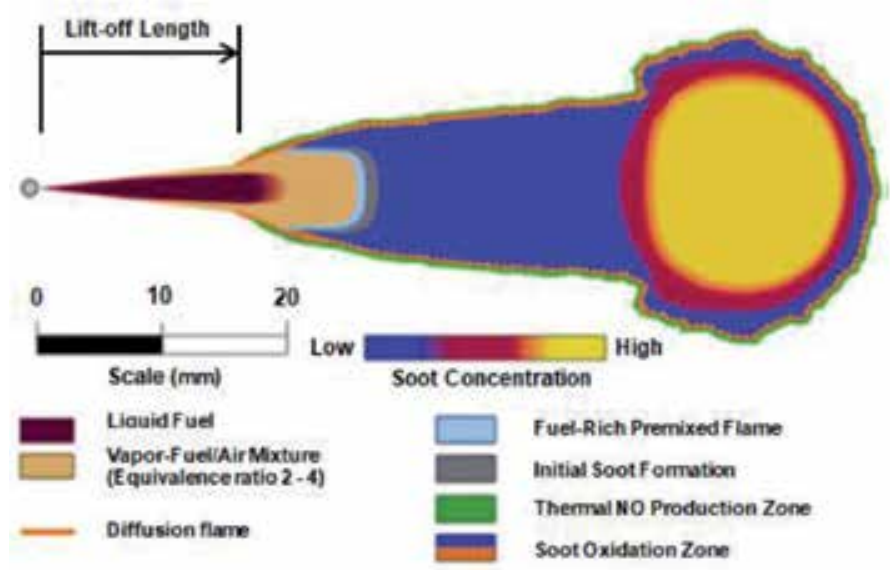

Figure 5.

Dec's conceptual model of quasi-steady spray combustion in conventional diesel engine [12].

\subsection{Spray structure}

The structure of spray evolving from the injector nozzle is related to the injection pressure, size of nozzle holes and their orientation in the combustion chamber. If flow through the nozzle is considered to be of a quasi-steady, incompressible nature in one dimension, the model for mass flow $\dot{\mathrm{m}}_{f}$ rate of fuel injected is given as [1]:

$$
\left.\dot{\mathrm{m}}_{f}=C_{d} A_{n} \sqrt{\left(2 \mathrm{p}_{f}\right.} \Delta P\right)
$$

Where the $C_{d}$ is the discharge coefficient, $A_{n}$ is the nozzle flow area, $p_{f}$ is fuel density, $\Delta \mathrm{P}=\left(\mathrm{P}_{f}-\mathrm{P}_{\text {cyl }}\right)$ the pressure drop across nozzle orifice, $\Delta \theta$ is the injection duration in crank angle degrees and $\mathrm{N}$ is the engine speed in RPM. If the pressure drop across the nozzle and nozzle open area are taken to be constant during the injection period, the mass of fuel injected is then

$$
\left.\dot{\mathrm{m}}_{f}=C_{d} A_{n} \sqrt{\left(2 \mathrm{p}_{f}\right.} \Delta P\right) \frac{\Delta \theta}{360 N}
$$

This relation gives the dependency of overall fuel delivery characteristics of the injection system on injection parameters [2]. However in practice diesel injection is unsteady, the injection pressure as well as in-cylinder pressure vary during the injection period. Similarly, there are significant compressibility effects on the injection process at the very high unsteady pressures encountered in operation; but these are not considered here.

Information about the spray structure has been established though modeling and simulation as well as through laser diagnostics as in the references given. Volumes of publications that describe spray structure through simulations, used Reynolds Average Navier-Stokes (RANS) model and large eddy simulation (LES). The LES turbulence model capture large unsteady flow structures that are responsible for mixing. At a finite distance after nozzle exit called break-up length $\left(\mathrm{L}_{b u}\right)$, the jet flow becomes fully turbulent and the liquid fuel starts to breaks into small droplets as in Figure 6. This development creates a large surface area for air to be entrained into the spray, making it to increase in diameter even as it trust axially away from the nozzle tip. As the bulk of the spray penetrates into the cylinder, the early droplets that encounter hot dense air especially at the periphery, loses momentum to the air and the droplets behind the wake penetrate deeper into the 


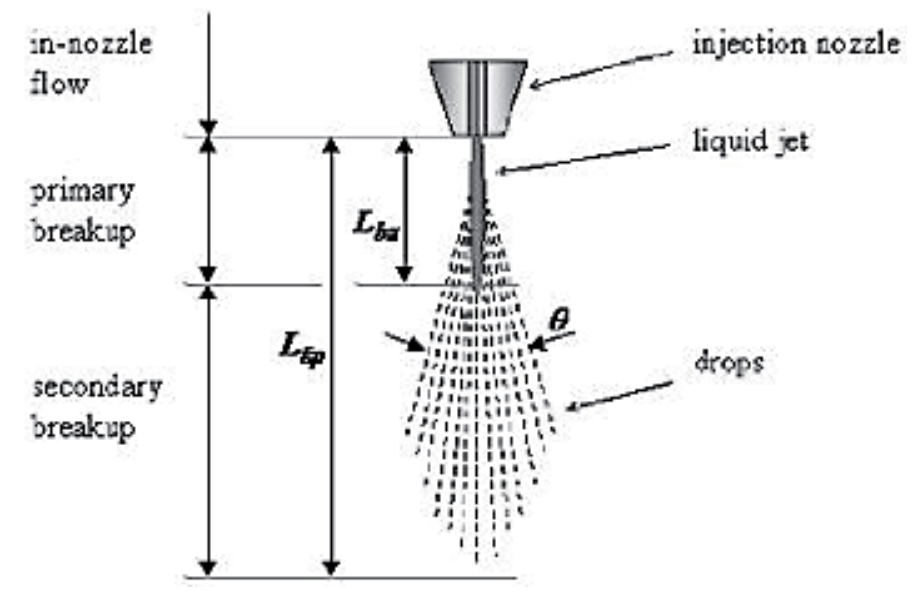

Figure 6.

Schematic of diesel spray structure (adapted from AdvancedEngineeringCenter@brighton.ac.uk).

combustion chamber. For large bore cylinders, the penetration is undisturbed and reaches full spray tip penetration length $\left(\mathrm{L}_{\text {tip }}\right)$; but for small bores cylinders, spray impinges on the chamber walls. This make the droplets to spread on the hot walls and experience quick evaporation and mixing with air.

\subsection{Spray atomization}

Diesel fuel is injected as conical-shaped spray jet into hot air at conditions that are higher than the critical temperatures and pressures of the fuel, and the increase in velocity of the jet leads to large scale instability. Studies have shown that the jet breakup depends on characteristic factors like the nozzle hole length to diameter ratio, its shape, smoothness, and the rate of injection pressure rise. The break-up mechanisms are classified into primary and secondary regimes depending on prevailing conditions $[1,22]$. Primary break-up occurs when the liquid jet near the injector nozzle disintegrates into very small droplets due to interaction with in-cylinder gas. Generally this regime is used to classify break-up at the outer surface of the plane of nozzle exit due to very high jet velocity. The average droplet diameter are much smaller than the nozzle diameter. This initial break-up are considered to be initiated by many factors like turbulence and collapse of cavitating bubbles causing unsteadiness in the nozzle flow and full interaction with swirling air, effects of surface tension and aerodynamic forces, leading to break-off of some filaments or droplets. The continued influence of aerodynamic forces induce further break-up and reduction of the droplets sizes as flow penetrates into the surrounding air. This is called secondary break-up and together with progressively strong evaporative effects, droplet size diminishes in axial flow direction. At the droplet level, the break-up is assumed to be controlled by droplet Weber number (We), defined as the ratio of inertia forces to surface tension forces:

$$
W e=\mathrm{p}_{a} D_{d} U_{r e l}^{2} / \sigma_{f}
$$

where $\mathrm{p}_{\mathrm{a}}$-ambient air density, $\mathrm{D}_{\mathrm{d}}$-droplet diameter, $\mathrm{U}_{\text {rel }}$-relative velocity between droplet and the ambient gases, $\sigma_{\mathrm{f}}$-surface tension of fuel.

Weber number is typically in excess of 100 in modern diesel engines implying that stripping and catastrophic regimes are the important modes of droplet breakup regime (Table $\mathbf{1}$ ). 


\begin{tabular}{ll}
\hline We & Break-up mode \\
\hline $\mathrm{We} \leq 12$ & Vibrational \\
\hline $12<\mathrm{We} \leq 18$ & Bag \\
\hline $18<\mathrm{We} \leq 45$ & Bag-and-stamen \\
\hline $45<\mathrm{We} \leq 100$ & Chaotic \\
\hline $100<\mathrm{We} \leq 350$ & Sheet stripping \\
\hline $350<\mathrm{We} \leq 1000$ & Wave crest stripping \\
\hline $1000<\mathrm{We} \leq 2670$ & Catastrophic \\
\hline Adapted from $[22,44-46]$. & \\
\hline
\end{tabular}

Table 1.

Secondary droplet break-up classification.

\subsection{Spray penetration}

Spray penetration is of great benefit for overall fuel-air mixing rates and degree of air utilization. Fuel atomization and evaporation enable fuel-air mixing in the immediate vicinity while substantial quantity of air may remain unutilized for combustion if not quickly reached by fuel species further inside the cylinder. Faster fuel spray penetration rate into the combustion chamber quickens the mixing rate. Many studies have been carried out to get good correlations both experimentally and by turbulent jet mixing theory to propose penetration models [23-25]. While it is good to achieve good penetration, in multi-spray nozzles in direct injection combustion engine, over-penetration leads to fuel impingement on the chamber walls which might be cool and lowers mixing rates thereby causing emissions of unburnt and intermediate hydrocarbon species.
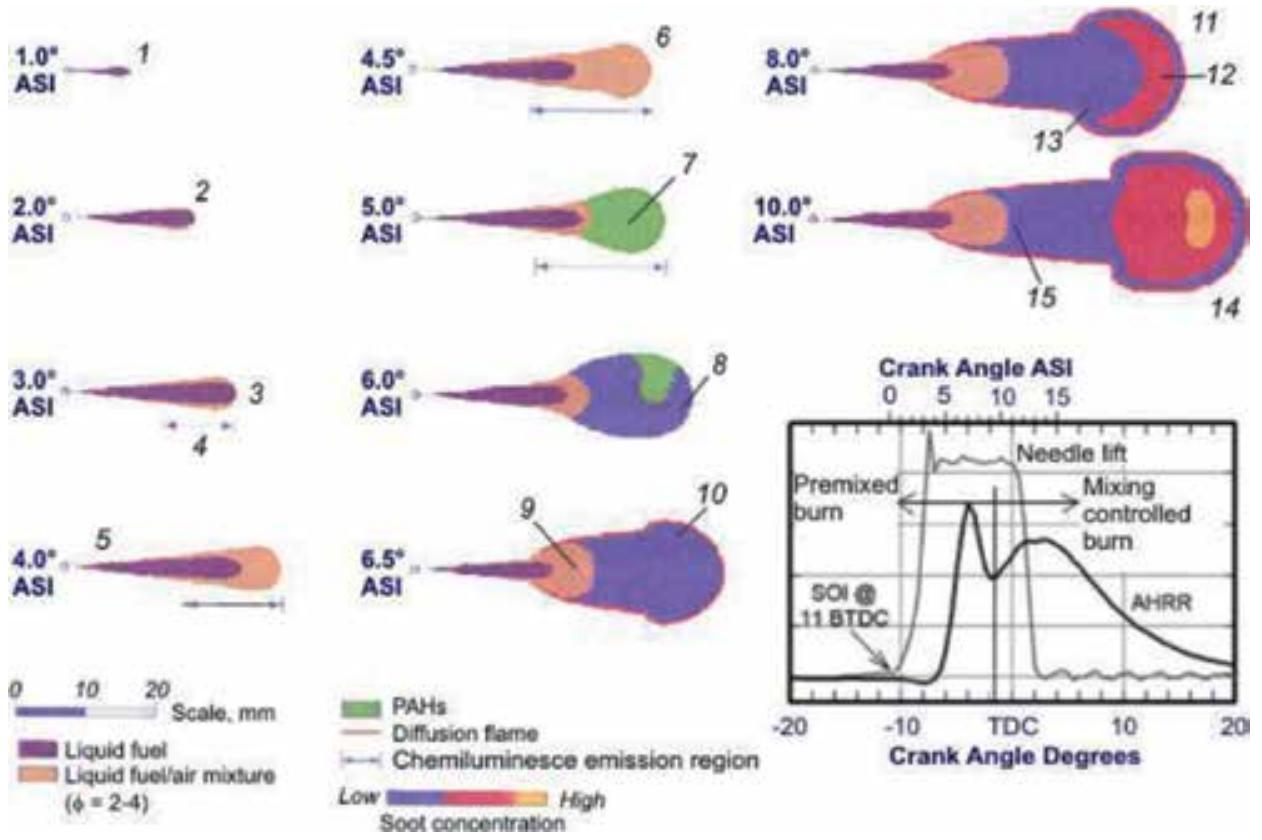

Figure 7.

Modified conceptual model [12, 19, 22]. 


\subsection{Spray combustion}

The original work of Dec used to establish the framework that described spray combustion used large bore diesel engine with near-quiescent flow-field, and represented 'quasi-steady' free jet combustion without collision or wall impingement. The temporal sequence of the conceptual model that have been modified to include some recent contributions [19] is described and adapted here as in Figure 7. The crank angle degree after the start of injection $(A S I)$ is indicated on each image, is used to trace the history of spray combustion in the chamber.

\subsubsection{Fuel jet and air entrainment $\left(0.0-4.5^{\circ} \mathrm{ASI}\right)$}

Fuel sprays exiting the nozzles penetrate into the chamber and expand to near conical shapes. Based on the investigations in [26], the images were captured from nozzle exit at intervals of $0.5^{\circ}$ of crank angle degrees. At $1.0^{\circ}$, liquid jet core (dark brown) moves a maximum of $23 \mathrm{~mm}$ downstream corresponding to $3.0^{\circ} \mathrm{ASI}$. The fuel is all vaporized by the entrained air and this limits liquid core penetration. The gas-phase jet penetrates downstream and develops vortex-head due to further entrainment. Correlations for entrainment in [27] and direct fuel vapor measurement in [28] show that as entrainment increased downstream, there is inverse variation of equivalence ratio along the jet axis. Here the description of equivalence ratio is given as the ratio of local fuel-ambient charge mass ratio to the stoichiometric fuel-ambient mass ratio. The liquid fuel is heated and vaporized by the thermal energy of the entrained air, therefore at some distance downstream referred as liquid length, all liquid fuel are vaporized. The entrainment correlations have been used to determine this distance and also establish that it could be shortened if the ambient charge density is increased.

\subsubsection{Auto-ignition (3.0-5.0 ASI)}

The beginning of flame initiation is not definite; however Chemiluminescence imaging offers opportunity to examine auto-ignition in diesel combustion. The arrows under the vortex head in jets 3.0-5.0 $\mathrm{ASI}$, indicate the Chemiluminescence region of the jet which may even appear earlier. At onset around 3.0-3.5 ${ }^{\circ}$ ASI, the vapor fuel-air mixture is thin and around $4.5^{\circ} \mathrm{ASI}$, most of the Chemiluminescence emerge from the leading edge portion of the vapor fuel-air mixture and indicates fuel breakdown and formation of $\mathrm{PAH}$ in the region $4.5-5.0^{\circ} \mathrm{ASI}$.

\subsubsection{Pre-mixed combustion (4.0-6.5 $\mathrm{ASI})$}

From the curve of heat release rate (insert), the rate starts to rise after $3.0^{\circ}$ and the sharply from $4.0-5.0^{\circ}$ ASI. During the same time, emergence of Chemiluminescence is followed by rapid fuel breakdown and formation of PAHs increasingly in the leading edge of the jet where an equivalence ratio is about 2-4.

The initial burning of this premixed rich mixture is indicated by sharp rise in the heat release rate followed by rapid PAH and soot formation between 5.0 and $6.0^{\circ} \mathrm{ASI}$ downstream of the jet. Upstream, there is more fuel break-down due to increase in temperature, as typified by jet at $6.0^{\circ}$ ASI.

\subsubsection{Early diffusion flame (5.5-6.5 $\mathrm{ASI})$}

As the apparent heat release peaks during pre-mixed burn period, there is corresponding appearance of thin diffusion flame on the periphery of the 
vapor-fuel/air mixture. This is a consequence of fuel rich premixed combustion that burns comfortably in the presence of air. Quickly, the whole periphery of the jet downstream is covered by this thin diffusion flame burning at high temperature with consequent formation of nitrogen oxides. The flame is limited upstream to a point referred as 'Lift-off Length' from the nozzle tip which corresponds to the border region of the vapor-fuel/air mixture. Here the flame is lifted and due to increased local heating, the rate of fuel break-up increases as evidenced by a decrease in the liquid-fuel length by about $2-3 \mathrm{~mm}$.

\subsubsection{Last part of pre-mixed combustion (7.0-9.0 ASI)}

As fuel-air mixing rate increases, $\mathrm{PAH}$ and soot formation are enhanced towards the end of pre-mixed combustion, and this extends length of the jet downstream. At about $8.0^{\circ} \mathrm{ASI}$, the soot concentration is high and almost fills the jet cross-section bulging more towards the leading edge to form a head vortex. At the periphery of the jet, the thin sheet of turbulent diffusion flame produces larger soot particles that move inwards to mix with the inner smaller soot particles in the bulk volume of the jet, this is more active at the leading edge where there is more soot concentration. As the last portion of the premixed charge burns, smaller size soot particles are formed over the entire jet volume extending up to $27 \mathrm{~mm}$ from the tip of the injector but soot is entirely lifted off the nozzle tip for the reference low sooting fuel.

\subsubsection{Mixing-controlled combustion (9.0 $0^{\circ}$ ASI to end of injection)}

At about $9.0^{\circ} \mathrm{ASI}$, the combustion has entirely become mixing-controlled and the appearance of the jet as used to hypothesize the conceptual model is fully established at about $10.0^{\circ} \mathrm{ASI}$. At this point, the sizes of soot particles remain small from upstream edge where the last portions of the premixed burns, but the concentration increases downstream. The concentration is more at the center of vortex head which becomes very prominent with large soot particles as signified by color codes. This last image is ordinarily taken as a representative of the final jet development. It is typical of the observations made of the remaining mixing-controlled combustion of injected fuel.

\subsubsection{The conceptual model}

The typical conceptual model is used to explain full spray combustion during mixing-controlled phase towards the end of fuel injection, Figure 8. The model is a modification of the last stage in jet development captured about $10.0^{\circ}$ ASI and to

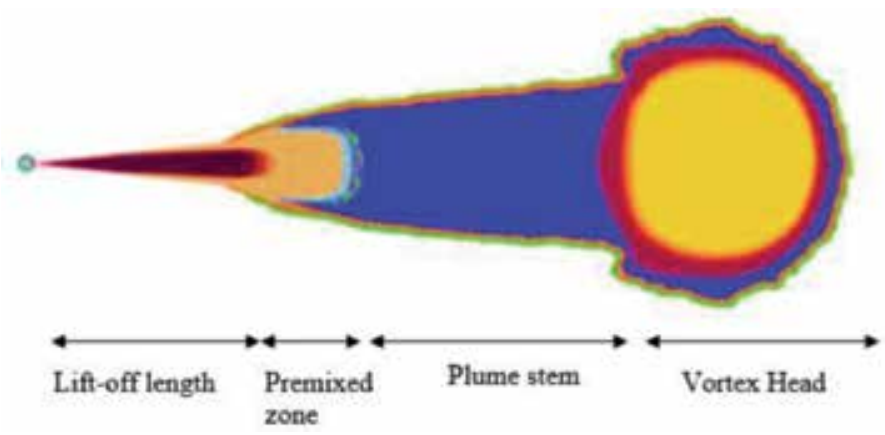

Figure 8.

Zones of Dec's conceptual model [29]. 
highlight the peripheral turbulent combustion. For the developed jet, the entrainment of turbulent air vaporize all liquid fuel after some distance from the nozzle tip leading to the formation of uniform fuel-air mixture. This is made up of fuel rich mixture and PAHs which afterwards, burn to generate small soot particles that fills and extends the jet length. The soot concentration and sizes increase downstream in a length referred to as 'plume stem' towards the leading edge and larger particles recirculate within the vortex. In the course of vortex recirculation, some soot particles reach peripheral flame front where they are further oxidized by $\mathrm{OH}$ radicals. Descriptively (using the same color codes as in Figure 5), the conceptual model could therefore be visualized as having four main zones: the lift-off length, the premixed zone, the plume stem and the vortex head [29]. The emissions and other contributions associated with combustion processes are still the subject of many further investigations.

\section{The diesel engine exhaust emissions}

Regulated exhaust emissions from the diesel engine include $\mathrm{HC}, \mathrm{CO}, \mathrm{NO}_{\mathrm{x}}$ and $\mathrm{PM}$. The conditions under which each of these is generated are interrelated in a complex web of factors; and much effort have focused on measures to improve the combustion process in order to counter their generation. These 'internal measures' target the highlighted emission factors like high injection pressures, injection rate shaping, combustion chamber designs, turbocharging and intercooling, transient control, spray-air interactions etc. Measures that target actual emissions in the exhaust system are considered as after-treatments. These measures deal with reduction or elimination of the emissions variables along the exhaust pipe prior to their release into the atmosphere.

\subsection{The hydrocarbon (HC)}

It is conventional in the domain of engine emission to refer the unburnt hydrocarbons (UHC) simply as 'hydrocarbons' (HC). The concentrations could range from 20 to $300 \mathrm{ppm}$; and for control purpose, distinction is often made of total hydrocarbons (THC) and non-methane hydrocarbons (NMHCs) by excluding methane gas from the total hydrocarbons. HC emissions contain several compounds, the variety and concentrations differ as the engine operating factors differ and vary. Small fractions of total unburnt hydrocarbons emerge as the originally sprayed fuel that survived oxidation during combustion, while higher proportions emerge as different intermediates due to pyrolysis and partial oxidation of fuel and lubricants. The diversity includes alkanes, alkene, alkynes and aromatic, meaning that $\mathrm{HC}$ emissions occur as single, double and triple bonds or in combinations; straight and branched chains or ringed chain structure as in aromatics. Aromatics with benzene basic ring structure are the building blocks for higher cyclic-structures of PAHs which can occur from fuel breakdowns and also from of incomplete combustion of fuel. The emission of hydrocarbons in diesel engines is significantly influenced by engine operating conditions of which, idling to light load modes are most culprits. The prevalent reasons include over-mixing of fuel with air which leads to over-leaning and therefore difficult to support combustion particularly at low temperatures; under-mixing which causes over-rich mixture and so difficult to ignite; and flame quenching at low temperature walls which causes partial burning. During ignition delay, the equivalence ratios attained by fuel-air mixture varies within a wide range. Some portions of the mixture are favorable to auto-ignition; some are locally too rich to burn while others are too lean to support combustion. For fuel injected when combustion has commenced, high temperature favors 
rapid oxidation of fuel-air charge towards complete combustion. However, there is over-rich portion of the mixture due to slow mixing of fuel and high quantity of intermediate products of pyrolysis due to high temperature and local starvation of air, fuel portions left in the nozzle sac, crevices volumes, as well as the effect of wall quenching as pointed. These lead to products of incomplete combustion and fuel in the exhaust. Many forms of intermediate products of incomplete combustion involve 'oxygenates' which are not pure hydrocarbons. Along with hydrocarbons, they constitute volatile components (VOCs) which condense as particulate matter as temperature drops on the exhaust line.

\subsection{Carbon monoxide (CO)}

During oxygen deficient combustion process, fuel is not fully oxidized; CO (which is an intermediate product on the fuel reaction-path), is produced along with $\mathrm{HC}$ as products of incomplete combustion. However combustion in most diesel engines are practically lean beyond stoichiometric, therefore $\mathrm{CO}$ emission is normally low except during transient operation and is easily oxidized to $\mathrm{CO}_{2}$ upon release to the atmosphere.

\subsection{Nitrogen oxides $\left(\mathrm{NO}_{\mathrm{x}}\right)$}

The oxides of nitrogen relevant to diesel engine emission are nitrogen oxide (NO) and nitrogen dioxide $\left(\mathrm{NO}_{2}\right)$. Nitrous oxide $\left(\mathrm{N}_{2} \mathrm{O}\right)$ is not a regulated emission; they are collectively referred to as oxides of nitrogen $\left(\mathrm{NO}_{\mathrm{x}}\right)$ of which, $\mathrm{NO}$ is dominantly emitted during combustion and $\mathrm{NO}_{2}$ is formed as a consequence of further oxidation. In the presence of ultra-violet light, $\mathrm{NO}_{2}$ forms a photochemical smog with non-methane hydrocarbon. During combustion, the main oxidant is oxygen, a constituent of air drawn together with nitrogen, which is technically non-reacting to fuel. However at high temperatures, nitrogen reacts with oxygen; and the mechanism follow many pathways. As adapted from [30] the NO formation mechanisms are: the thermal or Zeldovich mechanism, the Fenimore or prompt mechanism, the $\mathrm{N}_{2} \mathrm{O}$-intermediate mechanism and the NNH mechanism. The thermal mechanism is dominant in high temperature combustion over wide equivalent ratios while Fenimore mechanism is predominant in combustion of rich fuel mixture. The $\mathrm{N}_{2} \mathrm{O}$-intermmediate is considered to play an important role in the production of $\mathrm{NO}$ in very lean, low temperature combustion and the NNH is a new introduction to NO formation mechanisms.

Thermal or Zeldovich mechanism consists of two chain reactions.

$$
\begin{aligned}
& \mathrm{O}+\mathrm{N}_{2} \leftrightarrow \mathrm{NO}+\mathrm{N} \\
& \mathrm{N}+\mathrm{O}_{2} \leftrightarrow \mathrm{NO}+\mathrm{O}
\end{aligned}
$$

with an extended reaction.

$$
\mathrm{N}+\mathrm{OH} \leftrightarrow \mathrm{NO}+\mathrm{H}
$$

The forward $\left(_{\mathrm{f}}\right)$ and reverse $\left(_{\mathrm{r}}\right)$ reaction rate coefficients as in [31] are as follows:

$$
\begin{gathered}
k_{z 1, f}=1.8 \times 10^{11} \exp [-38,370 / \mathrm{T}(\mathrm{K})][=] \mathrm{m}^{3} / \mathrm{kmol}-\mathrm{s} \\
k_{z 1, r}=3.8 \times 10^{10} \exp [-425 / \mathrm{T}(\mathrm{K})][=] \mathrm{m}^{3} / \mathrm{kmol}-\mathrm{s}
\end{gathered}
$$




$$
\begin{gathered}
k_{z 2, f}=1.8 \times 10^{7} \mathrm{~T} \exp [-4,680 / \mathrm{T}(\mathrm{K})][=] \mathrm{m}^{3} / \mathrm{kmol}-\mathrm{s} \\
k_{z 2, r}=3.8 \times 10^{6} \mathrm{~T} \exp \left[-20,820 / \mathrm{T}(\mathrm{K})[=] \mathrm{m}^{3} / \mathrm{kmol}-\mathrm{s}\right. \\
k_{z 3, f}=7.1 \times 10^{10} \exp [-450 / \mathrm{T}(\mathrm{K})][=] \mathrm{m}^{3} / \mathrm{kmol}-\mathrm{s} \\
k_{z 3, r}=1.7 \times 10^{11} \exp [-24,560 / \mathrm{T}(\mathrm{K})][=] \mathrm{m}^{3} / \mathrm{kmol}-\mathrm{s}
\end{gathered}
$$

The reaction set are generally coupled to combustion chemistry through the $\mathrm{O}_{2}, \mathrm{O}$ and $\mathrm{OH}$ species. However depending on the time scale, it is also possible that combustion is completed before NO formation becomes significant, then the two processes can be decoupled and the formation rate of $\mathrm{NO}$ is expressed as:

$$
\frac{d[N O]}{d t}=2 k_{N, 1 f}[O]_{e q}\left[N_{2}\right]_{e q}
$$

Thermal mechanism is highly dependent on temperature; as typified by equation (z1), the activation energy is very large (about 319,050 kJ/kmol), giving insignificant NO formation in reactions where temperatures are below $1800 \mathrm{~K}$.

The NO formation by Fenimore mechanism is linked to the combustion chemistry of rapidly oxidizing flame zone of premixed hydrocarbon flames ahead of the NO formation through thermal mechanism. Fenimore [32] discovered this and gave it the appellation of prompt NO. The scheme is generally described as the reaction between hydrocarbon radicals and with molecular nitrogen leading to the formation of amines or cyano-compounds. These amines or cyano-compounds are then converted into intermediate compounds that yields NO. Starting from $\mathrm{CH}$ radicals in the formation process, the Fenimore mechanism can be expressed as:

$$
\begin{gathered}
\mathrm{CH}+\mathrm{N}_{2} \leftrightarrow \mathrm{HCN}+\mathrm{N} \\
\mathrm{C}+\mathrm{N}_{2} \leftrightarrow \mathrm{CN}+\mathrm{N}
\end{gathered}
$$

For air-fuel mixture where equivalence ratios $(\Phi)$ are less than 1.2, hydrogen cyanide (HCN) forms NO through the following the sequence:

$$
\begin{gathered}
\mathrm{HCN}+\mathrm{O} \leftrightarrow \mathrm{NCO}+\mathrm{H} \\
\mathrm{NCO}+\mathrm{H} \leftrightarrow \mathrm{NH}+\mathrm{CO} \\
\mathrm{NH}+\mathrm{H} \leftrightarrow \mathrm{N}+\mathrm{H}_{2} \\
\mathrm{~N}+\mathrm{OH} \leftrightarrow \mathrm{NO}+\mathrm{H}
\end{gathered}
$$

When $(\Phi)$ are greater than 1.2, other reaction pathways open up with more complex chemistry. As stated [33], the NO formation will cease to be rapid instead, it is recycled to HCN. In addition, the Zeldovich reaction that couples to prompt mechanism further reduces the formed NO to elemental nitrogen as $\mathrm{N}+\mathrm{NO} \rightarrow \mathrm{N}_{2}+\mathrm{O}$. 
The $\mathrm{N}_{2} \mathrm{O}$-intermediate mechanism is relevant in fuel-lean premixed combustion schemes where $(\Phi<0.8)$ and at low temperatures. Reaction steps for this mechanism are:

$$
\begin{gathered}
\mathrm{O}+\mathrm{N}_{2}+\mathrm{M} \leftrightarrow \mathrm{N}_{2} \mathrm{O}+\mathrm{M} \\
\mathrm{H}+\mathrm{N}_{2} \mathrm{O} \leftrightarrow \mathrm{NO}+\mathrm{NH} \\
\mathrm{O}+\mathrm{N}_{2} \mathrm{O} \leftrightarrow \mathrm{NO}+\mathrm{NO}
\end{gathered}
$$

In equations (17), ' $M$ ' represents a general third body; and by implication, the involvement of third bodies means that the mechanism is favored at elevated pressures. Similarly, equations (17) and (19) involve oxygen radical O, signifying that the mechanism favor oxygen rich conditions.

The NO formation by NNH mechanism is the most recently discovered reaction pathway and the steps involved are:

$$
\mathrm{N}_{2}+\mathrm{H} \rightarrow \mathrm{NNH}
$$

and

$$
\mathrm{NNH}+\mathrm{O} \rightarrow \mathrm{NO}+\mathrm{NH}
$$

This route to NO formation is linked to combustion of hydrogen, hydrocarbon fuels with high carbon-to-hydrogen ratios and certain fuels that contain nitrogen in their molecular structure (fuel nitrogen). The amount of fuel borne nitrogen is quite negligible with respect to diesel fuel and therefore insignificant.

Irrespective of the mechanism of formation, the NO in diesel engines is a byproduct of combustion and not a compound in transit like CO. Although NO formation is possible through any mechanism, it can either be sustained or destroyed depending on the prevailing equilibrium direction. It is expedient that in mitigation strategy, more emphasis is laid on the formation through thermal or Zeldovich mechanism since high temperature formation is related to the time of post-flame reactions. This is the reason why the NO formation in diesel combustion are associated with the extended Zeldovich mechanism, favored at high (local) temperature equilibrium diffusion flames.

\subsection{Particulate matter (PM)}

The term particulate matter (PM) is used to describe any matter that could be trapped on a sample filter paper when the exhaust gases are cooled to $52^{\circ} \mathrm{C}$ or less. It includes all condensates formerly in vapor state from various substances like sulfates, nitrates, organics, as well as solid black carbon particles (soot) and ash. The sources and reasons for PM emissions are immense when the variety of species are considered; however the $\mathrm{HC}$ and the soot particles are of more interest. The multi-phase and the complex nature of PM are characterized by its chemical composition and its physical characteristics. Physically, the sizes at which PM occur bears greatest attribute to the way it is characterized. Three customary sizes used to describe PM are the nucleation mode, accumulation mode and coarse mode particles. The nucleation mode particles are the smallest particles that occur by nucleation of species from its vapor state. The sizes vary from the small nuclei at formation, to identifiable film drops; and they usually attach to aggregates of solid 


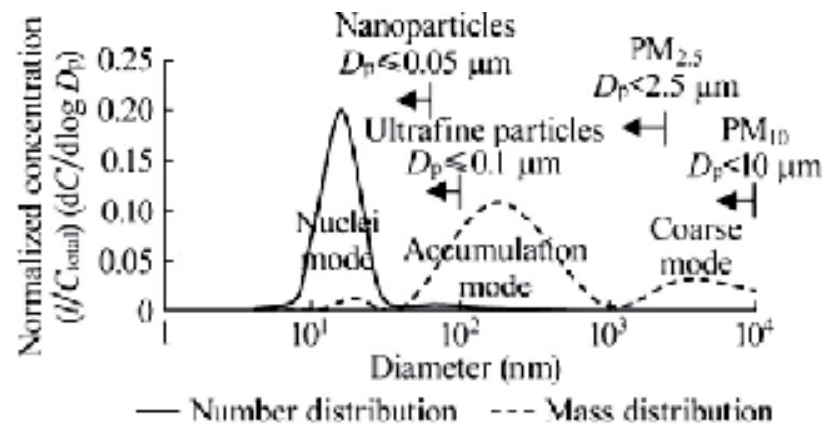

Figure 9.

Diesel engine exhaust PM size distributions expressed in number and mass metrics [34] as modified in [35].

particle if present. They are characterized by high number-concentrations, which are affected by heat, which cause vaporization and leads to drastic reduction in number concentration. The accumulation mode particles are usually aggregates of primary particles that form as solid carbonaceous core upon which condensates of volatile particles adhere. Coarse mode particles are larger, perceived as accretion of accumulation mode particles that were deposited at the walls and latter carried back to the aerosol bulk stream. These size distributions can be expressed either in number or mass metrics as shown in Figure 9. Chemically, the composition of PM are described as volatile or soluble; and the non-volatile or insoluble components (depending on method of separation). These are further classified according to their chemical speciation in assay as prescribed by various regulatory authorities that prescribe the acceptable test protocols and procedures.

Figure 10 gives conceptualization of composite fractions, typical of diesel PM emissions which include: sulfates, nitrates, organics carbonaceous and ash [1, 29, 34].

Sulfate ions $\mathrm{SO}_{4}{ }^{2-}$ commonly emitted from diesel engine is water-soluble sulfuric acid, therefore assayed through solubility. Other possible sulfate particulates include metallic salt like calcium sulfate $\mathrm{CaSO}_{4}$. The metal ion may originate from lubricant additives which actively react with sulfuric acid. They are less hydrophilic compared to sulfuric acid. Sulfate particulates have been drastically reduced in modern automotive engines as result of improvements in fuels technology leading to achievement of ultra-low sulfur diesels blended with synthetic lubricity additives.

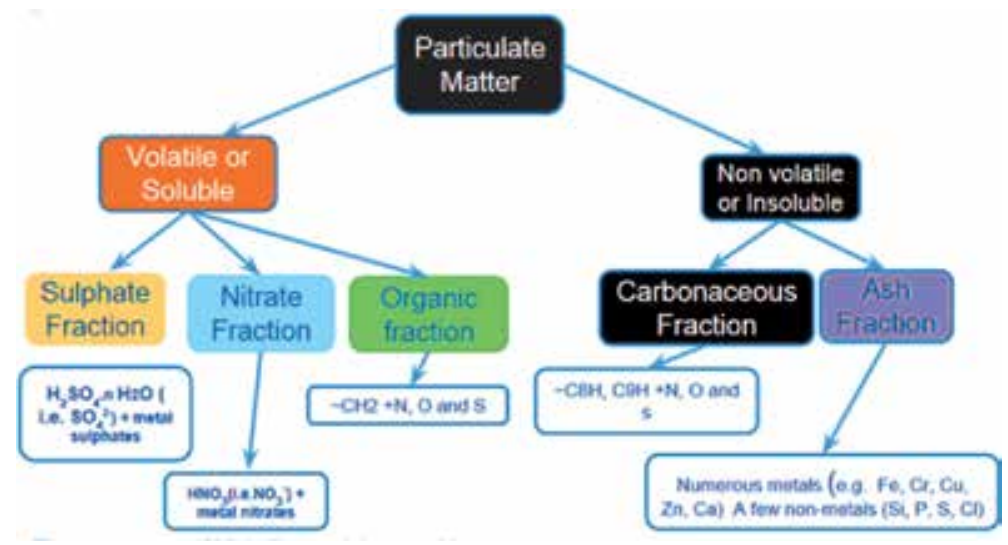

Figure 10.

Conceptualization of the composite fraction of particulate matter [6]. 
Nitrates are similarly water soluble and this also dictates the assaying technique. The major component formed by $\mathrm{NO}^{3-}$ ions is nitric acid $\left(\mathrm{HNO}_{3}\right)$ in the reaction perceived to be due to $\mathrm{NO}_{2}$ and water.

$$
\begin{aligned}
& 2 \mathrm{NO}_{2}+\mathrm{H}_{2} \mathrm{O} \rightarrow \mathrm{HNO}_{2}+\mathrm{HNO}_{3} \\
& 3 \mathrm{HNO}_{2} \rightarrow \mathrm{HNO}_{3}+2 \mathrm{NO}+2 \mathrm{H}_{2} \mathrm{O}
\end{aligned}
$$

Although the formation mechanism has not been well reported, the presence of $\mathrm{HNO}_{3}$ in diesel exhaust is not in doubt. Nitrate particulates are more researched in atmospheric science where acid-ammonia reactions dominate.

Organic fractions assayed by heating or vacuum evaporation are referred to as volatile organic fraction (VOF); and if by dissolution in organic solvent, it is called soluble organic fraction (SOF). In either approach, the masses obtained are closely equal if proper adjustments are made for the non-organic compound in the case of heating. During heating process, evaporated fraction may include water-bound species, and are therefore called volatile organic components (VOC) to distinguish pure organic and from the presence of non-organic particles. The VOF is by far the most complex of the diesel PM because many organic compounds are present. Typical diesel emitted VOF are from unburnt or partially combusted hydrocarbons arising from fuels and lubricants emitted during low engine loads when the exhaust temperatures are low [6].

The carbonaceous fractions are also referred in many ways as elemental carbon (EC), soot, black carbon (BC) and graphite carbon. Diesel soot particles are generated mainly during diffusion regimes of the heterogeneous combustion in engines. It basically occur as primary particles in sizes of 20-50 nm which accretes to form identifiable aggregate structures, whose size depends on material availability and exhaust line temperature $[29,34,36]$.

Ash fraction denotes the burnt or incombustible ashes that arise from metals. Substances such as oxides, sulfates and phosphates of metals used in lubricants additives are likely to be found as well as burnt material of the worn engine components.

\subsubsection{PM formation process in the engine}

The PM formation process in the engine is complex and majorly originate from fuel and lubricant. The spray combustion process presented earlier, is indeed the story of soot formation process. When fuel is only partially oxidized, it results in complex intermediates which constitute the volatile organic fractions in the exhaust stream and later condense as particles of organic compound along the exhaust line. The soot process in engine involves conversion of liquid fuel to vapor phase and then to solid particles which are oxidized back to gaseous products. The un-oxidized particles are emitted as the visible black soot. The identifiable steps in soot process could be outlined as pyrolysis, nucleation, coalescence, surface growth,

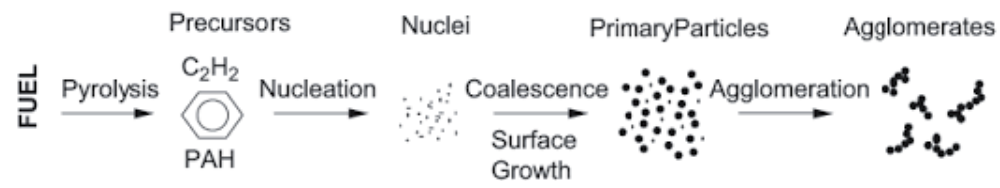

Figure 11.

Steps in soot formation process [37]. 
agglomeration and oxidation. The first five steps are outlined as in Figure $\mathbf{1 1}$ but, any of these activities in the formation process could be terminated through oxidation.

The soot oxidation process does not necessarily follow in the sequence but recognized as the final step in the combustion process which could occur anytime and convert hydrocarbons to $\mathrm{CO}, \mathrm{CO}_{2}$ and $\mathrm{H}_{2} \mathrm{O}$. This means that the precursor feedstock, the nuclei, the primary and agglomerated particles could be consumed in the oxidation process into gaseous products at any stage. In effect, this highlights soot emission as an intermediate product due to incomplete combustion in the engine. Therefore reduction of soot emission through engine combustion process will involve prevention of its formation, promotion of its complete oxidation or both.

\section{Mitigations of diesel engine emissions}

Many strategies are used to eliminate or reduce the amount of diesel engine exhaust emissions released to the atmospheric environment. For long, a wholesome approach of integrating 'internal factors' which aims to achieve better engine combustion and 'after-treatments' which aims at reducing already borne pollutants in the exhaust stream are considered in application. These internal factors include improvements in combustion chamber design, air cooling and boosting; and fuel delivery systems. They are usually modified according to how each parameter is viewed to influence the generation of particular emission variable. Management of these factors can be challenging because some conditions that favor reduction of one variable may be opposed to the other as is typically the case of $\mathrm{PM}$ and $\mathrm{NO}_{\mathrm{x}}$ reductions. The after-treatment technologies are also used in a way that, each or closely related emission variables are targeted for mitigation. These include the use of diesel oxidation catalysts to convert $\mathrm{CO}$ and HCs into $\mathrm{CO}_{2}$ and water; diesel particulate filter (DPF) to trap soot; and suitable reductant like urea or ammonia to reduce NO to elemental nitrogen. Integration of these technologies for smooth engine operation is also a big challenge in modern engine technology. In operation, sensors and control loops are used to monitor and coordinate related issues for example, catalysts in the exhaust system operate within a reference temperature window and good thermal management is an issue; the need for additional air requirement to strike the right balance for exhaust-gas quality control or the need for right dosage of urea based on limiting trade-offs. Equipment manufacturers usually describe these peculiarities depending on their compromise path to achieve attainment of the prevailing regulatory emissions levels. Many texts approach the complexities of diesel after-treatments with specialized details $[3,29,38]$. For simplicity, the way some factors affect diesel exhaust emissions and how the mitigation strategies are pursued by targeting those factors are itemized as follows:

\subsection{Mitigations by internal factors (air intake, engine-flow and injection related issues)}

The importance of achieving stoichiometric air-fuel ratio has been highlighted to be necessary towards ensuring quality combustion. This is usually achieved through design and operating considerations for intake port/injector profiles and orientations, swirl motion in relation to fuel injection timing and duration.

For naturally aspirated engines, fixed cylinder volume means air charge per cycle is constant; and for a constant engine speed, the load is controlled through fuel injection. Increase in fuel injection in order to increase the load will affect 
the mixture composition in many ways. Some portion of fuel is injected during ignition delay period and greater quantity injected as large droplets towards the end of injection. These trigger wide range of equivalence ratios during the combustion phase. For the pre-mixed portion, some will attain stoichiometric proportion, some too lean and others may even be locally too rich to support combustion. The portion injected later will need high temperature to vaporize, fresh air or lean mixture to mix with, and which must be at a fast rate in order to undergo complete combustion. Different emission scenario are possible here depending on engine operating factors. For engine started from cold, rich mixture is inevitable, therefore, exhaust stream will be smoky due to initial richness; allowing the engine to idle for warm up and gradual load increase during the transient period before engine attain its operating temperature, this will lead to more emission of unburnt hydrocarbons and intermediates. Similarly, if combustion rate is not fast enough, lately sprayed fuel and some portion still undergoing pyrolysis will be caught up by fast cooling as expansion stroke progresses and this will lead to emissions of unburnt hydrocarbon and intermediates.

Some of these drawbacks are usually overcome with the use of turbocharger to increase the mass of air inducted into the cylinder. This permits proportional increase in fuel injection to suit required power output of the engine. As air velocity will be higher through the intake ports, whether as in swirl-supported or quiescent combustion system, air-fuel mixing is enhanced. This leads to better fuel oxidation and reduction in emission of $\mathrm{HC}, \mathrm{PM}$ and $\mathrm{CO}$; however, it is responsible for increase in NO formation.

The influence of fuel injection scheme on emissions and possible improvements that could be achieved through their modifications are also interesting. Increase in injection pressure can be used to improve entrainment rate which leads to improved combustion efficiency. This reduces emission of hydrocarbon and intermediates; while increasing combustion temperature. Higher temperature regime is a veritable platform for NO formation. On the other hand, injection timing has its own influence on these variables. Advance of injection timing promotes mixture formation which similarly enhances combustion and increase in temperature with attendant NO formation, retard in injection timing has a reverse effect as the premixed portion is reduced and ultimately NO formation is reduced.

One technique that has been used to reduce NO formation is intake charge dilution. This may be accomplished through methods like recirculation of exhaust gas, introduction of water spray or nitrogen. The mechanism behind these is that as diluents, they possess high specific heat capacity which make them sources of thermal sink. Since their presence reduce oxygen concentration of the fresh air charge, they will slow down the rate of combustion and thereby lower the peak pressures and temperatures that promote the formation of NO.

\subsection{After-treatment mitigation technologies}

As has been highlighted, three after-treatment technologies used in diesel engine exhaust emissions mitigations are use of oxidation catalysts that oxidizes $\mathrm{CO}, \mathrm{HCs}$ (which includes PAHs) and SOF; catalyzed and non-catalyzed diesel particulate filters (DPF) to filter and regenerate soot and use of $N O_{x}$ reductants like selective catalytic reduction (SCR) with ammonia, SCR with hydrocarbons $\left(\mathrm{deNO}_{\mathrm{x}}\right.$ or lean $\mathrm{NO}_{\mathrm{x}}$ catalyst) and $\mathrm{NO}_{\mathrm{x}}$ adsorber-catalyst system.

\subsubsection{Diesel oxidation catalysts (DOCs)}

These catalysts further oxidizes $\mathrm{CO}, \mathrm{HC}$, SOF and $\mathrm{PAH}$ into $\mathrm{CO}_{2}$ and water as schematically represented in Figure 12. 
The following chemistry are involved with the compounds:

$$
\begin{gathered}
\mathrm{HC}+\mathrm{O}_{2} \rightarrow \mathrm{CO}_{2}+\mathrm{H}_{2} \mathrm{O} \\
2 \mathrm{CO}+\mathrm{O}_{2} \rightarrow 2 \mathrm{CO}_{2}
\end{gathered}
$$

It is pertinent to note that DOC oxidizes all compounds with reducing character, and not all these are beneficial. The oxidation of sulfur dioxide to sulfur trioxide is an example; it is highly soluble in water and consequently it leads to formation of sulfuric acid which is emitted in the tail pipe.

$$
\begin{gathered}
2 \mathrm{SO}_{2}+\mathrm{O}_{2} \rightarrow 2 \mathrm{SO}_{3} \\
\mathrm{SO}_{3}+\mathrm{H}_{2} \mathrm{O} \rightarrow \mathrm{H}_{2} \mathrm{SO}_{4}
\end{gathered}
$$

Similar incident occurs with the oxidation of $\mathrm{NO}$ to $\mathrm{NO}_{2}$ which is more toxic than NO.

$$
2 \mathrm{NO}+\mathrm{O}_{2} \rightarrow 2 \mathrm{NO}_{2}
$$

This was initially an undesirable development with the use of DOCs until it was discovered that $\mathrm{NO}_{2}$ is a beneficial oxidizer in the catalytic regeneration of DPF where it donates one oxygen atom and reduces back to NO. Platinum, a highly acclaimed noble metal enables a high conversion efficiency of up to $90 \%$ to be achieved at a sufficiently high exhaust temperature. It is highly durable in operation and commercially available, DOCs can also remove diesel odor.

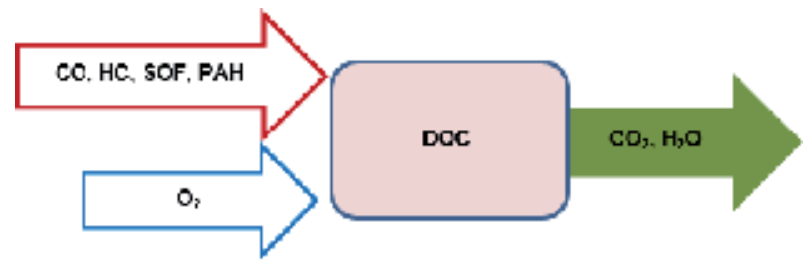

Figure 12.

Conversion chemistry with the use of DOC.

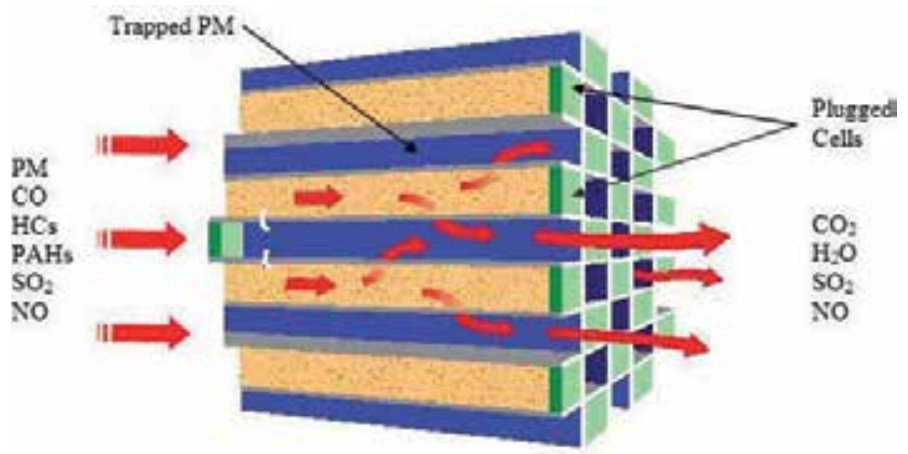

Figure 13.

Wall-flow diesel particulate filter. 


\subsubsection{Diesel particulate filter (DPF)}

Diesel particulate filters are used to trap particles of micron and sub-micron sizes carried in the exhaust stream. In effect, condensed SOF, water, soot and ash are contained in the particulate soup. In application, the most commonly used is wallflow DPF which has the cells alternately plug at each end, Figure 13. In this way, exhaust gas permeates through walls of the filter while the particles are trapped. The intricacies of PM depositions, measurements and removal are immense and beyond the scope of this piece, and the references already cited on 'after-treatments' can be further consulted. However, the key points to be noted are that PM filtration in the engine system has a technical problem of pressure drop across the filter when it is clogged with accumulated matter. The pressure drop across the DPF due to buildup of PM is critical for continuous safe engine operation. This is conventionally regarded as exhaust back pressure in a relaxed scientific sense.

The gas flow mechanics of the exhaust line is such that exhaust gas is driven by positive compression pressure of the engine, sufficiently high to overcome any obstruction along the exhaust flow line. In a strict sense therefore, the term 'back pressure' is more suitable to express the pressure drop across the entire exhaust line which is numerically equal to the exhaust pressure at the turbo (or exhaust manifold) outlet, not just the pressure drop across a component of the exhaust system [29,39]. The factors that contribute to pressure drop across the filter can be classified into four perspectives: (a) the geometrical properties where the length, frontal area, wall thickness and channel dimensions are considered; (b) the substrate material properties whereby the porosity, permeability and pore size are considered; (c) the exhaust gas flow characteristics where the temperature, flow rate and viscosity are considered; and $(d)$ the nature of PM membrane, where the particle size distribution, density and permeability are considered [38, 40]. These considerations are normally used to study pressure drop across DPF in both modelling and experimental efforts. With regards to engine operations, engine load and speed determines the exhaust flow rate. Increasing the load and speed increases the pressure upstream of the filter; this means that the quantity of soot accumulated by the filter depends on the usage of the engine. By implication, the pressure drop across the filter set at a pre-determined value has become a parameter to determine when to burn-off accumulated soot (to regenerate the filter). Many techniques are employed in regenerating DPF; these include the use of electric heaters, injection of fast burning fuel into the exhaust line upstream of the filter and use of microwave heating. Modern application adopt the use of catalyzed filters to lower the oxidation temperature of the trapped soot. This ensures continuous regeneration of DPF as the light-off temperature of the catalyst is reached. This is usually in the neighborhood of the exhaust line temperature. Further reading on filter loading and pressure drop across it can be seen in $[6,41-43]$.

\subsection{3 $\mathrm{NO}_{x}$ reduction}

Reduction of $\mathrm{NO}_{\mathrm{x}}$ has been successful with reduction catalysts both for lean burn gasoline engines and diesel engines. The reduction chemistry of NO which is favored thermodynamically under the prevailing engine temperatures and pressure can be simply describe as follows:

$$
2 \mathrm{NO} \rightarrow \mathrm{N}_{2}+\mathrm{O}_{2}
$$

One of the best described catalysts is the copper exchange zeolite, Cu/ZSM5 and the decomposition is very sensitive to water and $\mathrm{SO}_{2}$, and operates well at low 


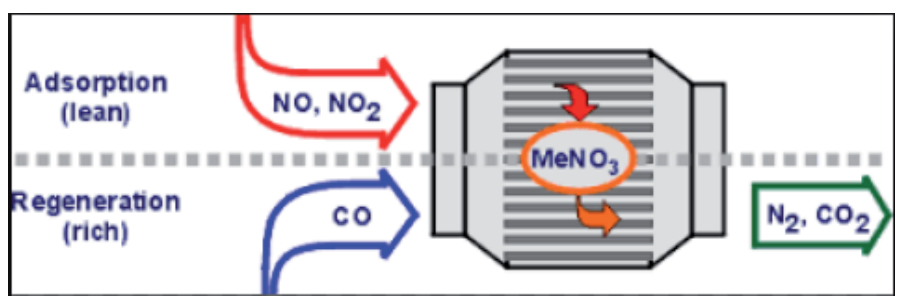

Figure 14.

Operations of $\mathrm{NO}_{x}$ adsorber. Adapted from [3].

space velocities. Ammonia and Urea offer good selective reduction in the presence of a catalyst over the competitively reaction process with oxygen. By far, this is the predominant technique in application. The chemistry can as well be simplified as:

$$
4 \mathrm{NO}+4 \mathrm{NH}_{3}+\mathrm{O}_{2} \rightarrow 4 \mathrm{~N}_{2}+6 \mathrm{H}_{2} \mathrm{O}
$$

SCR technique has a high $\mathrm{NO}_{\mathrm{x}}$ conversion efficiency of about $90 \%$ and this has made it the choice for large diesel engine, co-generation plants and non-engine installations. However, it has a major disadvantage of high installation, space and operating cost. In addition, during operation, there is problem of ammonia slip which leads to equipment fouling with ammonia sulfate.

Lean $\mathrm{NO}_{x}$ or deNO $\mathrm{O}_{x}$ catalysts act by the replacement of ammonia with hydrocarbon. Platinum-based catalysts and base-metal catalyst like $\mathrm{Cu} / \mathrm{ZsM} 5$ have proved successful but with the drawback of operating within a narrow temperature window and about $50 \%$ conversion efficiency in active systems and $10-20 \%$ in passive systems tested on regulatory test cycles.

$N O_{x}$ adsorber catalysts have up to $80 \%$ reduction efficiency but depends on drive cycle through two stages of operation. The first stage is that of $\mathrm{NO}_{\mathrm{x}}$ storage on the catalyst wash coat during lean operation also referred to as chemisorption stage. The second is regeneration of the trap through desorption and non-selective catalytic reduction of $\mathrm{NO}_{\mathrm{x}}$ during periods of rich operation. These phases of operation are shown in Figure 14 using upper and lower halves respectively; and a metal nitrate indicated as $\mathrm{MeNO}_{3}$ used to store $\mathrm{NO}_{\mathrm{x}}[3]$.

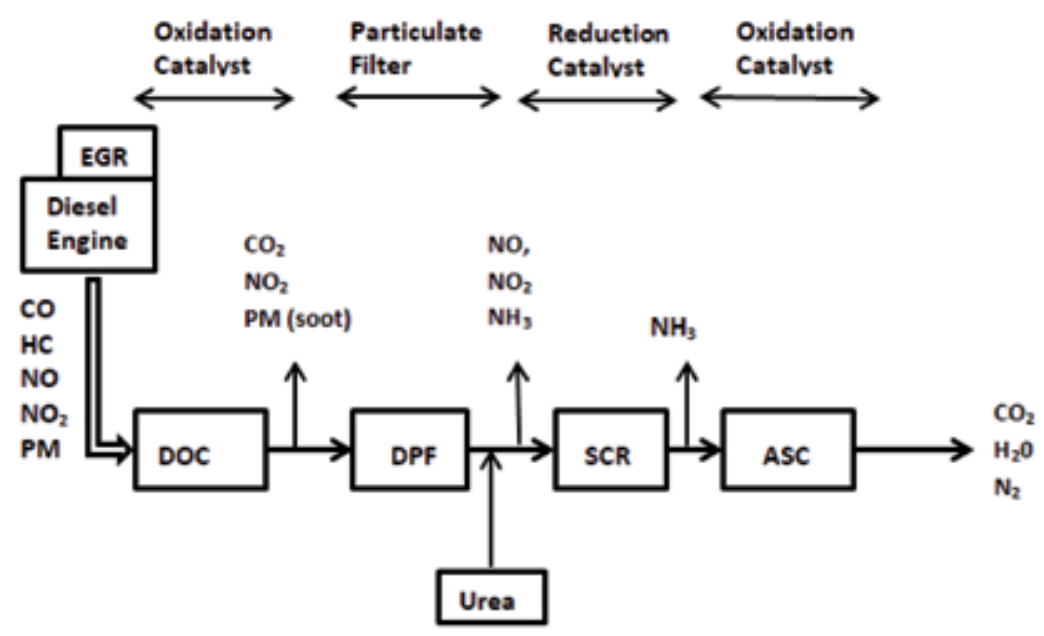

Figure 15.

Complete train of after-treatment technologies in the exhaust line. 


\section{Summary}

Diesel emissions and mitigations are complex and can be discussed in diverse topics as highlighted in this piece. Understanding of the subject matter involves good grasp of the engine systems designs, and interplay of relevant integrated technologies. The operational perspectives also demand attention. This starts with the nature of diesel fuel itself, how it is delivered to the engine, mixed and burnt with oxygen of the air. The efficiency of the in-cylinder combustion is central to the quality of emission occurring at the tail pipe. Inevitably, combustion event varies from cycle to cycle according to engine load requirements. Therefore even the best designed engines are prone to emit some unwanted pollutants into the atmosphere. To combat this, aftertreatment devices are now complementary to the overall engine technology.

The key after-treatment technologies have been briefly presented as independently considered techniques with respect to the variables they address. However this was for narrative convenience, as their inclusion extends the integration requirements of the engine. In a modern diesel engine especially for automotive applications, it is now customary that the exhaust train carry oxidation catalysts where $\mathrm{CO}, \mathrm{SOF}$ and $\mathrm{HCs}$ are essentially oxidized to $\mathrm{CO}_{2}$ and water. Further, $\mathrm{NO}$ is oxidized to $\mathrm{NO}_{2}$ which in turn becomes an oxygen carrier for catalytic soot regeneration in the DPF and reduces back to NO. Then NO is reduced to elemental nitrogen through a SCR (Figure 15).

\section{Nomenclature}

$\begin{array}{ll}\mathrm{A} / \mathrm{F}_{\mathrm{S}} & \text { stoichiometric air-fuel } \\ \mathrm{A}_{\mathrm{n}} & \text { nozzle flow area } \\ \mathrm{ASI} & \text { after start of injection } \\ \mathrm{BDC} & \text { bottom dead center } \\ \mathrm{DPF} & \text { diesel particulate filter } \\ \mathrm{HC} & \text { hydrocarbon } \\ \mathrm{LES} & \text { large eddy simulation } \\ \mathrm{N} & \text { engine speed } \\ \mathrm{PAH} & \text { poly aromatic hydrocarbon } \\ \mathrm{PM} & \text { particulate matter } \\ \mathrm{RANS} & \text { Reynolds average Navier-stokes } \\ \mathrm{SCR} & \text { selective catalytic reduction } \\ \mathrm{TDC} & \text { top dead center } \\ \mathrm{VOC} & \text { volatile organic component } \\ \mathrm{VOF} & \text { volatile organic fraction } \\ \mathrm{We} & \text { Weber number } \\ \mathrm{Symbol}_{\mathrm{CO}} & \\ \mathrm{CO}_{2} & \text { carbon monoxide } \\ \mathrm{H}_{2} \mathrm{SO}_{4} & \text { carbon dioxide } \\ \mathrm{HNO} & \text { sulfuric acid } \\ \mathrm{NH}_{3} & \text { nitric acid } \\ \mathrm{NO} & \text { ammonia } \\ \mathrm{NO}_{2} & \text { nitrogen oxide } \\ \mathrm{NO}_{\mathrm{x}} & \text { nitrogen dioxide } \\ \mathrm{SO}_{2} & \text { nitrogen oxides } \\ \mathrm{SO}_{3} & \text { sulfur dioxide } \\ & \text { sulfur trioxide }\end{array}$




\section{Author details}

Nehemiah Sabinus Alozie ${ }^{1 *}$ and Lionel Christopher Ganippa ${ }^{2}$

1 Department of Mechanical Engineering, University of Lagos, Nigeria

2 Department of Mechanical and Aerospace Engineering, Brunel University London, UK

*Address all correspondence to: nehi351@gmail.com

\section{IntechOpen}

(C) 2019 The Author(s). Licensee IntechOpen. This chapter is distributed under the terms of the Creative Commons Attribution License (http://creativecommons.org/licenses/ by/3.0), which permits unrestricted use, distribution, and reproduction in any medium, provided the original work is properly cited. (cc) BY 


\section{References}

[1] Heywood JB. Internal Combustion Engine Fundamentals. New York: Tata McGraw-Hill; 2011

[2] Pundir BP, Engines IC. Combustion and Emissions. New Delhi: Norosa; 2002

[3] Majewski WA, Khair M. Diesel Emissions and Controls. Warrendale: SAE International; 2006

[4] Stone R. Introduction to Internal Combustion Engines. London: Macmillan Press Ltd; 1999

[5] Owen K, Coley T. Automotive Fuels Reference Book. Warrendale: Society of Automotive Engineers, Inc.; 1995

[6] Alozie NSI. Issues of particulate matter emissions from diesel engines and its control [thesis]. London: Brunel University London; 2016

[7] Pesiridis A. Automotive Exhaust Emissions and Energy Recovery. New York: NOVA; 2014

[8] Osuka I et al. United States of America Patent 5,231,962, 1993

[9] Uludogan A, Xin J, Reitz RD. Exploring the use of multiple injectors and split injection to reduce di diesel engine emission. In: Society of Automotive Engineers; Detroit: 1996

[10] Jafarmadar S. The effect of split injectionon the combustion and emissions in di and idi diesel engines. In: Diesel Engine Combustionemissions-and-condition-monitoring. 2013. Available form: https://www. intechopen.com/books/diesel-enginecombustion-emissions-and-conditionmonitoring

[11] Gugulotha SK, Reddy KHC. Effect of injection timing and Split injection on different piston bowl configurationns in a DI diesel engine. Procedia Engineering. 2015;127:924-931
[12] Dec JE. A conceptual model of DI diesel combustion based on laser-sheet imaging. In: Society of Automotive Engineers SAE 970873; Detroit: 1997

[13] Reitz RD, Patterson MA. Modeling the effects of fuel spray characteristics on diesel engine combustion and emission. In: Society of Automotuive Engineers in SAE Technical Paper 980131; Detroit; 1998. DOI: 10.4271/980131

[14] Naber J, Reitz R. Modeling engine spray/wall impingement. In: Society of Automotive Engineers SAE Technical Paper 880107; Detroit: 1988. DOI: 10.4271/880107

[15] Siebers DL. Liquid-phase fuel penetrationin diesel sprays. In: Society of Automotive Engineers, SAE Technical Paper; Detroit: 1998

[16] Pickett LM, Siebers DL. Soot in diesel fuel jets: Effects of ambient temperature, ambient density, and injection pressure. Combustion and Flame. 2004;138(1-2):114-135

[17] Kosaka H, Aizawa T, Kamimoto $\mathrm{T}$. Two-dimensional imaging of ignition and soot formation processes in a diesel flame. International Journal of Engine Research. 2005;6(1):21-42. DOI: 10.1243/146808705X7347

[18] Higgins B, Siebers D, Aradi A. Diesel-spray ignition and premixed burn behaviour. In: Society of Automotive Engineers, SAE Technical Paper 2000-01-0940; Detroit: 2000

[19] Musculus MPB, Miles PC, Pickett LM. Conceptual models for partially premixed low-temperature diesel combustion. Progress in Energy and Combustion Science. 2013;39:246-283

[20] Tree DR, Svensson KI. Soot processes in compression 
ignition Engines. Progress in Energy and Combustion Science. 2007;33(3):272-309

[21] Genzale CL, Reitz RD, Musculus MPB. Optical diagnostics and multidimensional modeling of spray targeting effects in late-injection low-temperature diesel combustion. In: Society of Automotive Engineers SAE Paper 2009-01-2699; Detroit; 2009

[22] Jääskeläinen $H$, Khair MK. DieselNet.com [Online]. Available from: https://dieselnet.com/tech/ diesel_combustion_spray.php [Accessed: 11 Augest 2017]. Copyright (C) Ecopoint Inc

[23] Reitz RD, Bracco FV. Mechanisms of atomization of a liquid jet. Physics of Fluids. 1982;25(10):1730-1742

[24] Hiroyasu H, Kadota T, Arai M. Supplementary comments: Fuel sprays characterization in diesel engines. In: Combustion Models in Reciprocating Engines. New York: Plenum Press; 1980. pp. 369-408

[25] Hay N, Jones PL. Comparisons of the various correlations for spray penetration. In: Society of Automotive Engineers SAE Paper 720776; Detroit: 1972

[26] Espey C, Dec JE. The effect of TDC temperature and density on the liquidphase fuel penetration in a D. I. Engine. In: Society of Automotive Engineers (SAE) Technical Paper 952456; Detroit: 1995

[27] Naber JD, Siebers DL. Effects of gas density and vaporisation on penetration and dispersion of diesel sprays. In: SAE Technical Paper 960034; Detroit: 1996

[28] Pickett LM, et al. Relationship between diesel fuel jet vapor penetration/dispersion and local fuel mixture-fraction. In: SAE Technical Paper 2011-01-0686; Detroit: 2011
[29] Eastwood P. Particulate Emissions from Vehicles. West Sussex, England: John Wiley and Sons Limited; 2008

[30] Turns SR. An Introduction to Combustion (Concepts and Applications). New Delhi: TataMcGrawHill; 2012

[31] Hanson RK, Salimian S. Survey of rate constants in the N/H/O systems. In: Combustion Chemistry. New York: Springer-Verlag; 1984. pp. 361-421

[32] Fenimore CP. Formation of nitric oxide in premixed hydrocarbon flames. In: Thirteenth Symposium (International) on Combustion, Pittsburgh, PA. 1970

[33] Miller JA, Bowman CT. Mechanisms and modeling of nitrogen chemistry in combustion. Progress in Energy and Combustion Science. 1989;15:287-338

[34] Kittelson DB. Engines and nanoparticles: A review. Journal of Aerosol Science. 1998;29, 5-6:575-588

[35] Chuang P, Xu G. A review of the health effects and exposure-responsible relationship of diesel particulate matter for underground mines. International Journal of Mining Science and Technology. 2017. DOI: 10.1016/j. ijmst.2017.07.020

[36] Maricq MM. Chemical Characteracterization of particulate emissions from diesel Engines. Journal of Aerosol Science. 2007;38:1079-1118

[37] Tree DR, Svensson KI. Soot process in compression ignition Engines. Progress in Energy and Combustion Science. 2007;33:272-309

[38] Eastwood P. Critical Topics in Exhaust Gas Aftertreatment, Baldock Hertfordshire. England: Research Studies Press; 2001

[39] Jääskeläinen H. Available from: http:/www.brunel.ac.uk [Online]. 
https://www.dieselnet.com/tech/ diesel_exh_pres.php [Accessed: 15 October 2007]

[40] Murtagh MJ, Johnson TV. Diesel particulate filter overview: Material, geometry and application. In:

Automotive Exhaust Emissions and Energy Recovery. New York: Nova Sciences Publishers Inc.; 2014. pp. 173-201

[41] Stobart R, Wijewardane A. Exhaust System heat exchanger design for thermal energy recovery in passenger vehicle applications. In: Vehicle Thermal Management Systems Conference and Exhibitions, Gaydon, Warwickshire, UK. 2011

[42] Hinds T, Twigg M, Gallinger M. A new instrument for diesel particulate filter functional tests in development and quality control applications. In: Society of Automotive Engineers, SAE 2010-01-0809; Detroit: 2010

[43] Bermudez V, Serrano JR, Piqueras P, García-Afonso O. Influence of DPF soot loading on engine performance with a pre-Turbo Aftertreatment exhaust line. In: Society of Automotive Engineers Paper 2012-01-0362; Detroit: 2012

[44] Reitz RD, Diwakar R. Structure of high-pressure fuel sprays. In: SAE Technical Paper 870598; Detriot: 1987. DOI: $10.4271 / 870598$

[45] Pilch M, Erdman CA. Use of breakup time data and velocity history data to predict the maximum size of stable fragments for accelerationinduced breakup of a liquid drop. International Journal of Multiphase Flow. 1987;13:741-757

[46] Tonini S et al. The role of droplet fragmentation in high pressure evaporating sprays. International Journal of Thermal Sciences. March 2009;48(3):554-572. DOI: 10:1016/j. ijthermalsci.2008.03.020 

Performance, Emissions, and Combustion Evaluations of a Diesel Engine Fuelled with Biodiesel Produced from High FFA Crude Mahua (Madhuca longifolia) Oil

\author{
Aman Hira, Debasish Das and Ranjna Thakur
}

\begin{abstract}
Biodiesel is one of the environment-friendly alternative fuels need to be developed in order to meet the increasing demand for mineral fuels for transportation. In this study, nonedible crude Mahua oil has been used to extract biodiesel. Performance, emission and combustion characteristics of Mahua oil biodiesel blends with conventional diesel are compared on a single cylinder, natural aspirated, water-cooled direct injection (DI) diesel engine. Brake thermal efficiency of an engine fuelled with Mahua biodiesel blend B30 has been shown nearly same or insignificant lower compare to mineral diesel. The optimum engine operating condition based on lower brake specific fuel consumption and higher brake thermal efficiency was observed at 60\% load for blend B30 of crude Mahua oil biodiesel. From an emissions point of view blend, $\mathrm{B} 30$ was found to be the best fuel as it showed lesser exhaust emission such as $\mathrm{CO}, \mathrm{HC}, \mathrm{CO}_{2}$, and $\mathrm{NOx}$. Heat and pressure curve with respect to crank angle showed the details of combustion characteristics and revealed that combustion starts earlier for higher biodiesel blends. Results show that biodiesel obtained from nonedible Mahua oil gave better results and can be used as an excellent substitute for fossil fuels.
\end{abstract}

Keywords: High FFA crude Mahua oil, transesterification, esterification, diesel engine, performance, emissions, combustion

\title{
1. Introduction
}

Biomass sources, especially vegetable oils have received much more attention as an alternative source of energy [1]. But its higher viscosity rises some problems like filter clogging, carbon deposition on injector nozzle, compression ring groove piston lend etc. $[2,3]$. To solve these problems following methods have been adopted to make it usable in the engine such as blending in small ratio with standard diesel fuel, emulsification, cracking and conversion into biodiesel through transesterification [4]. As per ASTM standard biodiesels are monoalkyl of long chain fatty acid [5]. 
Biodiesel is an alternative diesel fuel made from renewable biological sources such as vegetable oils and mineral oil $[6,7]$. It is biodegradable, nontoxic, renewable and environment-friendly [8-10]. Biodiesel makes the environment fairly less hazardous compared to petroleum diesel, such as decrease acid rain and greenhouse effect caused by combustion. Renewability, biodegradability, sustainability, and environment-friendly properties make it an advantage to that of fossil fuel [8]. Besides this, it protects the global from the exponentially increasing emission, such as $\mathrm{CO}_{2}$, $\mathrm{SOx}$ and unburned hydrocarbon (HC) during the combustion process [11]. India is a seventh largest and developing country in the world needs a large amount of energy source to sustain their social and economic growth in 2010 India was the world fifth largest net importer of oil, imported more than $2.2 \mathrm{million} \mathrm{bbl} / \mathrm{d}$ (Barrel per day), or about $70 \%$ of consumption [12]. It implies a dependency on petroleum imports. The supply of part of the demand with biodiesel can contribute to decreasing this dependency.

Many authors have reported that blends of vegetable oils (edible or non-edible) based biodiesel with diesel when used in a diesel engine, a reduction in emission and comparable performance were achieved [13,14]. Nabi et al. [15] conducted an experiment with Neem oil biodiesel blend in the comparison of diesel fuel on four-stroke natural aspirated (NA) direct injection (DI) diesel engine. Blend showed lower carbon monoxide (CO) emission but higher NOx emission compared to conventional diesel. Later in the second phase, NOx emission was slightly reduced compared to diesel when the engine was applied Exhaust gas recirculation (EGR). Atul Dhar et al. [16] evaluated performance, emission and combustion characteristics of Neem oil biodiesel in a constant speed direct injection (DI) diesel engine. Brake thermal efficiency of all biodiesel blend was found to be increased compared to mineral diesel however specific fuel consumption for biodiesel and its blends were higher than mineral diesel. $\mathrm{CO}$ and $\mathrm{HC}$ emissions for biodiesel were lower than mineral diesel while NOx emissions were higher for biodiesel blends. Combustion was started earlier for higher blends while for lower blends combustion was slightly delayed in comparison to standard diesel. All biodiesel blends were shown almost same heat release trend and shorter combustion duration in comparison of standard diesel.

In his study, the biodiesel from nonedible Mahua oil has been produced by two step acid-alkaline base catalyst transesterification. There has been substantial research on other non-edible oils like Jatropha, Pongamia, Karanja, and Sunflower for their suitability in Indian conditions and also to meet the automobile blending requirements. However, we are required to be focused on the Mahua oil. It is mainly a nonvolatile oil compressed from Mahua (Madhuca longifolia). Mahua is perhaps the widely grown tree in India after mango and almost all parts of Mahua tree are saleable.

\section{Methodology}

Mahua oil was purchased from a local general store in Uttar Pradesh market, chemical items which play an important role in converting fatty acid content of oil into ester like methanol $\left(\mathrm{CH}_{3} \mathrm{OH}\right),(\mathrm{KOH})$ and $\mathrm{H}_{2} \mathrm{SO}_{4}$.

\subsection{Biodiesel production and specifications}

The biodiesel fuel used in this study was produced from the two-step acid-base catalyst transesterification of crude Mahua oil with methanol $\left(\mathrm{CH}_{3} \mathrm{OH}\right)$ catalyzed by sulfuric acid in the first step called esterification process followed by the second 
step called transesterification process in which esterifies crude oil Mahua with methanol was catalyzed by potassium hydroxide $(\mathrm{KOH})$. In first step acid quantity and methanol to oil molar ratio both were varied but another reaction parameter as reaction time $1 \mathrm{~h}$ stirrer speed $300 \mathrm{rpm}$ and reaction temperature $60^{\circ} \mathrm{C}$ were kept constant. Acid quantity $0.8 \%$ wt of oil and molar ratio of $18: 1$ was obtained as an optimized parameter at which maximum yield of esters was obtained. This oil had an initial acid value of $29 \mathrm{mg} \mathrm{KOH} / \mathrm{g}$, corresponding to a free fatty acid (FFA) level of $14.5 \%$, which is far above the $1 \%$ limit for satisfactory transesterification reaction using an alkaline catalyst. The process of transesterification is complicated if oil contains large amounts of acid value that will form soap with an alkaline catalyst. The soap can rise difficulties or prevent separation of the biodiesel from the glycerol [17]. Therefore, free fatty acids were first converted to esters in a pretreatment process, an acid value of crude Mahua oil reduced to below $1 \mathrm{mg}$ $\mathrm{KOH} / \mathrm{g}$ approximate and completed transesterification with an alkaline catalyst to produce biodiesel $[18,19]$. A titration was performed to determine the amount of $\mathrm{KOH}$ needed to neutralize the free fatty acids in esterified crude sunflower oil. The amount of $\mathrm{KOH}$ needed as a catalyst for every liter of crude Mahua oil was determined as $9.9 \mathrm{~g}$. For transesterification, $250 \mathrm{ml} \mathrm{CH}_{3} \mathrm{OH}$ (molar ratio 6:1) plus the required amount of $\mathrm{KOH}$ were added for every liter of esterified $\mathrm{CNO}$, and the reactions were carried out at $60^{\circ} \mathrm{C}$ for $1 \mathrm{~h}$. The mixture was stirred at a constant speed of $300 \mathrm{rpm}$ continuously and then allowed to settle under gravity in a separating flask. Two separate layers form due to gravity settling after $24 \mathrm{~h}$. The upper layer was of ester and the lower layer was of glycerol. The lower layer was separated out. The separated ester was mixed with some warm water at $\left(40-42^{\circ} \mathrm{C}\right)$ around $30 \%$ volume of ester to remove the excess catalyst present in ester and allowed to settle under gravity for 4-6 h. At least three times this washing was done to ensure no catalyst present in esters. The catalyst got dissolved in water, which was separated and removed from the ester. After washing, a drying process was followed to make ester moisture free in which washed ester was allowed to heat at $\left(100-120^{\circ} \mathrm{C}\right)$ for $(1-1.5) \mathrm{h}$. The important properties of Mahua oil biodiesel are taken from references [20] and compared with those of diesel fuel [21] in Table 1. Some properties like density, viscosity acid values of Mahua oil biodiesel were found out at NIT-Hamirpur, Himachal Pradesh, India (177005). Then Mahua oil biodiesel was mixed with standard diesel in various concentrations such as $\mathrm{B} 10, \mathrm{~B} 20, \mathrm{~B} 30, \mathrm{~B} 40$ and B50 for preparing biodiesel blends for conducting various engine tests.

\begin{tabular}{lc}
\hline Properties & Oil biodiesel \\
\hline Density @ $21^{\circ} \mathrm{C}(\mathrm{cc} / \mathrm{gm})$ & 0.916 \\
\hline Viscosity $(\mathrm{cSt}) @ 40^{\circ} \mathrm{C}$ & 3.58 \\
\hline Flash point $\left({ }^{\circ} \mathrm{C}\right)$ & 129 \\
\hline Fire point $\left({ }^{\circ} \mathrm{C}\right)$ & - \\
\hline Cloud point $\left({ }^{\circ} \mathrm{C}\right)$ & 1 \\
\hline Pour point $\left({ }^{\circ} \mathrm{C}\right)$ & 5 \\
\hline Calorific value $(\mathrm{Mj} / \mathrm{Kg})$ & 42.8 \\
\hline Cetane number & 51 \\
\hline Acid value $(\mathrm{mg} \mathrm{KOH} / \mathrm{g})$ & 0.532 \\
\hline
\end{tabular}

Table 1.

Specification of biodiesel and diesel. 


\subsection{Experimental setup}

The setup for the study consists of a single cylinder, four strokes naturally aspirated water cooled, and direct injection (DI) diesel engine connected to eddy current type dynamometer for loading (see Figure 1). The detailed specifications of the engine and uncertainty of some measured parameter are given in Table 2. Windows-based Engine Performance Analysis Software Package "Engine soft" was taken for online performance evaluation. Emission characteristics like $\mathrm{CO}, \mathrm{CO}_{2}$, unburned HC, smoke and NOx by the combustion of biodiesel was measured by the online five-gas analyzer and smoke meter. The experiments were conducted under varying load condition at the rated speed of $1500 \mathrm{rpm}$ in IC engine laboratory at NIT-Jalandhar, Punjab, India (144001). The engine was started with standard diesel fuel and warmed up. The warm-up period ends when cooling water temperature is stabilized. Then brake specific fuel consumption, brake power, brake thermal efficiency, and exhaust gas temperature were measured.

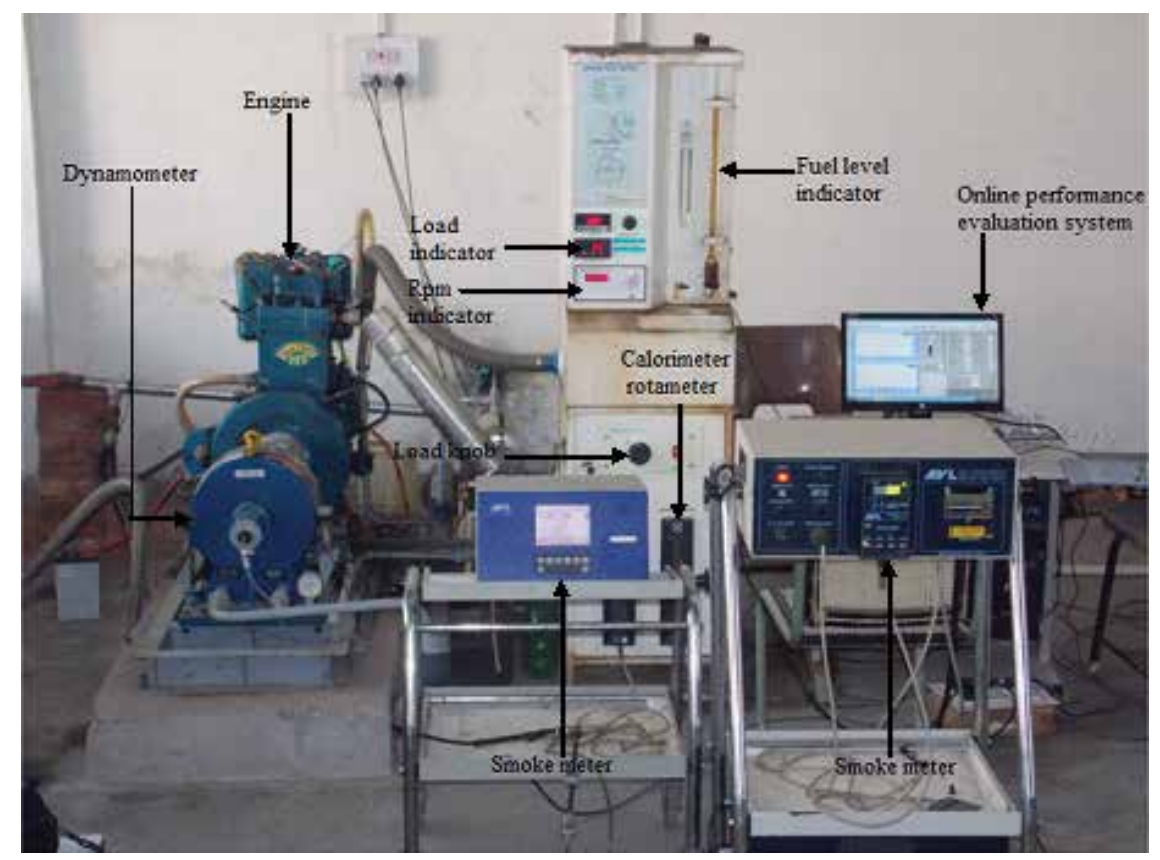

Figure 1.

Schematics of the test set-up.

\begin{tabular}{lc}
\hline Engine type & Single cylinder 4 stroke, DI \\
\hline Bore & $87.5 \mathrm{~mm}$ \\
\hline Stroke & $110 \mathrm{~mm}$ \\
\hline Power & $5.2 \mathrm{KW}$ \\
\hline Compression ratio & $17.5: 1$ \\
\hline Speed & $1500 \mathrm{rpm}$ \\
\hline Air box & MS fabricated with orifice meter and manometer \\
\hline Fuel tank & Capacity 15 lit with glass fuel metering column \\
\hline
\end{tabular}

Table 2.

Specification of diesel engine. 
Performance, Emissions, and Combustion Evaluations of a Diesel Engine Fuelled with Biodiesel... DOI: http://dx.doi.org/10.5772/intechopen. 83845

\section{Result and discussions}

Performance, emissions and combustion characteristics of blends B10, B20, B30, $\mathrm{B} 40$ and $\mathrm{B} 50$ with conventional diesel are investigated on single cylinder computerized diesel engine and are discussed in the following subsections.

\subsection{Brake thermal efficiency, brake-specific fuel consumption, and exhaust gas temperature}

Figure 2a shows that the variation of brake thermal efficiency (BTE) with a load for different blends. It has been observed that the brake thermal efficiency for all test fuel is increasing with the increase in applied load. It happens due to a reduction in heat land increase in power developed with an increase in load [22]. Blend B30 and diesel has been shown the BTE of 33.75 and 34.57\% respectively. Hence B20 gave the little difference in efficiency among all test fuel, which is about $0.82 \%$ less than the diesel. Initially, efficiency was found to be increased with increased blend ratios up to B30 and after that, it got a decrease as shown in Figure 2a. The decrease in brake thermal

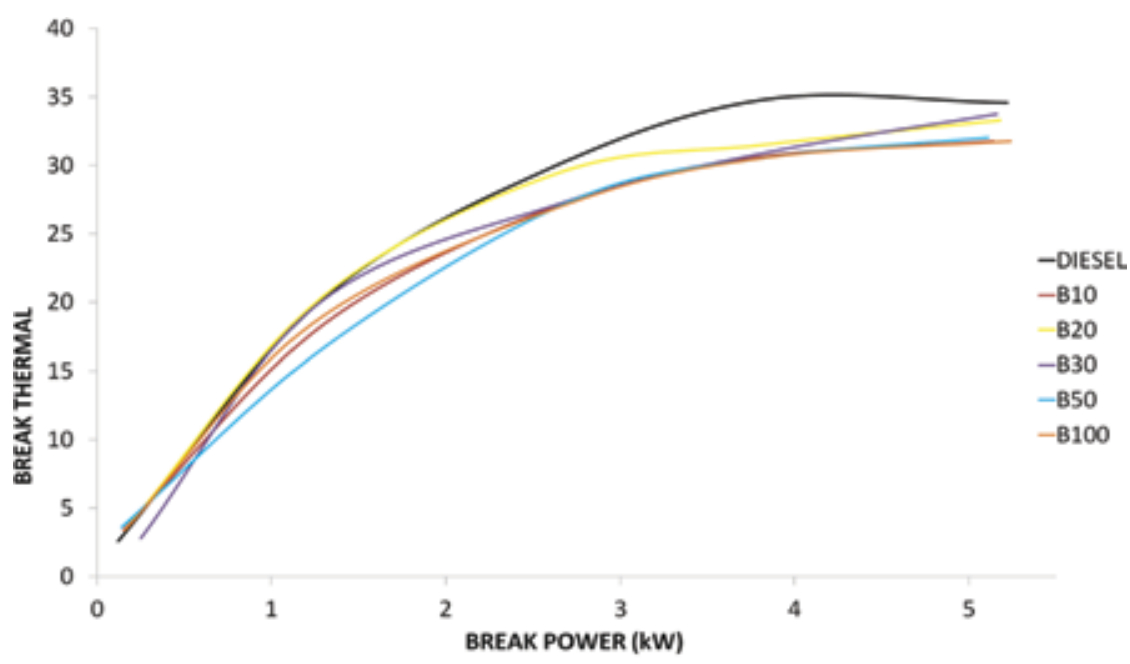

a)

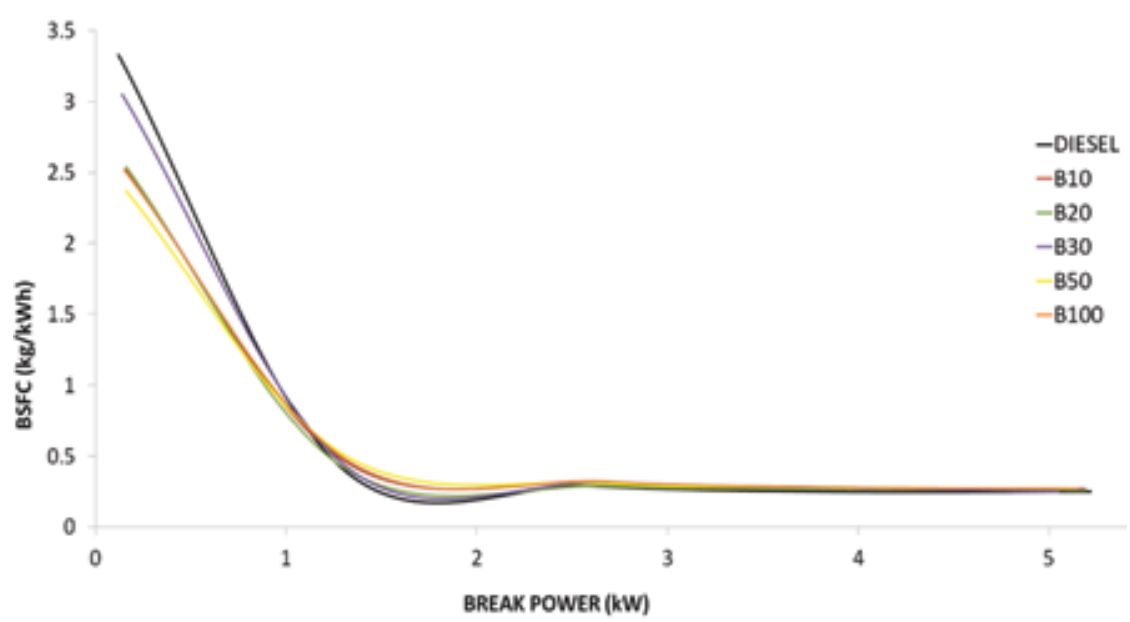

b)

Figure 2.

Variation of brake power with (a) BT efficiency and (b) BSFC. 
efficiency for higher blends may be due to the combined effect of its lower heating value and increase in fuel consumption [23]. In spite of this increasing viscosity may be the other reason for decreasing efficiency with higher blend ratio fuel, thereby, poor pray and poor atomization occurred due to which charge was not properly burned.

The variation of brake specific fuel consumption with regard to load is given in Figure $2 \mathbf{b}$. It is obvious from the name that the BSFC of the engine gradually decreases with increasing load and then becomes constant up to full load condition. The same trend for brake specific fuel consumption (BSFC) can be viewed as it was seen in efficiency Figure 2; B30 has given lowest brake specific fuel consumption to all other blends and diesel at full load condition [24-28]. Diesel and B30 have been read 0.25 and $0.25 \mathrm{~kg} / \mathrm{kWh}$ of BSFC respectively, at full load which is more or less same as diesel. For a higher percentage of biodiesel blends, BSFC is found to be increased. This may be due to high density, high viscosity and lower heating value of the fuels. B30 has a minimal value of fuel consumption among B10, B20, B50, and $\mathrm{B} 100$ at and above $100 \%$ load.

\subsection{Results and discussion regarding the engine emission in term $\mathrm{CO}, \mathrm{CO}_{2}, \mathrm{NOx}$, and unburned HC are as follows}

\subsubsection{Carbon monoxide (CO) emission}

The figure shows the variation of carbon monoxide emission of blends and diesel under various loads. The discharge of $\mathrm{CO}$ is found to be diminished with increasing load at the initial stage up to approximate $75 \%$ load after that it increases for B10 up to 0.2 (\%Volume). But for B30 decrement of 0.2 (\%Volume) of $\mathrm{CO}$ at the stage of $75-100 \%$ load. This is because of more fuel accumulates at a higher load to produce more power due to which higher temperature achieved in the fumes. This increased temperature helps in the oxidation of $\mathrm{CO}$ on account that its value decreases. Blend B10, B20, B50, and B100 have been given equal amount of CO to that of diesel at full load stage, because for B10 due to the inefficient inherited oxygen of biodiesel $\mathrm{CO}$ could not oxidize to $\mathrm{CO}_{2}$, and for $\mathrm{B} 50$ increased viscosity and high non-volatility of biodiesel caused poor spray, atomization and burning of $\mathrm{CO}$ into $\mathrm{CO}_{2}$ (Figure 3).

\subsubsection{Hydrocarbon emission}

Variation of unburned hydrocarbon can be seen in the figure. Significant reduction in $\mathrm{HC}$ emission has been found with decreasing the blend ratio of biodiesel in fuel. Blends B10, B20, B30, B50, B100 and diesel are given 36.5, 34.8, 30.2, 23, 23.2 and $27.4 \mathrm{ppm}$ of $\mathrm{HC}$ emission on an intermediate basis. Hence B50 and B100 have been given the lowest $\mathrm{HC}$ compare to all test fuels due to the optimum level of oxygen and viscosity of the fuel. This decrease indicates that more complete combustion of fuels due to which low HC level was obtained (Figure 4).

\subsubsection{NOx emission}

Variations of NOx emission with loads for different blends are presented in the figure.

The NOx emission is found to be increased with growth in shipment due to less heat rejection at higher load. That is the way all test fuels shows the highest value of discharge at full load condition. Blends B10, B20, B30, B50, B100 and diesel show $549,743,608,704,669$, and $730 \mathrm{ppm}$ respectively at full load condition. In initial blends, only B20 has been given higher. NOx due to higher temperature compared to B10 and B20. In universal, vegetable-based fuel contains a low quantity of 
Performance, Emissions, and Combustion Evaluations of a Diesel Engine Fuelled with Biodiesel... DOI: http://dx.doi.org/10.5772/intechopen.83845

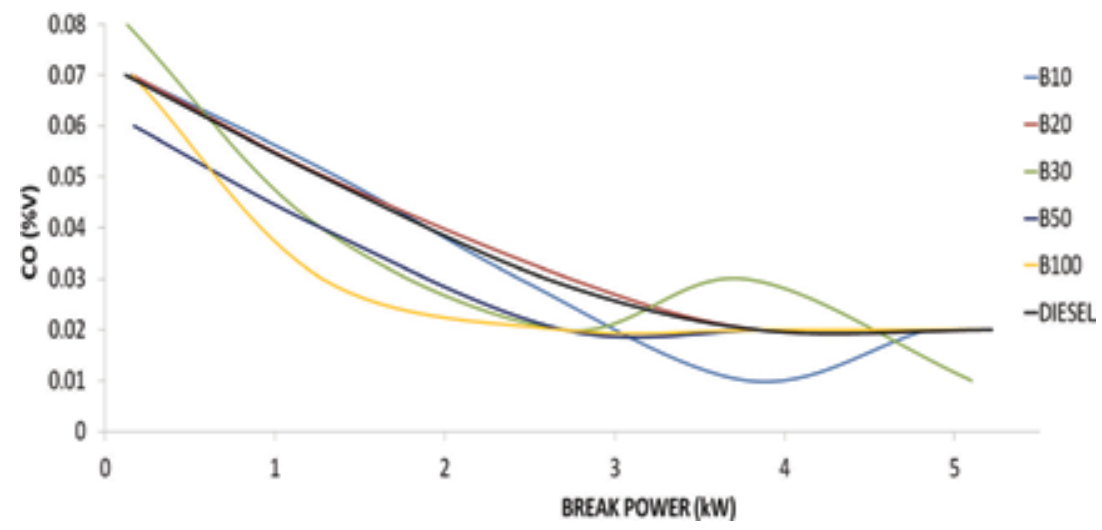

Figure 3.

CO vs. BP emission for Mahua oil BD blends and diesel.

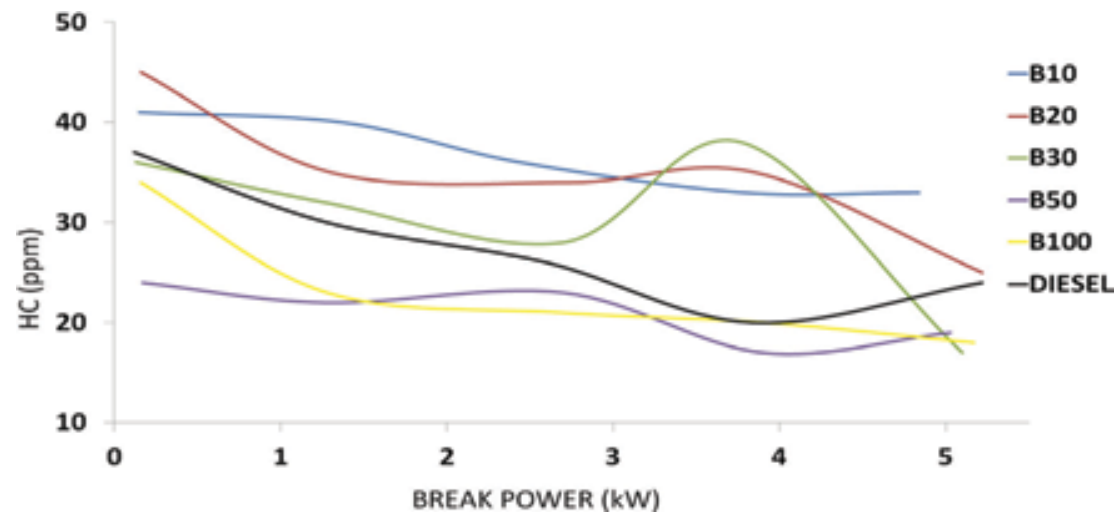

Figure 4.

BP vs. unburned HC for Mahua oil BD blends and diesel.

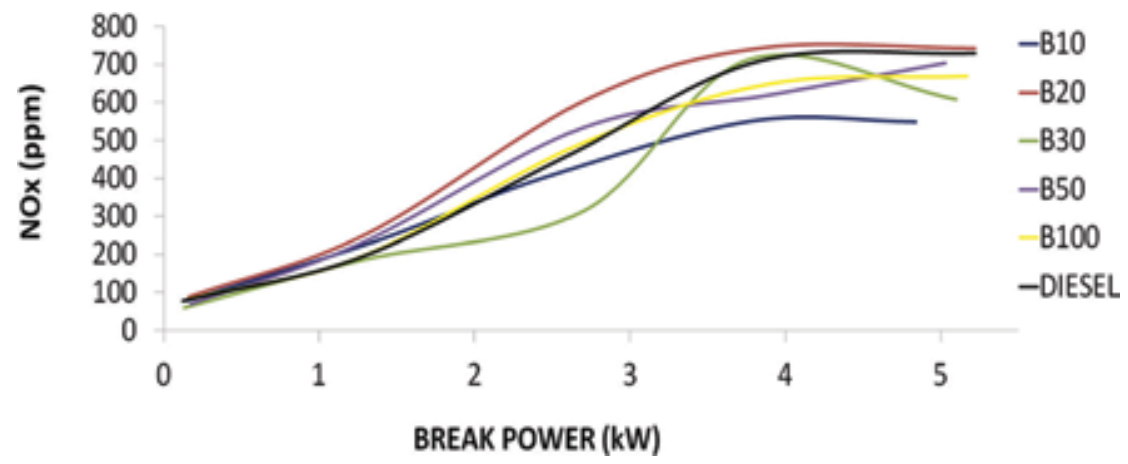

Figure 5.

$B P$ vs. NOx for Mahua oil BD blends and diesel.

nitrogen that contributes towards NOx production. In malice of this NOx emission is the function of temperature also, more NOx is emitted at high load because of the higher temperature of gas oxidized the nitrogen oxides into nitrogen and thus NOx increase. From this figure, it can be concluded that B20 exhibiting proper complete combustion compare to others fuels (Figure 5). 


\subsection{4 $\mathrm{CO}_{2}$ emission}

Percent of $\mathrm{CO}_{2}$ in the exhaust is the direct indication of complete combustion of fuel in the combustion chamber. The figure shows the variation of $\mathrm{CO}_{2}$ under varying load for different biodiesel blends. All test fuels show increasing trends, $\mathrm{CO}_{2}$ emission with an increase in shipment due to an increase in the accumulation of fuel. Blends B10, B20, B30, B50, B100 and diesel shows 3.6, 4, 3.7, 4.2, 3.7 and $4.5 \%$ of $\mathrm{CO}_{2}$ respectively at full load condition. Only $\mathrm{B} 50$ has been shown higher $\mathrm{CO}_{2}$ emission compare to diesel due to the significant issue of higher cetane number compare to other test fuel. Other blends have been presented the lower value of $\mathrm{CO}_{2}$ than diesel. It can also be cleared from exhaust gas temperature vs. load curves in which B50 has been shown a higher temperature than other blends (Figure 6).

\subsubsection{Combustion analysis}

Combustion characteristics parameter like pressure-crank angle, rate of cylinder pressure rise, heat release rate and cumulative heat release are analyzed for different blends of Soybean oil biodiesel under varying load to compare the combustion characteristics of the engine with conventional diesel fuel.

\subsubsection{In-cylinder pressure vs. crank angle}

The figure shows the variation of in-cylinder pressure with a crank angle for blends B10, B20, B30, B50 and B100 in comparison of baseline data obtained from standard diesel. Pressure rise has been found to be comparable with diesel for higher biodiesel blends fuel. Moreover, low biodiesel blends such as B10 and B20 show delayed pressure rise with respect to standard diesel at full load due to longer physical ignition delay period because of the higher boiling point range of biodiesel compared to diesel. It can as well be visualized in the figure that all test fuel has shown decreases in ignition delay with an increase in shipment. This was passed due to an increase in gaseous state temperature at high load operation; therefore, a reduction in the physical ignition delay period was held (Figure 7).

I all cases higher biodiesel blends as B100 and B50 has been shown higher incylinder peak pressure compared to diesel and other low biodiesel blends. Two elements are mostly responsible for that first presence of inherited oxygen molecules

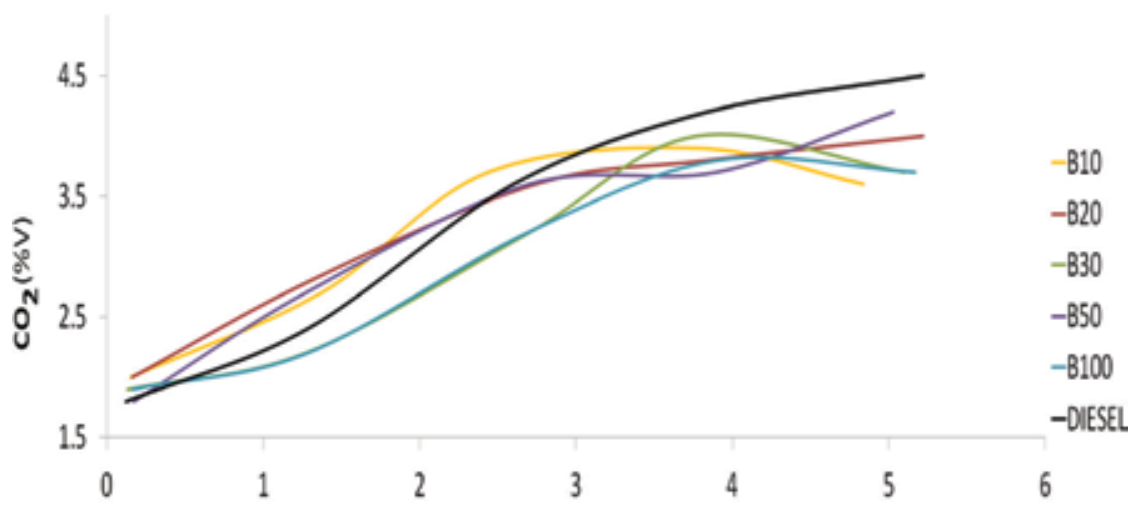

BREAK POWER

Figure 6.

$B P$ vs. $\mathrm{CO}_{2}$ for Mahua oil BD blends and diesel. 
Performance, Emissions, and Combustion Evaluations of a Diesel Engine Fuelled with Biodiesel... DOI: http://dx.doi.org/10.5772/intechopen.83845

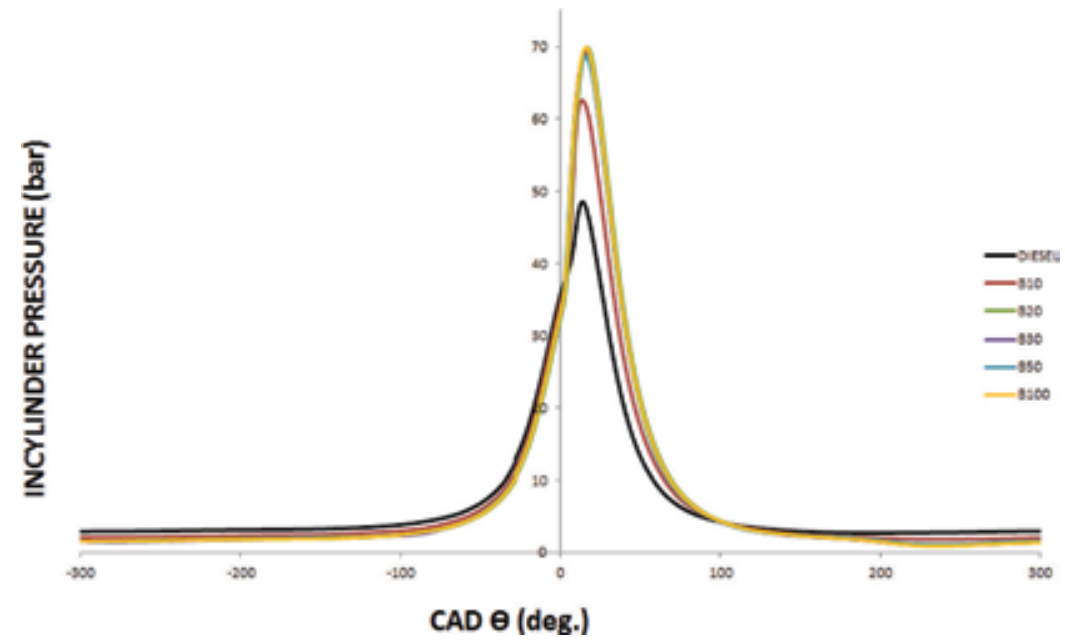

Figure 7.

In-cylinder pressure vs. crank angle.

in biodiesel helps in combustion and the second is the lower viscosity of mineral diesel which ensures adequate air-fuel blending.

\subsubsection{Rate of cylinder pressure rise vs. crank angle}

The figure shows the variation in the rate of pressure rise $(\mathrm{dP} / \mathrm{d} \theta)$ with a crank angle $(\theta)$ under varying load for all test fuels. It can as well be visualized in the figure that the maximum rate of pressure rise is $4.55 \mathrm{bar} / \mathrm{deg}$. for $\mathrm{B} 30 \mathrm{blend}$ and $4.51 \mathrm{bar} / \mathrm{deg}$. for B20 blend, biodiesel blend B20 has been shown the highest rate of pressure rise compares to diesel. It can be due to higher accumulation of fuel during premixed combustion on account of that B20 biodiesel blends showed the earlier start of combustion with a consequence high rate of pressure rise (Figure 8).

\subsubsection{Heat release rate vs. crank angle}

The figure shows the heat release rate for biodiesel blends in comparison of standard diesel at different engine operating conditions. After burning of fuel, fluctuation of heat release rate occurs. However, at B100 shows the highest rate of heat release compare to diesel and other biodiesel blends are two other blends, because of the higher cetane number and higher oxygen capacity of biodiesel that improves

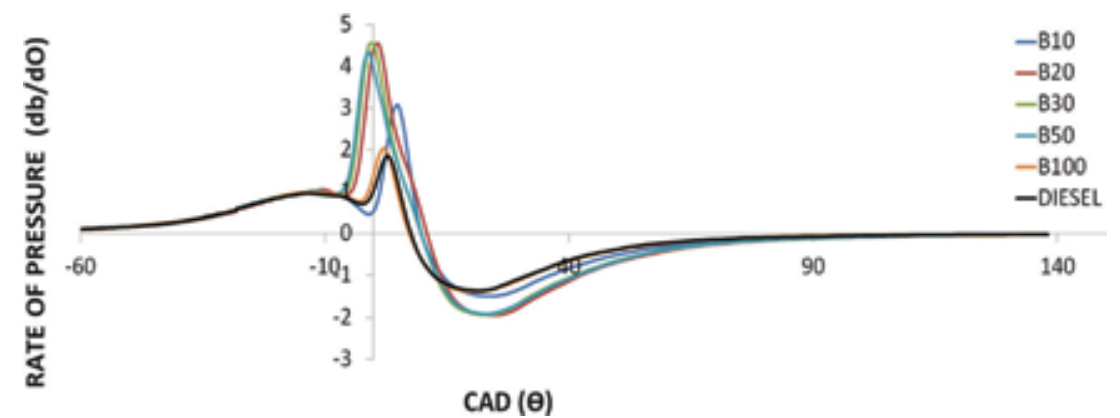

Figure 8.

Pressure rise rate vs. crank angle. 


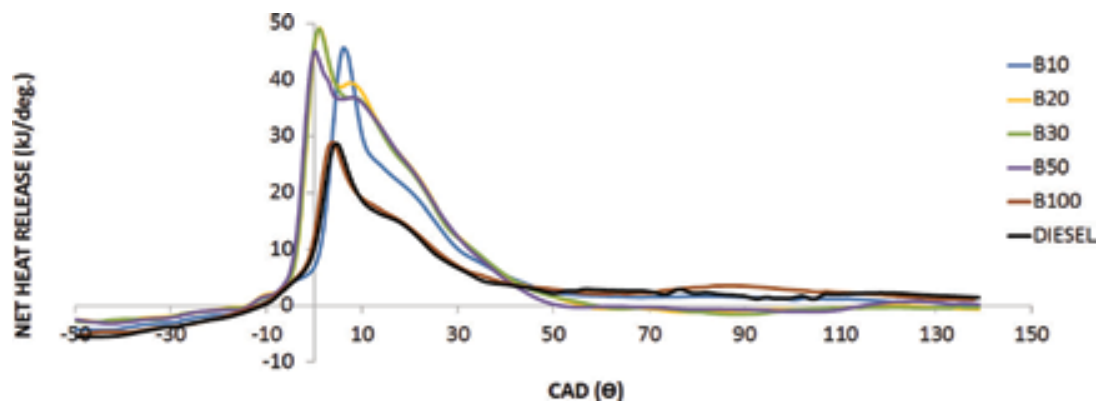

Figure 9.

Heat release rate vs. crank angle.

the burning quality of fuel and helps in firing at a higher charge per units. Moreover $\mathrm{B} 10, \mathrm{~B} 20$ and B50 have been established a corresponding rate of heat release with diesel. This is because in low blends the concentration of biodiesel is low, that is way fuel does not cause a significant force on a certain number, but it touches the air-fuel mixture formation due to changes in viscosity and evaporation properties of the fuel. That is way lower blends showed a less charge per unit of heat release than B100 (Figure 9).

\subsubsection{Cumulative heat release vs. crank angle}

Cumulative heat release is the total heat energy that has been dropped for a given production. The figure shows the cumulative heat release for all blends at various engine loads in comparison of diesel. It can be pictured in figures that cumulative heat increases with increasing engine load for all test fail because the bulk of the fuel increases with a gain in shipment. It is also cleared from the diagram that up to $40 \%$ load all blends show low cumulative heat compare to diesel, but after that, blends have been shown gradually increase in cumulative heat than diesel in which $\mathrm{B} 30, \mathrm{~B} 50$, and $\mathrm{B} 100$ show high cumulative heat.

\section{Conclusions}

High acid value Mahua oil was used to produce biodiesel by a two-step process of esterification followed by transesterification. In etherification, the molar ratio of methanol to oil and quantity of sulfuric acid was two main reaction parameters which were optimized to produce a low acid value of oil. Molar ratio 18:1 and $0.8 \% \mathrm{w} / \mathrm{w}$ to oil of sulfuric acid was observed optimum reaction parameters. While reaction temperature, reaction time and a stirrer speed of $60^{\circ} \mathrm{C}, 1 \mathrm{~h}$ and $300 \mathrm{rpm}$ respectively were maintained during esterification. For transesterification, the molar ratio of alcohol to oil of $6: 1,9.9 \mathrm{~g}$ of catalyst $(\mathrm{KOH}), 60^{\circ} \mathrm{C}$ temperature, $1 \mathrm{~h}$ reaction time and stirring speed $1300 \mathrm{rpm}$ were used.

The performance, emission and combustion characteristics of an engine fuelled with crude Mahua oil biodiesel and diesel blends were investigated and compared with that of standard diesel. The experimental results confirm that the BTE, BSFC, exhaust gas temperature is the function of biodiesel blend and load. For similar operating conditions, a particular blend gave better engine performance and reduced emissions compared to other blends in comparison of standard diesel. B30 of Mahua oil biodiesel blend gave the better overall performance among all other blends in comparison of diesel. However, Mahua oil gave 33.75\% BTE for B30, 
Performance, Emissions, and Combustion Evaluations of a Diesel Engine Fuelled with Biodiesel... DOI: http://dx.doi.org/10.5772/intechopen.83845

which is less compared to diesel, the increased value of BSFC reduced CO, HC, $\mathrm{NOx}$ and $\mathrm{CO}_{2}$ emissions with high-value smoke which indicates better combustion of fuel, which can be considered as acceptable results in overall performance with biodiesel without any modification of engine. In combustion characteristics, higher blends showed the earlier start of combustion and for lower blends start of combustion was slightly delayed in comparison of standard diesel. Almost identical trends were to be seen for all the biodiesel blends in heat release rate. The very negligible difference was seen in combustion duration for blends and diesel however under full load condition, blends showed insignificant shorter duration of combustion than diesel. Therefore, Mahua oil biodiesel blends, B30 can be used in unmodified CI engines.

\section{Author details}

Aman Hira*, Debasish Das and Ranjna Thakur

Department of Mechanical Engineering, National Institute of Technology,

Hamirpur, HP, India

*Address all correspondence to: amanhira55@yahoo.com

IntechOpen

(C) 2020 The Author(s). Licensee IntechOpen. This chapter is distributed under the terms of the Creative Commons Attribution License (http://creativecommons.org/licenses/ by/3.0), which permits unrestricted use, distribution, and reproduction in any medium, provided the original work is properly cited. (cc) BY 


\section{References}

[1] Utlua Z, Kocakb MS. The effect of biodiesel fuel obtained from waste frying oil on direct injection diesel engine performance and exhaust emissions. Renewable Energy. 2008;33:1936-1941

[2] Hebbal OH, Reddy KV, Rajagopal K. Performance characteristics of a diesel engine with deccan hemp oil. Fuel. 2006;85:2187-2194

[3] Sahoo PK, Das LM, Babu MKG, Naik SN. Biodiesel development from high acid value polanga seed oil and performance evaluation in a CI engine. Fuel. 2007;86:448-454

[4] Rakopoulos CD, Rakopoulos DC, Hountalas DT, Giakoumis EG, Andritsakis EC. Performance and emissions of bus engine using blends of diesel fuel with bio-diesel of sunflower or cottonseed oils derived from Greek feedstock. Fuel. 2008;87:147-157

[5] Pradeep V, Sharma RP. Use of HOT EGR for NOx control in a compression ignition engine fuelled with bio-diesel from Jatropha oil. Renewable Energy. 2007;32:1136-1154

[6] Qian J, Wang F, Liu S, Yun Z. In situ alkaline transesterification of cottonseed oil for production of biodiesel and nontoxic cottonseed meal. Bioresource Technology. 2008;99:2009-9012

[7] Saravanan S, Nagarajan G, Rao GL, Sampath S. Combustion characteristics of a stationary diesel engine fuelled with a blend of crude rice bran oil methyl ester and diesel. Energy. 2010;35:94-100

[8] Godiganur S, Murthy CHS, Reddy RP. 6BTA 5.9 G2-1 Cummins engine performance and emission tests using methyl ester Mahua (Madhuca indica) oil/dieselblends. Renewable Energy. 2009;34:2172-2177
[9] Lin BF, Huang JH, Huang DY. Experimental study of the effects of vegetable oil methyl ester on DI diesel engine performance characteristics and pollutant emissions. Fuel. 2009;88:1779-1785

[10] Qi DH, Geng LM, Chen H, Bian YZH, Liu J, Ren XCH. Combustion and performance evaluation of a diesel engine fueled with biodiesel produced from soybean crude oil. Renewable Energy. 2009;34:2706-2713

[11] Antolın G, Tinaut FV, Briceno Y, Castano V, Perez C, Ramirez AI. Optimisation of biodiesel production by sunflower oil transesterification. Bioresource Technology. 2002;83:111-114

[12] Karmakara A, Karmakar S, Mukherjee S. Biodiesel production from neem towards feedstock diversification: An Indian perspective. Renewable and Sustainable Energy Reviews. 2012;16:1050-1060

[13] Agarwal AK, Das LM. Biodiesel development and characterization for use as a fuel in compression ignition engines. Transactions of ASME. 2001;123:440-447

[14] Rahman H, Phadatare AG. Diesel engine emissions and performance from blends of Karanja methyl ester and diesel. Biomass and Bioenergy. 2004;27:393-397

[15] Nabi MN, Akhter MS, Shahad MMZ. Improvement of engine emissions with conventional diesel fuel and diesel-biodiesel blends. Bioresource Technology. 2006;97:372-378

[16] Dhar A, Kevin R, Agarwal AK. Production of biodiesel from high-FFA neem oil and its performance, emission and combustion characterization in a single cylinder DICI engine. Fuel Processing Technology. 2012;97:118-129 
[17] Demirbas A. Biodiesel fuels from vegetable oils via catalytic and non-catalytic supercritical alcohol transesterification and other methods: A survey. Energy Conversion and Management. 2003;44:2093-2109

[18] Canakci M, Gerpen JV. Biodiesel production from oils and fats with high free acids. Transactions of ASAE. 2001;44:1429-1436

[19] Ghadge SV, Raheman H. Biodiesel production from Mahua (Madhuca indica) oil having high free fatty acids. Biomass and Bioenergy. 2005;28:601-605

[20] Godiganur S, Murthy CS, Reddy RP. 6BTA5.9G2-1Cummins engine performance and emission tests using methyl ester Mahua (Madhuca indica) oil/diesel blends. Renewable Energy. 2009;34:2172-2177

[21] Ragit SS, Mohapatra SK, Kundu K, Gill P. Optimization of neem methyl ester from the transesterification process and fuel characterization as a diesel substitute. Biomass energy. 2011;35:1138-1144

[22] Panwar NL, Shrirame Hemant Y, Rathore NS, Jindal S, Kurchania AK. Performance evaluation of a diesel engine fueled with methyl ester of castor seed oil. Applied Thermal Engineering. 2010;30:245-249

[23] Ramadhas AS, Muraleedharan C, Jayaraj S. Performance and emission evaluation of a diesel engine fueled with methyl esters of rubber seed oil. Renewable Energy. 2005;30:1789-1800

[24] Guru M, Koca A, Can O, Cinar C, Sahin F. Biodiesel production from waste chicken fat based sources and evaluation with the Mg-based additive in a diesel engine. Renewable Energy. 2010;35:637-643

[25] Muralidharan K, Vasudevan D, Sheeba KN. Performance, emission and combustion characteristics of biodiesel fuelled variable compression ratio engine. Energy. 2011;36:5385-5393

[26] Nabi MN, Hoque SMN, Akhter MS. Karanja (Pongamia Pinnata) biodiesel production in Bangladesh, characterization of karanja biodiesel and its effect on diesel emissions. Fuel Processing Technology. 2009;90:1080-1086

[27] Rakopoulos CD, Antonopoulos KA, Rakopoulos DC, Hountalas DT, Giakoumis EG. Comparative performance and emissions study of a direct injection diesel engine using blends of diesel fuel with vegetable oils or bio-diesels of various origins. Energy Conversion and Management. 2006;47:3272-3287

[28] Hira A, Das D. Performance and emission evaluation of diesel engine fuelled with biodiesel produced from high free fatty acid crude soyabean oil. Biofuels. 2016;7(4) 

Section 2

\section{Biodiesel and Alternative Fuels}





\title{
Alcohol Contribution over Conventional Fuel
}

\author{
Melvin Victor Depoures, Damodharan Dillikannan \\ and Gopal Kaliyaperumal
}

\begin{abstract}
Biofuels have caught the eye of engine specialists as far back as the oil emergency and heightening expenses of petro-synthetic compounds cropped up in the 1970s. Ethanol and methanol were the most broadly inquired alcohols in IC engines. Higher alcohols are alluring second/third era biofuels that can be created from sugary, dull and lignocellulosic biomass feedstocks utilizing reasonable pathways. Developing worries of petroleum product consumption, oil-value variances, heightening vitality requests and stringent discharge guidelines are driving established researchers to discover elective sustainable biofuels for use in diesel engines. Among the biofuels like biogas, bioalcohol and biodiesel, alcohol is by all accounts generally appealing. Biogas requires high weight for its utilization in vehicle and its spillage can be risky. Biodiesel from consumable vegetable oil can cause insufficiency in sustenance supply. Everything being considered, the utilization of lower alcohols like methanol and ethanol in slow speed engines shows certain complexities because of their low cetane number, high inert warmth of vaporization and high protection from auto-start. Further the less calorific respect and poor miscibility with diesel limit their utilization in diesel motors.
\end{abstract}

Keywords: diesel engine, bioalcohols, butanol, pentanol, hexanol, octanol, performance and emission

\section{Introduction}

High-carbon bioalcohol with higher cetane number and higher vitality thickness than the prevalently looked higher alcohols makes it an appealing fuel for diesel engines [1]. Studies are quickly developing on high-yield biocombination of higher alcohols from glucose and lignocellulosic biomass feedstock utilizing built smaller scale creatures like Escherichia coli and Clostridium species [2]. Regardless of its good properties and promising prospects for creation in biorefineries, higher alcohol has been scarcely researched in engines. Higher alcohol is an advanced biofuel derived from lignocellulosic biomass, which is suitable for compression ignition technology with several properties closer to fossil diesel [3]. A few methods like alcohol fumigation, double infusion, alcohol-diesel mixes and alcohol-diesel emulsions have been utilized to manage these constraints of the alcohols as a diesel motor fuel [4]. From the wellbeing viewpoint, lower alcohols have low glimmer point (FP) and are delegated Class I fluids (FP beneath $37.8^{\circ} \mathrm{C}$ ) alongside fuel by the National Fire Protection Association (NFPA) in the US. In the meantime, diesel fuel 
is arranged under Class II fluids ( $\mathrm{FP}$ above $37.8^{\circ} \mathrm{C}$ ). Yet, expansion of lower alcohols to diesel brings down the blaze point and would make the mix to fall under Class I fluids, subsequently requiring a similar framework as gas for capacity and taking care off [5]. Then again, there are some positive parts of alcohols that can be profitable in diesel engines. The decrease of smoke is firmly identified with the oxygensubstance of the mixes. Alcohols being oxygenated energize with a hydroxyl $(\mathrm{OH})$ bunch increment the accessibility of oxygen amid burning and diminish smoke outflows in diesel engines particularly at high motor burdens [6]. Concerning the substance structure, it is affirmed that smoke decrease effectiveness is high in liquor and low in ether.

As of late higher alcohols have accumulated enthusiasm among the specialist sowing to their higher vitality thickness, higher cetane number, better mix dependability and less hygroscopic nature when contrasted with other generally considered lower alcohols like ethanol, methanol. Increment long of the carbon chains additionally improves the start nature of alcohol atoms. The term "higher alcohol" more often than not alludes to the arrangement of straight chain alcohols containing at least four carbon iotas, viz. butanol (C4), pentanol (C5), hexanol (C6), octanol (C8), dodecanol (C12), phytol (C20) and so on. Anyway propanol (C3) is additionally incorporated into this examination, as this three-carbon alcohol is used as a dissolvable to tie lower alcohols with diesel and moreover as a blending portion with diesel fuel in diesel engine [7]. Table 1 presents a relationship of physical and substance properties of some lower and higher alcohols with diesel. It might be gotten from the table that higher alcohols (when appeared differently in relation to bring down alcohols like methanol and ethanol) have increasingly unmistakable potential outcomes to supersede fossil diesel totally or to some degree. Higher alcohols can mix with diesel with no stage detachment which is credited to their high carbon content, low extremity and less hygroscopic nature [8]. Subsequently no co-solvents or emulsifying operators would be required to keep up mix dependability when higher alcohols are utilized. The development of long carbon chain and the nonappearance of branches in liquor give high calorific regard, thickness and cetane number while sparing self-lighting credits less penchant to knock [9]. Higher alcohols have less dangerous movement on materials used in the fuel transport. Higher the water content in the alcohols, higher the ruinous action is higher alcohols are less hygroscopic and thusly can be less dangerous. Moreover alcohols with high subnuclear burdens are known to be less ruinous.

\begin{tabular}{|c|c|c|c|c|c|c|c|}
\hline Propertivs & Diesel & Metkand & Ethambl & In-Butanol & n-Ftatand & n-Hesund & a-0tand \\
\hline S(decular weider (kglistol) & 191.2127 & 321 & 461 & 4.1 & 8.1 & 102.2 & 1312 \\
\hline Cproyut & 86.1 & 375 & 523 & 61.8 & 68.2 & 746 & 73.8 \\
\hline $11(86 \%$ का.) & 139 & 126 & 130 & 13.6 & 136 & 137 & 13.8 \\
\hline 0 (\$) को: & 0 & 499 & 347 & 21.6 & 182 & 157 & 12.4 \\
\hline Cotsn: aumket & $51 \cdot 57$ & $5 \cdot-7$ & $8 \cdot 9$ & $16-18$ & $18.5-20.1$ & 23 & 3) \\
\hline Lower heatreg value (kl Kgi & 42500 & 1958: & 26830 & 33080 & 3455 & 3910 & 39040 \\
\hline Detsity $\left(\right.$ lgwit) it $15^{5} \mathrm{C}$ & 834 & 291.4 & 785.5 & 806 & 8147 & 821.6 & 8272 \\
\hline 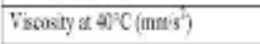 & 272 & 0.58 & 1.13 & 222 & 289 & 5.32 & - \\
\hline Latert bex of rapsizstion (kJkg) & 270.375 & 116264 & 918.42 & 5814 & 508.05 & 485 & 466 \\
\hline V.rar pressire immitg) & (1145) & 127 & 55 & $?$ & 6 & 1 & $0 C 8$ \\
\hline Soll-igniticn tamęcreture (" $\mathrm{C}$ ) & 254ain & 464 & 421 & 349 & औ) & 287 & 271 \\
\hline Boing pirt $(\mathrm{C})$ & $180-350$ & 646 & 782 & 117.4 & 137.8 & 157.2 & 1953 \\
\hline Selduilộ̣ igl) & 0 & Miselte & Yisclle & 78 & 21 & 78 & 43 \\
\hline Fladpsire $(10)$ & Abse 55 & $11-12$ & 17 & 35537 & 9 & 59 & 81 \\
\hline
\end{tabular}

Table 1.

Properties of alcohols [4]. 
Flashpoints of higher alcohols are very high which makes them more secure to store, handle and convey in the current circulation foundation. The lower vapor weights of higher alcohols likewise results in lower evaporative discharges. In spite of the fact that more drawn out chain alcohols have less oxygen content, they can in any case upgrade the premixed burning stage with their generally longer start delay permitting adequate blending of air/fuel and furthermore improve the dissemination ignition stage. In addition, alcohols with longer carbon chains consume lesser essentialness in the midst of its age when appeared differently in relation to other lower alcohols since the regular method of isolating far reaching macromolecules can stop prior [10]. The use of higher alcohols was before frustrated by high age costs, gainful use in sustenance industry and compelled creation from nonoil resources [11]. The latest decade has seen a reestablished energy for higher alcohols (as pragmatic vehicle fills) which resuscitated many research social events and bio-development associations to grow the yield of higher alcohols like butanol and pentanol from cellulose by flow development structures using new strains of Clostridium species and by biosynthesis from glucose utilizing hereditarily designed smaller scale living beings like Escherichia coli, Cyanobacteria and Saccharomyces cerevisiae. There is likewise an elective course in which biomass can be gasified or steam improved or somewhat oxidized to create blend gas $(\mathrm{CO}, \mathrm{H} 2$ and $\mathrm{CO}_{2}$ ) which can be chemically changed over in to higher alcohols by a procedure called Higher alcohol amalgamation (HAS). Higher alcohols can likewise be created by direct electromicrobial transformation or photosynthetic reusing of carbon-dioxide. This strategy can in reality help reusing $\mathrm{CO}_{2}$ (an ozone depleting substance) into higher alcohols without the need to deconstruct biomass. Further, select biochemical pathways for broad scale business making of higher alcohols are being made by biofuel producers to diminish the stunning costs included like Gevo and Butamax [12]. The U.S. Boundless Fuel Standard (RFS) program requires blending of forefront biofuels in growing aggregates with fossil transportation fuel every year which should raise up to 36 billion gallons by 2022 [13]. According to this program, each endless fuel characterization ought to convey lower greenhouse gas releases appeared differently in relation to petroleum product or diesel it replaces. In this one of a kind circumstance, higher alcohols can be used to meet these targets as they qualify as bleeding edge biofuels that can be gotten from lignocellulose [14]. The essential focus of this examination is to give an expansive overview of composing related to the usage of higher alcohols in diesel motor and their effects on the start, execution and spreads of diesel motors. Various analysts and experts have mulled over the use of higher alcohols running from 3-carbon propanol to 20 carbon phytolin different extents with diesel to evaluate their appropriateness as a fuel in the current CI engines [15]. The on-going examinations and the past discoveries about the substitution (entire or incomplete) of fossil diesel fuel with higher alcohols in diesel engines were observed to be commonly fruitful in light of the fact that they diminished directed outflows with improved proficiency other than expanding the inexhaustible portion in the fuel.

\section{Perspective view}

\subsection{Diesel engine and its significance}

Diesel engines are imperative gear in open transportation, rock solid hardware, control age, agrarian and modern hardware attributable to their higher fuel-change profitability, higher power yield, higher torque limit, higher sturdiness, and higher trustworthiness than gas motors. Moreover they radiate lesser carbon monoxide 
(CO), hydro carbons ( $\mathrm{HC})$ and carbon dioxide $\left(\mathrm{CO}_{2}\right)$ floods than diesel motors [16]. The utilization of fossil diesel in diesel motors passes on high NOx (nitrogen oxides) and buildup radiation that are unpleasant to both regular and human prosperity [17]. Diesel fumes is named harm causing to people by the International association for research on infection (IARC) in perspective on satisfactory evidence that its presentation is connected with an extended peril of lung threatening development while:

- Soot outflows can cause cardiovascular illnesses

- NOx present in diesel fumes is a central reason for exhaust cloud

- Ground level ozone

- Corrosive downpour

- Debilitated structure disorder

- Diesel engines offer un-paralleled fuel conversion efficiency, high torque capability at low engine speeds and durability.

Diesel engines are widely employed prime-movers for public transit systems, agricultural equipment, industrial implementations, power generation, construction and heavy machinery because of its un-matched fuel conversion efficiency, durability and torque capability [18]. The performance of diesel engines is usually higher than that of a gasoline engine of similar size. While the current state-ofthe-art diesel engines are typically turbocharged with cooled EGR, equipped with common rail direct injection (CRDI) and after-treatment for soot and NOx, a larger population of diesel engines sold in agricultural and construction equipment during the last few decades in India include naturally aspirated stationary diesel engines [19]. These engines are widely used in the Indian agricultural sector to drive siphon sets to supply water for water system purposes [20]. The present quantities of these diesel driven siphon sets in the nation is about 14.42 million. As indicated by a study completed by the Indian Petroleum Conservation Research Association (PCRA), the yearly generation of these diesel driven siphon sets is 1.5 million with a normal yearly development of $7 \%$. It is important to note that Indian agricultural sector recorded a consumption of 6 million metric tons (MMT) of diesel, which is about $8.55 \%$ of India's total diesel consumption (69 MMT) in the year 2012-2013. This statistic implies that a large population of farmers in India is severely exposed to the toxic diesel exhaust from these engines.

\subsection{Crude oil and its demand}

The burgeoning population, rapid industrialization and higher mobility have increased the demand and consumption of crude oil every year. The Figure 1 shows the crude oil consumption in the year 2014-2015 across the world. The International Energy Agency (IEA) has predicted that the global crude oil demand will rise to 99 million barrels per day by the year 2035. Diesel extracted from crude oil by fractional distillation faces depletion in future. There is an estimate that the reserves of crude oil are gradually depleting at the rate of $2.1 \%$ per annum. Hence it is imperative that alternative forms of diesel engine compatible fuels have to be identified to improve energy security by the way of bio-based renewable sources. Instability in crude oil prices has an impact on the economies of countries without oil reserves 


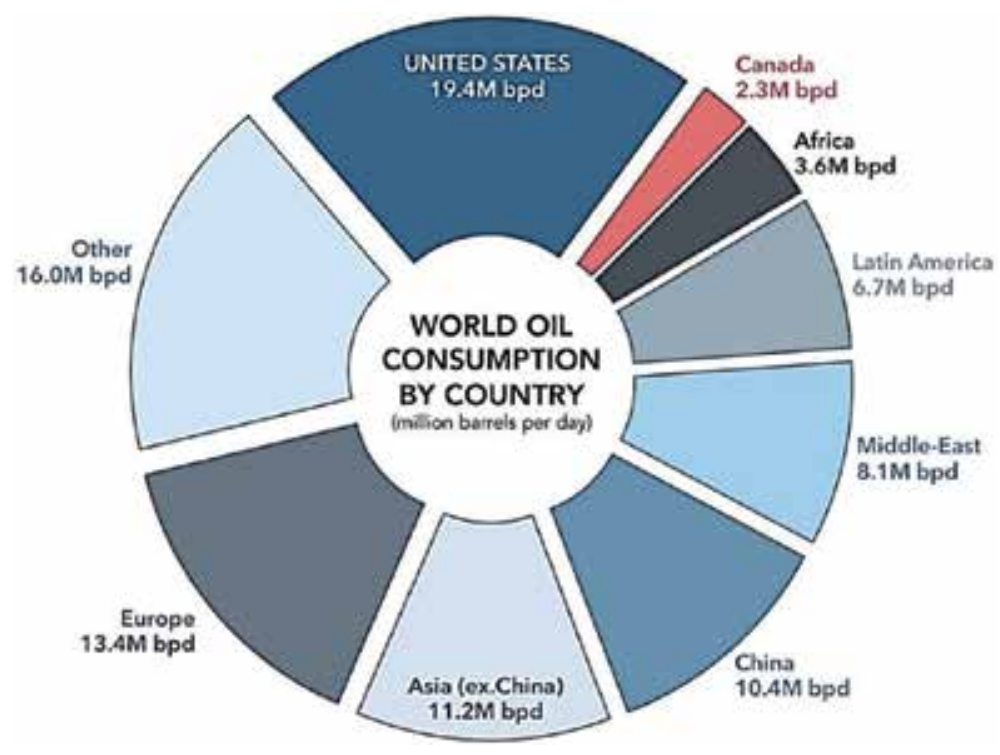

Figure 1.

Crude oil consumption in the year 2014-2015 [27].

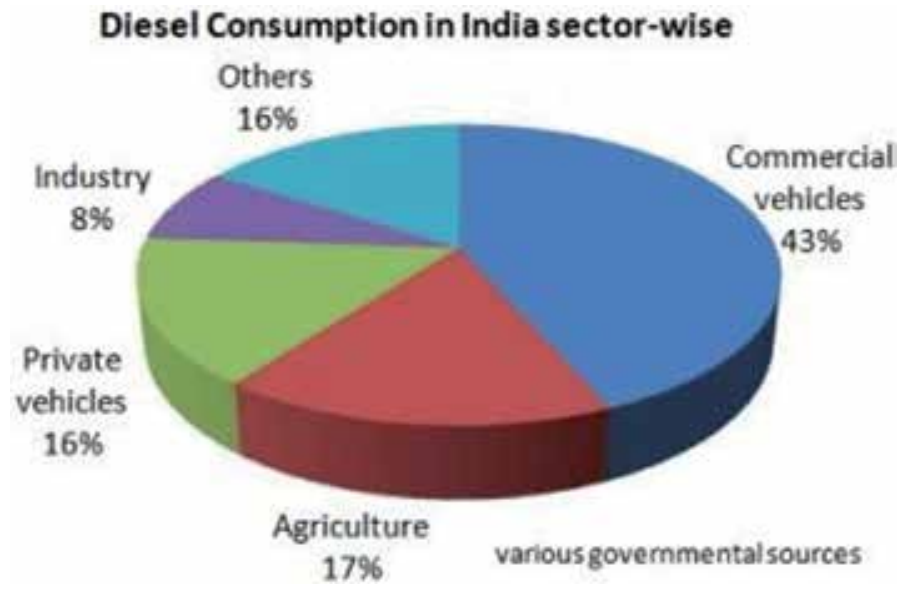

Figure 2.

Diesel consumption in India sector-wise [32].

and is heavily dependent on import. In the past 10 years, India relied heavily on imports to meet its increasing fuel demands [21]. High crude-oil imports suggest payments in dollars and depletion of foreign reserves which affects economy. India's domestic crude oil production plummeted for the fourth straight year in 2015-2016 which escalated India's import dependence to $81 \%$ in the last year from $78.5 \%$ in 2015-2016. Thus substitution of even a fraction of fossil fuel with a renewable biofuel will have positive impact on both the economy and environment. It has to be noted that India's fossil diesel consumption accounted more than that of gasoline. For instance, in 2012-2013, India consumed 69 million tons of diesel oil which is four times than that of gasoline. This consumption is primarily in transportation, industry and agriculture as shown in the graphic in Figure 2. The consumption in agriculture sector comprises tractors $17 \%$, pump-sets for $7.5 \%$ and agriculture equipment $9.5 \%$. All this indicates that a huge population is constantly exposed to hazardous gaseous emissions from diesel engines. 


\subsection{Hazards of diesel engine exhaust}

Diesel engines emits high levels of oxides of nitrogen (NOx) and particulate matter (PM) into the atmosphere which are proven to be harmful to both human and environmental health [22]. Smoke in diesel engine exhaust is carcinogenic and cause a cardio-respiratory diseases. The diesel exhaust is classified as carcinogenic and continuous exposure can increase the chances of lung cancer [23]. The nanosized particulate matter if inhaled is capable of trans-locating to the brain through olfactory nerves and can cause inflammation at deposition sites. In an experiment subjected 10 human volunteers to dilute diesel exhaust for an hour and showed that there is a functional effect in the human brain indicating a general cortical stress response [24]. Additionally, these smoke particles are also potential inducers of oxidative stress. The human brain is considered to be very sensitive to the damages caused by oxidative stress. Long term oxidative stress is found to be associated with diseases such as Alzheimer's and Parkinson's that leads to reduce cognitive function [25]. Further, when pregnant women are exposed to diesel fumes, adverse effect on fetal development is reported. NOx component present in diesel exhaust is a primary reason for smog, ground level ozone (1981), acid rain and sick building syndrome. NOx causes cyanosis and pulmonary diseases [26].

\section{Alternative source}

\subsection{Prospective diesel engine fuels}

Realizing a clean, affordable and safe energy future to address the growing concerns of fossil fuel dependence and the subsequent degradation of air quality by burning fossil fuels has been a challenge researchers relentlessly attempt to address [27]. Diesel engines could be perhaps fueled by a wide range of fuels like straight vegetable oil, biodiesel, biogas and bioalcohol adopting several strategies and modifications. The use of edible vegetable oils as diesel engine fuel threatens food security as the world community now embroiled in the "Fuel vs. Food" deliberation. Nonedible sources also have a concern. Their cultivation take up large land sources meant for food crop cultivation. Biodiesels are usually derived from edible and nonedible vegetable oils by transesterification which is a time consuming and expensive process. Biodiesels also presents the same concern as the vegetable oils because the feedstock they are derived from, takes up the acreage meant for the cultivation of food crop. Further the by-product of transesterification like glycerol poses another environmental challenge and has to be carefully disposed [28]. Biogas is typically a mixture of two potential greenhouse gases, methane and carbondioxide. Biogas is usually produced and used in as is where is basis because of the costs involved in its storage and distribution that require high pressure cylinders and safety measures to prevent leakage. Bioalcohols could be derived from both food and nonfood based feedstocks which makes them attractive [29]. Feedstock like lignocellulosic biomass which includes agricultural wastes (rice-straw, cornstalks and sugarcane-bagasse), forestry wastes (wood-pulp, saw-mill and papermill rejects) and energy crops (switch grass, elephant grass and agave) that can be subjected to gasification, pyrolysis, steam reforming and bacterial fermentation to yield platform chemicals. Valorization of biomass to esteem included items and vitality is set to occur in biorefineries which could be viewed as similar to the present oil refineries [30]. For a nation like India with huge prolific grounds thriven by ordinary regular precipitation through rainstorm, there is a monstrous open door for gathering enormous amounts of lignocellulosic biomass and to ubiquitous diesel 
engines. The present study utilizes two such bioalcohols namely cyclohexanol and n-octanol derived from nonfood based sources to power diesel engines. Low carbon bioalcohols like methanol and ethanol which are popularly researched in gasoline engines are incompatible with diesel engines owing to their low energy density and low cetane number. Higher carbon bioalcohols like n-butanol, n-pentanol, n-hexanol, cyclohexanol and n-octanol can be appropriate possibility for diesel engine innovation. These bioalcohols can be made from glucose by development using planned littler scale living things or by getting ready lignocellulosic biomass using enzymatic hydrolysis and maturing, anaerobic digestion, gasification, pyrolysis and biocatalysis. Table 1 exhibits the properties of some bioalcohols in examination with diesel and low carbon alcohols. It will in general be considered that to be the alcohols move higher, its cetane number, low warming quality, streak point, thickness and consistency increases while its oxygen content, vapor weight, dissolvability in water and unconventionality diminishes [31]. Also, the less vapor weight and less hygroscopic nature of high carbon alcohols offer better handling and storage. As a blend component, longer alkyl carbon chains also offer better miscibility with fossil diesel without any phase separation over a period of time.

\subsection{Lignocellulosic biomass}

Lignocellulose is the dry plant raw material that is abundantly available on the planet earth from which biofuels could be produced by processes like enzymatic and acid hydrolysis, pyrolysis, gasification, liquefaction and anaerobic digestion. Lignocellulose is composed of lignin $-\left(\mathrm{C}_{31} \mathrm{H}_{34} \mathrm{O}_{11}\right)_{\mathrm{n}}$, cellulose $-\mathrm{C}_{6} \mathrm{H}_{10} \mathrm{O}_{5}$, and hemicellulose $-\mathrm{C}_{5} \mathrm{H}_{8} \mathrm{O}_{4}$. Lignin is the second most available natural material in the world after cellulose. It is a complex aromatic polymer which could be processed to produce platform chemicals for biofuel production. Lignin has the highest specific energy content among the three and constitutes up to $15-30 \%$ by weight and contains up to $40 \%$ by energy in a lignocellulosic biomass feedstock. The cellulose component is much easier to degrade and process to several platform chemicals from which high carbon alcohols like n-pentanol, n-hexanol, cyclohexanol, and $\mathrm{n}$-octanol could be derived. Figure 3 shows the structure and composition of a typical lignocellulosic biomass feedstock.

\subsection{Production potential}

The estimated global biomass production is $1.70 \times 10^{11}$ tons per year. Global commercial lignin extraction is around $63 \mathrm{MMT}$ (million metric tons) per year.

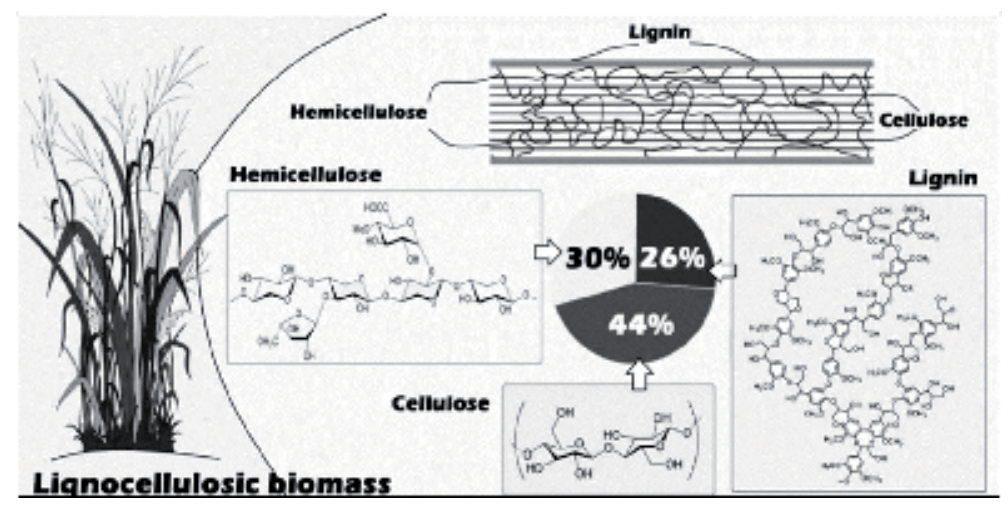

Figure 3.

Lignocellulosic biomass-Structure and composition. 
Lignocellulosic biomass is abundant in nature and is available at low cost and could easily form a new class of second generation biofuels. The production of high carbon alcohols using catalytic synthesis could be scaled up with much of the research required in engineering the reactor, process design and economic viability.

\subsection{Production pathways}

The present study utilizes biofuels that could be possibly derived from nonfood-based feedstock. Biofuels that could be derived from biomass feedstocks using microbial production include high carbon alcohols, biodiesels, jet fuels, and biogasoline [31]. As of now, mechanical microorganisms (like Escherichia coli and Saccharomyces cerevisiae) and photosynthetic life forms like cyanobacteria are built to follow up on non-sustenance-based sources and create petroleum like derivatives, called "progressed" or "drop-in" biofuels. The different pathways for the combination of biofuels derived from lignocellulosic biomass feedstock are presented in Figure 1. The current study utilized bioalcohols like n-octanol and cyclohexanol that could be derived from lignocellulosic biomass feedstock. $\mathrm{n}$-Octanol is an aliphatic straight chain alcohol that has superior cetane number, calorific value, oxygen content, and solubility with diesel [32]. Cyclohexanol is an aromatic ring chained alcohol. Cyclohexanol has superior oxygen content but slightly lower cetane number and energy density than n-octanol. Both these bioalcohols are excellent biofuels that has huge prospects for synthesis in biorefineries. Cellulose and hemi-cellulose can be subjected to enzymatic or acid hydrolysis to be broken down to sugars. $\mathrm{C}_{5}-\mathrm{C}_{6}$ sugars could be dehydrated to platform chemicals like furfurals, levulinic acid. Selective microbial fermentation of $\mathrm{C}_{5}-\mathrm{C}_{6}$ sugars can be employed to extract high carbon alcohols using engineering micro-organisms like E. coli. During the past 3 years, microbial production of n-octanol has gained the interest of researchers and extended the n-butanol pathway to obtain a yield of $70 \mathrm{mg} / \mathrm{L}$ of 1 -octanol using the Clostridium species. Several pathways were later developed with improved yield of n-octanol. Biosynthetic pathway employing multi-functional catalysts to derive linear C8 products like 1-octanol and di-octyl ether from lignocellulose. A yield of up to $93 \%$ of linear C8 alcohol products was achieved using this innovative route. Subramanian et al. proposed 1-octanol as a biofuel with diesel-like properties and engineered a biosynthetic pathway to extract it from E. coli. Recently, they developed an energy-efficient catalytic system that could produce a highest yield of 1-octanol (62.7\%) from biomass-derived furfuralacetone and synthesized phenolic compounds like cycloalkanes, cyclohexanol and linear alkenes from a pyrolytic lignin-oil fraction using catalytic valorization through hydro-treatment [32]. Cyclohexanol can also be obtained from guaiacol which is one of the most abundant lignin de-polymerization products. They introduced an in situ catalytic hydrogenation system to convert lignin-depolymerized compounds like guaiacol and phenol to cyclohexanol using Raney nickel catalyst and devised another highly efficient hydrothermal conversion of biomass derived cyclohexanone to cyclohexanol with high yield and high selectivity using in situ hydrogenation in the presence of a copper catalyst. It achieved more than $97.74 \%$ of guaiacol conversion with $100 \%$ cyclohexanol selectivity in the presence of $20 \%$ Nickel/Magnesium-oxide catalyst. Recently, they achieved highly efficient hydrogenation of a lignin-derived monophenol (4-ethylphenol) to cyclohexanol over $\mathrm{Pd} / \gamma$ $\mathrm{Al}_{2} \mathrm{O}_{3}$ (Palladium/gamma-Alumina) catalyst with selectivity up to $98.6 \%$. Lignin can also be biodegraded to renewable biofuels using genetically modified microbes. Bacterial lignin degradation activity has been best characterized in actinobacteria. The use of microbes like Pseudomonas stutzeri to breakdown lignin to aromatic 
monomers has been identified already. The utilization of biocatalysts could address every ones issues for high profitability and high prospects for feasible cyclohexanol process advancement.

\section{Background}

Smoke and NOx emissions in diesel engines have an inherent exchange off connection among them and in this way endeavors to limit one of them would normally bring about expanding the other. To add to this hopelessness, endeavors to decrease outflows would regularly result in misfortune in execution of the engine. This is because efficient combustion often results in high cylinder temperatures and reduces smoke but promotes NOx formation. On the other hand, lowering the combustion temperature results in incomplete combustion and favors NOx emissions but increases smoke formation and reduce engine performance. Adding oxygenated biofuels like bioalcohols to diesel reduces smoke emissions by the way of providing additional oxygen during combustion in fuel-rich zones via fuel-bound oxygen content. However this often results in higher NOx emissions. Exhaust gas recirculation (EGR) is a NOx reduction technology which involves bypassing a percentage of the combusted gases back to engine cylinder along with the intake charge that reduces peak combustion temperatures responsible for NOx formation by the way of its thermal, chemical and dilution effects. However, EGR causes a drop in engine performance as it disturbs the normal combustion process. Modifying the injection timing also affects the emission and performance characteristics. Delaying the injection up to the TDC causes low combustion temperatures and reduces NOx emissions and engine performance. Early injection improves air-fuel mixing and promotes complete combustion. This increases peak combustion temperatures and reduce NOx emissions. Hence it could be inferred that optimization of parameters like oxygenate composition in diesel, EGR and injection timing could achieve low emission and high performance in a diesel engine.

\section{Conclusion}

Higher alcohols are second/third era biofuels that can be gotten from lignocellulosic biomass utilizing maintainable way and absent much any dependence on sustenance crops. As run of the mill biofuels, they are equipped for tending to the two dimensional issue of natural debasement and vitality weakness. The accompanying ends can be drawn after this broad study concerning the utilization of 3-carbon propanol to 20-carbon phytol in diesel engines.

Alcohol expansion drags out the start postponement of the mix. Higher alcohol/ diesel mixes show higher pinnacle chamber weights and higher pre-blended warmth discharge rates contrasted with diesel. The more extended the length of the carbon chain of the alcohol, the more ignitable the alcohol is. BTE of the engine energized with alcohols like propanol and butanol for the most part demonstrated improved execution:

- Higher level of premixed burning

- Low cetane number of propanol and improved shower attributes

- Decline in consistency and thickness of the mixes. 
BTE drops with the use of pentanol and other higher alcohols in diesel engine. Longer chain fatty alcohols like hexanol, octanol and dodecanol are prevalently utilized as surfactants to balance out lower alcohol/diesel mixes and diesel oil miniaturized scale emulsions.

NOx emissions for the most part diminished with expanding propanol or butanol substance in the mix. In any case, alcohols including pentanol and higher, expanded NOx discharges directly with their substance particularly at high loads. This variety is because of the distinction in mastery between the impacts of higher warmth of vaporization and cetane number. This fragile adjusting likewise relied upon the particular motor and its working conditions.

\title{
Abbreviations
}

ASTM

BDC

Bmep

$\mathrm{BP}$

BSEC

BSFC

BTE

But

CA

CCI

CI

CR

CRDI

EGR

Eth

Hex

HRR

LHV

Meth

MMT

Oct

Pen

ULSD

\author{
American Society of Testing and Materials \\ bottom dead center \\ brake mean effective pressure \\ brake power \\ brake-specific energy consumption \\ brake-specific fuel consumption \\ brake thermal efficiency \\ n-butanol \\ crank angle \\ calculated cetane index \\ compression ignition \\ compression ratio \\ common rail direct injection \\ exhaust gas recirculation \\ ethanol \\ n-hexanol \\ heat release rate \\ low heating value \\ methanol \\ million metric tons \\ n-octanol \\ n-pentanol \\ ultra low sulfur diesel
}




\section{Author details}

Melvin Victor Depoures $^{1 *}$, Damodharan Dillikannan ${ }^{2}$ and Gopal Kaliyaperumal ${ }^{3}$

1 Department of Mechanical Engineering, Saveetha School of Engineering, Chennai, India

2 Department of Mechanical Engineering, Jeppiaar Engineering College, Chennai, India

3 Department of Mechanical Engineering, New Horizon College of Engineering, Bangalore, India

*Address all correspondence to: melvin.victor02@gmail.com

\section{IntechOpen}

(C) 2019 The Author(s). Licensee IntechOpen. This chapter is distributed under the terms of the Creative Commons Attribution License (http://creativecommons.org/licenses/ by/3.0), which permits unrestricted use, distribution, and reproduction in any medium, provided the original work is properly cited. (cc) BY 


\section{References}

[1] Agudelo JR, Lapuerta M, Moyer O, Boehman AL. Autoignition of alcohol/ C7-esters/n-heptane blends in a motored engine under HCCI conditions. Energy \& Fuels. 2017;31:2985-2995

[2] Ananthakumar S, Jayabal S, Thirumal P. Investigation on performance, emission and combustion characteristics of variable compression engine fuelled with diesel, waste plastics oil blends. Journal of the Brazilian Society of Mechanical Sciences and Engineering. 2017;39:19-28

[3] Atmanlı A, İleri E, Yüksel B. Effects of higher ratios of n-butanol addition to diesel-vegetable oil blends on performance and exhaust emissions of a diesel engine. Journal of the Energy Institute. 2015;88:209-220

[4] Atmanli A, Ileri E, Yuksel B, Yilmaz N. Extensive analyses of dieselvegetable oil-n-butanol ternary blends in a diesel engine. Applied Energy. 2015;145:155-162

[5] Coughlin B, Hoxie A. Combustion characteristics of ternary fuel blends: Pentanol, butanol and vegetable oil. Fuel. 2017;196:488-496

[6] Devarajan Y, Munuswamy DB, Mahalingam A, Nagappan B.

Performance, combustion, and emission analysis of neat palm oil biodiesel and higher alcohol blends in a diesel engine. Energy \& Fuels. 2017;31:13796-13801

[7] Dhanasekaran R, Krishnamoorthy V, Rana D, Saravanan S, Nagendran A, Rajesh Kumar B. A sustainable and eco-friendly fueling approach for directinjection diesel engines using restaurant yellow grease and n-pentanol in blends with diesel fuel. Fuel. 2017;193:419-431

[8] Emiroğlu AO, Şen M. Combustion, performance and exhaust emission characterizations of a diesel engine operating with a ternary blend (alcoholbiodiesel-diesel fuel). Applied Thermal Engineering. 2018;133:371-380

[9] Emiroğlu AO, Şen M. Combustion, performance and emission characteristics of various alcohol blends in a single cylinder diesel engine. Fuel. 2018;212:34-40

[10] Gülüm M, Bilgin A. A comprehensive study on measurement and prediction of viscosity of biodieseldiesel-alcohol ternary blends. Energy. 2018;148:341-361

[11] Imdadul HK, Masjuki HH, Kalam MA, Zulkifli NWM, Alabdulkarem A, Rashed MM, et al. Influences of ignition improver additive on ternary (diesel-biodiesel-higher alcohol) blends thermal stability and diesel engine performance. Energy Conversion and Management. 2016;123:252-264

[12] Jenkins RW, Bannister CD, Chuck CJ. The emissions and the performance of diethyl succinate in a diesel fuel blend. Proceedings of the Institution of Mechanical Engineers, Part D: Journal of Automobile Engineering. 2017;231:1889-1899

[13] Jiang L, Xie XL, Wang LW, Wang RZ, Roskilly AP. Performance analysis on a novel self-adaptive sorption system to reduce nitrogen oxides emission of diesel engine. Applied Thermal Engineering. 2017;127:1077-1085

[14] Jiang L, Xie XL, Wang LW, Wang RZ, Wang YD, Roskilly AP. Investigation on an innovative sorption system to reduce nitrogen oxides of diesel engine by using carbon nanoparticle. Applied Thermal Engineering. 2018;134:29-38

[15] Kumar P, Sharma MP, Dwivedi G. Impact of ternary blends of biodiesel 
on diesel engine performance. Egyptian Journal of Petroleum. 2016;25:255-261

[16] Lapuerta M, Hernández JJ, Rodríguez-FernándezJ, BarbaJ, RamosA, Fernández-Rodríguez D. Emission benefits from the use of n-butanol blends in a Euro 6 diesel engine. International Journal of Engine Research. 2018;19:1099-1112

[17] Mahalingam A, Devarajan Y, Radhakrishnan S, Vellaiyan S, Nagappan B. Emissions analysis on mahua oil biodiesel and higher alcohol blends in diesel engine. Alexandria Engineering Journal. 2018;57:2627-2631

[18] Mofijur M, Rasul MG, Hyde J, Azad AK, Mamat R, Bhuiya MMK. Role of biofuel and their binary (dieselbiodiesel) and ternary (ethanolbiodiesel-diesel) blends on internal combustion engines emission reduction. Renewable and Sustainable Energy Reviews. 2016;53:265-278

[19] Nanthagopal K, Ashok B, Saravanan B, Korah SM, Chandra S. Effect of next generation higher alcohols and Calophyllum inophyllum methyl ester blends in diesel engine. Journal of Cleaner Production. 2018;180:50-63

[20] Pandian AK, Munuswamy DB, Radhakrishanan S, Devarajan Y, Ramakrishnan RBB, Nagappan B. Emission and performance analysis of a diesel engine burning cashew nut shell oil bio diesel mixed with hexanol. Petroleum Science. 2018;15:176-184

[21] Prakash T, Geo VE, Martin LJ, Nagalingam B. Effect of ternary blends of bio-ethanol, diesel and castor oil on performance, emission and combustion in a CI engine. Renewable Energy. 2018;122:301-309

[22] Preuß J, Munch K, Denbratt I. Performance and emissions of longchain alcohols as drop-in fuels for heavy duty compression ignition engines. Fuel. 2018;216:890-897

[23] Redel-Macías MD, Pinzi S, Leiva-Candia DE, López I, Dorado MP. Ternary blends of diesel fuel oxygenated with ethanol and castor oil for diesel engines. Energy Procedia. 2017;142:855-860

[24] Saleh HE, Selim MYE. Improving the performance and emission characteristics of a diesel engine fueled by jojoba methyl ester-diesel-ethanol ternary blends. Fuel. 2017;207:690-701

[25] Selim MYE, Ghannam MT, Awad ASA, Sabek MSA. Combustion and exhaust emissions of a directinjection diesel engine burning jojoba ethyl ester and mixtures with ethanol. Biofuels. 2017;10:545-551

[26] Subramanian T, Varuvel EG, Martin LJ, Beddhannan N. Effect of lower and higher alcohol fuel synergies in biofuel blends and exhaust treatment system on emissions from CI engine. Environmental Science and Pollution Research. 2017;24:25103-25113

[27] Yilmaz N, Atmanli A. Experimental evaluation of a diesel engine running on the blends of diesel and pentanol as a next generation higher alcohol. Fuel. 2017;210:75-82

[28] Yilmaz N, Atmanli A. Experimental assessment of a diesel engine fueled with diesel-biodiesel-1-pentanol blends. Fuel. 2017;191:190-197

[29] Yilmaz N, Atmanli A, Vigil FM. Quaternary blends of diesel, biodiesel, higher alcohols and vegetable oil in a compression ignition engine. Fuel. 2018;212:462-469

[30] Yusri IM, Mamat R, Najafi G, Razman A, Awad OI, Azmi WH, et al. Alcohol based automotive fuels from first four alcohol family in compression and spark ignition engine: A review 
on engine performance and exhaust emissions. Renewable and Sustainable Energy Reviews. 2017;77:169-181

[31] Zaharin MSM, Abdullah NR, Najafi G, Sharudin H, Yusaf T. Effects of physicochemical properties of biodiesel fuel blends with alcohol on diesel engine performance and exhaust emissions: A review. Renewable and Sustainable Energy Reviews. 2017;79:475-493

[32] Rajesh Kumar B, Saravanan S. Use of higher alcohol biofuels in diesel engines: A review. Renewable and Sustainable Energy Reviews. 2016;60:84-115. DOI: 10.1016/j.rser.2016.01.085 
Section 3

Soot and Diesel Particulate Matter 



\title{
Comparison of Different Techniques for Measurement of Soot and Particulate Matter Emissions from Diesel Engine
}

\author{
Richard Viskup
}

\begin{abstract}
The research presented here is the comparison studies between different commercially available techniques for measurement of soot and particulate matter (PM) emissions from passenger car diesel engine. The compared devices are filter paper-type smoke meter, photoacoustic spectrometer, opacimeter, differential mobility spectrometer and laser-induced incandescence. The focus is to study static and dynamic transient exhaust emissions from the location position closer to the actual combustion event-downstream of the turbine, position characterised by the higher temperature and higher pressure of the emission gas - than the standard measurement position, in the tailpipe of the exhaust manifold. The main task is to compare an accuracy and sensitivity of individual devices at static and dynamic soot and PM emissions.
\end{abstract}

Keywords: soot emission, particulate matter, diesel engine, smoke meter, photoacoustic spectroscopy, opacimeter, differential mobility spectrometer, laser-induced incandescence

\section{Introduction}

The combustion engine-driven vehicles are one of the main consumers of petroleum natural resources and are mainly responsible for air pollution in the heavily traffic regions, in the cities and in large metropolitan areas $[1,2]$. To minimise the pollutant emission from vehicles, an effective combustion control and monitoring plays a very important role [3]. Measurements of diesel emissions are usually performed by using various measurement techniques [4]. The limits for exhaust emission of newly produced vehicles are regulated in the European Union (EU) by European emission standards and are defined in a series of European Union directives. These regulations are usually amended every half of the decade and are published in a form of standards like first Euro 1 norm set in year 1992 to current Euro 6 valid from year 2014. In the case of passenger cars, the emission standards are defined for particulate matter (PM), total hydrocarbon, non-methane hydrocarbon (NMHC), carbon monoxide and nitrogen oxide emissions. The basic idea of these norms is to contribute to the reduction of emissions by newly produced vehicles. However, with the strict limits given by the European regulation on pollutant emission, measurement of low-level emission concentrations from the engine is very 
challenging. This is mainly due to measurements of such as low concentrations and/or very short time duration peak emissions. Thus, the sensitivity of method and applied measurement techniques represent an important issue [5, 6]. Another important factor for minimising overall emissions is a high temporal resolution of the measurement device, mainly during the measurement of fast transient emission peaks. These are the emissions produced due to the rapid acceleration or deceleration phase of the vehicle. Nowadays there exist many different commercially available techniques for $\mathrm{PM}$ and soot concentration emission measurement, based on gravimetric analyses [7], paper filter-type smoke meter [8], measurement of continuous opacity [9, 10], differential mobility spectrometers [11-13], measurement of photoacoustic spectroscopy [14-16] and measurement of laser-induced incandescence (LII) [17-20].

The main differences between these techniques are in methodology and in measurement principle. Another issue is the sensitivity of the measurement itself, sampling time and dynamics response to fast emission detection. Additional criterion is the position-location of sensor during the measurement of emissions from engine. The optimal position of the sensor with respect to the measurement of the fast dynamic response would be as close as possible to the emission source, directly into the combustion chamber of the engine. The second alternative would be upstream of the turbine and the third possibility is downstream of the turbine in the exhaust manifold. The first position-directly into the combustion chamber-is due to the geometrical restrictions that are difficult to measure, and therefore the nearest possible location is in the exhaust manifold. However, due to high instantaneous pressure and temperatures of soot in this part, the measurements are usually performed far from exhaust manifold or directly in the tailpipe. The placement of the sensors into the tailpipe is introducing additional delay in measured emission signal and can negatively influence measured results. A next drawback of tailpipe position is the change in gas emission dynamics due to measurement in lowerpressure zone; however, high-pressure information can be very helpful in order to better characterise, control and minimise emissions during combustion process.

Up to now, the systematic studies dedicated to the differences in sensitivity and accuracy of transient PM emission by comparing available commercial devices were made by Viskup et al. in [21, 22]. The accuracy and reliability of measured emission data are very important information to eliminate toxic emissions from vehicle engines and to meet the future EU directives.

In this chapter, the comparison between different techniques for measurement of soot and particulate matter static as well as dynamic transient emissions is shown. The analysis presents differences in measured emission by individual techniques from a position closer to the actual combustion event, downstream of the turbine in the exhaust manifold. Measurement at this position is influenced by higher temperatures and higher pressures of emission gases than standard tailpipe position. However, this will influence the possibility of using a particular device as well as techniques for such a non-standard measurement location. High concern is given to comparing the device's sensitivity and dynamics at static as well as fast transient emission peaks, because these produce a main fraction of total emissions during the standardised test cycles from passenger car diesel engines [23]. The obtained results will allow better understanding of PM emissions, support dynamic emission modelling for control design and contribute to the development of virtual emission sensors [24, 25].

\section{Instrumentation}

Because this chapter is dedicated to the comparison between different commercial available measurement devices for the soot and particulate matter emission measurements, the basic measurement principle of each method is briefly discussed. 


\subsection{Basic principle of differential mobility spectrometer}

The basic principle of differential mobility spectrometer (DMS) is in charging of PM particles formed during the combustion and classifying them on the basis of its mobility. Particles of PM, which enter into differential mobility spectrometer, are charged by means of corona discharge. Each particle is charged proportionally to its surface area. Charged particles are then introduced into a strong radial electrical field inside a classifier column. Positively charged particles are further drifting through a sheath flow in the direction of the numerous segmented collection electrodes. Particles are then attached to different distances of the segmented electrode rings down the classifier column, according to their drag charge ratio. The current produced by particles on every sensitive electrometer is used to determine particle size and number of concentration. Basic schema of DMS is shown in Figure 1.

\subsection{Basic principle of laser-induced incandescence}

The laser-induced incandescence technique uses the laser radiation with short pulse duration and high power to irradiate particles formed during the combustion event. This process induces incandescence light emitted by the particulates, which is consecutively detected by fast photodiode, photomultiplier tube (PMT) or fast avalanche photodiode detector (APD) with nanosecond (ns) response time. The excitation of the soot particles by laser-induced incandescence is typically performed with pulsed laser radiation, e.g. Nd:YAG with pulse duration of $10 \mathrm{~ns}$ at fundamental laser wavelength $1024 \mathrm{~nm}$ with laser fluence $\sim 0.4 \mathrm{~J} / \mathrm{cm}^{2}$ or frequencydoubled $532 \mathrm{~nm}$ at $\sim 0.2 \mathrm{~J} / \mathrm{cm}^{2}$ [26]. The basic optical arrangement of LII setup is shown in Figure 2.

The LII scheme works as follows. The pulsed laser beam with Gaussian profile is converted into a homogeneous vertical sheet by using a combination of cylindrical and spherical lenses to achieve uniform intensity over spatial profile. Beam is then expanded and directed into the burner. Laser power meter and beam profiler monitors the emerging laser beam from the burner cell. Signal from LII emission is collected perpendicularly by the collecting lens and directed through attenuator into the beam splitter. Split signal is further filtered with interference filters and imaged into fast detector. The LII signal is sampled with nanosecond intervals with fast digital oscilloscope and further processed by the computer.

\subsection{Basic principle of opacimeter}

The basic principle of the opacimeter is measurement of attenuation of emitting light from the light source, which is transmitted through soot media and

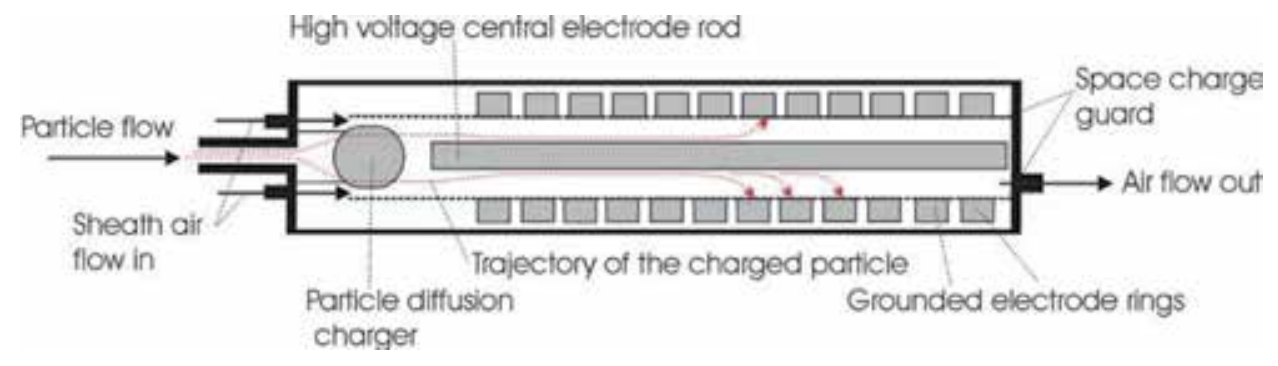

Figure 1.

Schema of differential mobility spectrometer. 


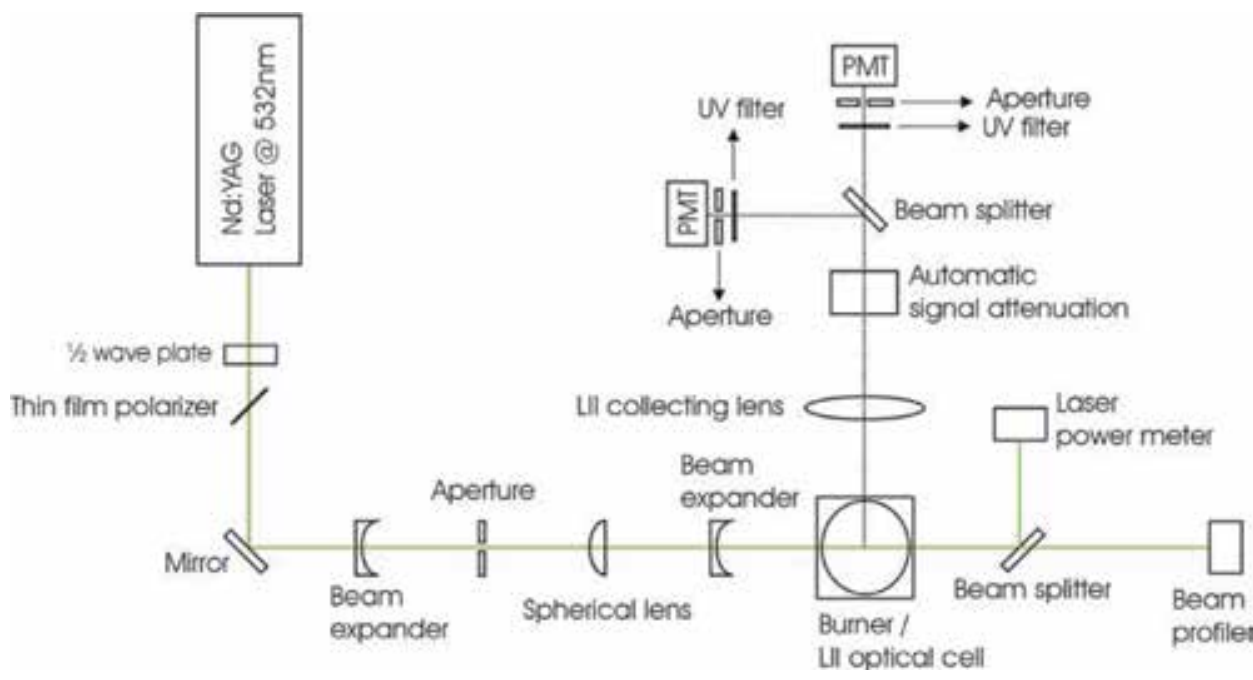

Figure 2.

Optical arrangement of laser-induced incandescence.

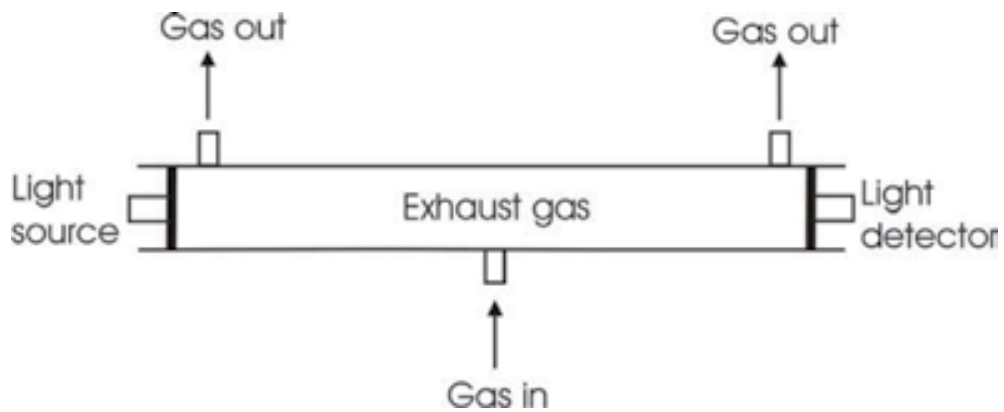

Figure 3.

Schematic arrangement of opacimeter.

consequently absorbed. A light transmitting-type opacimeter measures a soot concentration based on absorbed and scattered light. The measured density value is then the superposition of the black smoke (soot) due to high temperature fuel combustion, blue smoke hydrocarbon vapour and white smoke water vapour. The concentration of the soot is calculated from light attenuation using the BeerLambert law of light absorption. The measured results are then expressed as opacity (\%) or in absorption coefficient in $\left(\mathrm{m}^{-1}\right)$. Basic schematic arrangement of the opacimeter is shown in Figure 3.

\subsection{Measurement of soot concentration from the opacity}

Because the opacimeter measures the opacity in \%, it is necessary to recalculate the opacity values into soot concentrations. For this reason, the steady-state measurement outputs of the opacimeter and the smoke meter empirical correlation function can be used as:

$$
\text { Opacity }=1.67 . F S N^{2}+1.56 \cdot F S N+0.619
$$


which has been derived in [27], to obtain the filter smoke number (FSN) from opacity measurements. The soot concentration can be calculated from the empirical correlation equation [28].

$$
\operatorname{Soot}\left(m g / m^{3}\right)=\frac{1}{0.405} 4.95 . F S N . e^{(0.38 . F S N)}
$$

By this empirical correlation method, it is possible to obtain the soot concentration values in $\left(\mathrm{mg} / \mathrm{m}^{3}\right)$.

\subsection{Basic principle of paper filter-type smoke meter}

The basic principle of the smoke meter is in measurement of exhaust gas emissions sucked through a filter paper. The blackening of filter paper is measured with reflectometer and indicates the soot content in the exhaust gas. Smoke collected by the filter and the blackening of this filter depend primary on soot concentration and the effective filter length-exhaust gas volume related to the filter area. The measuring principle of the smoke meter is shown in Figure 4.

Rolled filter paper is fed through exhaust gas chamber where the soot particles are adsorbed at the surface. Afterwards the filter paper is further moved in the direction of the measurement section. Here the blackening of filter paper is measured with reflectometer and further directed out from this chamber. Used filter paper is rolled on the spool.

\subsection{Basic principle of photoacoustic spectroscopy}

The basic mechanism of photoacoustic spectroscopy is in measurement of acoustic response after absorption of modulated laser radiation by the PM. The laser radiation is absorbed by the PM and leads to heating and consequently to thermal expansion of the particles accompanied by acoustic waves in surrounding gas of the photoacoustic cell. Local expansion is modulated with the frequency of the light source. Generated sound waves resulting from the modulation of the light are

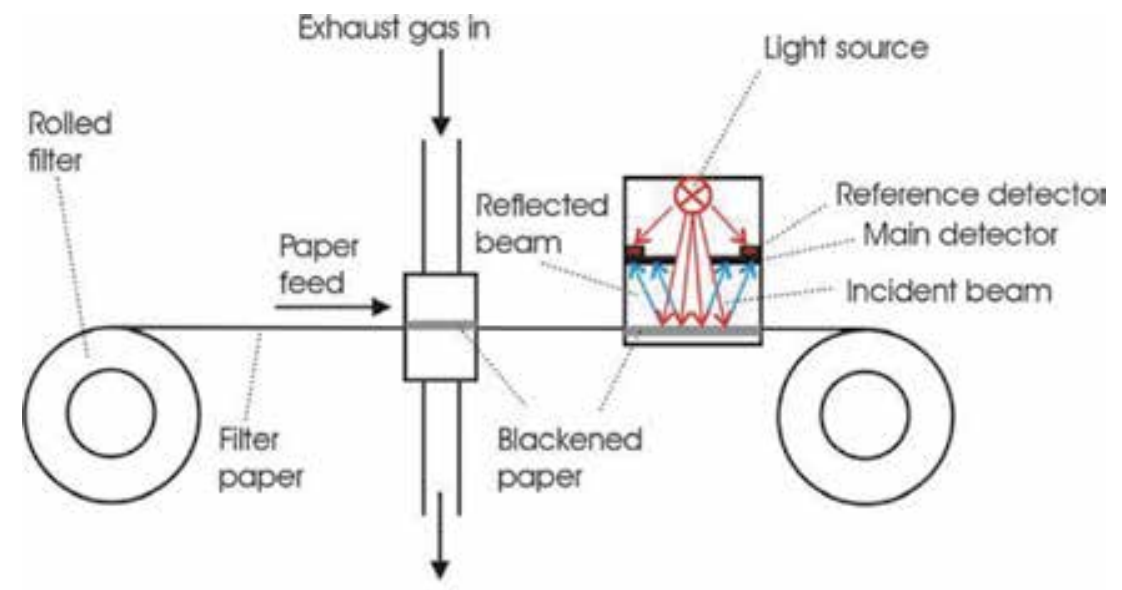

Exhaust gas out

Figure 4 .

Measuring principle of paper filter-type smoke meter. 
proportional to the absorbed laser energy. Sound waves are recorded by means of sensitive microphone built in the resonator. Intensity of the acoustic waves is proportional to the photoacoustic signal. Acoustic resonator acts as a longitudinal resonator for the amplification of the photoacoustic signal. Speaker is used to determine the exact resonance frequency and for controlling of microphone. Schematic arrangement of photoacoustic spectrometer is shown in Figure 5.

\section{Experimental}

Measurements of particulate matter emissions and soot were performed on Euro 5 standard passenger car diesel engine and on dynamic engine test bench system by applying the following measurement techniques:

1. Photoacoustic spectroscopy-AVL Micro Soot Sensor 483

2. Differential mobility spectrometer-Cambustion DMS500

3. Opacimeter-AVL Opacimeter 439

4. Laser-induced incandescence-Artium Technologies Inc. LII 200

5. Filter-type smoke meter-AVL Smoke meter $415 \mathrm{~S}$

Comparison of basic technical parameters-sensitivity, response, rise and sampling time, upper temperature and upper pressure limits of devices-is shown in Table 1.

All instruments were used simultaneously during measurements. Devices were placed downstream of the turbine location in the exhaust manifold part, as is shown in Figure 6.

It has to be mentioned that measurement location downstream of the turbineposition before the oxidising catalyst-is characterised by the higher temperature and higher pressure of the emission gases. Therefore, this position can influence the measured results from devices which are more sensitive for higher temperatures or pressures.

The test bench system has been controlled via AVL Puma Open test system automation. The Micro Soot Sensor and opacimeter were connected via dSPACE, DS 1006 Processor and DS2202 HIL I/O Board. Sampling time was set to $4 \mathrm{~ms}$. Data acquisition of laser-induced incandescence device was controlled via the Artium computer, due to the lack of output connection into dSpace, with a sampling time of

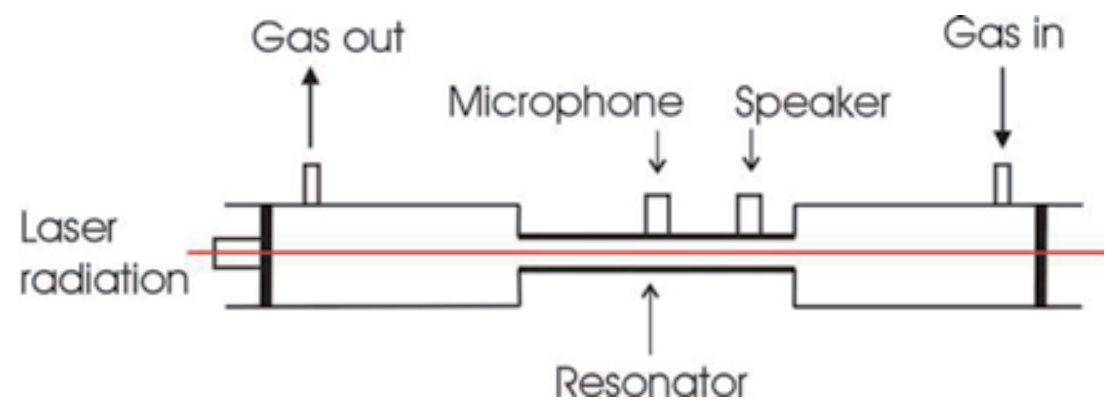

Figure 5.

Schematic arrangement of the photoacoustic spectrometer. 
Comparison of Different Techniques for Measurement of Soot and Particulate Matter Emissions... DOI: http://dx.doi.org/10.5772/intechopen.91186

\begin{tabular}{|c|c|c|c|c|}
\hline Method/Device & Sensitivity & Time & $\begin{array}{l}\text { Upper temperature } \\
\text { limit }\end{array}$ & $\begin{array}{c}\text { Upper pressure } \\
\text { limit }\end{array}$ \\
\hline $\begin{array}{l}\text { Laser induced incandescence } \\
\text { Artium Technologies LIl-200 }\end{array}$ & $-2 \mu g / m^{3}+-20 g / m^{3}$ & $\begin{array}{l}100 \mathrm{~ms} \\
\text { response time }\end{array}$ & $300^{\circ} \mathrm{C}$ & 5000 mbar \\
\hline $\begin{array}{l}\text { Photo-acoustic spectroscopy } \\
\text { Micro soot sensor AVL } 483\end{array}$ & $-5 \mu g / m^{3}+-50 m g / m^{3}$ & $\begin{array}{l}1000 \mathrm{~ms} \\
\text { rise time }\end{array}$ & $1000^{\circ} \mathrm{C}$ & 2000 mbar \\
\hline $\begin{array}{l}\text { Opacimeter } \\
\text { AVL } 439 \text { Opacimeter with }\end{array}$ & $\begin{array}{l}0.1 \% \text { opacity } \\
\text { or } 0.0025 \mathrm{~m}^{-} \\
\text {absorption }\end{array}$ & $\begin{array}{l}100 \mathrm{~ms} \\
\text { rise time }\end{array}$ & $600^{\circ} \mathrm{C}$ & $400 \mathrm{mbar}$ \\
\hline high pressure option & & & $800^{\circ} \mathrm{C}$ & 3000 mbar \\
\hline $\begin{array}{l}\text { Filter type smoke meter } \\
\text { AVL- } 415 S\end{array}$ & $-20,19 / \mathrm{m}^{3}+-10 \mathrm{mg} / \mathrm{m}^{3}$ & $\begin{array}{l}\text { 1s-100s } \\
\text { sampling time }\end{array}$ & $600^{\circ} \mathrm{C}$ & 400 mber \\
\hline $\begin{array}{l}\text { Differential mobility spectrometer } \\
\text { Cambustion model DMS } 500\end{array}$ & from $-2 \mu g / m^{3}$ & $\begin{array}{l}200 \mathrm{~ms} \\
\text { response time }\end{array}$ & $150^{\circ} \mathrm{C}$ & 2000 mbar \\
\hline
\end{tabular}

Table 1.

Specifications of different commercial devices for soot measurement. Upper temperature and pressure limits are for location of sensors in exhaust manifold position.

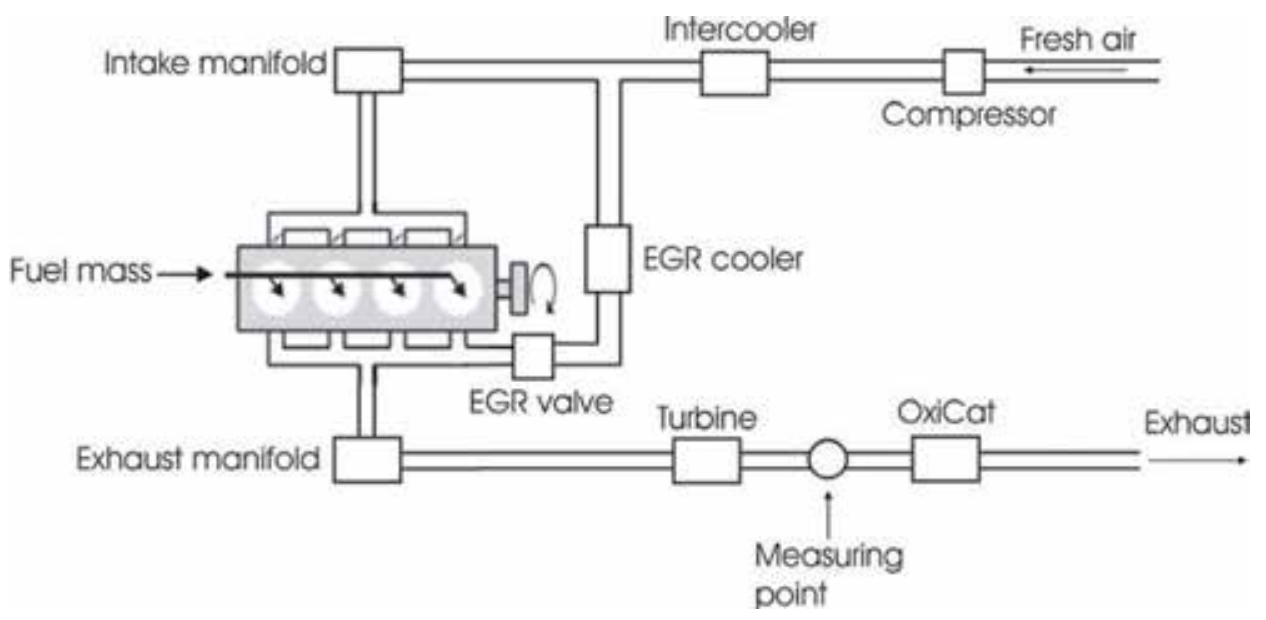

Figure 6.

The schema of the experimental setup and position location of devices during the soot emission measurement. EGR is the engine exhaust gas recirculation, and OxiCat is the oxidising catalyst.

$50 \mathrm{~ms}$. A signal from fast differential mobility spectrometer was recorded via both dSpace board and also Cambustion computer with sampling time of $100 \mathrm{~ms}$.

The experiments performed were mainly focused on measurement of soot and particulate matter emissions from diesel engine during static and dynamic transient cycle with special concern to compare the sensitivity and dynamics response of individual devices. The following measurements were performed:

\section{a. Static measurements}

To compare a sensitivity of applied instruments at specified input parameters, measurements of relatively long constant and continuous soot emissions (100 second) in the form of rising and falling steps were performed. This time was sufficiently enough for devices to respond on changes in soot level of injected fuel volume in a well-defined time. Injection of fuel volume gradually increases in the form of steps.

\section{b. Pulsed fuel injection}

Measurement of soot emission response related to fuel injection in the form of short pulses, with injected well-defined fuel volume (1 or $2 \mathrm{mg} / \mathrm{cycle})$ during a 
relatively short time ( 1 second, 500 or $250 \mathrm{~ms}$ ), to observe the sensitivity of individual devices, was also performed.

\section{c. Dynamic transient measurements}

To compare instruments at transient emission measurement conditions, a New European Driving Cycle (NEDC) has been chosen to analyse a sensitivity and response time of individual devices.

\section{Results and discussion}

\subsection{Static measurements: measurement of constant soot emissions}

In the case to study the static emissions from diesel engine, 100-second constant and continuous soot emissions, in the form of rising and falling steps, were measured. With the Puma control system, the defined volume of diesel fuel was injected into the engine. This injection function (fuel set) is shown in the first graph of Figure 7. The real injected volume has been also measured, and its profile is shown in the figure as "fuel actual." Both values have the same unit mg/cycle. In the second graph of Figure 7, the engine speed in rotation per minute unit (rpm) is shown. In the third graph, filtered data of soot concentration in $\mathrm{mg} / \mathrm{m}^{3}$ measured by photoacoustic spectroscopy, differential mobility spectrometer, opacimeter, laserinduced incandescence and filter-type smoke meter are shown.

Data recorded by filter-type smoke meter are constant over the individual steps of measurements. This is due to the fact that smoke meter is constructed to measure soot level during longer accumulation time. This is also the reason why the smoke meter has not been used for dynamic transient measurements but rather for static map test.

For very low soot emissions-below $\sim 1 \mathrm{mg} / \mathrm{m}^{3}$, in the case of opacimeter-the calculated soot values from the opacity are not so accurate, as the opacimeter
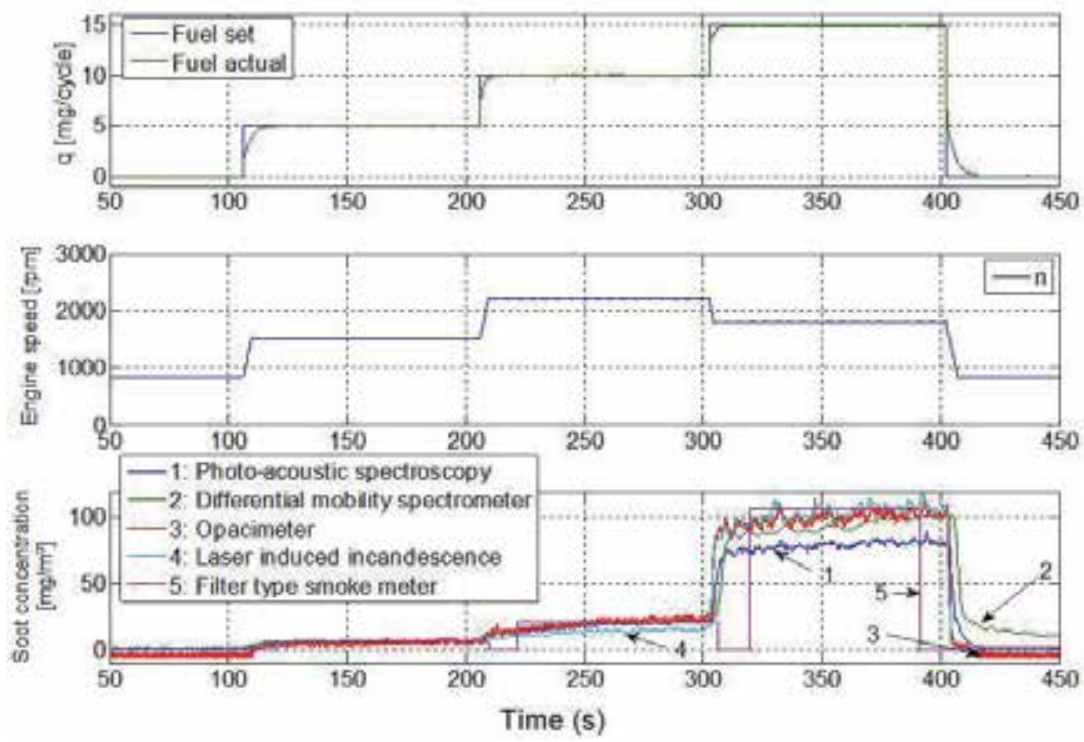

Figure 7.

Figure shows static measurement of soot emissions. Input parameters are injected fuel set, fuel actual and engine speed. Soot concentration in $\mathrm{mg} / \mathrm{m}^{3}$ was measured by photoacoustic spectroscopy, differential mobility spectrometer, opacimeter, laser-induced incandescence and filter-type smoke meter. 
measures also the opacity for the zero soot signal. This happens because the exhaust vapour and gases influence the opacity signal too, as the light rays from the opacimeter source scatters on this matter into the detector. Additional error is for small values of opacity, due to recalculation of opacity to soot concentration values using formulas (1) and (2).

For the moderate soot emissions, approximately $5 \mathrm{mg} / \mathrm{m}^{3}$, all instruments show more or less the same soot level. In the case of middle soot emission concentrations, $\sim 20 \mathrm{mg} / \mathrm{m}^{3}$, the values measured by laser-induced incandescence are lower than the values measured by the other methods. For high soot emission concentrations, $\sim 100 \mathrm{mg} / \mathrm{m}^{3}$, only photoacoustic spectroscopy shows lower level of the soot. At high level of soot emissions, one can easily observe oscillations in measured soot signal, captured by fast dynamic measurement devices.

\subsection{Fuel pulse response measurements at constant engine speed}

To further characterise a performance of individual methods, mainly the sensitivity to fuel volume and resulting emissions, the soot concentration from welldefined injected fuel volume was investigated. To this end, at the certain level ( $10.7 \mathrm{mg} / \mathrm{cycle})$ of engine load, a defined volume of additional fuel- 1 or $2 \mathrm{mg} / \mathrm{cycle}$ —during a short time of 1 second, 500 or $250 \mathrm{~ms}$, was injected in the form of short pulses into the engine, while all devices measured the soot emission response. The results are shown in Figure 8.

The fuel injections were performed extra to constant engine load, whereas the engine speed was kept constant at $1800 \mathrm{rpm}$. From this measurement, one can clearly observe emission peaks related to each fuel injection. A difference in measured peaks is that the certain technique resolved individual fuel injection and consequent soot emission with better resolution. Indeed, some devices show broader pulse width and different shape profile. The peaks measured by

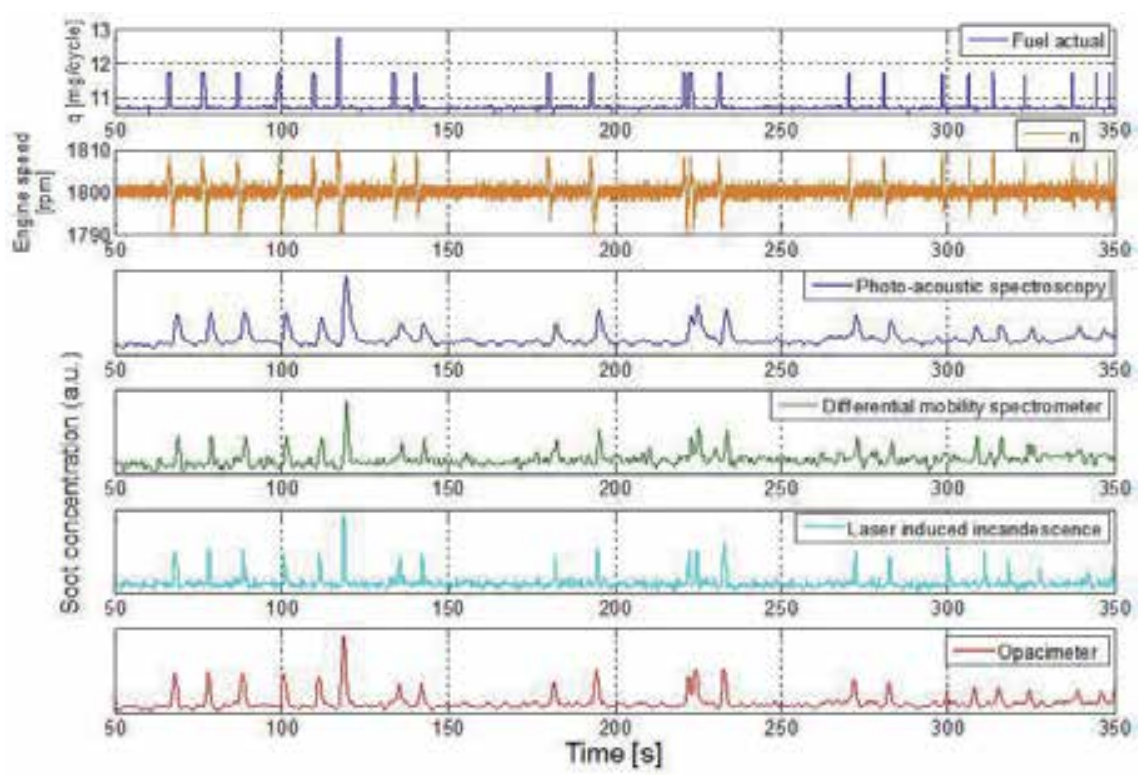

Figure 8.

Figure shows the injected fuel, engine speed and filtered data of soot concentration measured by photoacoustic spectroscopy, differential mobility spectrometer, opacimeter and laser-induced incandescence within 1000, 500 and $250 \mathrm{~ms}$ injection time at $10.7 \mathrm{mg} / \mathrm{cycle}$ fuel load. 
the photoacoustic spectroscopy are generally broader than peaks measured by the other methods.

A detailed picture of three injected peaks (two consequent) and measured soot emission response is shown in Figure 9. From filtered data in Figure 9, one can observe very fast response measured by laser-induced incandescence where two sequential peaks separated by 1 second are well resolved (time scale between 220 and 230 seconds). In the case of differential mobility spectrometer, photoacoustic spectroscopy and opacimeter, the peaks are less pronounced.

\subsection{Comparison of dynamics from injected pulse emission peak}

The comparison of dynamics was made from measurement of short emission pulses. The main concern was to compare fast dynamics response of individual devices during a well-defined injected fuel volume in the form of short pulses. Due to that reason, one single pulse from this injection which has been further analysed in detail is selected. In Figure 10 the fuel peak profile with $2 \mathrm{mg} /$ cycle injected during 1 second, corresponding engine speed profile and raw data of soot concentration measured at $10.7 \mathrm{mg} / \mathrm{cycle}$ load are shown. The shape of the engine speed curve is increasing due to injected fuel volume up to $1808 \mathrm{rpm}$ and consecutively decelerating due to dynamometer braking force. Dynamometer further compensates an engine speed to $1800 \mathrm{rpm}$. The event from the fuel injection with rectangular profile function lasts approximately $1000 \mathrm{~ms}$, while the engine speed response (with reversed profile) to this injection lasts approximately $2000 \mathrm{~ms}$. After that time $(2000 \mathrm{~ms})$, the engine speed settles to a constant value of $1800 \mathrm{rpm}$. Consequently, measured response to soot emission is broadening of peak function in direction to later times (to right side). The peak response measured by laser-induced incandescence lasts $1500 \mathrm{~ms}$; in the case of differential mobility spectrometer, it lasts $1700 \mathrm{~ms}$; for opacimeter it lasts $2900 \mathrm{~ms}$; and in the case of photoacoustic spectroscopy, it lasts $4400 \mathrm{~ms}$. From

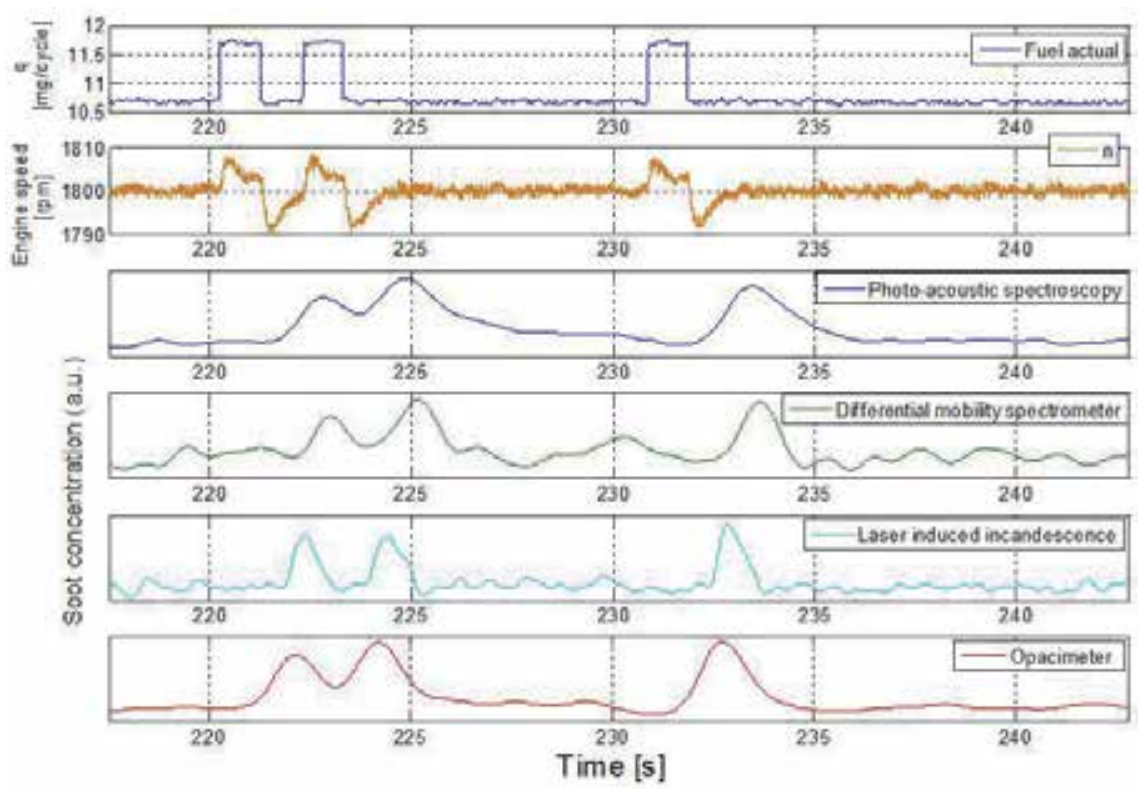

Figure 9.

The injected fuel, engine speed and filtered data of soot concentration measured by photoacoustic spectroscopy, differential mobility spectrometer, opacimeter and laser-induced incandescence within 1000 ms pulses injected at $10.7 \mathrm{mg} / \mathrm{cycle}$ fuel load are shown. 
Comparison of Different Techniques for Measurement of Soot and Particulate Matter Emissions... DOI: http://dx.doi.org/10.5772/intechopen.91186
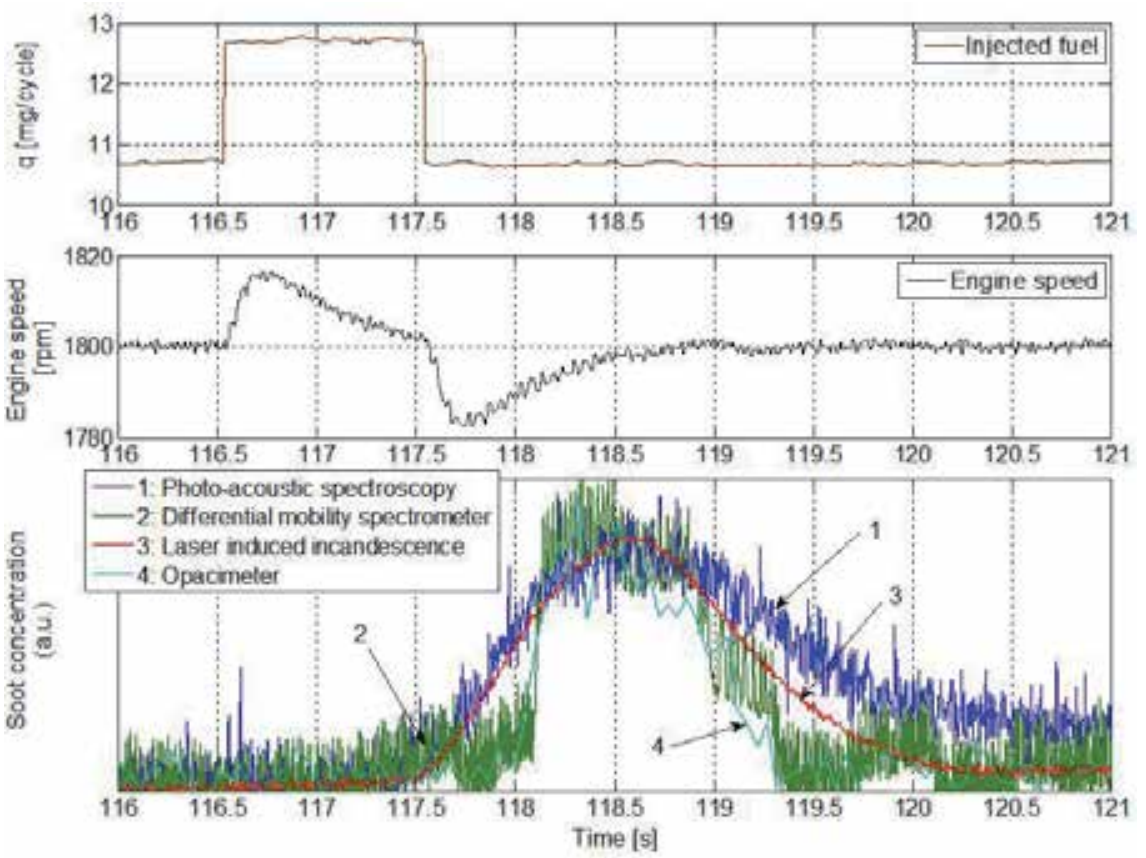

Figure 10.

Single $1000 \mathrm{~ms}$ pulse of injected fuel shows engine speed and raw data of soot concentration measured by photoacoustic spectroscopy, differential mobility spectrometer, opacimeter and laser-induced incandescence at constant $10.7 \mathrm{mg} /$ cycle fuel load.

this measurement the differences in measured speed to fast transient peak and dynamic response of devices are well differentiated.

In Figure 11 filtered data from selected upslope (rise time) of soot emission from a single peak, normalised to $100 \%$, are shown. Measured peak response from devices was shifted so that the maximum $100 \%$ of soot concentration is located in zero-time coordinate. The largest negative time value, where the function has $\mathrm{x}$ intercept (zero concentration), corresponds to the slowest measured response, in

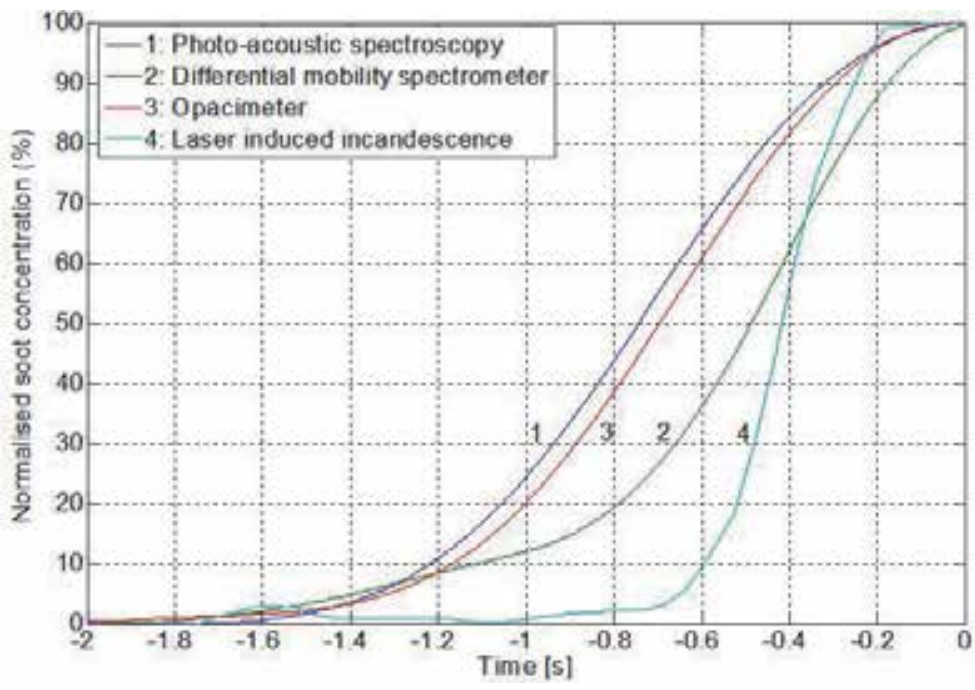

Figure 11.

Filtered data of normalised upslope (rise time) peak from selected part of test soot emission. Note the negative time delay. 


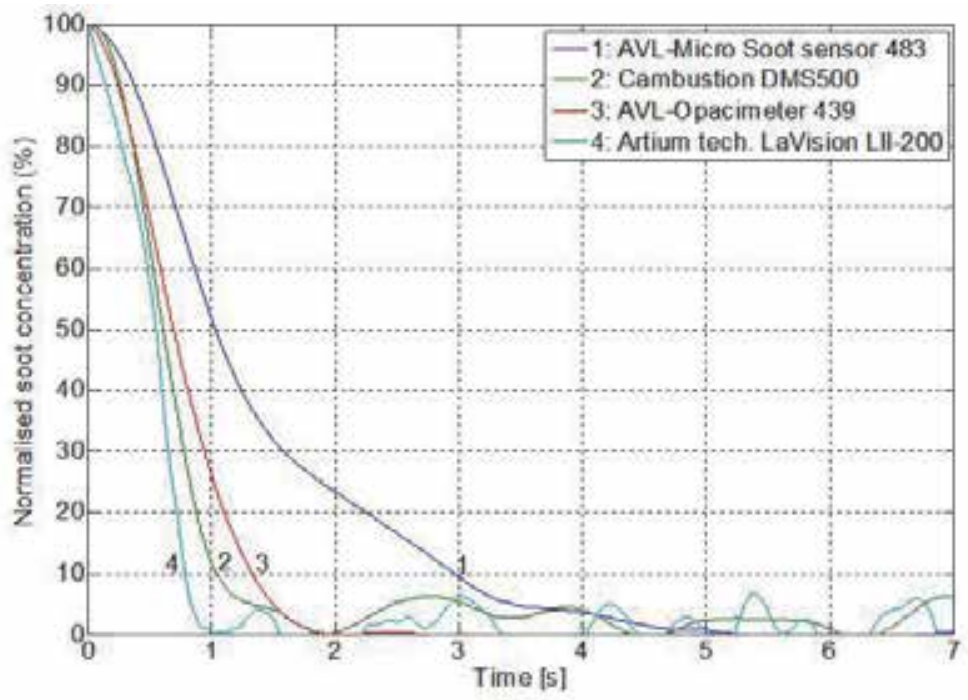

Figure 12.

Filtered data of normalised downslope (fall time) peak from selected part of test soot emission.

this case to photoacoustic spectroscopy (1). The steepest slope and the fastest rise time of soot level have been measured by the laser-induced incandescence (4).

In Figure 12 the filtered data from selected downslope (fall time) peak of soot emission normalised to $100 \%$ are shown. Resulting data shows similar tendency. The steepest decay was measured by the laser-induced incandescence, the second fastest by the differential mobility spectrometer and opacimeter. The slowest response was measured by photoacoustic spectroscopy device.

Measured rise time during upslope peak, normalised soot concentration from 10 to $90 \%$ and downslope (fall time) peak from 90 to $10 \%$ are summarised in Table 2.

Obtained results are better pronounced in a bar graph (Figure 13). Here, an overview of measured rise time (10-90\%) and fall time (90-10\%) of normalised soot concentration emission measured from 1000 ms injection peak during static pulse test at $10.7 \mathrm{mg} /$ cycle fuel load are shown.

\subsection{Dynamic transient measurements}

Comparison of the results from dynamic transient test PM emission measurement during standard New European Driving Cycle measured by photoacoustic

\begin{tabular}{lcc}
\hline & $\begin{array}{c}\text { Up-slope time (s) } \\
10 \%-90 \%\end{array}$ & $\begin{array}{c}\text { Down-slope time (s) } \\
90 \%-10 \%\end{array}$ \\
\hline \hline Photo-acoustic spectroscopy & 0.89 & 2.59 \\
Differential mobility spectrometer & 0.93 & 0.77 \\
Opacimeter & 0.86 & 1.08 \\
Laser Induced Incandescence & 0.34 & 0.64 \\
\hline
\end{tabular}

Table 2.

Summary of measured upslope (rise) time from 10 to $90 \%$ and downslope (fall) time from 90 to $10 \%$ of normalised soot concentration measured from 1000 ms injection peak during static pulse test at $10.7 \mathrm{mg} / \mathrm{cycle}$ fuel load. 
Comparison of Different Techniques for Measurement of Soot and Particulate Matter Emissions... DOI: http://dx.doi.org/10.5772/intechopen.91186

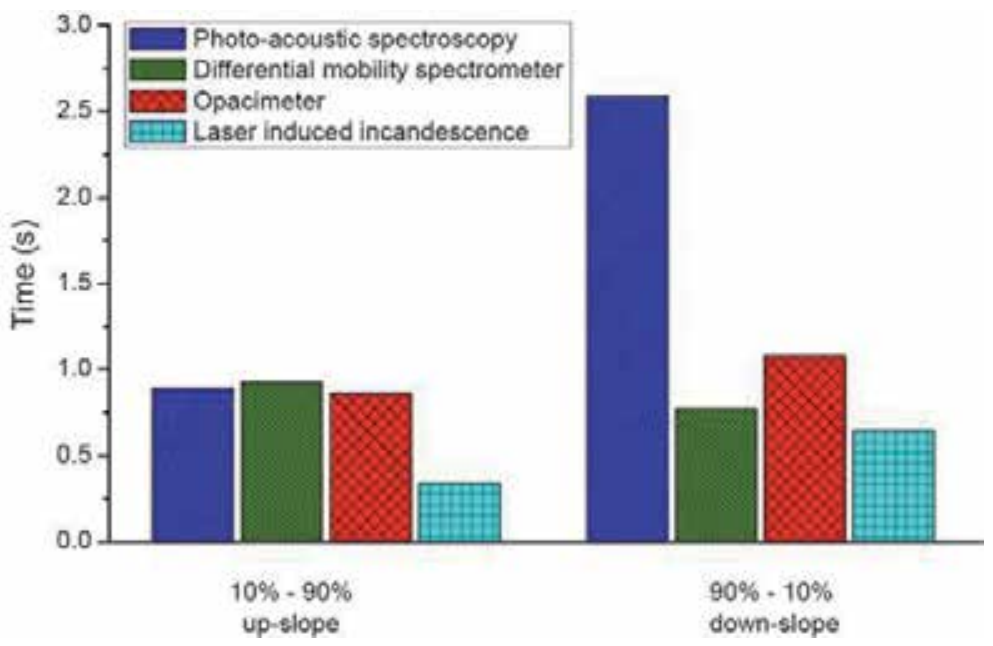

Figure 13.

The overview of measured rising (10-90\%) and falling (90-10\%) time of normalised soot emission concentration measured from $1000 \mathrm{~ms}$ injection peak during static pulse test at $10.7 \mathrm{mg} / \mathrm{cycle}$ fuel load.

spectroscopy, differential mobility spectrometer, opacimeter and laser-induced incandescence method is shown in Figure 14. Shown recorded data are in raw, not filtered format. The time delay has been individually shifted, in such a way that the signals were overlapped in the centre of the first transient measured peak. Generated time delay of the individual devices is caused by the different length of the sampling line to the detectors. It has to be considered that recording of the signal via dSpace board is not continuous, but it has a saving procedure in approximately
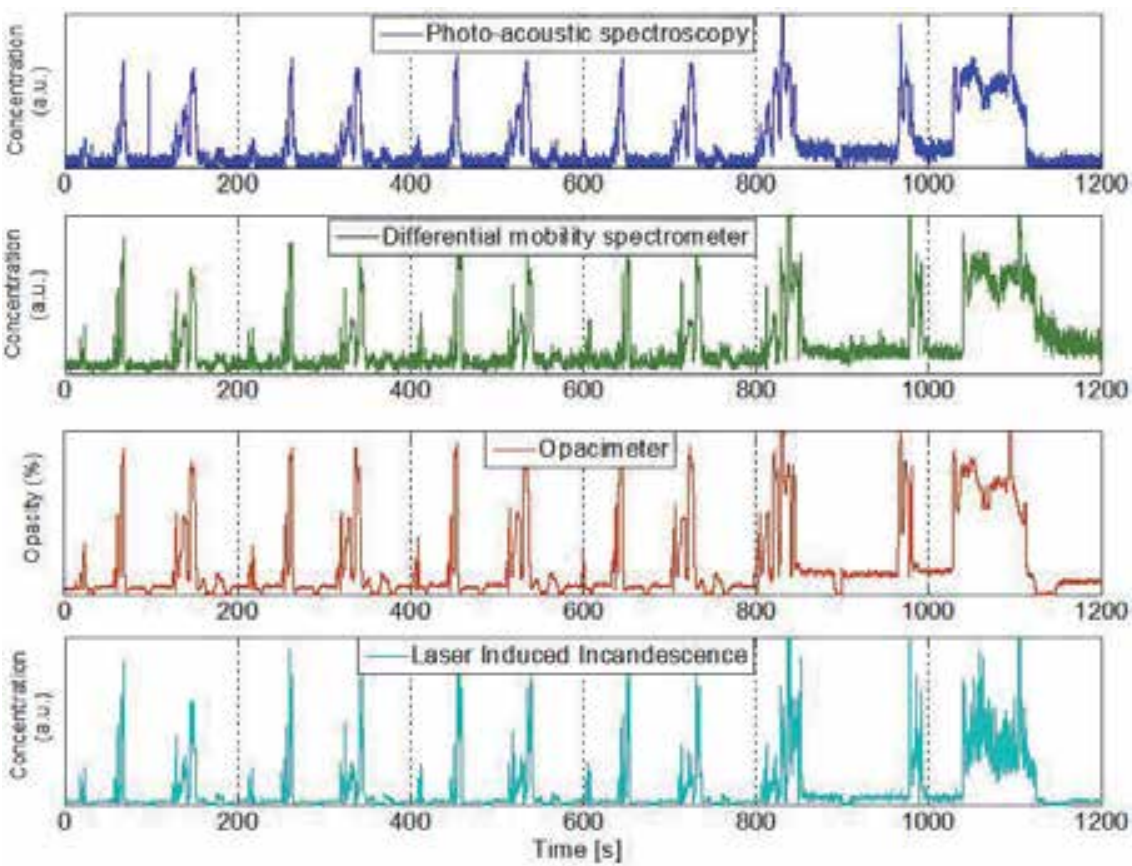

Figure 14.

Raw data shows comparison of transient test soot emission during NEDC cycle measured by photoacoustic spectroscopy, differential mobility spectrometer, opacimeter and laser-induced incandescence. 
every 400 seconds. Hence, the signals experience recorded gaps in a duration of approximately 4 seconds. This generates a shift in NEDC data, mainly visible at the end of the cycle in the case of photoacoustic and opacimeter devices.

Generally, all instruments have shown similar response to soot emission, without cut-off in signal during measurement. Main differences are noticeable in the soot emission measured mainly during the fast transient peaks. In the case of differential mobility spectrometer, the continuously increasing background level of soot emission, mainly visible in the second part of the NEDC cycle, is conspicuously observed. However, this can negatively affect the precision of measurement. This effect can be associated with the increasing gas emission temperature during the NEDC cycle itself and due to the downstream of the turbine sensor location in the exhaust manifold. In Figure 15 the injected fuel to the engine as an input parameter and output parameters measured pressure and temperature from the location downstream of the turbine are shown. The temperature of gas emission is continuously increasing from $90^{\circ} \mathrm{C}$ at the beginning of the test cycle up to $205^{\circ} \mathrm{C}$ nearly at the end of the NEDC test cycle at this measurement location.

Commonly, all devices are taking partial stream emission measurement through heated sample line to the measuring cells. In this cell, the temperature of the measured gas is stabilised and compensated. However, the incoming gas temperature is limited to the maximum recommended value during the measurement, shown in Table 1, where the upper temperature limit for DMS is specified to $150^{\circ} \mathrm{C}$. Therefore, a measurement above these temperature limits should be taken with the higher uncertainty for the DMS device. Besides the temperature in the manifold, a very important parameter is the gas pressure signal. In Figure $\mathbf{1 5}$ one can observe fast dynamic changes in pressure of exhaust emissions, inside the exhaust manifold, particularly downstream of the turbine position, due to fast dynamic NEDC test cycle measurement. The pressure here varies from 960 to 1800 mbar. For that reason, measurement devices usually dilute the exhausted gas before it is essentially
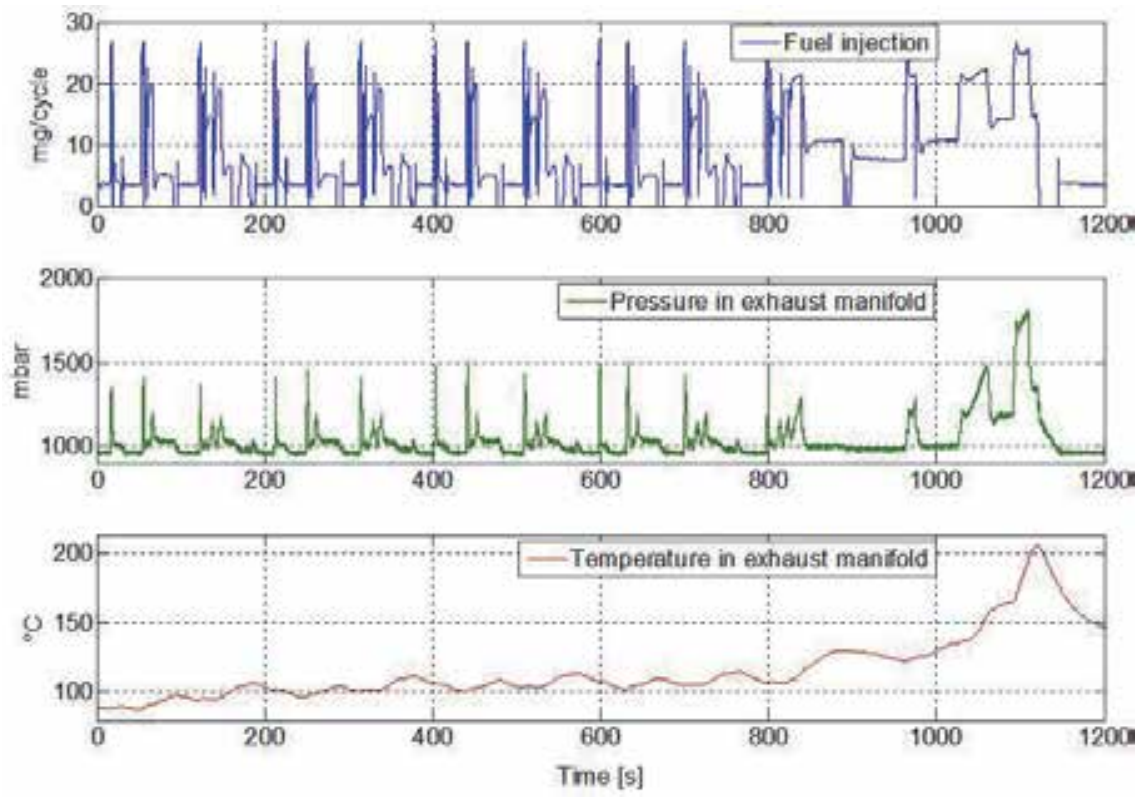

Figure 15.

Graph shows injected fuel into the engine as an input parameter and output parameters measured pressure and temperature from the location downstream of the turbine in the exhaust manifold during one NEDC cycle. 
Comparison of Different Techniques for Measurement of Soot and Particulate Matter Emissions... DOI: http://dx.doi.org/10.5772/intechopen.91186
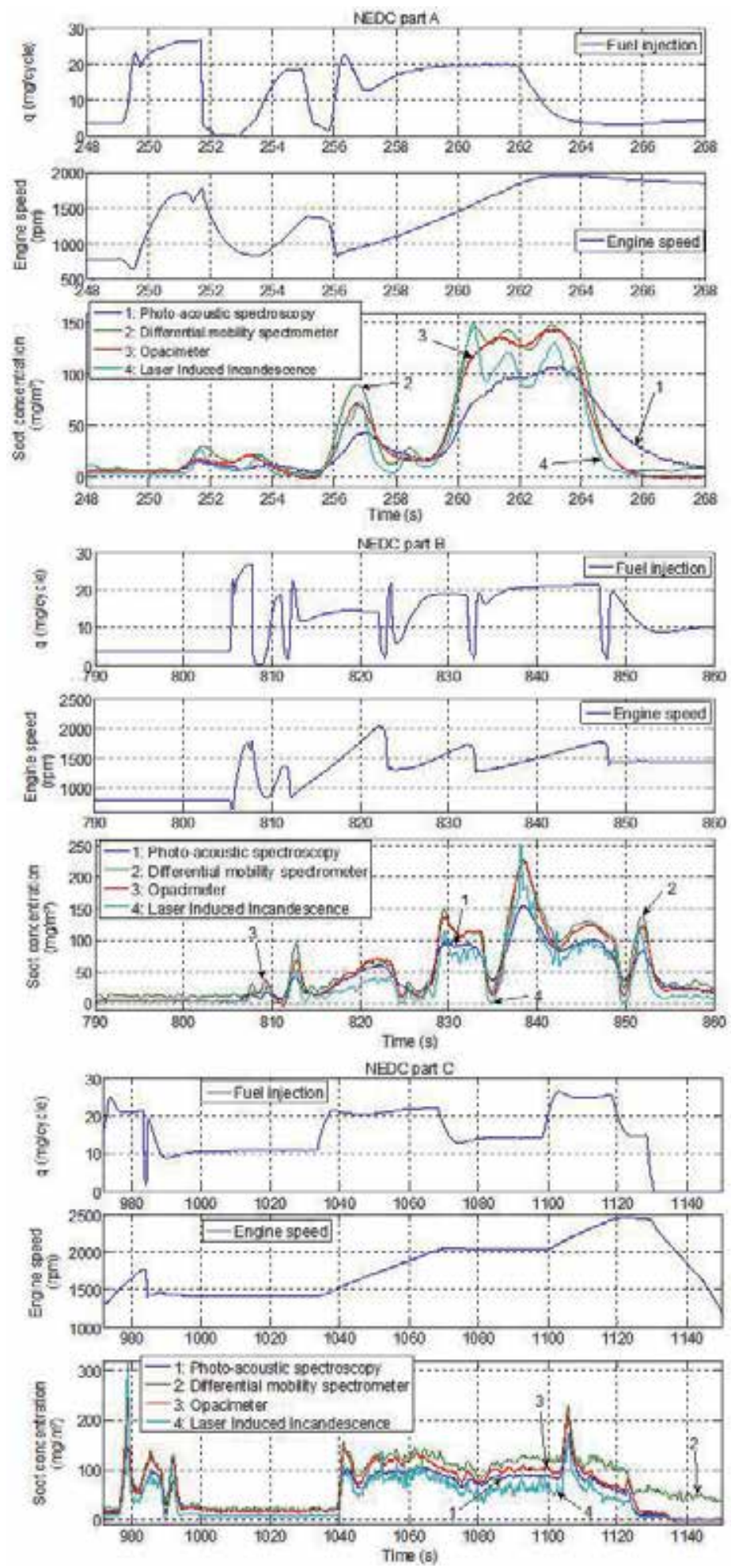

Figure 16.

Selected three parts $A, B$, and $C$ of the NEDC test cycle show the input parameters of fuel injection function ( $\mathrm{mg} / \mathrm{cycle})$ and the engine speed (rpm). Soot emissions were simultaneously measured by photoacoustic spectroscopy (1), differential mobility spectrometer (2), opacimeter (3) and laser-induced incandescence (4) devices. 
measured. To maintain a constant volume sampling (CVS), total flow of exhaust gas emission is kept constant during the measurement in dilution tunnel. On the other hand, diluting an exhaust gas can negatively influence the measurement with low concentration of soot emission, because soot particles might not be detected.

In Figure 16 three selected parts of the NEDC test cycle are shown in detail: first part A from 248 to 268 seconds, second part B from 790 to 860 seconds and third part C from 970 to 1150 seconds. Additional input parameters are fuel injection function (mg/cycle) and the engine speed profile in rotation per minute (rpm). In these figures differences between transient emission peaks in measured profile by four devices are significantly pronounced.

On bases of measured soot concentrations from NEDC, one can easily differentiate from the point of sensitivity measurement devices into two groups. First is the group with higher temporal resolution of the measured soot emission signal, with more like spiky profiles. In the first group, the signals from laser-induced incandescence and differential mobility spectrometer can be considered. The second group has a lower temporal resolution and more smooth concentration function profile. In this group the signal measured via photoacoustic spectroscopy and opacimeter can be included. An advantage of devices in the first group is that these are capable to resolve sensitive emission fluctuation and fast transient peaks in soot dynamic signal, better than the second and slower group.

\section{Conclusions}

In this book chapter, the comparison between the five different commercially available techniques for soot and particulate matter emission measurement from diesel engine is shown. The comparison has been made from static and dynamic transient measurement tests with special concern to compare the sensitivity and dynamics response of individual methods. Measurements were performed by filtertype smoke meter, from AVL Smoke meter 415S; by photoacoustic spectroscopy, from AVL Micro soot sensor 483; by differential mobility spectrometer from Cambustion model DMS 500 and opacimeter from AVL Opacimeter 439; and by laser-induced incandescence from Artium Technologies Inc. LII 200. The filter-type smoke meter was selected due to conventional use as a standard device for measurement of soot concentration. The other fast devices were selected due to their relatively high accuracy and fast response, which is often needed for characterisation of soot and PM during the combustion process. Devices were placed in to the location downstream of the turbine, to be as close to the actual combustion event. All instruments have shown similar response to soot emission with no cut-off or disruption in measured signal. However, detailed time-resolved measurements during static and dynamic transient tests revealed differences in sensitivity and dynamics response of individual methods. From the point of view of sensitivity, the laser-induced incandescence and differential mobility spectrometer resolved small oscillations in soot emissions during fast transient's measurement with higher temporal resolution than the opacimeter or photoacoustic spectrometer. The dynamics response was measured from the slope of static peaks with individual concern to upslope and downslope of normalised soot concentration. In any case, the fastest technique has been laser-induced incandescence, then the differential mobility spectrometer, afterwards the opacimeter and in the last place the signal from the photoacoustic spectrometer. Compared measurements provide useful information concerning sensitivity and dynamics characteristics of the selected techniques for static and dynamic measurements of soot and particulate matter emissions from diesel engine. 
Comparison of Different Techniques for Measurement of Soot and Particulate Matter Emissions... DOI: http://dx.doi.org/10.5772/intechopen.91186

\section{Acknowledgements}

The author would like to thank Mr. Richard Fürhapter and Mr. Gerhard Wurzinger for their perfect test bench support, and to Austrian Research Promotion Agency (FFG) and to Austrian Science Fund, FWF (Fonds zur Förderung der wissenschaftlichen Forschung) for providing financial support. Part of this study was funded with the grant number FWF_-P27967. This work has been also supported by the COMET-K2 Center of the Linz Center of Mechatronics (LCM), funded by the Austrian federal government and the federal state of Upper Austria. Additionally, the author would like to thank Dr. Maria Rusnak for the proofreading and for valuable corrections.

\section{Author details}

Richard Viskup

Johannes Kepler University Linz, Linz, Austria

*Address all correspondence to: richard.viskup@jku.at; viskup@gmail.com

\section{IntechOpen}

(C) 2020 The Author(s). Licensee IntechOpen. This chapter is distributed under the terms of the Creative Commons Attribution License (http://creativecommons.org/licenses/ by/3.0), which permits unrestricted use, distribution, and reproduction in any medium, provided the original work is properly cited. (c) BY 


\section{References}

[1] Lighty JS, Veranth JM, Sarofim AF. Combustion aerosols: Factors governing their size and composition and implications to human health. Journal of the Air and Waste Management Association. 2000;50(9):1565-1618. DOI: $10.1080 / 10473289.2000 .10464197$

[2] McAdam K, Steer P, Perrotta K. Using continuous sampling to examine the distribution of traffic related air pollution in proximity to a major road. Atmospheric Environment. 2011;45(12):2080-2086. DOI: 10.1016/j.atmosenv.2011.01.050

[3] Wichmann HE, Peters A. Epidemiological evidence of the effects of ultrafine particle exposure. Philosophical Transactions of the Royal Society of London, Series A: Mathematical, Physical and Engineering Sciences. 2000;358(1775):2751-2768. DOI: $10.1098 /$ rsta.2000.0682

[4] Burtscher H. Physical characterization of particulate emissions from diesel engines: A review. Journal of Aerosol Science. 2005;36(7):896-932. DOI: 10.1016/j.jaerosci.2004.12.001

[5] ACEA program on emissions of fine particles from passenger cars. Available from: www.acea.be

[6] Vouitsis E, Ntziachristos L, Samaras Z. Particulate matter mass measurements for low emitting diesel powered vehicles: What's next? Progress in Energy and Combustion Science. 2003;29(6):635-672. DOI: 10.1016/j. pecs.2003.08.002

[7] Ayrault C, Chang JS, Ewing D, Cotton JS, Gerges IE, Burgers J.

Differential thermal analysis, thermal gravimetric analysis, and solid phase micro-extraction gas chromatography analysis of water and fuel absorption in diesel soot. Journal of Aerosol Science. 2010;41(2):237-241. DOI: 10.1016/j. jaerosci.2009.10.006
[8] Choi MY, Mulholland GW, Hamins A, Kashiwagi T. Comparisons of the soot volume fraction using gravimetric and light extinction techniques. Combustion and Flame. 1995;102(1-2):161-169. DOI: 10.1016/ 0010-2180(94)00282-W

[9] Main RP, Bauer E. Opacities of carbon-air mixtures at temperatures from 3000-10000 degrees K. Journal of Quantitative Spectroscopy \& Radiative Transfer. 1966;6(1):1-30. DOI: 10.1016/ 0022-4073(66)90061-6

[10] Zahoransky RA, Saier T, Laile E, Nikitidis M, Konstandopoulos A. Optical Multiwavelength Technique Applied to the Online Measurement of Particle Emissions from Engines. SAE Paper No. 2001-01-047. 2001. DOI: 10.4271/2001-24-0074

[11] Schneider J, Weimer S, Drewnick F, Borrmann S, Helas G, Gwaze P, et al. Mass spectrometric analysis and aerodynamic properties of various types of combustion-related aerosol particles. International Journal of Mass Spectrometry. 2006;258(1-3):37-49. DOI: 10.1016/j.ijms.2006.07.008

[12] Symonds JPR, Reavell KSJ, Olfert JS, Campbell BW, Swift SJ. Diesel soot mass calculation in real-time with a differential mobility spectrometer. Journal of Aerosol Science. 2007;38(1):52-68. DOI: 10.1016/ j.jaerosci.2006.10.001

[13] Filipi Z, Hagena J, Fathy H. Investigating the impact of in-vehicle transients on diesel soot emissions. Thermal Science. 2008;12(1):53-72. DOI: 10.2298/TSCI0801053F

[14] Faxvog FR, Roessler DM. Optoacoustic measurements of diesel particulate-emissions. Journal of Applied Physics. 1979;50(12):7880-7882. DOI: $10.1063 / 1.325978$ 
[15] Adams KM. Real-time insitu measurements of atmospheric optical absorption in the visible via photoacoustic-spectroscopy 1 . Evaluation of photoacoustic cells. Applied Optics. 1988;27(19):4052-4056. DOI: 10.1364/AO.27.004052

[16] Beck HA, Niessner R, Haisch C. Development and characterization of a mobile photoacoustic sensor for on-line soot emission monitoring in diesel exhaust gas. Analytical and Bioanalytical Chemistry. 2003;375(8):1136-1143. DOI: $10.1007 / \mathrm{s} 00216-003-1810-8$

[17] Snelling DR, Smallwood GJ, Sawchuk RA, Neill WS, Gareau D, Clavel D, et al. Particulate Matter Measurements in a Diesel Engine Exhaust by Laser-Induced Incandescence and the Standard Gravimetric Procedure. SAE Paper No. 1999-01-3653. 1999. DOI: 10.4271/1999-01-3653

[18] Axelsson B, Witze PO. Qualitative Laser-Induced Incandescence Measurements of Particulate Emissions During Transient Operation of a TDI Diesel Engine. SAE Paper No. 2001-013574. 2001. DOI:10.4271/2001-01-3574

[19] Witze PO, Payne GA, Bachalo WD, Smallwood GJ. Influence of Measurement Location on Transient Laser-Induced Incandescence Measurements of Particulate Matter in Raw Diesel Exhaust. SAE Paper No. 04ANNUAL-174. 2004

[20] Thomson KA, Snelling DR, Smallwood GJ, Liu F. Laser induced incandescence measurements of soot volume fraction and effective particle size in a laminar co-annular nonpremixed methane/air flame at pressures between 0.5-4.0 MPa. Applied Physics B: Lasers and Optics. 2006;

83(3):469-475. DOI: $10.1007 /$ s00340-006-2198-x

[21] Viskup R, Alberer D, Oppenauer K, del Re L. Measurement of Transient PM
Emissions in Diesel Engine. SAE

Technical Paper 2011-24-0197. 2011. DOI:10.4271/2011-24-0197

[22] Viskup R, Alberer D, Oppenauer K, del Re L. Fast detection of transient emission from diesel engine using optical and differential mobility spectrometer method. Technisches Messen. 2011;78(11):520-525. DOI: 10.1524/teme.2011.0207

[23] Oppenauer K, Alberer D, del Re L. Control Oriented Crank Angle Based Analysis of Soot Dynamics During Diesel Combustion, SAE Powertrains. SAE Paper No. 2010-01-2105. 2010. DOI:10.4271/2010-01-2105

[24] Alberer D, del Re L. Optimization of the Transient Diesel Engine Operation.

SAE Paper No. 2009-01-0622. 2009.

DOI:10.4271/2009-24-0113

[25] Alberer D, del Re L, Winkler S, Langthaler P. Virtual Sensor Design of Particulate and Nitric Oxide Emissions in a DI Diesel Engine. SAE Paper No. 2005-24-063. 2005. DOI:10.4271/ 2005-24-063

[26] Dasch CJ. Continuous-wave probe laser investigation of laser vaporization of small soot particles in a flame.

Applied Optics. 1984;23(13):2209-2215.

DOI: $10.1364 / A O .23 .002209$

[27] Alberer D. Fast oxygen based transient diesel engine control

[Dissertation]. Linz, Austria: Johannes

Kepler University, JKU; 2009

[28] Smoke value measurement with the filter paper method [Application Notes]. AT1007E, Rev. 02, AVL List. Graz, Austria: GmbH; 2005 



\title{
Analysis of Diesel Particulate Matter Flow Patterns in Different Ventilation and Operational Conditions of Underground Mines
}

\author{
Ramakrishna Morla, Shivakumar Karekal and Ajit Godbole
}

\begin{abstract}
Diesel-operated vehicles are commonly used by personnel in underground mines. Although these vehicles facilitate travel within the mine, their main disadvantage is that they generate diesel particulate matter (DPM), a known carcinogenic agent. This calls for research to control the spread of DPM in underground mines in order to ensure the safety of mine personnel. In this article, the flow patterns of DPM generated by two types of diesel-operated vehicles are modeled using computational fluid dynamics (CFD) simulations. The simulation results are validated using field experimental measurements. The models show that if the vehicle is stationary, DPM particles are dispersed towards the center of the gallery and occupy the entire cross section of the road way. Vehicle movement induces air currents that may result in the miners being exposed to high DPM concentrations. The results show that if the DPM and the intake air counter-flow (flow in opposite directions), the DPM spread occurs throughout the entire cross-section of the roadway. This research is expected to contribute to the formulation of effective DPM control strategies in underground mines.
\end{abstract}

Keywords: underground mines, DPM, diesel-powered man riding vehicle

\section{Introduction}

As underground mines go ever deeper and spread over larger areas in an attempt to meet ever-increasing production targets, there is a correspondingly significant increase in the usage of diesel-powered vehicles. Most of the mines in the world have been using diesel-operated vehicles for transportation of men, material, ore, waste rock, coal and for various other mining operations. The commonly used diesel-operated vehicles in underground coal, metal and non-metal mines are trucks, load haul dumpers (LHD), Jumbos, cable bolters, long hole drilling rigs, man-riding vehicles, telehandlers, graders, water tankers, forklifts, articulated wheel loaders, agitators, shotcrete sprayers, etc.

Diesel-powered vehicles offer greater flexibility than electric and batteryoperated vehicles because they can travel over longer distances and between working sections. The use of diesel vehicles is efficient, as evidenced by ease of 
maintenance, consistency and durability. Many nations have depended on these vehicles for these reasons [1].

Diesel is a mixture of hydrocarbons. In a perfect diesel engine, oxygen $\left(\mathrm{O}_{2}\right)$ from the air converts all the hydrogen $\left(\mathrm{H}_{2}\right)$ in the fuel to $\mathrm{H}_{2} \mathrm{O}$ and the carbon $(\mathrm{C})$ to $\mathrm{CO}_{2}$, while the nitrogen $\left(\mathrm{N}_{2}\right)$ in the air remains unaffected. But in the reality, the combustion process is not perfect, and the engine emits several pollutants due to incomplete combustion [2].

$$
\text { Fuel }+ \text { Air } \rightarrow \text { Unburned hydrocarbons }+\mathrm{NO}_{\mathrm{x}}+\mathrm{CO}_{2}+\mathrm{CO}+\text { Water }
$$

The diesel engine exhaust fumes mainly contain a mixture of diesel particulate matter (DPM) and other pollutant gases such as nitrogen oxides $\left(\mathrm{NO}_{\mathrm{x}}\right)$, hydrocarbons (HC), including either total hydrocarbons (THC) or non-methane hydrocarbons (NMHC) and carbon monoxide (CO) [3].

Different nations recommend different safe occupational exposure limits (OEL). Table 1 shows the OEL used in Australian underground mines.

The ventilation air requirement to dilute any of the gases $\left(\mathrm{CO}, \mathrm{CO}_{2}, \mathrm{SO}_{2}, \mathrm{NO}\right.$ and $\mathrm{NO}_{2}$ ) or DPM emitted by a diesel engine to the targeted concentration level $\left(\mathrm{Q}_{\mathrm{V}}\right)$ can theoretically be calculated for any given movement using the following equation [2]:

$$
\mathrm{Q}_{\mathrm{V}}\left[m^{3} / s\right]=\frac{\mathrm{Q}_{E}\left[m^{3} / s\right] X\left(\mathrm{C}_{\mathrm{E}}\left[p p m \text { or } \mu g / m^{3}\right]-\mathrm{C}_{T}\left[p p m \text { or } \mu g / m^{3}\right]\right)}{\mathrm{C}_{T}\left[p p m \text { or } \mu g / m^{3}\right]-\mathrm{C}_{B}\left[p p m \text { or } \mu g / m^{3}\right]}
$$

Where $Q_{E}$ is exhaust flow rate, $C_{E}$ is the concentration of the specific pollutant (gas or DPM) in the exhaust, $\mathrm{C}_{T}$ is target concentration of the corresponding gas or DPM and $C_{B}$ is the concentration of the specific pollutant (gas or DPM) in the dilution air.

As per the Australian Mines Regulations and Act [4-6], to minimize exposure of mine personnel to diesel emissions, the mine operator must collect diesel engine

\begin{tabular}{lcccc}
\hline Contaminant & $\begin{array}{c}\text { OEL } \\
\text { (TWA 8) }\end{array}$ & $\begin{array}{c}\text { OEL } \\
\text { (TWA 10) }\end{array}$ & $\begin{array}{c}\text { OEL } \\
\text { (TWA 12) }\end{array}$ & $\begin{array}{c}\text { OEL } \\
\text { (STEL) }\end{array}$ \\
\hline Carbon dioxide- $\mathrm{CO}_{2}(\mathrm{ppm})^{* *}$ & 5000 & 3500 & 2500 & 30,000 \\
\hline Carbon monoxide-CO $(\mathrm{ppm})^{* *}$ & 30 & 21 & 15 & - \\
\hline Nitrogen dioxide- $\mathrm{NO}_{2}(\mathrm{ppm})^{* *}$ & 3 & 2.1 & 1.5 & 5 \\
\hline Nitrous oxide-NO $(\mathrm{ppm})^{* *}$ & 25 & 17.5 & 12.5 & - \\
\hline Sulfur dioxide $(\mathrm{ppm})$ & 2 & 1.4 & 1 & 5 \\
\hline $\begin{array}{l}\text { Diesel particulate matter-total particulate- } \\
\text { DPM }\left(\mathrm{mg} / \mathrm{m}^{3}\right)^{* * *}\end{array}$ & 0.16 & - & - & - \\
\hline Elemental carbon-EC $\left(\mathrm{mg} / \mathrm{m}^{3}\right)^{* * *}$ & 0.1 & - & - & - \\
\hline
\end{tabular}

Where, TWA 8 is 8-hour time weighted average and STEL is short term exposure limit.

${ }^{*}$ STEL refers to the maximum concentration where personnel can work for a maximum of 15 minutes at a time. A maximum of 1 hour per shift can be allowed provided that it is broken up into four 15-minute work intervals, with a minimum 1-hour break in between work intervals.

${ }^{* *}$ Gases are treated as acute hazards; therefore, reduction factors based on hours worked per shift can be applied to the standard OEL (TWA 8). A 10-hour shift will have a reduction factor of 0.7 and 12-hour shift will have a reduction factor of 0.5 applied to the target gas.

${ }_{* * *}$ Particles are treated as chronic hazards. The OEL (TWA 8) needs to be adjusted according to the shift roster worked by the work group. Reference can be made to the formula: Reduction factor $=170 / x$ where $x$ is the number of hours worked per month.

Table 1.

Workplace exposure limits of diesel vehicle emissions [3]. 
exhaust samples in underground mines and analyze the samples. The results of the analysis are compared with the baseline exhaust emissions for the diesel engine. All underground diesel engines are regularly maintained so that emissions from the engine are as low as is reasonably practicable with respect to the base line exhaust emissions. The mine operator must also maintain the standard fuel or fuel additive quality and DPM filters.

\subsection{DPM}

The chemical composition of DPM depends on the compositions of the fuel and the lubricating oil, engine technology, operating conditions, and the technology used to treat the exhaust. The major contributors to the total particle mass emitted by diesel engines include elemental carbon (EC), organic carbon (OC), inorganic ions such as sulfates, nitrates, ammonia, sodium, chloride ions, and trace metallic compounds [2].

EC and OC emissions, cumulatively known as 'total carbon (TC)', make up the largest fraction of aerosols emitted by diesel engines. TC is generally considered to make up about $70-90 \%$ of DPM. On an average, elemental carbon comprises 50$70 \%$ of TC and greater than $45 \%$ of 'total engine-out' DPM emissions. The engineout organic carbon makes up between 10 and $80 \%$ of total carbon [2].

The EC fraction of DPM is a product of the pyrolysis of the fuel and the lubricating oil in the combustion chamber. The OC fraction of exhaust emissions from a diesel engine is a complex mixture of burned and unburned lubricating oil and fuel compounds.

\subsection{DPM size distribution}

DPM particles are very small and are subdivided into three categories with respect to size: Nano-particles less than $50 \mathrm{~nm}$ in diameter, ultra-fine particles less than $100 \mathrm{~nm}$ in diameter and fine particles less than $2.5 \mu \mathrm{m}$ in diameter. Figure 1 shows a typical DPM size distribution weighted by number, surface area, and mass [7].

The DPM is composed of numerous small particles with very little mass, mixed with relatively few larger particles, which contain most of the total mass. A small fraction of diesel particles resides in the third, 'coarse' mode.

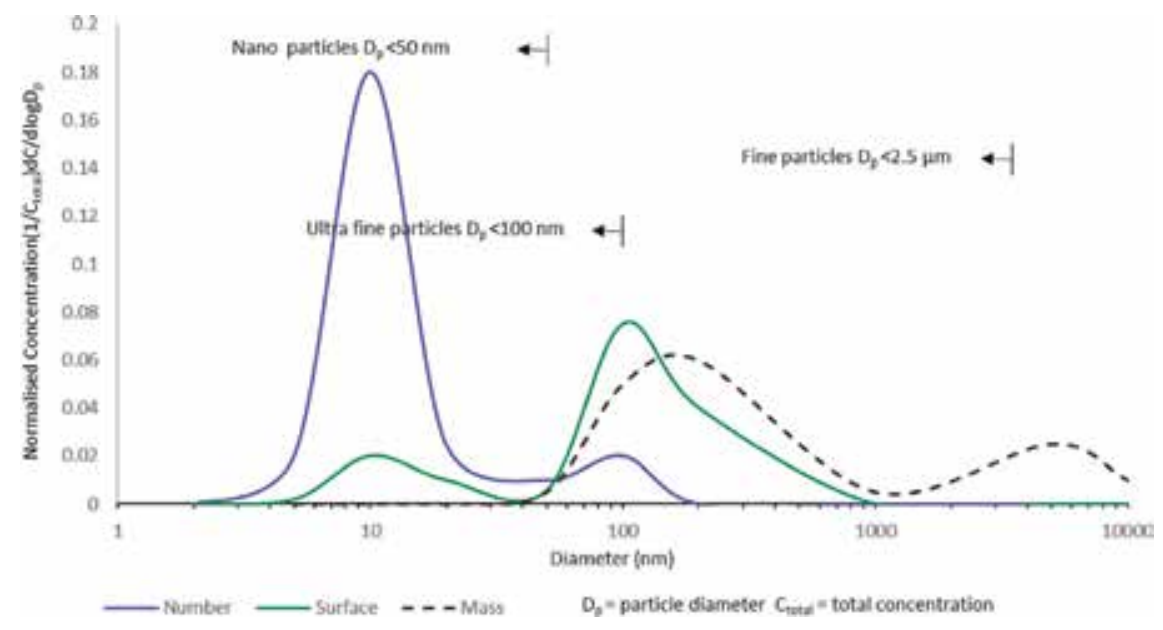

Figure 1.

DPM particles size distribution [7]. 
The DPM particles of size ranging from 3 to $500 \mathrm{~nm}$ are more dangerous for human health. These particles can get lodged in the alveolar regions of the longs where gas exchange takes place [2].

Various research studies have been conducted to better understand the effects of DPM on human health $[1,8-10]$. These studies have concluded that exposure to diesel exhaust may cause cancer in humans.

The effective density of DPM decreases sharply from $1.2 \mathrm{~g} / \mathrm{cm}^{3}$ for $30 \mathrm{~nm}$ particles to $0.3 \mathrm{~g} / \mathrm{cm}^{3}$ for $300 \mathrm{~nm}$ particles. The effective density of agglomerated diesel particles varies from 1.1 to $1.2 \mathrm{~g} / \mathrm{cm}^{3}$. The chemical composition of DPM has not been observed to follow any trend and it mainly depends on engine oil and diesel chemical composition [11].

\subsection{Workplace exposure limits on DPM in underground mines}

Different countries follow different workplace exposure limits and mine ventilation standards to deal with DPM. Table 2 shows a summary of DPM exposure limits and ventilation requirements. The regulations in different countries are outlined in the following sections.

\begin{tabular}{|c|c|c|c|}
\hline \multicolumn{2}{|l|}{ Country } & \multirow{2}{*}{$\begin{array}{l}\text { DPM exposure } \\
\text { limits }\left(\boldsymbol{\mu g} / \mathbf{m}^{3}\right)\end{array}$} & \multirow{2}{*}{$\begin{array}{l}\text { Ventilation standards } \\
\text { Ventilation as per CSA, minimum } 0.06 \mathrm{~m}^{3} / \mathrm{kWs}\end{array}$} \\
\hline & $\begin{array}{l}\text { British } \\
\text { Columbia }\end{array}$ & & \\
\hline \multirow[t]{9}{*}{ Canada } & Alberta & ACGIH & $\begin{array}{l}\text { Minimum air volume of } 1.9 \mathrm{~m}^{3} / \mathrm{s} \text { at active headings, and } \\
\text { minimum air velocity } 0.3 \mathrm{~m} / \mathrm{s}\end{array}$ \\
\hline & Saskatchewan & - & $\begin{array}{l}\text { Ventilation as per CANMET approval, minimum of } \\
0.06 \mathrm{~m}^{3} / \mathrm{kWs}\end{array}$ \\
\hline & Manitoba & ACGIH & $\begin{array}{l}\text { Ventilation as per CANMET or MSHA approval, or } \\
0.092 \mathrm{~m}^{3} / \mathrm{kWs} \text { for non-approved engine }\end{array}$ \\
\hline & Ontario & $400(\mathrm{RCD})$ & Minimum ventilation of $0.06 \mathrm{~m}^{3} / \mathrm{kWs}$ \\
\hline & Quebec & $600(\mathrm{RCD})$ & $\begin{array}{l}\text { Ventilation as per CANMET or MSHA approval, or } \\
0.092 \mathrm{~m}^{3} / \mathrm{kWs} \text { for non-approved engine }\end{array}$ \\
\hline & New Brunswick & $1500(\mathrm{RCD})$ & Minimum ventilation of $0.067 \mathrm{~m}^{3} / \mathrm{kWs}$ \\
\hline & Nova Scotia & $1500(\mathrm{RCD})$ & Minimum air velocity $0.33 \mathrm{~m} / \mathrm{s}$ \\
\hline & $\begin{array}{l}\text { Newfoundland } \\
\text { \& Labrador }\end{array}$ & ACGIH & $\begin{array}{l}\text { Engine approval is required from the Chief Inspector of } \\
\text { mines minimum ventilation of } 0.047 \mathrm{~m}^{3} / \mathrm{kWs}\end{array}$ \\
\hline & $\begin{array}{l}\text { Northwest, } \\
\text { Yukon \& } \\
\text { Nunavut }\end{array}$ & $1500(\mathrm{RCD})$ & Minimum ventilation of $0.06 \mathrm{~m}^{3} / \mathrm{kWs}$ \\
\hline \multicolumn{2}{|l|}{ China } & - & Minimum ventilation of $0.067 \mathrm{~m}^{3} / \mathrm{kWs}$ \\
\hline \multicolumn{2}{|c|}{ South Africa } & $\mathrm{N} / \mathrm{A}$ & Minimum ventilation of $0.063 \mathrm{~m}^{3} / \mathrm{kWs}$ \\
\hline \multicolumn{2}{|l|}{ USA } & $160(\mathrm{TC})$ & As per MSHA certificate \\
\hline \multicolumn{2}{|l|}{ India } & $100(\mathrm{EC})$ & Minimum ventilation of $0.06 \mathrm{~m}^{3} / \mathrm{kWs}$ \\
\hline \multicolumn{2}{|c|}{ Germany } & $100(\mathrm{EC})$ & Minimum ventilation of $0.06 \mathrm{~m}^{3} / \mathrm{kWs}$ \\
\hline \multicolumn{4}{|c|}{$\begin{array}{l}\text { MSHA: Mine Safety and Health Administration. } \\
\text { ACGIH: American Conference of Governmental Industrial Hygienists. } \\
\text { RCD: Respirable Combustible Dust. } \\
\text { CANMET: Canada Centre for Mineral and Energy Technology. }\end{array}$} \\
\hline
\end{tabular}

Table 2.

International DPM exposer limits and ventilation standards [12]. 
As per the Australian Coal Mines Work Health and Safety (WHS) Regulations 2006 [6], WHS (mines) Act 2013 [5] and WHS (mines) Regulations 2014 [4], the maximum allowable workplace exposure (mine atmosphere) for DPM in the elemental carbon (EC) form when expelled from a diesel engine is $0.1 \mathrm{mg} / \mathrm{m}^{3}$. This is approximately equal to $0.16 \mathrm{mg} / \mathrm{m}^{3}$ of TC or $0.2 \mathrm{mg} / \mathrm{m}^{3} \mathrm{DP}$.

As per Australian WHS mines act and regulations, the volume of air in each place where a diesel engine operates must be such that a ventilating current of not less than:

- $0.06 \mathrm{~m}^{3} / \mathrm{s}$ for each kilowatt of maximum output capacity of the engine, or

- $3.5 \mathrm{~m}^{3} / \mathrm{s}$,

The ventilation air flow is directed along the airway in which the engine operates. If more than one diesel engine is being operated in the same ventilating current, the engine kilowatts must be added, and the minimum ventilation requirement is $0.06 \mathrm{~m}^{3} / \mathrm{s} / \mathrm{kW}$ or $3.5 \mathrm{~m}^{3} / \mathrm{s}$, whichever is greater.

The minimum mine ventilation quantity to dilute diesel particulate exhaust emissions to $0.1 \mathrm{mg} / \mathrm{m}^{3}$ (diesel particulate signature) $\mathrm{Q}_{\mathrm{DP}(\min )}$ can be calculated using the following equation [3]:

$$
\mathrm{Q}_{\mathrm{DP}(\min )}=\frac{\mathrm{EC}_{\mathrm{kW}}}{3600 \mathrm{DP} \mathrm{P}_{(\text {Exposure limit })}} \mathrm{P}_{\mathrm{WA}}
$$

where $\mathrm{Q}_{\mathrm{DP}(\min )}$ is minimum mine ventilation quantity $\left(\mathrm{m}^{3} / \mathrm{s}\right), \mathrm{DP}_{\text {(Exposure limit) }}$ is $0.1 \mathrm{EC}\left(\mathrm{mg} / \mathrm{m}^{3}\right), \mathrm{EC}_{\mathrm{kW}}=$ sum of weighted average diesel particulate (EC) per hour emitted from the diesel engine exhaust over the specified duty cycle $(\mathrm{mg} / \mathrm{h})$ and PWA is sum of weighted average power for the diesel engine over the duty cycle $(\mathrm{kW})$.

\subsection{Previous DPM field investigations in underground mines}

The National Institute of Occupational Health and Safety (NIOSH) organized a detailed DPM field study on the effectiveness of diesel-vehicle filters and bio-diesel in isolated underground environment at the Nye Mine run by the Stillwater Mining Company [13]. This study was conducted by a partnership formed by NIOSH, the National Mining Association (NMA), the National Stone, Sand and Gravel Association (NSSGA), the United Steel Workers of America (USWA) and the MARG Diesel Coalition [13]. Two trucks and three load haul dumpers (LHDs) were used for this experiment. The main aim of this study was to study the effectiveness of the diesel particulate filter (DPF) systems. In this study, the tested DPF systems were Engelhard DPX, DCL MineX, Clean Air System, DCL Blue Sky, Mac's Mining Repair/Donaldson P604516, ECS Cattrap and Biodiesel [13].

Subsequently, the effectiveness of the DPF systems to control DPM and gases was assessed under the diesel emissions evolution program (DEEP). This study was conducted at an isolated mine zone of Narannda's Brunswick Mine in Bathurst. This study involved the Burnswick mine, Natural Resources Canada, Canada Centre for Mineral and Energy Technology (CANMET), National Institute of Occupational Safety and Health (NIOSH), Andreas Mayer of VERT and DPF systems suppliers [14]. Four $242 \mathrm{~kW}$ LHDs and two $278 \mathrm{~kW}$ haulage trucks were used for this study. The tested DPF systems were ECS catalyzed filter, ECS octel filter, DCL catalyzed/ electric filter and Oberland Mangold octel filter [14]. 
Recently, as a part of Ph.D. research, a DPM field study has been conducted at an experimental mine at the Missouri University of Science and Technology. The aim of the research was to study DPM dispersion in underground metal/non-metal mines [15]. A $30 \mathrm{~kW}$ Skid-steer loader was used for this study [15].

A greater understanding of DPM flow patterns in different conditions will help control the miners' exposure to the high concentrations of DPM in the vicinity of diesel-operated vehicles. This chapter describes a detailed study of DPM flow patterns generated by diesel-operated man-riding vehicles and LHDs, using field experiments and computational fluid dynamics (CFD) investigations. The field experiments and CFD simulation studies were conducted in two stages: stage 1 with a man-riding vehicle and stage 2 with an LHD, both with different air flow directions.

\section{Experimental investigation}

\subsection{The experimental site}

Field experiments were conducted in an Indian coal mine, 'mine A', in one of the eight working seams in the mine. The mine has a number of bord and pillar and long wall working sections. The mine uses diesel-operated man-riding vehicles, LHDs and shuttle cars. The ventilation system of the mine consists of five intakes and two return shafts with two main axial flow fans. The operating parameters of the two fans are: air flow of $150 \mathrm{~m}^{3} / \mathrm{s}$ at $510 \mathrm{~Pa}$ pressure and air flow of $140 \mathrm{~m}^{3} / \mathrm{s}$ at $400 \mathrm{~Pa}$ pressure respectively.

\subsection{Details of field experiment 1}

A calibrated 'Airtec' real-time DPM monitoring instrument was used for these field experiments. This instrument measures the concentration of elemental carbon (EC) or total carbon (TC) in real time. This instrument works on the principle of laser diode absorption technique $[16,17]$. This monitor uses technology developed by the diesel particulate group at the NIOSH Pittsburgh Research Laboratory and has been determined to precisely replicate results from their method 5040 test. This monitor can help prevent safety non-compliances, ensuring increased miner safety [18].

The flow rate and sampling time of the DPM monitor was adjusted to $2.83 \times 10^{-5} \mathrm{~m}^{3} / \mathrm{s}$ (1.7 liters per minute) and 5 minutes respectively. Before the experiment, the location of vehicle, smoke pipe (DPM source), sampling stations were determined and marked on the gallery. During the experiment, the vehicle position was not changed. An average of three 5-minute sample were taken at each sampling station.

Figure 2 shows the locations and arrangements of sampling stations and sampling points ( $\mathrm{a}, \mathrm{b}$ and $\mathrm{c}$ ). During this experiment, the engine was run under a 'no-load' condition.

To ensure that the intake air was devoid DPM, the experiment was conducted in one of the intake airways near the bottom of the shaft. The length, width and height of the gallery were measured to be 100, 6 and $2.7 \mathrm{~m}$ respectively. During the experiment, the intake air velocity was maintained at $1.26 \mathrm{~m} / \mathrm{s}$. The velocity and temperature of the vehicle exhaust fumes were measured to be $29 \mathrm{~m} / \mathrm{s}$ and $323 \mathrm{~K}$ respectively. 
Analysis of Diesel Particulate Matter Flow Patterns in Different Ventilation and Operational... DOI: http://dx.doi.org/10.5772/intechopen.84651

\subsection{Details of field experiment 2}

In this experiment, the LHD exhaust smoke was directed opposite to the ventilation air flow. DPM samples were measured downstream side of the LHD. In this case, DPM samples were collected around the LHD and also at 6, 10 and $20 \mathrm{~m}$ downstream of the LHD at a height of $1.2 \mathrm{~m}$ from the floor. At each sample station, three samples were measured, each over a 5-minute duration. The average of the three readings was considered as representative of that sample station.

Figure 3 shows the location and details of the sampling points. DPM was measured at 11 sampling stations, Figure 3. During this experiment, the air flow in the experimental gallery was $20.4 \mathrm{~m}^{3} / \mathrm{s}$.

As in field experiment 1 , the flow rate and sampling time of the DPM monitor was adjusted to $2.83 \times 10^{-5} \mathrm{~m}^{3} / \mathrm{s}$ (1.7 liters per minute) and 5 minutes respectively. Before the experiment, location of vehicle, smoke pipe, sampling stations were measured and marked on the gallery. During the experiment, the vehicle position was not changed. Average of three 5-minute samples were taken at each sampling station.

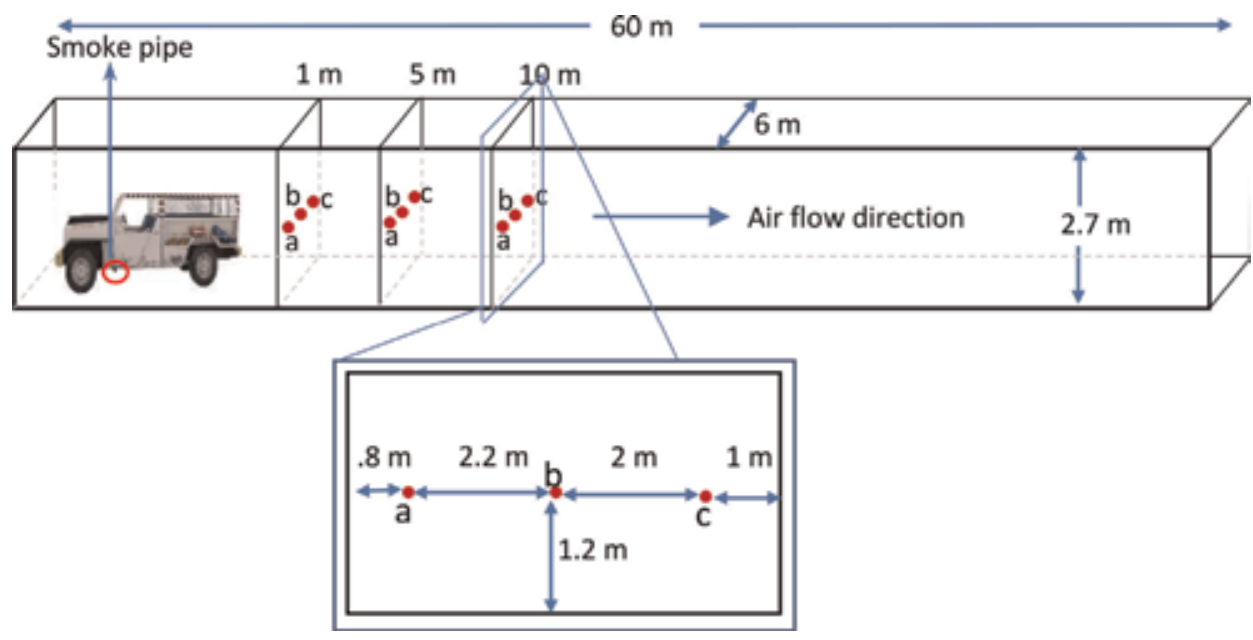

Figure 2.

Locations of sampling stations and sampling points w.r.t DPM source (vehicle).

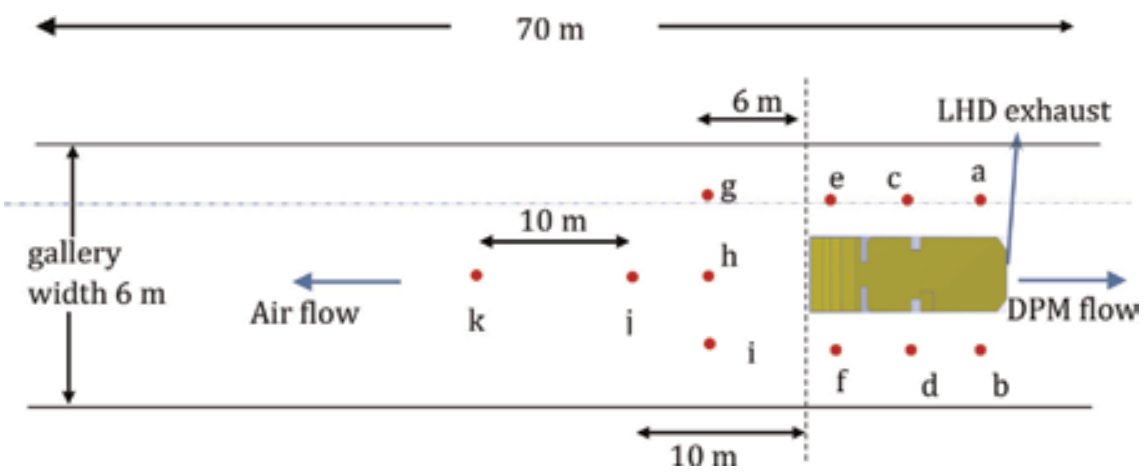

Figure 3.

Locations of sampling stations and sampling points, top view. 


\section{CFD modeling}

CFD modeling techniques have been used to study the flow patterns of DPM generated by $30 \mathrm{~kW}$ stir skid loaders in metal mines [15, 19-22]. More recently, CFD simulations of the dispersion of DPM generated by diesel-driven man-riding vehicles in coal mines have been reported $[23,24]$. Here, we present simulations of DPM generated by a diesel-operated man-riding vehicle and an LHD/loader/utility vehicle in an underground coal mine. The commercially available CFD package ANSYS Fluent (v. 19.1) was used.

\subsection{Construction of computational domain and mesh for experiment-1}

A 60-m long ventilation gallery was designed for simulations width and height of the gallery were 6 and $2.7 \mathrm{~m}$. Man riding vehicle was designed and imported from the 3D CAD modeling. The overall dimensions of the man-riding were length $6.25 \mathrm{~m}$, width $2 \mathrm{~m}$ and height $1.95 \mathrm{~m}$. The location of the smoke pipe (DPM source) was just behind the left front wheel on the opposite side to the vehicle operator. The engine was equipped with a diesel particulate filter and the exhaust flow was a mixture of DPM and air. Figure 4 shows the details of the constructed CFD model.

Figure 5 shows the details of the surface mesh on the man riding vehicle (a) and man riding vehicle with gallery (b). To achieve accurate results, finer mesh was used with half-million computational cells. The minimum size of the cells was $7.3 \times 10^{-3} \mathrm{~m}$, minimum edge length of cells was $0.025 \mathrm{~m}$ and size function was 'proximity and curvature'. The program-controlled 'inflation' feature was used with seven layers was used to generate finer cells in the boundary layers adjacent to solid boundaries.

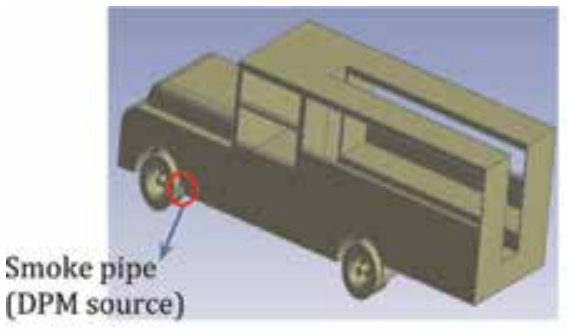

ล

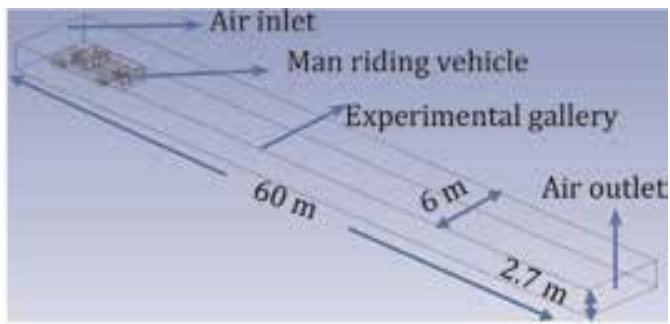

b

Figure 4.

CFD model of man riding vehicle and experimental gallery. (a) Man riding vehicle-CAD model.

(b) Experimental gallery.

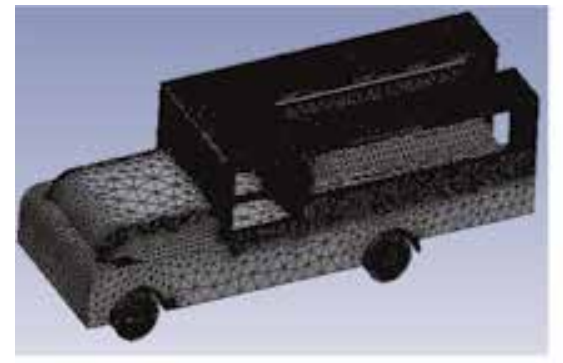

a

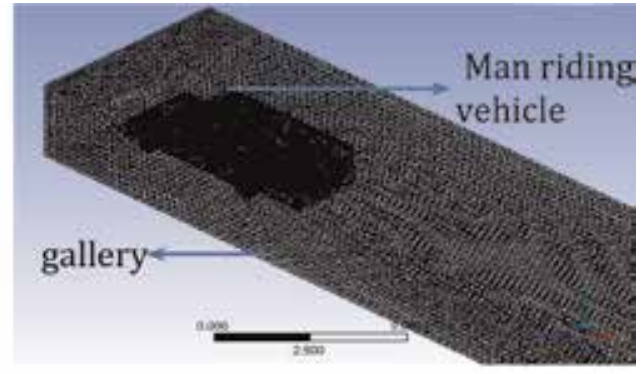

b

Figure 5.

Mesh model of man riding vehicle and experimental gallery. (a) Surface mesh on man riding vehicle. (b) Mesh for airway. 


\subsection{Construction of computational domain and mesh for experiment-2}

The computational domain is a $70 \mathrm{~m}$ long tunnel with a rectangular cross section (width $6 \mathrm{~m}$, height $2.7 \mathrm{~m}$ ). A CAD model of an LHD vehicle was designed and imported into the computational domain. The location of the exhaust is at the rear end of the LHD. The exhaust flow is a mixture of DPM and air. Figure 6(a) shows the CAD model representing the vehicle, and Figure 6(b) shows the experimental gallery with LHD. Figure 7(a) shows the mesh generated for the complex surfaces of the vehicle and (b) shows the details of the computational domain and mesh made up of about half-million computational cells. Finer cells were used to capture details of the flow in regions such as small gaps and adjacent to solid surfaces.

\subsection{Setting up the flow conditions}

Intake air was supplied through the inlet of the gallery with $1.26 \mathrm{~m} / \mathrm{s}$ velocity for experiment- 1 and $2 \mathrm{~m} / \mathrm{s}$ for experiment- 2 at $300 \mathrm{~K}$ temperature. DPM was released from the smoke pipe with a velocity of $29 \mathrm{~m} / \mathrm{s}$ and temperature of $323 \mathrm{~K}$. For these investigations, DPM is treated as a gas, chemical reactions were not considered. The Boussinesq approximation was used to simulate buoyancy and the effect of turbulence was taken into account.

\subsection{Governing equations}

To model turbulent flow of mine air, Reynolds-Averaged Navier-Stokes equation was used. In Reynold's averaging, the solution variables in the exact

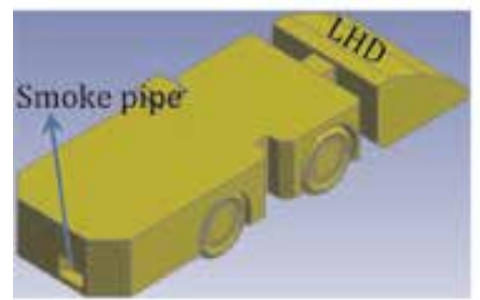

a

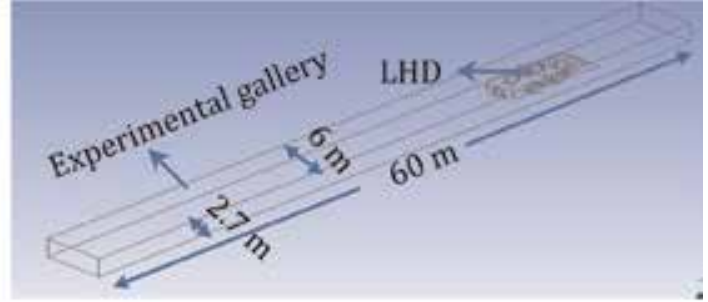

b

Figure 6.

CFD model of man riding vehicle and experimental gallery. (a) LHD-CAD model. (b) Experimental gallery with LHD.

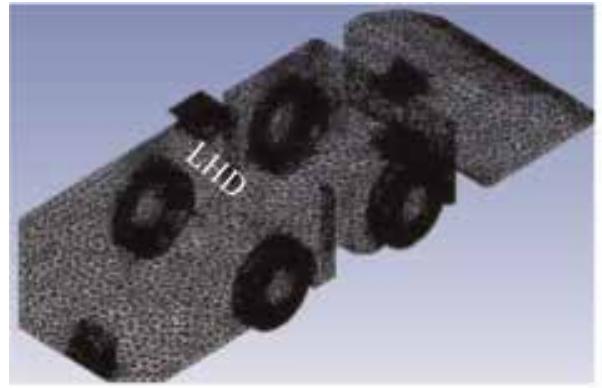

a

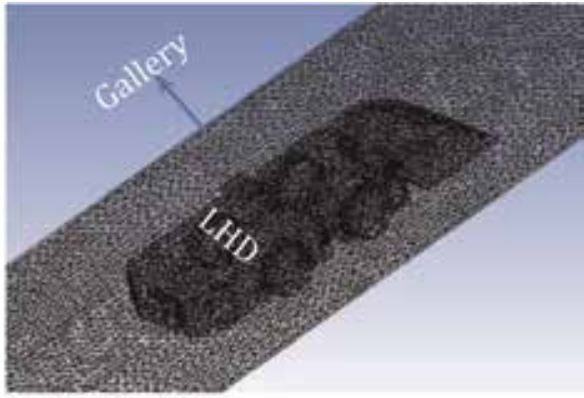

$\mathrm{b}$

Figure 7.

Surface mesh on LHD \& mesh in gallery with LHD. (a) Surface mesh of LHD. (b) Surface mesh of LHD \& gallery. 
Navier-Stokes equations are consisting of time averaged and fluctuated components for velocity components [25].

$$
u_{i}=\bar{u}_{i}+u_{i}^{\prime}
$$

Where $\bar{u}_{i}$ and $u_{i}^{\prime}$ are mean and fluctuating velocity components $(i=1,2,3)$.

Reynolds-averaged Navier-Stokes (RANS) equation was obtained by substituting time and average velocity in momentum equation:

$$
\begin{gathered}
\frac{\partial \rho}{\partial t}+\frac{\partial}{\partial x_{i}}\left(\rho u_{i}\right)=0 \\
\frac{\partial}{\partial x}\left(\rho u_{i}\right)+\frac{\partial}{\partial x_{j}}\left(\rho u_{i} u_{j}\right)=-\frac{\partial p}{\partial x_{i}}+\frac{\partial}{\partial x_{j}}\left[\mu\left(\frac{\partial u_{i}}{\partial x_{j}}+\frac{\partial u_{j}}{\partial x_{i}}-\frac{2}{3} \delta_{i j} \frac{\partial u_{l}}{\partial x_{l}}\right)\right]+\frac{\partial}{\partial x_{j}}\left(-\rho \overline{u_{i^{\prime}} u_{j^{\prime}}}\right)
\end{gathered}
$$

Where $-\rho \overline{u_{i}{ }^{\prime} u_{j}}$ is Reynolds stress can be solved with Boussinesq hypothesis and Reynolds stress models (RSM). In Boussinesq hypothesis, the Reynolds stress are related to the mean velocity gradient [25].

$$
-\rho \overline{u^{\prime} u_{j^{\prime}}}=\mu_{t}\left(\frac{\partial u_{i}}{\partial x_{j}}+\frac{\partial u_{j}}{\partial x_{i}}\right)-\frac{2}{3}\left(\rho k+\mu_{t} \frac{\partial u_{k}}{\partial x_{k}}\right) \delta_{i j}
$$

To determine turbulent viscosity $\mu_{\mathrm{t}}, \mathrm{k}-\varepsilon$ model was used.

$$
\mu_{t}=\rho C_{\mu} \frac{k^{2}}{\varepsilon}
$$

Where $\mathrm{C}_{\mu}$ is a constant, $k$ is the turbulence kinetic energy and $\varepsilon$ is the turbulent dissipation rate and turbulent heat transport is modeled using the concept of the Reynolds analogy to turbulent momentum transfer. The modeled energy equations are as follows:

$$
\frac{\partial}{\partial t}(\rho E)+\frac{\partial}{\partial x_{i}}\left[u_{i}(\rho E+p)\right]=\frac{\partial}{\partial x_{j}}\left[\left(k+\frac{c_{p} \mu_{t}}{\sigma_{k}}\right) \frac{\partial T}{\partial x_{j}}+u_{i}\left(\tau_{i j}\right)_{e f f}\right]+S_{h}
$$

Where $k$ is the thermal conductivity, E is the total energy and $\left(\tau_{\mathrm{ij}}\right)_{\text {eff }}$ is the deviatoric stress tensor, defined as

$$
\left(\tau_{i j}\right)_{e f f}=\mu_{e f f}\left(\frac{\partial u_{j}}{\partial x_{i}}+\frac{\partial u_{i}}{\partial x_{j}}\right)-\frac{2}{3} \mu_{e f f} \frac{\partial u_{k}}{\partial x_{k}} \delta_{i j}
$$

The standard $k-\varepsilon$ model is based on the model transport equations for the turbulence kinetic energy $(\mathrm{k})$ and its dispersion rate $(\varepsilon)$. The model transport equation for $\mathrm{k}$ is derived from the exact equation, while the model transport equation for $\varepsilon$ was obtained using physical reasoning and bears little resemblance to its mathematically exact counterpart.

In the derivation of the $\mathrm{k}-\varepsilon$ model, the assumption is that the flow is fully turbulent, and the effect of molecular viscosity is negligible. As the mine air considered as fully turbulent flow, $\mathrm{k}-\varepsilon$ model is valid for mine air.

The turbulent kinetic energy, $\mathrm{k}$, and its rate of dissipation, $\varepsilon$, are obtained from the following governing equations [25]: 


$$
\begin{gathered}
\frac{\partial}{\partial t}(\rho k)+\frac{\partial}{\partial x_{i}}\left(\rho k u_{i}\right)=\frac{\partial}{\partial x_{j}}\left[\left(\mu+\frac{\mu_{t}}{\sigma_{k}}\right) \frac{\partial k}{\partial x_{j}}\right]+G_{k}+G_{b}-\rho \varepsilon-Y_{M}+S_{k} \\
\frac{\partial}{\partial t}(\rho \varepsilon)+\frac{\partial}{\partial x_{i}}\left(\rho \varepsilon u_{i}\right)=\frac{\partial}{\partial x_{j}}\left[\left(\mu+\frac{\mu_{t}}{\sigma_{\varepsilon}}\right) \frac{\partial \varepsilon}{\partial x_{j}}\right]+C_{1 \varepsilon} \frac{\varepsilon}{K}\left(G_{k}+C_{3 \varepsilon} G_{b}\right)-C_{2 \varepsilon} \rho \frac{\varepsilon^{2}}{K}+S_{\varepsilon}
\end{gathered}
$$

Where $G_{b}$ is the generation of turbulence kinetic energy due to buoyancy, $G_{k}$ is the production of turbulence kinetic energy due to the mean velocity gradient, $\mathrm{Y}_{\mathrm{M}}$ is the contribution of the fluctuating dilation in compressible turbulence to the overall dissipation rate, $\mathrm{C}_{1 \varepsilon}, \mathrm{C}_{2 \varepsilon}$ and $\mathrm{C}_{3 \varepsilon}$ are constants. $\mathrm{S}_{\mathrm{k}}$ and $\mathrm{S}_{\varepsilon}$ are user defined source terms.

\section{Results and discussions}

\subsection{Experiment 1}

Figure 8 shows the DPM cloud in top view. From the figure, high DPM concentration is seen between the smoke pipe side of the vehicle and wall. No DPM concentration is observed near the operator and passenger seat. Downstream of the vehicle, DPM particles spread throughout the whole gallery.

Figure 9 shows the DPM concentration at 1 and $5 \mathrm{~m}$ downstream to the vehicle. At $1 \mathrm{~m}$ downstream to the vehicle, Figure 9(a) shows that the maximum DPM concentration is near the left half of the roof and the side. Traces of DPM are observed in the blue-green band across the airway, and negligible concentration on the right side. Figure 9(b) shows the DPM concentration at $5 \mathrm{~m}$ downstream to the vehicle. The DPM is seen to flow towards the smoke pipe side of the roadway. The maximum DPM concentration is near the middle of the roadway. Figure 9(c) shows the DPM concentration at $10 \mathrm{~m}$ downstream to the vehicle. DPM concentration at the middle of the road way is $110 \mu \mathrm{g} / \mathrm{m}^{3}$ and the right side of the road way $57 \mu \mathrm{g} / \mathrm{m}^{3}$.

\subsection{Experiment-1 model validation}

Table 3 compares the field measurements with results of the CFD simulations. The CFD results are seen to be in fair in agreement the field data, with the difference varying from -14.2 to $+14 \%$. In some cases, the simulated values are different

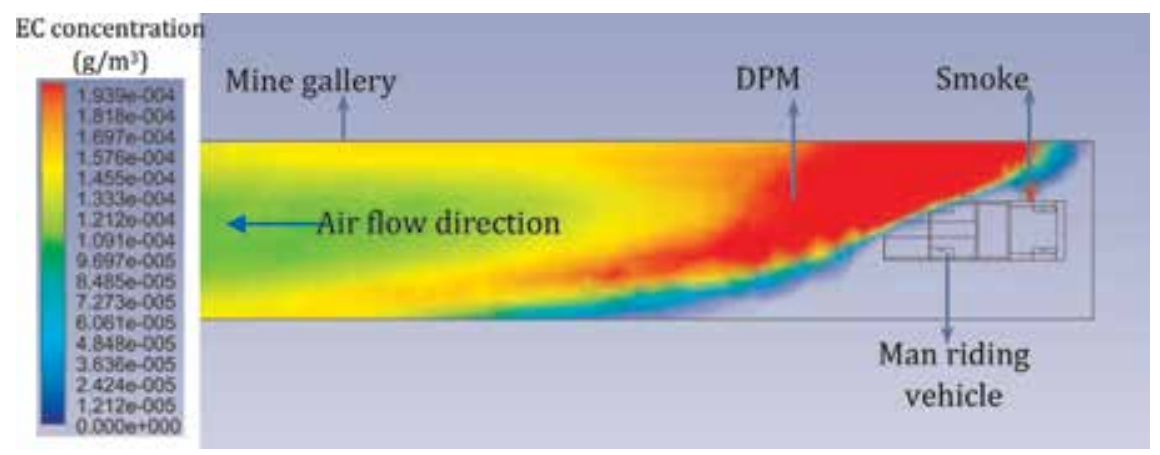

Figure 8.

DPM flow pattern - top view, $2 D$ concentration contours in a plane near the ceiling. 


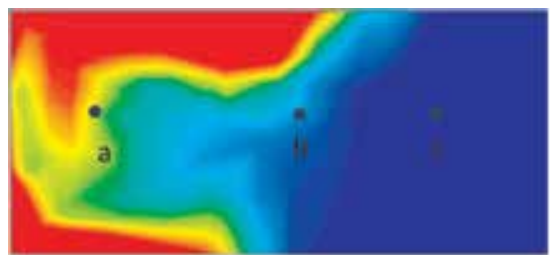

a

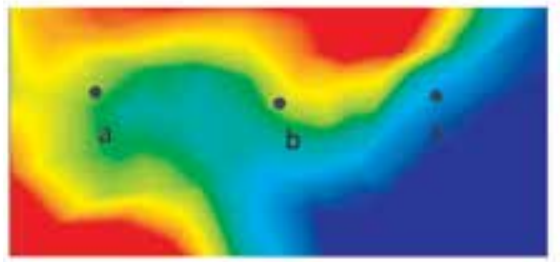

b
DPM concentration

$\left(\mathrm{g} / \mathrm{m}^{3}\right)$

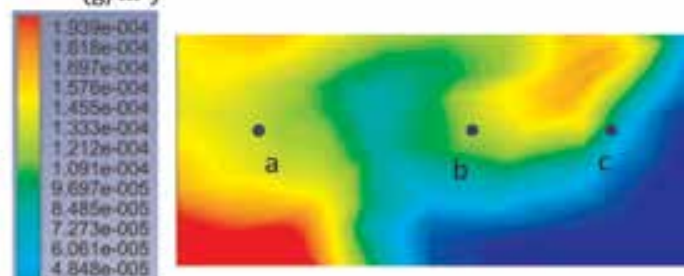

C

Figure 9.

DPM concentration at 1, 5 and $10 m$ downstream of the vehicle. (a) DPM concentration $1 m$ downstream of the vehicle. (b) DPM concentration at $5 \mathrm{~m}$ downstream of the vehicle. (c) DPM concentration $10 \mathrm{~m}$ downstream of the vehicle.

\begin{tabular}{|c|c|c|c|c|c|c|}
\hline \multirow{2}{*}{$\begin{array}{l}\text { Sampling } \\
\text { point }\end{array}$} & \multicolumn{3}{|c|}{ At sample station $1 \mathrm{~m}$} & \multicolumn{3}{|c|}{ At sample station $5 \mathrm{~m}$} \\
\hline & $\begin{array}{l}\text { Experimental } \\
\text { value }\left(\mu \mathrm{g} / \mathrm{m}^{3}\right)\end{array}$ & $\begin{array}{c}\text { Simulation } \\
\text { value }\left(\mu \mathrm{g} / \mathrm{m}^{3}\right)\end{array}$ & $\begin{array}{c}\text { Difference } \\
\%\end{array}$ & $\begin{array}{l}\text { Experimental } \\
\text { value }\left(\mu \mathrm{g} / \mathrm{m}^{3}\right)\end{array}$ & $\begin{array}{c}\text { Simulation } \\
\text { value }\left(\mu \mathrm{g} / \mathrm{m}^{3}\right)\end{array}$ & $\begin{array}{c}\text { Difference } \\
\%\end{array}$ \\
\hline $\mathrm{a}$ & 185.8 & 176 & -5.2 & 149.0 & 130 & -12.7 \\
\hline $\mathrm{b}$ & 50 & 46 & -8.0 & 117 & 110 & -5.9 \\
\hline c & 0 & 0 & 0 & 16 & 16 & 0 \\
\hline \multicolumn{4}{|c|}{ At sample station $10 \mathrm{~m}$} & & & \\
\hline $\mathrm{a}$ & 127.4 & 130 & 2.0 & & & \\
\hline $\mathrm{b}$ & 116.6 & 100 & -14.2 & & & \\
\hline c & 50.0 & 57 & 14.0 & & & \\
\hline
\end{tabular}

Table 3 .

Comparison of simulated results with experimental results.

from the measured data. This may be because the uneven texture of the gallery surface was not considered in the CFD model.

\subsection{Experiment-1 DPM model validation}

Table 3 shows the compared results of base case simulations and field experiments at 1, 5 and $10 \mathrm{~m}$ downstream of the vehicle and at the sample point $\mathrm{a}, \mathrm{b}$ and $\mathrm{c}$. The simulated results were in fair agreement with the measured data at a number of instances and such results which slightly deviated from the measured data can be due uneven gallery walls surface were not considered while modeling. The difference varies from -14.2 to $+14 \%$.

\subsection{DPM exposure levels for passenger during vehicle movement}

DPM concentration was measured in the passenger seat during vehicle movement. The vehicle engine was assumed to run at full capacity so that the engine 
emitted maximum amount of fumes. DPM measurements were recorded as the vehicle traveled from the pit bottom to the work place, a distance of $4 \mathrm{~km}$. The maximum speed of the vehicle on level ground is $25 \mathrm{~km} / \mathrm{h}$. During the experiment, the average velocity of the vehicle was $10 \mathrm{~km} / \mathrm{h}(2.7 \mathrm{~m} / \mathrm{s})$. Figure 10 shows the DPM concentration at different time periods during $4 \mathrm{~km}$ travel distance. The concentration changes with relative velocities between vehicle and air.

\subsection{Changes of DPM concentration with intake air velocity}

To understand the effect of intake air velocity on DPM dispersion, simulation studies were conducted with the air velocity ranging from 0.5 to $3 \mathrm{~m} / \mathrm{s}$.

Figure 11 shows the DPM concentration in the vertical mid-plane of the mine gallery when the intake air velocity is $0.5 \mathrm{~m} / \mathrm{s}$. The results show that high DPM concentration of over $200 \mu \mathrm{g} / \mathrm{m}^{3}$ is observed in almost the entire roadway. High DPM concentration is also observed on the passenger side of the vehicle. Downstream of the vehicle, high DPM concentration spreads across almost the entire cross-section of the roadway.

Figure 12 shows the DPM concentration corresponding to an intake air velocity $3 \mathrm{~m} / \mathrm{s}$. most of the DPM concentration is at the smoke pipe side of the gallery roof

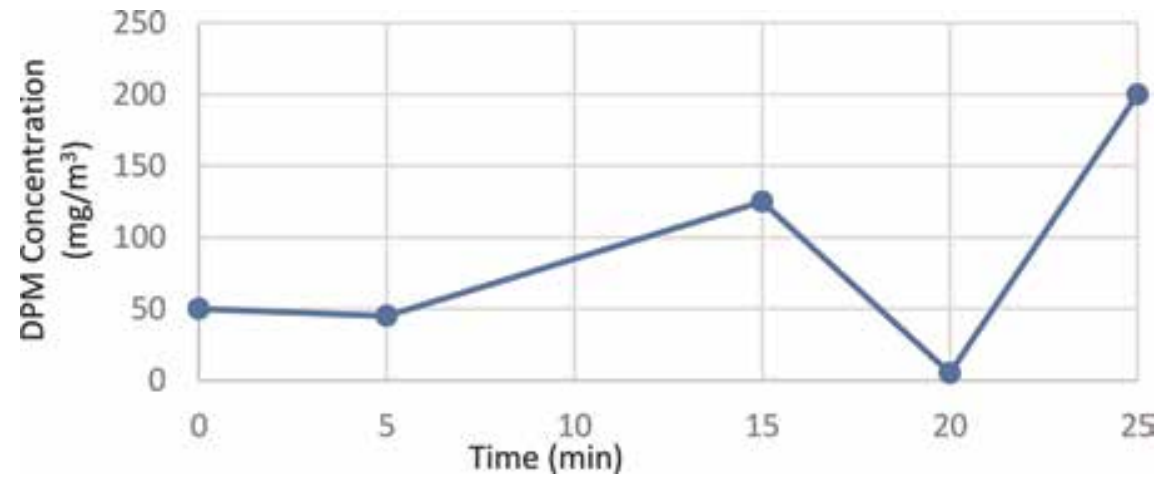

Figure 10.

EC concentration at passenger seat (moving vehicle).

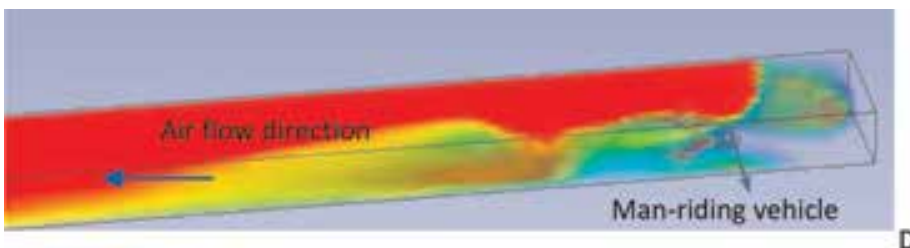

a

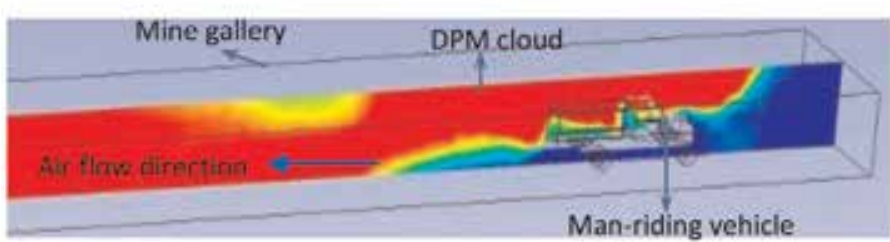

b

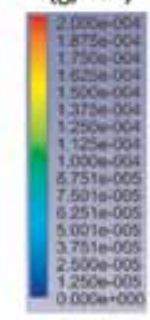

Figure 11.

DPM distribution with $0.5 \mathrm{~m} / \mathrm{s}$ air velocity, center section of the mine gallery. (a) DPM concentration at mine gallery. (b) DPM concentration in vertical mid-plane of the gallery. 


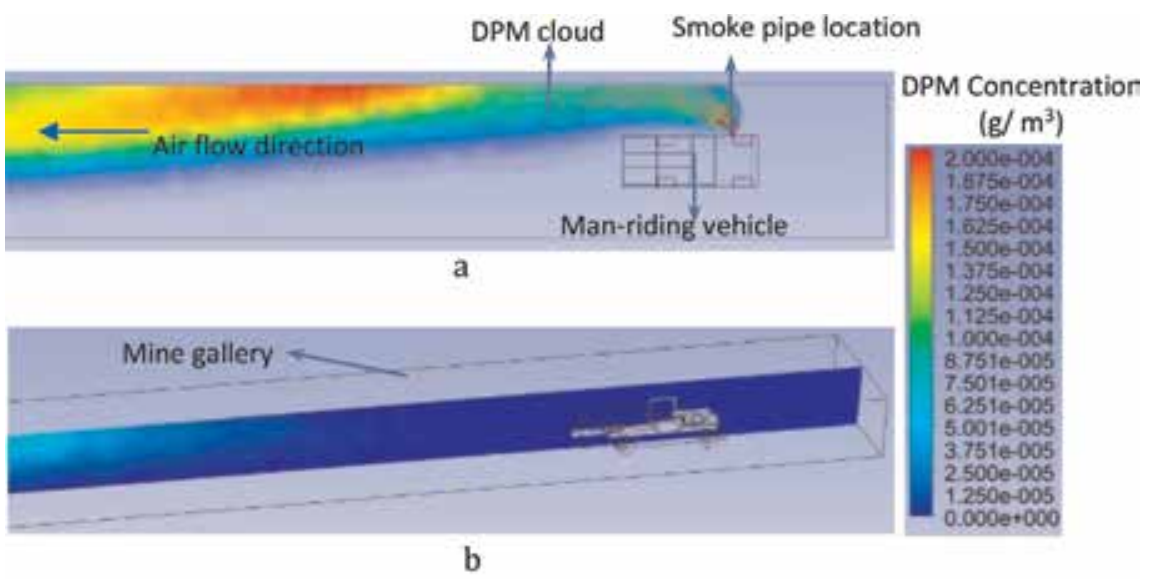

Figure 12.

$D P M$ distribution with $3 \mathrm{~m} / \mathrm{s}$ air velocity, top and center section view of mine gallery. (a) DPM concentration at mine gallery, top view. (b) DPM concentration in vertical mid-plane of the gallery.

due to high air velocity. Negligible DPM concentration was observed at the middle of the roadway up to $20 \mathrm{~m}$ downstream of the vehicle. Beyond $20 \mathrm{~m}$ downstream of the vehicle, DPM concentration of $60 \mu \mathrm{g} / \mathrm{m}^{3}$ is observed near the ceiling and concentration reduced to zero towards the floor.

\section{Results and discussions-experiment 2}

\subsection{DPM and air flow in opposite directions}

Figure 13 shows the results of CFD simulations in isometric view when DPM and air flow are in opposite directions (counter-flow). Near the LHD, it can be observed that high DPM concentration is at middle of the gallery and above the LHD. At downstream side of the LHD, DPM particles spreads throughout the gallery, with the maximum concentration is in the middle and at sides of the gallery.

Figure 14 shows the DPM concentration patterns at 2, 5 and $8 \mathrm{~m}$ downstream of the vehicle rear end. Figure 14(a) shows the high DPM concentration near the top and bottom portions of the vehicle. Figure 14(b) shows the maximum

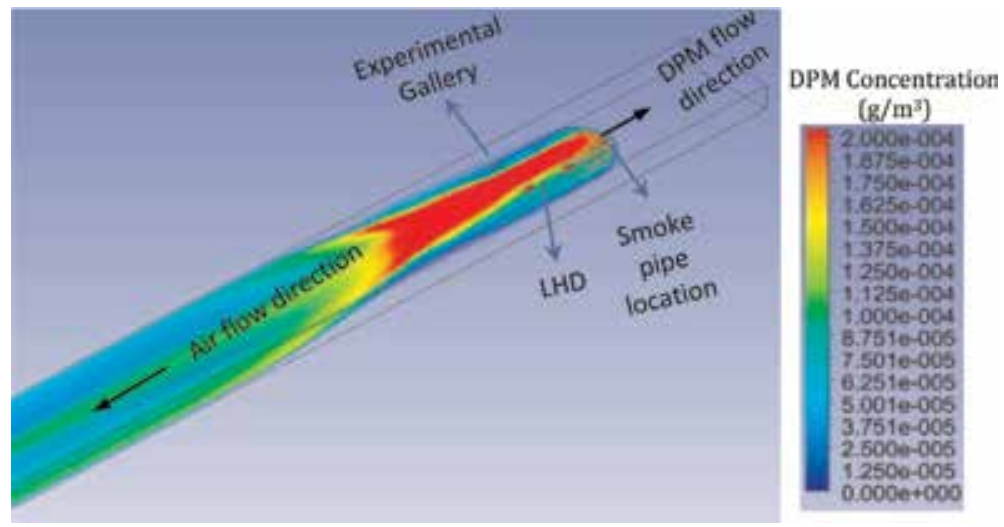

Figure 13.

DPM flow pattern-isometric view. 
Analysis of Diesel Particulate Matter Flow Patterns in Different Ventilation and Operational... DOI: http://dx.doi.org/10.5772/intechopen.84651

concentration is at top and bottom portions of the vehicle, concentrations also spreads at left and right sides of the road ways. DPM concentration at LHD operator is $125 \mu \mathrm{g} / \mathrm{m}^{3}$. Figure 14(c) shows the DPM flow moved towards the roof and bottom of the road way, DPM concentration spreads at towards left and right sides of the road way.

Figure 15 shows the DPM concentration field at 6,10 and $20 \mathrm{~m}$ downstream of the vehicle. Figure 15(a) shows the DPM concentration at $6 \mathrm{~m}$ downstream of the vehicle. Here, high DPM concentration is observed near the floor of the roadway, and the concentrations gradually reduces towards the roof.

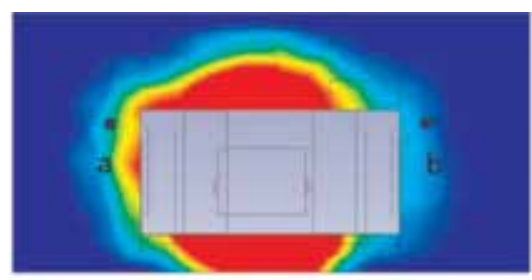

a

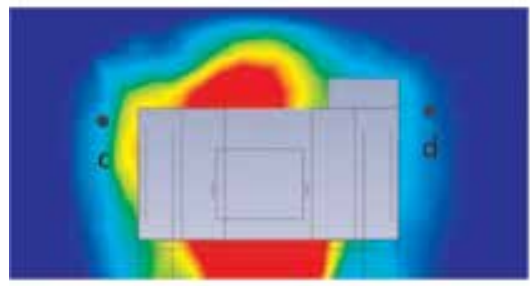

b

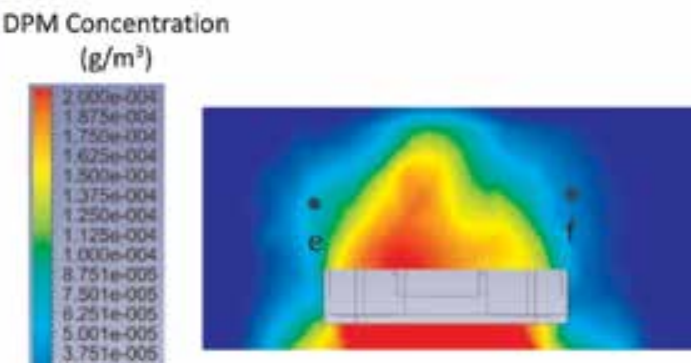

c

Figure 14 .

$D P M$ concentration at 2, 5 and $10 m$ downstream of the vehicle. (a) DPM concentration at $2 m$ downstream of the smoke pipe. (b) DPM concentration at $5 \mathrm{~m}$ downstream of the smoke pipe. (c) DPM concentration at $8 \mathrm{~m}$ downstream of the smoke pipe.

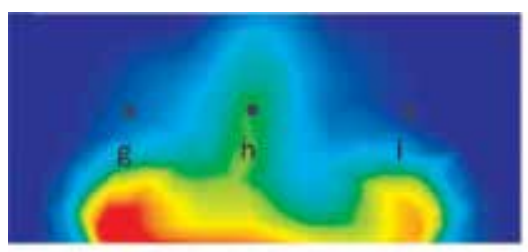

a

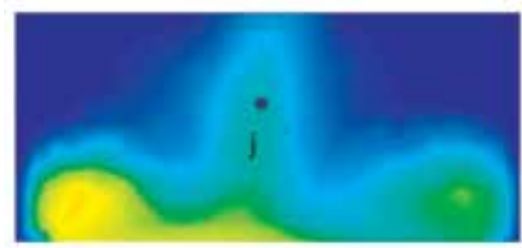

b
DPM Concentration

$\left(\mathrm{g} / \mathrm{m}^{3}\right)$

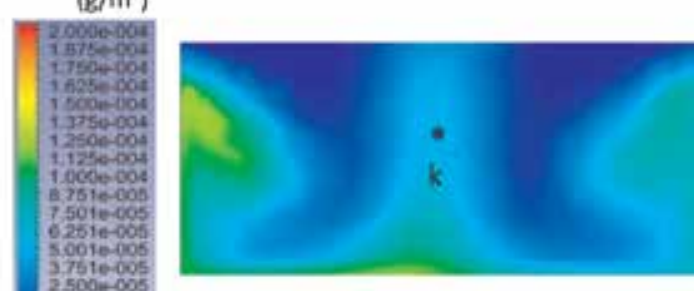

C

Figure 15.

DPM concentration at 2, 5 and $10 m$ downstream of the vehicle. (a) DPM concentration at $6 m$ downstream of the vehicle. (b) DPM concentration at $10 \mathrm{~m}$ downstream of the vehicle. (c) DPM concentration at $20 \mathrm{~m}$ downstream of the vehicle. 
Figure 15(b) shows the DPM concentration field at $10 \mathrm{~m}$ downstream of the vehicle. Here, the maximum concentration is at middle of the gallery and left and right sides of the road ways.

Figure 15(c) shows the DPM concentration field at $20 \mathrm{~m}$ downstream of the vehicle. Here, the DPM is found to spread throughout the entire roadway. The DPM concentration at the center of the road way is $34 \mu \mathrm{g} / \mathrm{m}^{3}$ and similar concentrations observed at left and right sides of the road way.

\subsection{Experiment-2 DPM model validation}

Table 4 compares the experimental results (ER) and simulation results of spot values of DPM concentration results at downstream side of the vehicle at different sampling points. From the table it can be observed that the simulated results were in fair agreement with the measured data, the difference is varies from -21 to $+21 \%$.

\subsection{DPM flow pattern when air flow and DPM in the same direction}

Figure 16 shows the results of CFD simulations in isometric view when DPM and air flow are in the same direction (co-flow). High DPM concentration is observed in the middle of the gallery. At $50 \mathrm{~m}$ downstream of the vehicle, DPM particles are seen to spread over most of the middle gallery.

\begin{tabular}{lccccccc}
\hline Sample point & ER & SR & Difference $\%$ & Sample point & ER & SR & Difference $\%$ \\
\hline 2 m to source (a) & - & 125 & - & 6 m to vehicle $(g)$ & 14 & 17 & 21 \\
\hline 2 m to source (b) & 70 & 55 & -21 & 6 m to vehicle $(\mathrm{h})$ & 42 & 48 & 14 \\
\hline 5 m to source (c) & 56 & 60 & 7 & $6 \mathrm{~m}$ to vehicle $(\mathrm{i})$ & 26 & 25 & -3 \\
\hline $5 \mathrm{~m}$ to source $(\mathrm{d})$ & 55 & 43 & -21 & $10 \mathrm{~m}$ to vehicle $(\mathrm{j})$ & 42 & 48 & 14 \\
\hline $8 \mathrm{~m}$ to source $(\mathrm{e})$ & 42 & 35 & -16 & $20 \mathrm{~m}$ to vehicle $(\mathrm{k})$ & 28 & 34 & 21 \\
\hline $8 \mathrm{~m}$ to source $(\mathrm{f})$ & 27 & 27 & 0 & & & & \\
\hline
\end{tabular}

Table 4.

Comparison of simulated results (SR in $\mu g / \mathrm{m}^{3}$ ) with experimental results (ER in $\mu \mathrm{g} / \mathrm{m}^{3}$ ).
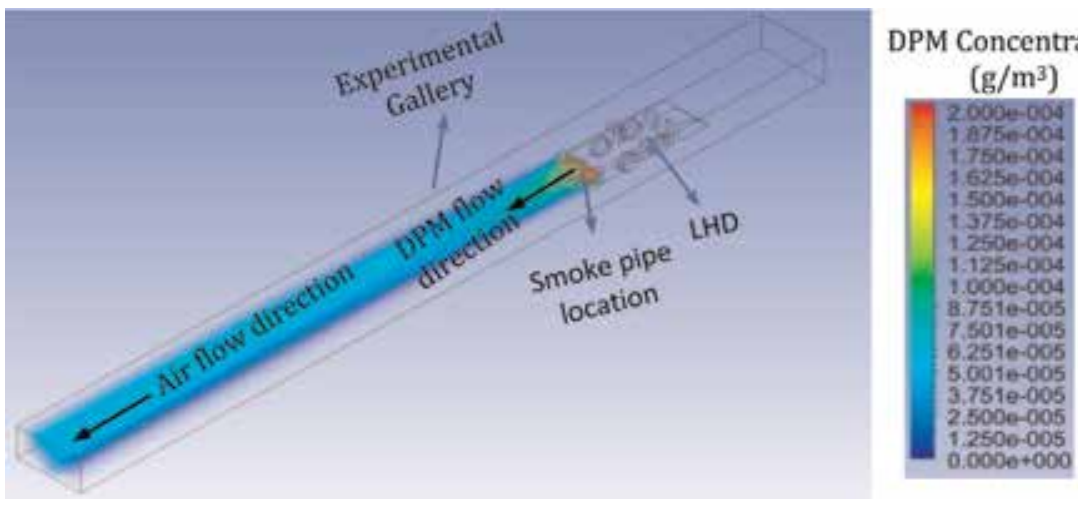

Figure 16.

$D P M$ flow pattern for co-flow (flows in the same direction). 


\section{Conclusions}

In this study, field measurements and CFD simulations were used to map contours of diesel particulate matter (DPM) generated by a man riding vehicle and an LHD located in the gallery of an underground mine. CFD models were validated against the field experimental data, and simulation results were found to be in fair agreement with the measured data. Studies with a man-riding vehicle showed that if the vehicle is stationary, high DPM concentration tends to flow moves towards the center of the gallery. At $20 \mathrm{~m}$ downstream of the vehicle, DPM particles spread throughout the entire roadway. Studies also shows that DPM concentration levels reduce with increase in ventilation air velocity. Experiments showed that during vehicle movement, the passenger may be exposed to higher DPM concentration due to airflows induced by the vehicle movement.

The LHD studies show that if the DPM flow and ventilation air co-flow (are in the same direction), the DPM is confined predominantly to the middle of the road way. If the DPM flow and the ventilation air flow are in counter-flow (opposite directions), the DPM spreads throughout the entire cross-section of the roadway. In this case, the vehicle operator will be more susceptible to exposure to high concentrations of DPM.

\section{Acknowledgements}

The authors sincerely thank M/s Coal India Limited, DGMS, Govt. of India and IIT (ISM) Dhanbad for providing the necessary resources and extending cooperation during the field experiments.

\section{Conflict of interest}

On behalf of all authors, the corresponding author affirms that there is no conflict of interest.

\section{Nomenclature}

$\begin{array}{ll}\text { ACGIH } & \text { American Conference of Governmental Industrial Hygienists } \\ \text { CANMET } & \begin{array}{l}\text { Canada Centre for Mineral and Energy Technology } \\ \text { computational fluid dynamics }\end{array} \\ \text { CFD } & \begin{array}{l}\text { carbon monoxide } \\ \text { CO }\end{array} \\ \text { DEEP } & \begin{array}{l}\text { diesel emissions evolution program } \\ \text { diesel particulate filter }\end{array} \\ \text { DPF } & \text { diesel particulate matter } \\ \text { DPM } & \text { elemental carbon } \\ \text { EC } & \text { experimental results } \\ \text { ER } & \text { hydrocarbons } \\ \text { HC } & \text { load haul dumper } \\ \text { LHD } & \text { Mine Safety and Health Administration } \\ \text { MSHA } & \text { National Institute of Occupational Health and Safety } \\ \text { NIOSH } & \text { National Mining Association } \\ \text { NMA } & \text { non-methane hydrocarbons } \\ \text { NMHC } & \text { nitrogen oxides } \\ \text { NOx } & \end{array}$


NSSGA National Stone, Sand and Gravel Association

OC

OEL organic carbon

RCD occupational exposure limits

STEL

TC respirable combustible dust

TWA

USWA

WHS short term exposure limit total carbon time weighted average United Steel Workers of America Work Health and Safety

\section{Author details}

Ramakrishna Morla ${ }^{1 *}$, Shivakumar Karekal ${ }^{2}$ and Ajit Godbole ${ }^{2}$

1 CSA Mine, Glencore, Cobar, NSW, Australia

2 School of Civil, Mining and Environmental Engineering, University of Wollongong, Australia

*Address all correspondence to: ramsiit99@gmail.com

\section{IntechOpen}

(C) 2019 The Author(s). Licensee IntechOpen. This chapter is distributed under the terms of the Creative Commons Attribution License (http://creativecommons.org/licenses/ by/3.0), which permits unrestricted use, distribution, and reproduction in any medium, provided the original work is properly cited. (cc) BY 


\section{References}

[1] AIOH. Diesel Particulate Matter \& Occupational Health Issues. Position Paper. AIOH Exposure Standards Committee. 2013. Available from: https://www.aioh.org.au/documents/ item/15 [Accessed: 09 December 2018]

[2] Bugarski AD, Janisko SJ, Cauda EG, Noll JD, Mischler SE. Controlling Exposure to Diesel Emissions in Underground Mines. Englewood, Colorado: Society for Mining, Metallurgy, and Exploration, Inc. (SME); 2012

[3] MDG 29 (Mine Design Guideline 29). Guideline for the Management of Diesel Engine Pollutants in Underground Environments. Produced by Mine Safety Operations Division, New South Wales Department of Primary Industries. 2008. Available from: http://www. resourcesandenergy.nsw.gov.au/_data/ assets/pdf_file/0011/419465/MDG-29. pdf

[4] Work Health and Safety (Mines and Petroleum Sites) Regulations. 2014. Available from: https://www.legislation. nsw.gov.au/inforce/500011c6-2a 99-440f-8799-8cbf39393930/2014-799. pdf [Accessed: 17 December 2018]

[5] Work Health and Safety (Mines and Petroleum Sites) Act. 2013. Available from: https://www.legislation.nsw.gov. au/inforce/2452de08-45ac-4954-856faf17f88c9fc3/2013-54.pdf [Accessed: 09 December 2018]

[6] Coal Mines Health and Safety Regulations. 2006. Australia. Available from: http://www.dpi.nsw.gov.au/_ data/assets/pdf_file/0018/101745/ CMHS-Regulation-2006.pdf [Accessed: 17 December 2018]

[7] David BK. Measurement of Engine Exhausts Particle Size. University of California; 2002. Available from: http:// www.me.umn.edu/centers/mel/reports/ dbkucdavis.pdf

[8] Attfield MD, Schleiff PL, Lubin JH, Blair A, Stewart PA, Vermeulen R, et al. The diesel exhaust in miners study: A cohort mortality study with emphasis on lung cancer. Journal of the National Cancer Institute. 2012;104(11):869-883. DOI: 10.1093/jnci/djs035

[9] Silverman D, Samanic C, Lubin J, Blair E, Stewart P, Vermeulen R, et al. The Diesel Exhaust in Miners Study: A Cohort Mortality Study with Emphasis on Lung Cancer. Oxford University Press; 2011. Available from: https:// www.ncbi.nlm.nih.gov/pmc/articles/ PMC3369553/pdf/djs034.pdf

[10] Cox A, Costle D, King S, Huang A, Stewart R, Kennedy D, et al. Diesel Emissions and Lung Cancer.

Epidemiology and Quantitative Risk Assessment. Health Effect Institute; 1999. Available from: https://www. healtheffects.org/system/files/Diese 1Epi.pdf [Accessed: 09 December 2018]

[11] Bartlett CJS, Betts WE, Booth M, Giavazzi F, Guttmann H, Heinze P, et al. The Chemical Composition of Diesel Particulate Emissions. Report No. 92/51. 1992. Available from: https:// www.concawe.eu/wp-content/uploads/ 2017/01/rpt_92-51ocr-2004-01337-01-e. pdf

[12] Gangal M. Summary of Worldwide Underground Diesel Regulations, CANMET Mining. 2012. Available from: http://www.mdec.ca/2012/S3P3-Gangal. pdf [Accessed: 15 January 2019]

[13] Bugarski A, George S, Jim N, Steve $\mathrm{M}$, Larry $\mathrm{P}$, Jon $\mathrm{H}$, et al. The Effectiveness of Selected Technologies in Controlling Diesel Emissions in an Underground Mine Isolated Zone Study at Stillwater Mining company's Nye 
Mine. Final Report to Metal/Non-Metal Diesel Partnership. 2004. Available from: https://stacks.cdc.gov/view/cdc/ 9387/cdc_9387_DS1.pdf? [Accessed: 15 January 2019]

[14] McGinn S, Grenier M, Gangal M, Rubeli B, Bugarski A, Schnakenberg G, et al. Final Report of Investigation to the Diesel Emissions Evaluation Program (DEEP), Noranda Inc.-Brunswick Mine Diesel Particulate Filter (DPF) Field Study. 2004. Available from: https:// www.cdc.gov/niosh/mining/UserFiles/ works/nordpf_final.pdf [Accessed: 15 January 2019]

[15] Zheng Y. Diesel particulate matter dispersion analysis in underground metal/non-metal mines using CFD [thesis]. Missouri University of Science and Technology; 2011, 2011. Available from: https://scholarsmine.mst.edu/cgi/ viewcontent.cgi?article $=3018 \&$ conte $\mathrm{xt}=$ doctoral_dissertations

[16] Janisko S, Noll J. Near real time monitoring of diesel particulate matter in underground mines. In: 12th U.S/ North American Mine Ventilation Symposium; 9-11 June 2008; Reno, NV. 2008. pp. 509-513

[17] Khan UM. Real-time diesel particulate matter monitoring in underground mine atmospheres, association with the standard method and related challenges [thesis]. Missouri University of Science and Technology; 2017. Available from: http:// scholarsmine.mst.edu/doctoral_ dissertations/2625/

[18] Flir Airtec DPM Monitor. Available from: https://www.flir.com/globalasse ts/imported-assets/.../airtec-datasheetenglish.pdf [Accessed: 15 January 2019]

[19] Zheng Y, Magesh T, Lan H, Ten CJ. Simulation of DPM distribution in a long single entry with buoyancy effect. International Journal of Mining Science and Technology. 2016;25(1):47-52. DOI: 10.1016/j.ijmst.2014.11.004

[20] Zheng Y, Magesh T, Lan H, Ten CJ. Effect of auxiliary ventilations on diesel particulate matter dispersion inside a dead-end entry. International Journal of Mining Science and Technology. 2015; 25(6):927-932. DOI: 10.1016/j.ijmst. 2015.09.008

[21] Zheng Y, Magesh T, Lan H, Tien CJ. Simulation of DPM distribution in a long single entry with buoyancy effect. International Journal of Mining Science and Technology. 2015;25(1):47-52

[22] Zheng Y, Lan H, Magesh T, Tien JC. DPM dispersion experiment at MST's experimental mine and comparison with CFD simulation. Journal of Coal Science and Engineering. 2011;17(3):285-289.

DOI: $10.1007 / \mathrm{s} 12404-011-0311-1$

[23] Morla R, Godbole A, Karekal S, Bhattacharjee R, Nasina B. Fundamental understanding of diesel-operated man riding vehicle DPM dispersion-A case study. Journal of Sustainable Mining. 2018;17(3):105-110

[24] Morla R, Karekal S. Diesel particulate matter investigations in underground coal mines. International Journal of Engineering and Technology. 2018;9(4):2698-2703. Available from: http://www.enggjournals.com/ijet/ abstract.html?file $=17-09-04-401$

[25] ANSYS Fluent Theory Guide. Canonsburg, PA: ANSYS, Inc; 2013 


\title{
Major Chemical Elements in Soot and Particulate Matter Exhaust Emissions Generated from In-Use Diesel Engine Passenger Vehicles
}

\author{
Richard Viskup, Christoph Wolf and Werner Baumgartner
}

\begin{abstract}
In this research we apply a sensitive laser optical technique for the measurement of main chemical elements present in the exhaust emissions generated from different in-use Diesel engine passenger vehicles. We use the laser-induced breakdown spectroscopy (LIBS) technique for diagnostics of miscellaneous Diesel particulate matter (DPM) formed from combustion Diesel engine exhaust emissions. Here we analysed particulate matter (PM) extracted from exhaust manifold part, from 67 different passenger vehicles of major brands from European car producers, that are used in daily life environment. The aim of this study is to develop LIBS technique for measurement of PM and to compare the emission matrix composition and major chemical elements within the Diesel particulate matter from exhaust manifold part. The presence of these elements in PM is linked with various processes inside the Diesel combustion engine.
\end{abstract}

Keywords: laser-induced breakdown spectroscopy, LIBS, particulate matter, soot, emissions, emissions standards, diesel, diesel engine, diesel vehicles

\section{Introduction}

Problems with Diesel emissions and control failures [1-3] are well known to anyone in the world. Breathing of clean air is very important for a healthy human body-mainly for the brain and nervous system. Therefore, it should be in our first priority to find a new technique to successfully solve these issues. The current existing emission standards in Europe, like European emission standards Euro [4, 5], or in the US, like Tier [6] or LEV [7], for Diesel engine passenger vehicles are the norms for hydrocarbons, carbon monoxide, nitrogen oxides, and particulate matter (PM) from Diesel exhaust emissions. Currently, there are no specific emission standards for additional compounds or chemical elements contained in the exhaust vapour [8], particulate matter $[9,10]$, or soot, formed by the Diesel combustion engine [11]. But in fact, the composition of chemical elements and extra carbon corresponds to a very important fraction of the total PM or black soot emission contents from Diesel engine-driven vehicles. Figure 1 shows the black cloud of Diesel exhaust emissions emitted from the tail pipe of on-road Diesel engine passenger vehicle.

One of the early pioneering groups in measurement of particulate trace emissions from vehicles was the group of Schauer et al. [9], where they used comprehensive 


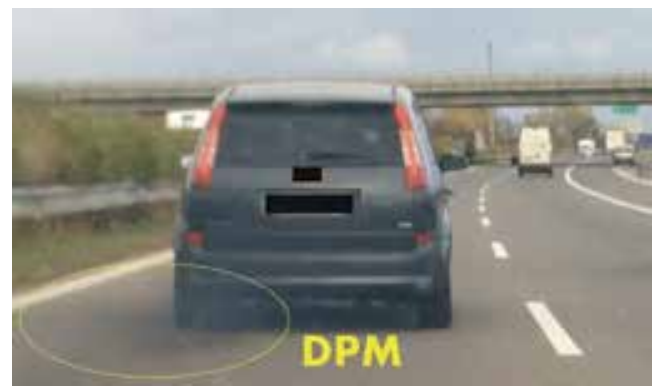

Figure 1.

Black cloud of particulate matter and soot exhaust emissions from the tail pipe of on-road diesel engine passenger vehicle.

dilution source sampler, organic chemical analysis, and X-ray fluorescence for fine particle mass and chemical composition measurements. Other groups [8, 10-12] used ICP-MS and XRF for characterisation of metals and other components from on-road motor vehicles. They found the following trace elements: $\mathrm{Al}, \mathrm{Ba}, \mathrm{Be}, \mathrm{Ca}, \mathrm{Cd}$, $\mathrm{Co}, \mathrm{Cr}, \mathrm{Cu}, \mathrm{Fe}, \mathrm{K}, \mathrm{Mg}, \mathrm{Mn}, \mathrm{Mo}, \mathrm{Na}, \mathrm{Ni}, \mathrm{Pb}, \mathrm{Pt}, \mathrm{S}, \mathrm{Sr}, \mathrm{Ti}, \mathrm{V}$, and $\mathrm{Zn}$ in the particles.

In this research we apply the laser-induced breakdown spectroscopy (LIBS) technique [13-15] for diagnostics of DPM, formed from combustion Diesel engine exhaust emissions, mainly concerning the comparison of major chemical components present in various DPM matrices.

Laser-induced breakdown spectroscopy is an emerging measurement technique [16] for rapid qualitative [17] and sensitive quantitative compositional analysis [18, 19] of various forms of materials like solids [20], liquids [21], gases [22], powders [23], or nanoparticles [24].

\section{Materials and methods}

\subsection{Experimental procedure}

An experimental setup, used to obtain LIBS spectra from various materials, generally consists of a high-intensity pulsed laser system, with nanosecond laser pulse duration, an experimental chamber, a collection optics, and a high-precision optical spectrometer. Plasma is generated by focusing the high-intensity laser pulses into the material; usually a Nd:YAG laser is applied at its fundamental laser wavelength of $1064 \mathrm{~nm}$ or its second harmonic $532 \mathrm{~nm}$ with different repetition rates from $1 \mathrm{~Hz}$ to a few $\mathrm{kHz}$ [25-27]. A schematic of the experimental LIBS setup is shown in Figure 2.

\subsection{LIBS setup}

For laser-induced breakdown, a Nd:YAG solid-state laser from Quantel was used. It was operated at the fundamental laser wavelength $1064 \mathrm{~nm}$ with $8.5 \mathrm{~ns}$ pulse duration and a laser energy of $300 \mathrm{~mJ}$ per pulse. The laser radiation was focused into the plane solid target surface, using a $10 \mathrm{~cm}$ focusing lens, to create the plasma. Optical emission from the plasma was collected perpendicularly via optical telescope, into the highresolution Echelle spectrograph (model Aryelle Butterfly from LTB Berlin), equipped with an ICCD detector. Optical emission from plasma has been collected from UV as well as from VIS parts; thus the total spectral window from 190 to $800 \mathrm{~nm}$ wavelength has been recorded. The spectral resolution capability is from 3 to $7 \mathrm{pm}$ for the UV range and from 4 to $8 \mathrm{pm}$ for the VIS range, thus providing spectral information of a 


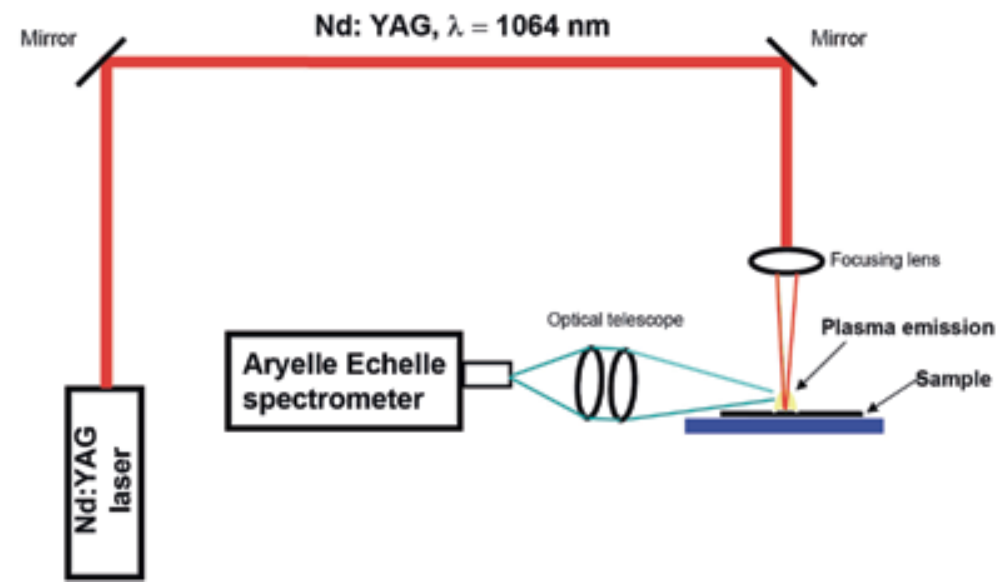

Figure 2.

Layout of the laser-induced breakdown spectroscopy experimental setup [28].

broad range with very high resolution and variability. The delay time for LIBS spectral signal was set to $1 \mu \mathrm{s}$ and the time window for spectral acquisition to $2 \mu \mathrm{s}$. In early delay time, less than $1 \mu \mathrm{s}$, the black body radiation is dominating in the laser-produced plasma, while in later delay time, $3 \mu \mathrm{s}$, the atomic, ionic, and molecular emissions are more pronounced. The laser-induced plasma has been created in open air atmosphere under the normal atmospheric pressure and at room temperature.

\subsection{Diesel particulate matter (DPM) collection and sample preparation}

Sixty-seven different PM samples, extracted from exhaust manifold part from in-use Diesel engine passenger vehicles of major brand car producers in Europe, have been analysed by LIBS. Passenger vehicles selected for the DPM sample collection were from our daily life environment, as anyone is using to drive to work, etc. No special driving test cycles, neither test vehicles nor engine test bench systems, were used during these LIBS measurements. Diesel particulate matter has been collected and extracted from the exhaust manifold part tail pipe at the end of the exhaust manifold. Selections of the vehicles were performed randomly, and no company was given preference. The results presented here are from a selection of eight different DPM matrices with respect to the LIBS signal variation. The reason is to compare the elemental composition of these different DPM matrices by LIBS technique. A special emphasis is given to observe the individual spectral lines that are mostly dominating in the UV and VIS optical emission from the DPM, thus influencing the overall LIBS spectrum. The collected DPM from Diesel engine vehicles' exhaust has been mechanically pressed into pellets with a flat disc shape. Each displayed spectrum has been averaged over 12 laser shots.

\section{Results and discussion}

\subsection{Identification of the main chemical elements in different DPM matrices}

For an elemental understanding of the laser-induced breakdown spectroscopy signal from DPM in the first stage, we selected from 67 different samples only 3 LIBS optical emission spectra. Signals from these measurements are shown in Figure 3. Obtained LIBS spectra have characteristic features with strong atomic and ionic lines and also molecular bands in the signal. 
Pressed solid samples of DPM were irradiated by high-power laser pulses to create a plasma above the surface. The optical emission from laser-induced plasma has been measured, and the raw spectral signal from $200 \mathrm{~nm}$ to $800 \mathrm{~nm}$ is plotted in the Figure 3. The major signal that is present in the LIBS spectrum is characterised by strong optical emission lines from the elements carbon, calcium, iron, chromium, sodium, zinc, aluminium, magnesium, oxygen, and hydrogen. These chemical elements show up in the spectrum as high-intensity lines. The relative intensity and broadening of the spectral lines are correlated with the chemical concentration of the elements. That means with higher intensity of atomic and ionic lines, we can expect a higher concentration of the studied chemical element.

In the next section, we will focus our study on the chemical elements and spectral lines that are most abundant in the LIBS spectra under investigation. Optical emission spectra of $\mathrm{C}, \mathrm{Ca}, \mathrm{Fe}, \mathrm{Cr}, \mathrm{Na}, \mathrm{Zn}, \mathrm{Al}, \mathrm{Mg}, \mathrm{O}$, and $\mathrm{H}$ measured from 67 different Diesel particulate matter samples are shown in Figure 4. Spectra shown here are selections of the most dominant lines in the signal. PM were collected from 67 different in-use Diesel engine passenger vehicles.

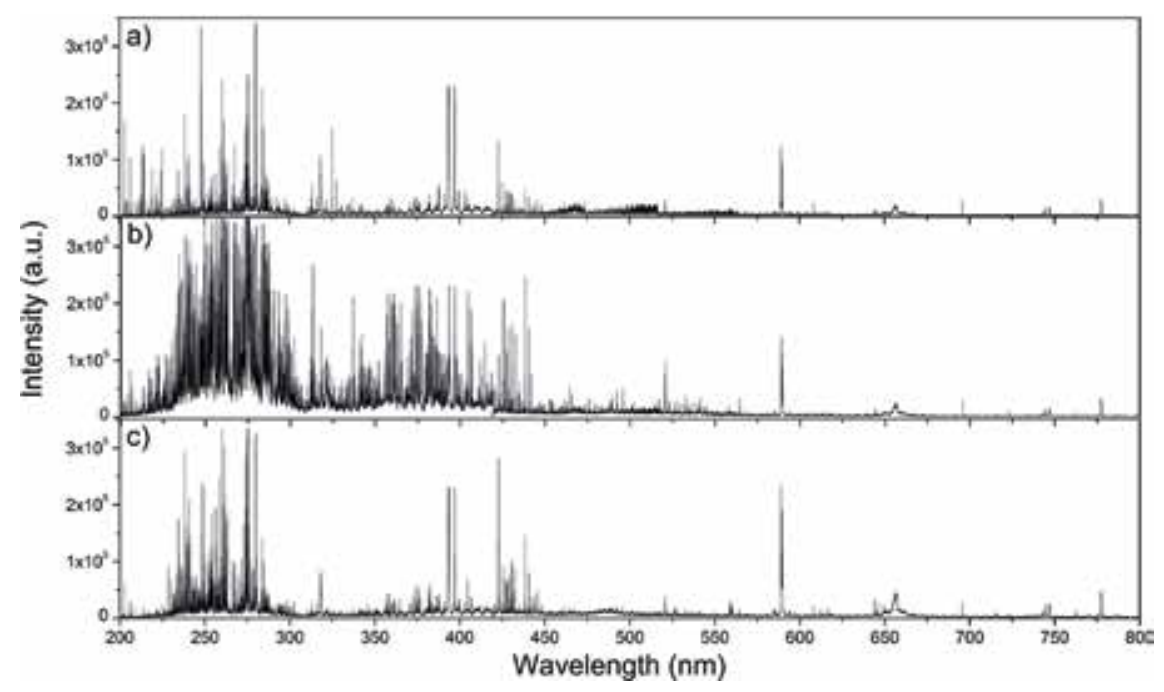

Figure 3.

LIBS spectra from three selected Diesel Particulate Matter samples, with high content of a) Ca, $\mathrm{Mg}, \mathrm{Zn} ; b) \mathrm{Ca}$, $\mathrm{Cr}, \mathrm{Fe}, \mathrm{H}, \mathrm{Mg}, \mathrm{Na}$ and $c$ ) $\mathrm{Al}, \mathrm{C}, \mathrm{Ca}, \mathrm{Cr}, \mathrm{Mg}, \mathrm{O}$.

\subsubsection{Carbon spectral line}

In Figure 4a a comparison of the atomic carbon spectral line C I at $247.85 \mathrm{~nm}$ optical emission from different particulate matter matrices measured by LIBS is shown. One can easily observe that the peak intensity, peak shape, and peak width vary for each obtained spectrum. Samples with high content of iron particles possess an additional iron peak Fe II at $248.015 \mathrm{~nm}$ interfering with the carbon signal line C I at $247.85 \mathrm{~nm}$. Here, it is obvious that the line emission from carbon is not the only dominant spectral line in the LIBS signal.

\subsubsection{Calcium spectral line}

An important major chemical component of the DPM is calcium. A comparison of LIBS signals from calcium (atomic spectral line Ca I at $422.67 \mathrm{~nm}$ ) is shown in Figure 4b. Calcium emission shows to be always present in DPM samples, and 
due to its strong optical emission, it can be assumed as one of the main components of the DPM matrix.

\subsubsection{Iron spectral line}

In Figure 4c comparisons of the ionic optical emission from iron spectral line Fe II at $238.20 \mathrm{~nm}$ are shown. Additional four iron spectral lines are also visible in the graph: Fe II at $237.92 \mathrm{~nm}$, Fe II at $238.07 \mathrm{~nm}$, Fe II at $238.32 \mathrm{~nm}$, and Fe II at $238.43 \mathrm{~nm}$. From the shown optical iron spectra, one can clearly see that the iron content is quite high in many PM samples. Iron is one of the components that is often present in the Diesel particulate matter and plays an important role in PM composition. High concentrations of iron are responsible for the transition of the DPM matrix.

\subsubsection{Chromium spectral line}

In Figure 4d comparisons of the optical emission from atomic chromium triplet lines Cr I at $520.44 \mathrm{~nm}, \mathrm{Cr}$ I at $520.60 \mathrm{~nm}$, and Cr I at $520.84 \mathrm{~nm}$ obtained from different DPM samples are shown. The presence of chromium is significant in most of the samples and therefore plays an important role in PM composition.

\subsubsection{Sodium spectral line}

Comparisons of the optical emissions from sodium atomic doublet spectral line ( $\mathrm{Na} \mathrm{I}$ at $588.99 \mathrm{~nm}$ and $\mathrm{Na} \mathrm{I}$ at $589.59 \mathrm{~nm}$ ) are shown in Figure 4e. Sodium is one of the elements that are perpetually present in the DPM matrix. The sodium atomic line intensity is relatively high and is dominating in the optical infrared spectrum. Thus it also plays an important role in the DPM content.

\subsubsection{Zinc spectral line}

Comparisons of the zinc ionic spectral line ( $\mathrm{Zn}$ II at $202.54 \mathrm{~nm}$ ) are shown in Figure 4f. Optical emission from zinc is usually present in all DPM samples. However, the intensity of $\mathrm{Zn}$-induced emission is quite high in some individual samples, which is related to a high zinc content. It is therefore expected that the element $\mathrm{Zn}$ also influences the DPM matrix.

\subsubsection{Aluminium spectral line}

In Figure 4g optical emissions from atomic aluminium, $\mathrm{Al}$ I at $309.27 \mathrm{~nm}$ line, are shown. Aluminium-induced optical emission is strongly present in a few DPM samples, and this high peak in the LIBS signal is indicating higher concentrations of $\mathrm{Al}$ in these matrices.

\subsubsection{Magnesium spectral line}

In Figure 4h, emissions from the doublet of ionic magnesium spectra lines (Mg II at $279.55 \mathrm{~nm}$ and $\mathrm{Mg}$ II at $280.27 \mathrm{~nm}$ ) are shown. From these spectra it is possible to observe that magnesium lines are present in most of the particulate matter.

\subsubsection{Oxygen spectral line}

Strong signal from the atomic oxygen line (O I at $777.19 \mathrm{~nm}$ ) in Figure $4 \mathbf{i}$ is visible from all DPM samples. This signal is partially due to laser-induced breakdown in air 

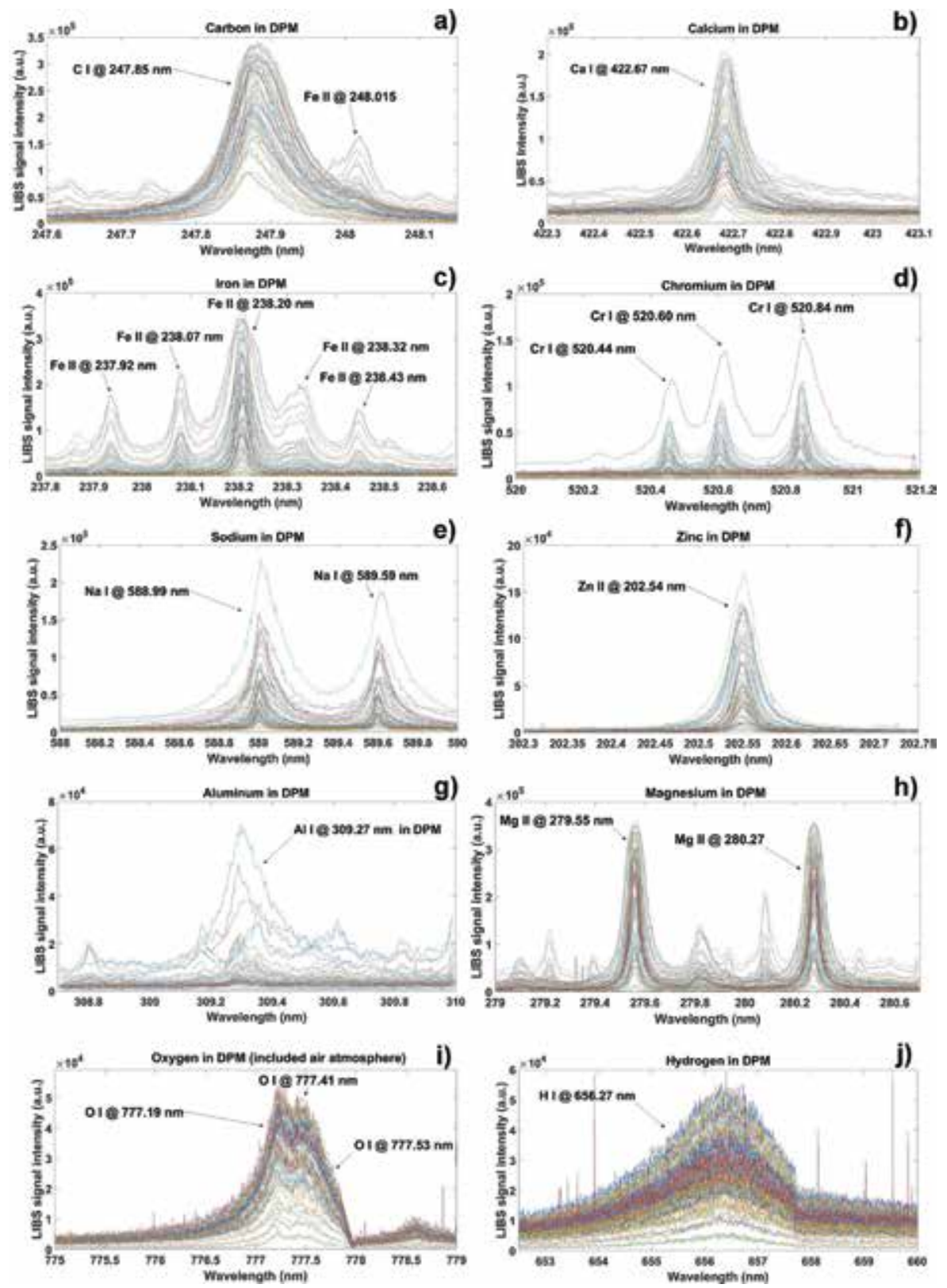

Figure 4.

Optical emission spectrum of (a) carbon, (b) calcium, (c) iron, $(d)$ chromium, $(e)$ sodium, $(f)$ zinc, $(g)$ aluminium, (h) magnesium, (i) oxygen, and $(j)$ hydrogen, measured by LIBS from 67 different diesel particulate matter samples.

atmosphere; nevertheless the other contribution in the signal is from residual oxygen present in the particulate matter. In some cases, this signal is very intense, indicating rather high concentrations of oxygen or different oxides in the sample itself.

\subsubsection{Hydrogen spectral line}

A very important indicator is the hydrogen $\mathrm{H}$ I at $656.27 \mathrm{~nm}$ line profile in the laser-induced plasma emission. From Balmer series $\mathrm{H}$ alpha line and from Stark 
broadening, the concentration of the plasma electron density can be calculated. Further $\mathrm{H}$ alpha line intensity and width can be used for electron temperature estimation. In Figure $4 \mathbf{j}$ one can observe that $\mathrm{H}(\alpha)$ has enormous intensity and broadening variations across different DPM matrices.

The chemical composition of individual DPM matrices varies considerably. This is due to the different origins of each particulate matter, which is given by the unique originality of the exhaust emission. In fact, the source of different elemental compositions of this matrix is the combination of the Diesel fuel, fuel additives, composition of the intake air, quality of the combustion process, type and performance of the Diesel engine, lubrication oil, erosion on the piston rings, or cylinder liner. Other parts that influence the matrix composition are applied pretreatment and after-treatment devices, like Diesel particle filters (DPF) or catalysts like selective catalytic reduction devices. All of them are involved in the final chemical composition of DPM.

\subsection{Calculation of the LIBS signal}

To process LIBS spectral signals, we integrated the spectral peak area for each atomic or molecular line shown in Figure 4. With numerical integration, we obtained relative qualitative information about concentration variations of major chemical elements inside the different Diesel particulate matter matrices. Results from these calculations are shown in Figure 5. In the bar graph, individual columns represent the calculated integral values of accumulated signal responses obtained for each particular wavelength, after the signal background correction and the fitting of spectral signal curve. Integral calculated values are for 67 DPM samples and for 10 major chemical elements. These are carbon, calcium, iron, chromium, sodium, zinc, aluminium, magnesium, oxygen, and hydrogen.

The carbon signal (Figure 5a) in individual Diesel particulate matter samples varies substantially, and these variations influence the entire matrix composition. In some samples, the signal from carbon dominates, which indicates carbon as a major element in these matrices, while in other samples, the influence of carbon is much lower. From an integral calculation, carbon has been detected in all 67 DPM samples. Very high carbon content was measured in samples \# 45, 44, 39, and 42, while very low content was detected in samples \# 67, 3, and 8.

The calcium (Figure 5b) concentration in PM can be quite high. This is visible in Figure 5 where the integral values are shown. High content of calcium is present in samples \# 66,67, and 25 . The minimum content of calcium was found in samples \# 55, 11, and 39. Calcium has been detected in 66 of the 67 samples.

The most significant contribution to the entire PM composition comes from iron (Figure 5c). Iron has been detected in 66 out of 67 different DPM samples. From Figure 5, maximum content of iron was found in samples \# 55, 12, 58, 59, and 34. Minimum content has been measured in samples \# 37, 13, 2, 53, 30, 11, and 3.

Chromium (Figure 5d) content also plays a major role in DPM matrices. Its presence has been measured in 60 from 67 different DPM samples. Its maximum concentration has been measured in samples \# 59, 4, 12, 28, 34, and 50. Minimum concentration of Cr has been measured in samples \# 9, 13, 17, 24, 30, 55, and 58.

Sodium (Figure 5e) can reach relatively high values in some samples, mainly in \# 54, 59, 27, and 12. Minimum concentration of Na was found in \# 39, 11, 48, 30, and 15. Overall, sodium has been detected in almost all samples (66/67).

Zinc (Figure 5f) is another important major element in various Diesel particulate matter matrices. Its concentration can be quite high, as we can observe in samples \# 44, 37, 18, 35, 33, 41, 52, and 5. On the other hand, low concentrations of 

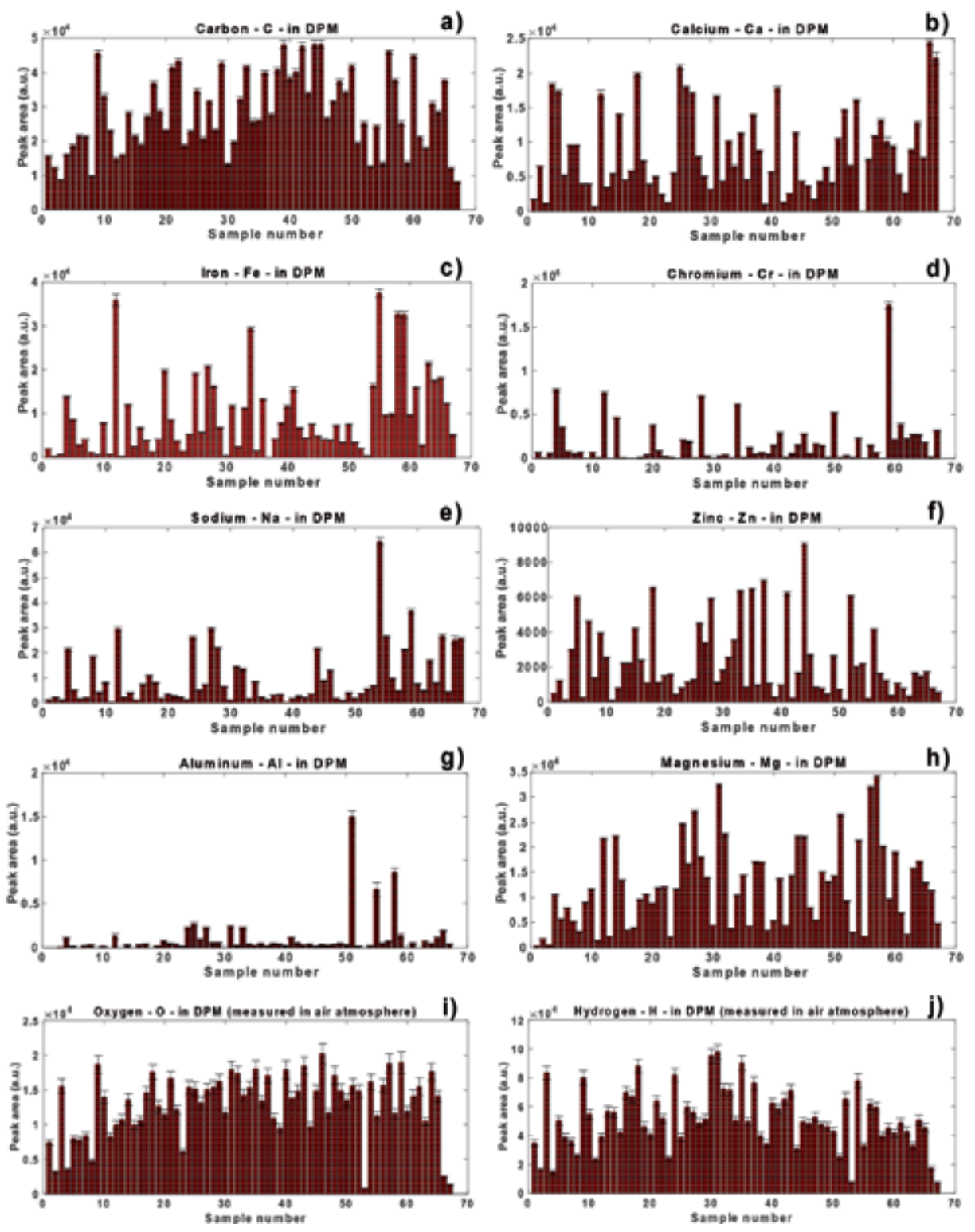

Figure 5 .

Qualitative comparison of (a) carbon, (b) calcium, (c) iron, $(d)$ chromium, $(e)$ sodium, $(f)$ zinc,

$(g)$ aluminium, $(h)$ magnesium, $(i)$ oxygen, and $(j)$ hydrogen content in DPM from 67 different in-use diesel engine passenger vehicles measured by LIBS.

Zn were measured in 51, 11, 30, 55, 42, and 39. Zinc content has been detected in all 67 different DPM samples.

Three samples of DPM possess higher content of aluminium (Figure $5 \mathrm{~g}$ ), particularly samples \# 51, 58, and 55. Lower content of Al has been measured in \# 1, 2, $3,6,9,11,13,15,18,30,53,60$, and 62 . Aluminium has been detected in 54 samples.

A major fraction in the DPM composition consists of magnesium (Figure 5h). Its high concentrations were measured in samples \# 57, 31, 56, 27, 51, and 25. Lower concentrations of $\mathrm{Mg}$ were found in \# 1, 3, 11, 2, 23, and 55. Magnesium has been ascertained in all 67 DPM samples.

Oxygen (Figure 5i) contribution in DPM is meaningful, and its content forms a major part in matrices. Oxygen has been detected in all samples, with high 
concen-trations in \# 46, 9, 59, and 57 and with lower concentrations in samples \# $53,67,66,2$, and 4 .

Hydrogen (Figure 5j) content is likewise very substantial in DPM. It is a major chemical element of DPM and it has been detected in all samples. High concentrations were measured in samples \# 31, 30, 35, 18, 3, 24, 9, 54, and 37; while low content in samples \# 53, 67, 4, and 2.

\subsection{Quantitative diesel particulate matter analysis}

Every knowledge about the qualitative and quantitative atomic composition of the studied material is contained in the LIBS spectrum. This originates from excited atoms, ions, and molecules, in the laser-induced plasma. Different methods exist to extract quantitative information from LIBS spectra. One technique determines the concentration of chemical elements by calculation of the line spectral emission from transition probabilities and from absolute measurements of the line intensities. A different strategy is to calculate, from the obtained signal, the integral of the emission line relative to the integral of a spectral line from the abundant element. Quite often approaches to get quantitative results are the spectral intensities in relation to known calibration standards or certified reference materials. By assuming the optical emission line intensity to be proportional to the concentration of the emission inducing species, the ratio of the concentrations of two species A and B can be expressed as a function ratio of the line intensity of species A to the line intensity of species B. Considering that the concentration ratio is directly proportional to the ratio of corresponding line intensities, it is possible to establish a calibration curve. This curve is basically a plot of relative concentrations of an element obtained by LIBS measurements versus the known relative concentrations of this element in the samples. Calibration curves can then be used for the quantitative determination of unknown concentrations in the examined material.

Special concern has been given to the quantification of the LIBS spectral signal and to the calibration curves from selected main matrix elements of DPM. The calibration function for carbon, iron, magnesium, aluminium, chromium, zinc, sodium, and calcium was constructed, to understand the complex composition of DPM.

\subsubsection{Preparation of the calibration samples}

To obtain quantitative information from the LIBS signal, calibration samples with various concentrations of expected chemical elements were prepared. We selected the elements carbon, iron, magnesium, aluminium, chromium, zinc, sodium, and calcium that form the major part of DPM matrix. Based on our previous qualitative LIBS measurements of different DPM matrices, we produced similar matrices, in our laboratory. These have been compounded by preparing different mixtures of selected elements in various concentrations and pressing them into pellets, exactly like the original DPM samples. All calibration samples have been prepared from certified nano-powders bought either from Carl Roth $\mathrm{GmbH}$ or from Sigma-Aldrich Inc. Company.

\subsubsection{Measurement of calibration samples by LIBS}

The calibration samples were measured under the same experimental conditions as the DPM samples. Consistent experimental parameters as optical setup, laser energy, spectrometer detector settings, particularly spectral window, and delay 
a)

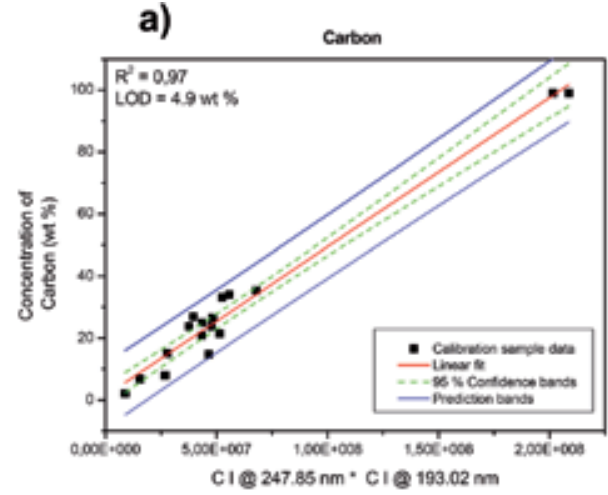

c)

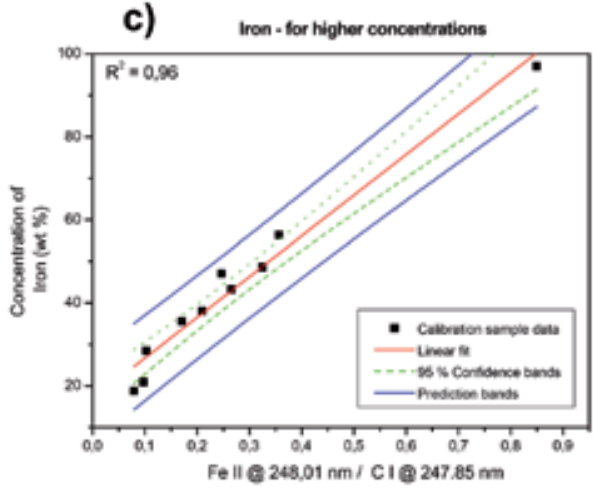

b)

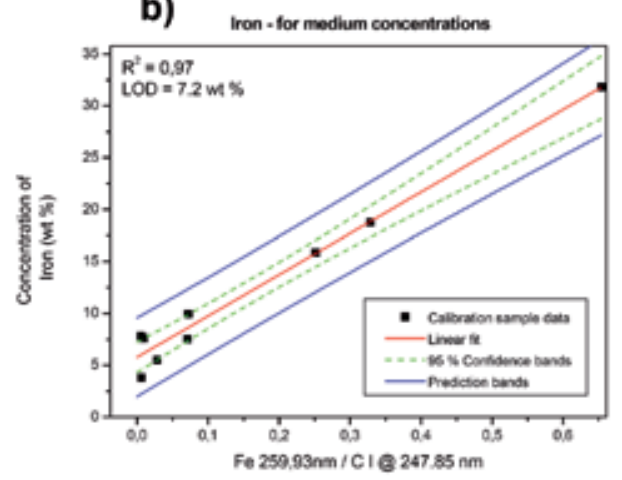

d)

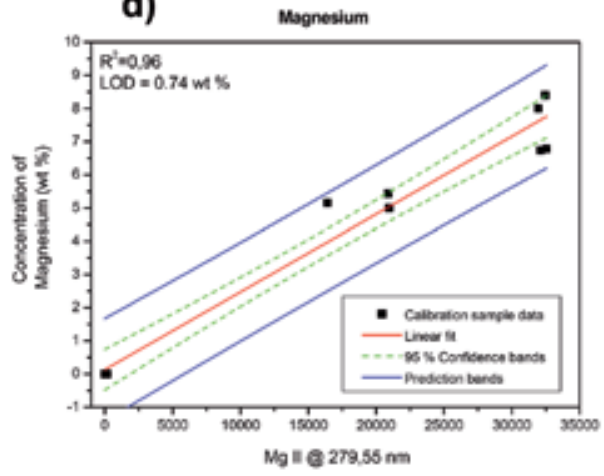

Figure 6.

Calibration curves including regression parameter $R^{2}$, limit of detection (LOD), 95\% confidence limits, and prediction bands for (a) carbon, (b) iron (medium concentrations), (c) iron (high concentrations), and (d) magnesium calibration samples.

time remained unchanged. Experimental LIBS measurements were performed in air atmosphere at normal atmospheric pressure. Obtained calibration curves (together with calculated regression parameter $\mathrm{R}^{2}$, limit of detection (LOD), 95\% confidence limits, and prediction bands) for (a) carbon, (b) iron (medium concentrations), (c) iron (high concentrations), (d) magnesium, (e) aluminium, (f) chromium, (g) zinc, (h) sodium, and (i) calcium, in the laboratory-prepared PM calibration samples, are shown in Figure 6(a-d) and Figure 7(e-i).

In these figures, the calculated ratios are denoted in the graphs as black squares, linear fit by solid line (red), 95\% confidence limits by dashed lines (green), and prediction bands by solid lines (blue). It is important to mention that the LOD for elemental carbon is relatively high. This is due to the fact that we assume DPM as a carbon-dominated matrix. Therefore, this calibration protocol is not intended to be applied to low carbon concentrations. The obtained calibration curve will yield the possibility to predict the level of carbon concentrations in various Diesel particulate matrices.

Selected spectral lines used for calculation of LIBS signal, obtained regression parameters $\mathrm{R}^{2}$ together with LOD, and calibration functions for different chemical elements are summarised in Table 1.

\subsection{Quantitative composition of eight different DPM matrices}

By means of calibration functions and the DPM-LIBS signal, it is possible to obtain the quantitative information and distribution of major chemical elements in Diesel particulate matter from different in-use Diesel engine passenger vehicles. 
Major Chemical Elements in Soot and Particulate Matter Exhaust Emissions Generated... DOI: http://dx.doi.org/10.5772/intechopen.90452
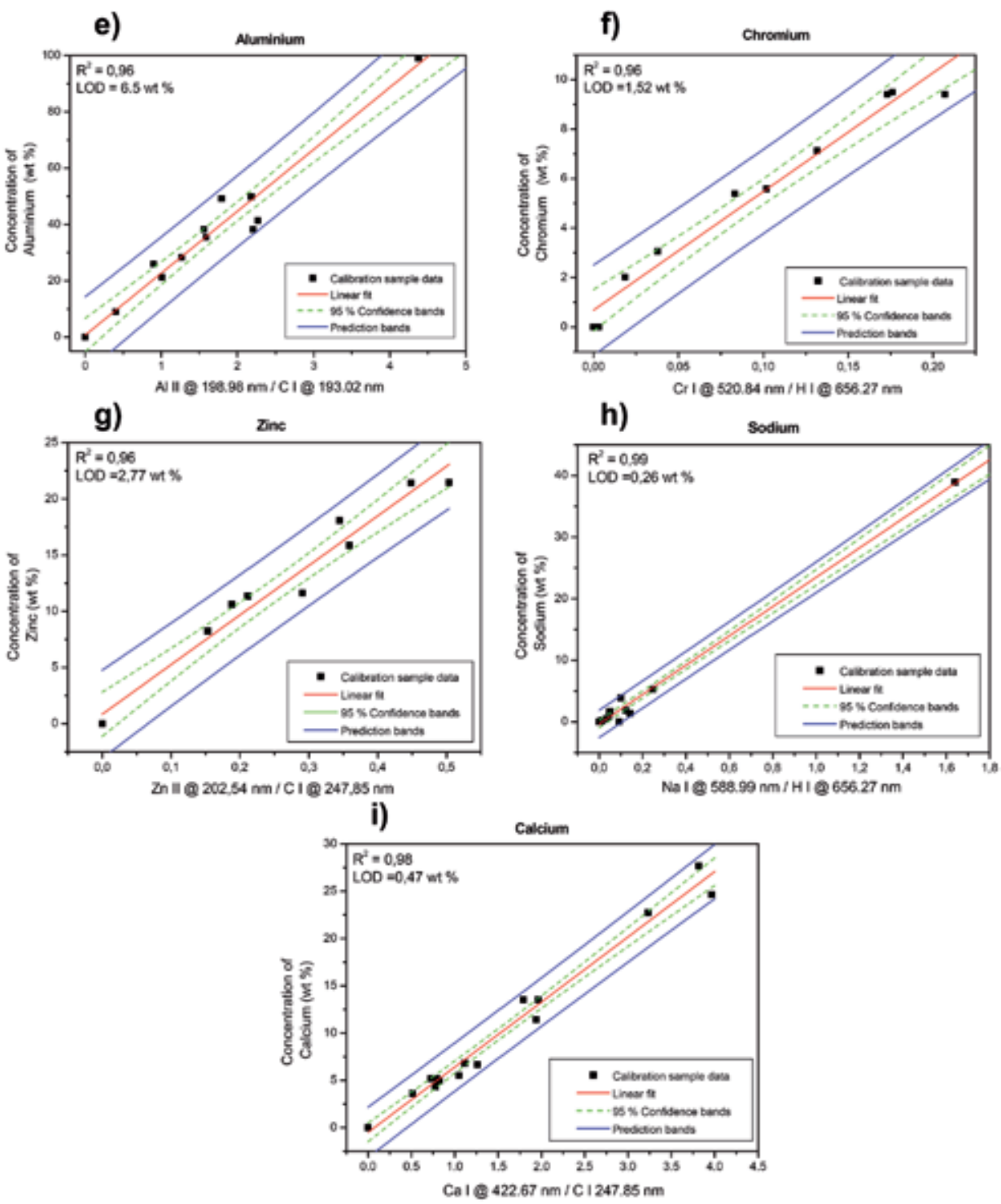

Figure 7 .

Calibration curves including regression parameter $R^{2}$, limit of detection (LOD), 95\% confidence limits, and prediction bands for $(e)$ aluminium, $(f)$ chromium, $(g)$ zinc, $(h)$ sodium, and $(i)$ calcium calibration samples.

\begin{tabular}{|c|c|c|c|}
\hline Analyte & $\begin{array}{l}\text { Regression } \\
\text { parameter } \\
\mathbf{R}^{2}\end{array}$ & $\begin{array}{c}\text { LOD } \\
(w+\%)\end{array}$ & Spectral lines used for calculation \\
\hline $\mathrm{C}$ & 0.97 & 4.9 & $\mathrm{CI} 2247.65 \mathrm{~nm}, \mathrm{Cl} 9193.02 \mathrm{rm}$ \\
\hline $\mathrm{Fe}$ medium wo & 0.97 & 7.2 & $\mathrm{Fe} I \mathrm{2} 25 \mathrm{~s} .93 \mathrm{n}, \mathrm{Cl} \cong 247.25 \mathrm{~nm}$ \\
\hline Fe h gh wo & 0.96 & - & $\mathrm{Fe} \| \cong 248.01 \mathrm{rm}, C \mid @ 247.25 \mathrm{~nm}$ \\
\hline $\mathrm{Ng}$ & 0.96 & 0.74 & $\mathrm{Mg} \| \Leftrightarrow 279.55 \mathrm{~nm}$ \\
\hline $\mathrm{N}$ & 0.96 & 6.5 & 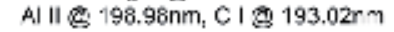 \\
\hline $\mathrm{Gr}$ & 0.96 & 1.52 & $\mathrm{Crl} 2520.847 \mathrm{HI} 655.27 \mathrm{~nm}$ \\
\hline $\mathrm{Zn}$ & 0.96 & 2.77 & $\mathrm{ZnII} 202.54 \mathrm{~nm}, \mathrm{Gl}$ \& $247.85 \mathrm{~nm}$ \\
\hline Na & 095 & 0.25 & Na I $683.99 \mathrm{~nm}, \mathrm{H} @ 65627 \mathrm{~nm}$ \\
\hline $\mathrm{Ca}$ & 0.92 & 0.47 & 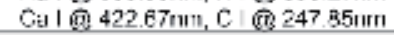 \\
\hline
\end{tabular}

Table 1.

Selected spectral lines of chemical elements, regression parameter $R^{2}$, and limit of detection (LOD) from calculated calibration functions. 
In this case, we only present the results from eight of the most diverse DPM matrices with respect to the LIBS spectrum, to demonstrate the quantitative comparison of elemental compositions of DPM using laser-induced break-down spectroscopy technique. From qualitative LIBS measurements, these eight samples were characterised to have high content of certain chemical elements: sample \#1 with high content of $\mathrm{Cr}$, sample \#2 with high content of $\mathrm{Ca}$, sample \#3 with high content of $\mathrm{Zn}$, sample \#4 with high content of $\mathrm{C}$, sample \#5 with high content of $\mathrm{Na}$, sample \#6 with high content of $\mathrm{Fe}$, sample \#7 with high content of $\mathrm{Mg}$, and sample \#8 with
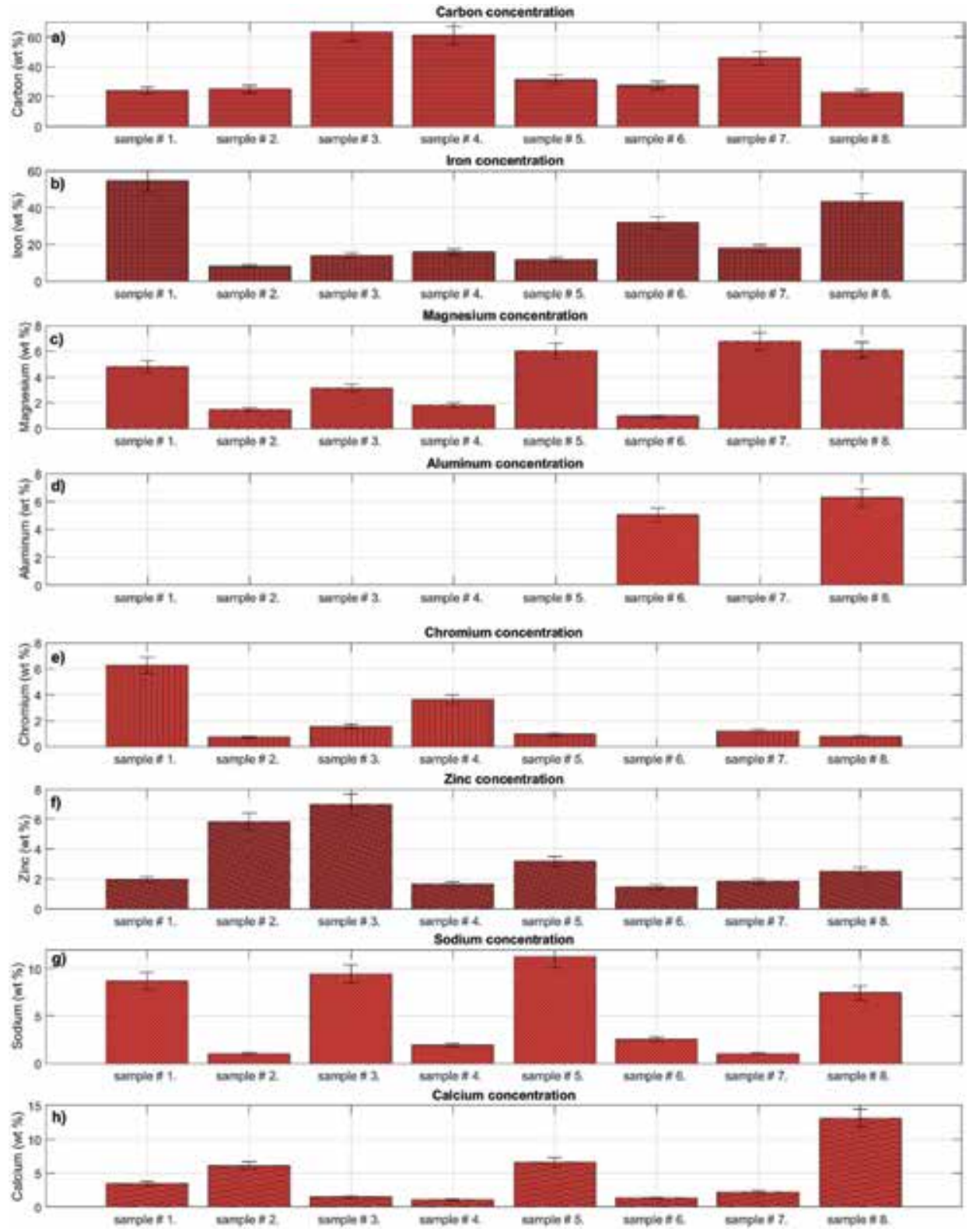

Figure 8.

Quantitative determination of major chemical elements in particulate matter collected from in-use Diesel engine passenger vehicles. The bar graph shows the average concentrations of major element in $w t \%$ of (a) carbon, (b) Iron (c) magnesium, $(d)$ aluminium, $(e)$ chromium, $(f)$ zinc, $(g)$ sodium and $(h)$ calcium in eight different DPM samples. 
high content of Al. These quantitative determinations of major chemical elements in DPM samples from eight in-use Diesel engine passenger vehicles are shown in Figure 8(a-h).

In the bar graph (Figure $8(\mathbf{a}-\mathbf{h})$ ), each individual bar represents the average value of calculated concentrations. These average values were obtained from three different position measurements by LIBS at the same DPM sample. The quantitative concentration of each element has been determined from spectral line ratios by means of calibration curves, obtained for each element. The quantitative determination of major chemical elements is shown in weight percent ( $w \mathrm{t} \%)$ in each sample. From the bar graphs, it is possible to obtain quantitative information about the major chemical element concentrations and variations of the DPM chemical composition. The following information can be read by either horizontal or vertical reading of Figure $8(\mathbf{a}-\mathbf{h})$ :

From horizontal reading of the bar graph (Figure $\mathbf{8}(\mathbf{a}-\mathbf{h})$ ), it is possible to observe that the carbon concentration (a) is not constant for all DPM samples; instead it is changing rather extremely in between individual samples, ranging from maximum concentration (approximately $64 \mathrm{wt} \%$ ) to minimum concentration (22 wt\%), in different DPM matrices. Iron (b) concentration also varies significantly, from as high as $55 \mathrm{wt} \%$ to as low as $8 \mathrm{wt} \%$. Magnesium (c) content is maximum $7 \mathrm{wt} \%$ and minimum $1 \mathrm{wt} \%$. Some DPM shows higher value of aluminium (d) with more than $6 \mathrm{wt} \%$, meanwhile for some samples, the $\mathrm{Al}$ concentration can be zero. Almost all (except for one) samples contain chromium (e) with minimum concentration below $1 \mathrm{wt} \%$, while maximum can be more than $6 \mathrm{wt} \%$. The zinc (f) content is playing a dominant role within the DPM matrices with concentrations from $1 \mathrm{wt} \%$ up to $7 \mathrm{wt} \%$. The sodium ( $\mathrm{g}$ ) concentration also influences the DPM matrices with its concentrations reaching $12 \mathrm{wt} \%$. Calcium $(\mathrm{h})$ concentrations are substantial and can be more than $13 \mathrm{wt} \%$.

From vertical reading of Figure 8, one can gain information about average concentrations (due to LIBS measurements at different sample position and averaging) of chemical elements in each DPM sample.

Sample \#1: contains in average iron $\sim 54 \mathrm{wt} \%$, carbon $\sim 23 \mathrm{wt} \%$, sodium $\sim 8 \mathrm{wt} \%$, chromium $\sim 6 \mathrm{wt} \%$, magnesium $\sim 5 \mathrm{wt} \%$, calcium $\sim 3 \mathrm{wt} \%$, and zinc $\sim 2 \mathrm{wt} \%$.

Sample \#2: contains carbon $\sim 25 \mathrm{wt} \%$, iron $\sim 8 \mathrm{wt} \%$, calcium $\sim 6 \mathrm{wt} \%$, zinc $\sim 6$ $\mathrm{wt} \%$, magnesium $\sim 1 \mathrm{wt} \%$, sodium $\sim 1 \mathrm{wt} \%$, chromium $\sim 1 \mathrm{wt} \%$, and other elements.

Sample \#3: contains carbon $\sim 63 \mathrm{wt} \%$, iron $\sim 14 \mathrm{wt} \%$, sodium $\sim 9 \mathrm{wt} \%$, zinc $\sim 7 \mathrm{wt} \%$, magnesium $\sim 3 \mathrm{wt} \%$, chromium $\sim 1 \mathrm{wt} \%$, calcium $\sim 1 \mathrm{wt} \%$, and other elements.

Sample \#4: contains carbon $\sim 61 \mathrm{wt} \%$, iron $\sim 16 \mathrm{wt} \%$, chromium $\sim 3 \mathrm{wt} \%$, sodium $\sim 2 \mathrm{wt} \%$, magnesium $\sim 2 \mathrm{wt} \%$, zinc $\sim 1 \mathrm{wt} \%$, calcium $\sim 1 \mathrm{wt} \%$, and other elements.

Sample \#5: contains carbon $\sim 31 \mathrm{wt} \%$, iron $\sim 12 \mathrm{wt} \%$, sodium $\sim 11 \mathrm{wt} \%$, calcium $\sim 6 \mathrm{wt} \%$, magnesium $\sim 6 \mathrm{wt} \%$, zinc $\sim 3 \mathrm{wt} \%$, chromium $\sim 1 \mathrm{wt} \%$, and other elements.

Sample \#6: contains iron $\sim 32 \mathrm{wt} \%$, carbon $\sim 27 \mathrm{wt} \%$, aluminium $\sim 5 \mathrm{wt} \%$, sodium $\sim 2 \mathrm{wt} \%$, zinc $\sim 1 \mathrm{wt} \%$, calcium $\sim 1 \mathrm{wt} \%$, magnesium $\sim 1 \mathrm{wt} \%$, and other elements.

Sample \#7: contains carbon $\sim 46 \mathrm{wt} \%$, iron $\sim 18 \mathrm{wt} \%$, magnesium $\sim 7 \mathrm{wt} \%$, calcium $\sim 2 \mathrm{wt} \%$, zinc $\sim 2 \mathrm{wt} \%$, chromium $\sim 1 \mathrm{wt} \%$, sodium $\sim 1 \mathrm{wt} \%$, and other elements.

Sample \#8: contains carbon $\sim 22 \mathrm{wt} \%$, iron $\sim 43 \mathrm{wt} \%$, calcium $\sim 13 \mathrm{wt} \%$, sodium $\sim 7 \mathrm{wt} \%$, aluminium $\sim 6 \mathrm{wt} \%$, magnesium $\sim 6 \mathrm{wt} \%$, zinc $\sim 2 \mathrm{wt} \%$, and chromium $\sim 1$ wt $\%$.

In this research we performed qualitative and quantitative composition of major chemical elements contained in DPM by means of high-resolution LIBS technique. However, further research is necessary to obtain a detailed picture of additional 
major and minor chemical elements also present in DPM, for which our current LIBS setup does not have the spectral resolution, particularly sulphur and chlorine.

All these qualitative and quantitative LIBS studies were performed on DPM collected from in-use Diesel engine passenger vehicles and nonspecial driving test cycles; neither test vehicles nor engine test bench systems were used during the LIBS measurements. Therefore for future measurements of particulate matter and soot emissions, it would be important to perform LIBS qualitative and quantitative measurements on dynamic engine test bench system. The focus should be to study static exhaust emissions at different Diesel engine operating points like power, torque, engine speed, fuel injection, brake specific fuel consumption BSFC, etc. and thus perform engine static map measurements. With these engine data and LIBS analytical results from DPM, it would be possible to establish respective correlations.

All acquired knowledge about Diesel particulate matter can help to better control the engine, as well as combustion process, and thus reduce unwanted emissions generated by Diesel engine-powered vehicles in real driving situations to meet future strict emission standards.

\section{Conclusions}

In this study we present qualitative and quantitative analytical studies of Diesel particulate matter collected from 67 different in-use, Diesel combustion enginepowered, passenger vehicles. DPM samples have been analysed spectrochemically by means of a high-resolution laser-induced breakdown spectroscopy technique. Selections of Diesel passenger vehicles have been performed randomly, from daily life environment and from major brand car producers in Europe. We found that Diesel particulate matter from in-use vehicles does not consist solely or at least mainly of pure carbon particles. Instead it consists of many chemical elements with diverse concentrations. The high-resolution LIBS technique can instantly measure major chemical elements within the Diesel particulate matter matrix. From qualitative LIBS measurements, we found that the major compounds of DPM are carbon (C), iron $(\mathrm{Fe})$, magnesium $(\mathrm{Mg})$, aluminium $(\mathrm{Al})$, chromium $(\mathrm{Cr})$, zinc $(\mathrm{Zn})$, sodium $(\mathrm{Na})$, and calcium $(\mathrm{Ca})$.

We have shown that the composition of DPM matrices is not fixed but rather variable for particular in-use Diesel engine passenger vehicles. We have shown 3 optical emission LIBS spectra from VUV to VIS spectral region and 67 different spectra from major chemical elements contained in different Diesel particulate matter samples.

We qualitatively compared the carbon, calcium, iron, chromium, sodium, zinc, aluminium, magnesium, oxygen, and hydrogen distribution in DPM from 67 different in-use Diesel engine passenger vehicles by LIBS.

Special concern has been given to the quantification of the LIBS signal obtained from the different DPM matrices. With this intent calibration samples, containing selected major matrix elements with different concentrations, have been prepared from certified nano-powder materials in our laboratory. This way, it was possible to construct calibration curves for $\mathrm{C}, \mathrm{Fe}, \mathrm{Mg}, \mathrm{Al}, \mathrm{Cr}, \mathrm{Zn}, \mathrm{Na}$, and $\mathrm{Ca}$.

By applying calibration curves, we quantitatively characterised eight different Diesel particulate matter samples and their major chemical compositions. We found that the carbon concentration in DPM matrices varies extremely from 64 to $22 \mathrm{wt} \%$. The iron concentration is alternating from 55 to $8 \mathrm{wt} \%$ for different DPM samples. Magnesium concentrations rise up to $7 \mathrm{wt} \%$, and aluminium content can be more than $6 \mathrm{wt} \%$ in different Diesel particulate matter matrices. 
Chromium concentration can reach $6 \mathrm{wt} \%$ and zinc concentration $7 \mathrm{wt} \%$. In some samples sodium and calcium concentrations are up to $12 \mathrm{wt} \%$ or more than $13 \mathrm{wt} \%$, respectively.

In this study we have assessed the qualitative and quantitative compositions of major elements within the various DPM matrices using a high-resolution LIBS technique. However, further research is necessary to obtain a detailed picture of additional major elements also present in DPM, for which our current LIBS setup does not have the spectral resolution, particularly sulphur and chlorine. Understanding the chemical composition of Diesel particulate matter can help to better control the engine, as well as combustion process, and thus reduce unwanted emissions generated by Diesel engine-powered vehicles in real driving situations, to meet future emission standards.

\section{Acknowledgements}

The authors would like to thank the Austrian Science Fund-FWF (Fonds zur Förderung der wissenschaftlichen Forschung)_for providing financial support. This study was funded with the grant number FWF-P27967. Additionally the authors would like to thank Dr. Maria Rusnak for the proofreading and for the corrections.

\section{Author details}

Richard Viskup*, Christoph Wolf and Werner Baumgartner

Institute of Biomedical Mechatronics, Johannes Kepler University Linz, Linz, Austria

*Address all correspondence to: richard.viskup@jku.at

IntechOpen

(C) 2020 The Author(s). Licensee IntechOpen. This chapter is distributed under the terms of the Creative Commons Attribution License (http://creativecommons.org/licenses/ by/3.0), which permits unrestricted use, distribution, and reproduction in any medium, provided the original work is properly cited. (cc) BY 


\section{References}

[1] Ntziachristos L, Papadimitriou G, Ligterink N, Hausberger S. Implications of Diesel emissions control failures to emission factors and road transport NOx evolution. Atmospheric Environment. 2016;141:542-551. DOI: 10.1016/j.atmosenv.2016.07.036

[2] Zacharof N, Tietge U, Franco V, Mock P. Type approval and real-world $\mathrm{CO} 2$ and NOx emissions from EU light commercial vehicles. Energy Policy. 2016;97:540-548. DOI: 10.1016/j. enpol.2016.08.002

[3] Commission Regulation (EU) 2016/646. Commission Regulation (EU) 2016/646 of 20 April 2016 Amending Regulation (EC) (No 692/2008) as Regards Emissions from Light Passenger and Commercial Vehicles (Euro 6) [Online]. Available from: http://eur-lex. europa.eu/eli/reg/2016/646/oj

[4] Commission Regulation (EC) 692/2008. Commission Regulation (EC) 692/2008 of 18 July 2008 Implementing and Amending Regulation (EC) No 715/2007 of the European Parliament and of the Council on Type-approval of Motor Vehicles with Respect to Emissions from Light Passenger and Commercial Vehicles (Euro 5 and Euro 6) and on Access to Vehicle Repair and Maintenance Information [Online]. Available from: http://eur-lex.europa. eu/eli/reg/2008/692/oj

[5] Regulation (EC) No 715/2007. Regulation (EC) No 715/2007 of the European Parliament and of the Council of 20 June 2007 on Type Approval of Motor Vehicles with Respect to Emissions from Light Passenger and Commercial Vehicles (Euro 5 and Euro 6) and on Access to Vehicle Repair and Maintenance Information [Online]. Available from: http://eur-lex.europa. eu/eli/reg/2007/715/oj

[6] United States Environmental Protection Agency, Regulations for
Emissions from Vehicles and Engines, Tier 3 Motor Vehicle Emission and Fuel Standards [Online]. Available from: https://www.epa.gov

[7] California Environmental Protection Agency. Low-Emission Vehicle

Program-LEV III [Online]. Available from: https://www.arb.ca.gov/

[8] Lough GC, Schauer JJ, Park JS, Shafer MM, Deminter JT, Weinstein JP. Emissions of metals associated with motor vehicle roadways. Environmental Science \& Technology. 2005;39(3):826836. DOI: $10.1021 / \mathrm{es} 048715 f$

[9] Schauer JJ, Kleeman MJ, Cass GR, Simoneit BRT. Measurement of emissions from air pollution sources. 2. C-1 through C-30 organic compounds from medium duty diesel trucks. Environmental Science \& Technology. 1999;33(10):15781587. DOI: $10.1021 / \mathrm{es} 980081 \mathrm{n}$

[10] Cheung KL, Ntziachristos L, Tzamkiozis T, Schauer JJ, Samaras Z, Moore KF, et al. Emissions of particulate trace elements, metals and organic species from gasoline, diesel, and biodiesel passenger vehicles and their relation to oxidative potential. Aerosol Science and Technology. 2010;44(7):500-513. DOI: $10.1080 / 02786821003758294$

[11] Ntziachristos L, Ning Z, Geller MD, Sheesley RJ, Schauer JJ, Sioutas C. Fine, ultrafine and nanoparticle trace element compositions near a major freeway with a high heavy-duty diesel fraction. Atmospheric Environment. 2007;41(27):5684-5696. DOI: 10.1016/j. atmosenv.2007.02.043

[12] Kleeman MJ, SchauerJJ, Cass GR. Size and composition distribution of fine particulate matter emitted from motor vehicles. Environmental Science \& Technology. 2000;34(7):1132-1142. DOI: $10.1021 / \mathrm{es} 981276 \mathrm{y}$ 
[13] Noll R. Laser-Induced Breakdown Spectroscopy, Fundamentals and Applications. Berlin Heidelberg: Springer-Verlag; 2012. ISBN 978-3-642-20667-2

[14] Miziolek AW, Palleschi V, Schechter I. Laser-induced breakdown spectroscopy (LIBS). In: Fundamentals and Applications. New York, USA: Cambridge University Press; 2006. ISBN 978-0-521-85274-6

[15] Cremers DA, Radziemski LJ. Handbook of Laser-Induced Breakdown Spectroscopy. New Delhi, India: John Wiley \& Sons Inc; 2013. ISBN 978-1-119-97112-2

[16] Hahn DW, Omenetto N. Laserinduced breakdown spectroscopy (LIBS), part II: Review of instrumental and methodological approaches to material analysis and applications to different fields. Applied

Spectroscopy. 2012;66(4):347-419. DOI: $10.1366 / 11-06574$

[17] Noll R, Fricke-Begemann C, Brunk M, Connemann S, Meinhardt C, Scharun M, et al. Laser-induced breakdown spectroscopy expands into industrial applications. Spectrochimica Acta Part B: Atomic Spectroscopy. 2014;93:41-51. DOI: 10.1016/j. sab.2014.02.001

[18] Fortes FJ, Moros J, Lucena P, Cabalin LM, Laserna JJ. Laser-induced breakdown spectroscopy. Analytical Chemistry. 2013;85(2):640-669. DOI: 10.1021/ac303220r

[19] Wang ZZ, Deguchi Y, Zhang ZZ, Wang Z, Zeng XY, Yan JJ. Laser-induced breakdown spectroscopy in Asia.

Frontiers of Physics. 2016;11(6):114213. DOI: $10.1007 / \mathrm{s} 11467-016-0607-0$

[20] Viskup R, Praher B, Linsmeyer T, Scherndl H, Pedarnig JD, Heitz J. Influence of pulse-to-pulse delay for $532 \mathrm{~nm}$ double-pulse laser-induced breakdown spectroscopy of technical polymers. Spectrochimica Acta Part B: Atomic Spectroscopy. 2010;65:935. DOI: 10.1016/j.sab.2010.09.003

[21] Samek O, Beddows DCS, Kaiser J, Kukhlevsky SV, Liska M, Telle HH, et al. Application of laser-induced breakdown spectroscopy to in situ analysis of liquid samples. Optical Engineering. 2000;39(8):2248-2262. DOI: $10.1117 / 1.1304855$

[22] Effenberger AJ, Scott JR. Effect of atmospheric conditions on LIBS spectra. Sensors. 2010;10(5):4907-4925. DOI: 10.3390/s100504907

[23] Stehrer T, Praher B, Viskup R, Jasik J, Wolfmeir H, Arenholz E, et al. Laser-induced breakdown spectroscopy of iron oxide powder. Journal of Analytical Atomic Spectrometry. 2009;24:973-978. DOI: 10.1039/b817279j

[24] Viskup R, Praher B, Stehrer T, Jasik J, Wolfmeir H, Arenholz E, et al. Plasma plume photography and spectroscopy of Fe-oxide materials. Applied Surface Science. 2008;255:52155219. DOI: 10.1016/j.apsusc.2008.08.092

[25] Viskup R. Single and double laser pulse interaction with solid stateApplication to plasma spectroscopy. In: Dumitras DC, editor. Nd:YAG Laser. Rijeka, Croatia: IntechOpen; 2012. ISBN: 978-953-51-0105-5

[26] Pedarnig JD, Heitz J, Ionita R, Dinescu G, Praher B, Viskup R. Combination of RF-plasma jet and laser-induced plasma for breakdown spectroscopy analysis of complex materials. Applied Surface Science. 2011;257(12):5452-5455. DOI: 10.1016/j. apsusc.2010.11.112

[27] Noll R, Sturm V, Aydin Ü, Eilers D, Gehlen C, Höhne M, et al. Laser-induced breakdown spectroscopy-From research to industry, new frontiers for process control. Spectrochimica 
Acta Part B. 2008;63:1159-1166. DOI:

10.1016/j.sab.2008.08.011

[28] Viskup R, Baumgartner W.

Measurement of the main compounds present in the diesel particulate matter exhaust emissions generated from the real diesel combustion engine passenger vehicles. In: Proc. SPIE 10680, Optical

Sensing and Detection V, 1068017.

[Published: 09 May 2018]. DOI: 10.1117/ 12.2307357 



\section{Edited by Richard Viskup}

The first invention and development of the functional diesel engine was in 1897 by Rudolf

Christian Karl Diesel, German inventor. Until now, this invention has been superseded

by the development of very productive engines and mechanics. Current diesel engines are well known to many people around the world and serve in innumerable applications for various types of public transport, light and heavy duty transportation,

for automotive, railway, maritime or aviation transportation, in different harsh environments, in construction, in mining, and for diverse industries. The light duty or heavy-duty diesel engines have some drawbacks. One of the main concerns is connected with exhaust emissions generated by diesel engines. This book discusses the generation of diesel exhaust emissions and mitigations, performance, emissions and combustion evaluations, utilisation of alternative biodiesel fuels, comparison of different techniques for measurement of soot and diesel particulate matter, analyses of diesel particulate matter flow pattern, and chemical composition of diesel particulate matter. The main concern of this book is to expand knowledge of readers and bring together the latest research findings related to diesel engine exhaust emissions. 